CESAR GIACOMINI PENTEADO

\title{
ARQUITETURA MODULAR DE PROCESSADOR MULTICORE, FLEXÍVEL, SEGURA E TOLERANTE A FALHAS, PARA SISTEMAS EMBARCADOS CIBERFÍSICOS
}

Tese apresentada à Escola Politécnica da Universidade de São Paulo para obtenção do título de Doutor em Engenharia Elétrica

São Paulo 
Este exemplar foi revisado e alterado em relação à versão original, sob responsabilidade única do autor e com a anuência de seu orientador

São Paulo, 23 de dezembro de 2010.

Assinatura do autor

Assinatura do orientador

\section{FICHA CATALOGRÁFICA}

Penteado, Cesar Giacomini.

Arquitetura modular de processador multicore, flexível, segura e tolerante a falhas, para sistemas embarcados ciberfísicos / Cesar Giacomini Penteado. -ed.rev.-- São Paulo, 2010.

$138 \mathrm{p}$.

Tese (Doutorado) - Escola Politécnica da Universidade de São Paulo. Departamento de Engenharia Elétrica.

1. Arquitetura e organização de computadores. 2. Sistemas embarcados. 3. Sistemas ciberfísicos. 4. Desempenho de sistemas computacionais. 5. Arquiteturas multicore. I. Universidade de São Paulo. Escola Politécnica. Departamento de Engenharia Elétrica. II. T. 


\title{
CESAR GIACOMINI PENTEADO
}

\section{ARQUITETURA MODULAR DE PROCESSADOR MULTICORE, FLEXÍVEL, SEGURA E TOLERANTE A FALHAS, PARA SISTEMAS EMBARCADOS CIBERFÍSICOS}

\author{
Tese apresentada à Escola Politécnica da \\ Universidade de São Paulo para obtenção do \\ título de Doutor em Engenharia Elétrica
}

Área de Concentração:

Sistemas Eletrônicos

Orientador:

Prof. Dr. Sérgio Takeo Kofuji

São Paulo 


\section{DEDICATÓRIA}

Dedico este trabalho aos portadores de doenças crônicas. 


\section{AGRADECIMENTOS}

Agradeço ao meu orientador Sérgio Takeo, principal pessoa que me proporcionou esta oportunidade. Pelo enorme tempo de extrema dedicação a mim. Pela paciência e pelas broncas extremamente pesadas, mas que me fizeram crescer muito. Por acreditar em mim e no meu trabalho. Aprendi a admirar sua forma de orientar as pessoas a sua volta.

Agradeço ao Edward Moreno, por ter me incentivado tanto por toda a vida. Pelas horas de apuros em que pedi ajuda e rumo. Por ter me acolhido de forma tão carinhosa. Por sua família, que sempre irão morar em meu coração.

Agradeço ao meu Pai Juvenal e minha Mãe Vera Lúcia, sem os quais, possívelmente eu não estaria nem andando. Pelo eterno carinho, apoio e dedicação, sem medir esforços para me ajudar... em nenhum momento da minha vida. Obrigado!

Agradeço ao meu grande irmão Maurício, o qual me ajudou em muitas de minhas angústias. Pelas horas, semanas e meses em que acabei ficando distante devido a este trabalho, peço desculpas. Pela sua compreensão, só tenho a agradecer. Conte sempre comigo Maurício.

Agradeço a minha irmã Agnes, pela sua capacidade de me animar nos momentos mais difíceis, mesmo estando fisicamente longe. Agnes, você sempre esteve perto de mim.

Agradeço a minha grande família pelo apoio constante. Em especial, agradeço a minha tia Helena, por me abrigar e cuidar de mim na reta final do trabalho.

Agradeço ao meu grande amigo Fernando Muzzi, o qual me acompanhou desde o início do doutorado, em todas as disciplinas, nos momentos de pressão forte e angústias pesadas. Muito obrigado Muzzi,pelo apoio que recebi, mesmo nas horas em que era você quem precisava de apoio...

Agradeço ao meu grande amigo Fábio Pereira, o qual me apóia desde quando entramos na faculdade em 1999. Muito obrigado Fábio, por termos estudado e trabalhado juntos, viagens constantes para São Paulo, e filosofar sobre a vida.

Agradeço ao pessoal da Design House - LSITEC - SP, pela oportunidade de trabalho, amizade, conhecimento e apoio nesta minha jornada. Tenho orgulho de trabalhar com pessoas tão ricas em conhecimento.

Agradeço aos meus médicos, enfermeiras e pessoal do Hemocentro de Marília. Sem seu apoio, tudo seria muito mais difícil para mim. Obrigado ! 
"Não se pode enxergar além de uma escolha que não se entende."

Matrix - O filme 


\section{RESUMO}

Sistemas Ciberfísicos (SCF) são sistemas onde existe uma união entre computação e física. Os SCF serão utilizados nas mais diversas áreas, formando uma nova era de produtos e estarão em qualquer lugar, sendo utilizados por qualquer um e para qualquer tarefa. Aplicações para SCF incluem sistemas e dispositivos médicos altamente confiáveis, controle de tráfego e segurança, sistemas automotivos avançados, controle de processos, conservação de energia, controle ambiental, aviação, instrumentação, controle de infra estrutura crítica, sistemas de defesa, fabricação e estruturas inteligentes. O cenário de sistemas ciberfísicos (SCF) exigirá dos processadores de sistemas embarcados melhorias em características além de processamento de $\mathrm{I} / \mathrm{O}$, consumo de energia e comunicação, ou seja, as futuras arquiteturas de processadores deverão possuir também características de segurança, tolerância à falhas e flexibilidade arquitetural para adequação aos diversos cenários alvo de SCF. Neste contexto, nesta tese de doutorado, idealizouse uma arquitetura modular multicore (AMM), voltada à SCF, composta por processadores multicore, hardware dedicado ou ambos. Dessa maneira, propõe-se um processador para a arquitetura AMM e avalia-se seu correto funcionamento por meio de simulações no software Modelsim e ferramentas de simulação de circuitos integrados. Apresenta-se um protótipo para uma primeira versão da arquitetura AMM e detalham-se alguns programas especificamente escritos para comprovar as principais características da arquitetura. Na tese, apresentam-se testes funcionais em FPGA para o processador base do protótipo AMM, dados de utilização do protótipo do processador da arquitetura AMM em FPGA e um protótipo do processador da AMM em silício. Analisa-se o protótipo da arquitetura AMM com aplicações criticas e de uso em SCF, tais como: segurança, redundância, e tolerância a falhas; as quais permitem concluir que os processadores futuros de SCF devem ter essas características. A tese mostra que esses quesitos podem ser incluídos em sistemas embarcados com características multicore dedicados a aplicações e necessidades de sistemas SCF

Palavras-chave: Arquitetura de computadores, Arquitetura e organização de computadores, Sistemas embarcados, Sistemas ciberfísicos, Confiabilidade 


\begin{abstract}
Cyber-physical Systems (CPS) are systems where there is an union between computing and physics. The CPS will be used in several areas, forming a new era of systems or devices and could be anywhere, being used by anyone and anything. Applications for CPS include highly reliable medical systems and devices, traffic control and security, advanced automotive, process control, energy conservation, environmental control, aviation, instrumentation, control of critical infrastructure, defense systems, manufacturing, and smart structures. So, CPS scenario needs requirements design of embedded systems, composed by processors with new features in addition to $1 / O$ processing, power consumption, and communication. Then, the future of processor architectures should also have security, fault tolerance, architectural adaptation and flexibility to various and different scenarios. In this context, in this thesis, it is proposed a modular architecture to multicore processor (AMM) to use in the CPS. It is composed by multicore processors, dedicated hardware or both. Thus, in this thesis, we have proposed one processor architecture and we have done verification based on simulations using Modelsim software and simulation tools for integrated circuits, and we have running applications programs to demonstrate the main features of the AMM architecture. We also show a prototype of AMM using FPGA as well as implementation data such as FPGA usage and resources in silicon area. It is also presented an ASIC prototype of AMM core. The prototype architecture of the AMM was analyzed with critical applications which are used in CPS, such as security, redundancy and fault tolerance, and these tests suggest that the future CPS processors must have those characteristics. Thus, the thesis shows that these aspects can be included in embedded systems with dedicated features to multicore applications and systems used in CPS.
\end{abstract}

Keywords: Computer architecture, Computer architecture and organization, Embedded systems, Reliability 


\section{LISTA DE ILUSTRAÇÕES}

Figura 1.1: Lacunas para novas pesquisas em SCF (ECKER, 2009) ..........................17

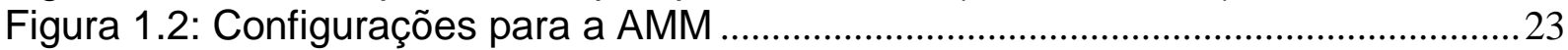

Figura 2.1: Três configurações de sistema (DOMEIKA, 2008) .......................................30

Figura 2.2: Proposta de anel de interconexão, (GOLANDER, A.;

WEISS, S.; RONEN, R, 2008).

Figura 2.3: Arquitetura sequencial com redundância seletiva,

(MILLER et al., 2009)

Figura 2.4: Exemplo simples para Redundância Modular Tripla,

(JOHNSON, J.;WIRTHLIN, M., 2010)

Figura 2.5: Diagrama do multicore Noc e configuração RNI para a

RAM, (MINHASS, W. H.; ÖBERG, J.; SANDER, I., 2009)

Figura 2.6: Protótipo do sistema com 4 Xilinx Microblaze e um

network (Kavadias, et al., 2010)

Figura 2.7: Sistema proposto com quatro processadores Xilinx

Microblaze, BOBDA,C.;HALLER,T.;MUEHLBAUER,F., 2007) ....

Figura 2.8: Modelo do ambiente de emulação ACME (IHRIG, J. C.;

MELHEM, R.; JONES, A.K. 2010)

Figura 2.9: Arquitetura do MP-SoC desenvolvido com CONCORD,

(CHUN-MING, et al 2009)

Figura 2.10: Arquitetura interna padrão do Leon3 (Aeroflex Gaisler) .............................4 44

Figura 2.11: Arquitetura interna do Propeller chip, da Parallax

(MARTIN, 2009)

Figura 3.1: Conceito da AMM proposta

Figura 3.2: Mapeamento da estrutura de intercomunicação para

configurações da AMM

Figura 3.3: Comunicação entre processadores da AMM ..................................................55

Figura 3.5: Detalhes de um canal de recepção da AMM ...............................................57

Figura 3.6: Detalhes de um canal de transmissão da AMM ...........................................58

Figura 3.7: Componentes de comunicação desenvolvidos e respectivos registradores

Figura 3.8: Quatro processadores totalmente interconectados

Figura 3.9: Interconexão entre TX e RX para quatro processadores ............................60

Figura 3.10: Arquitetura da AMM configurada com quatro

processadores

Figura 3.11: AMM composta com 8 processadores totalmente

interconectados.

Figura 3.12: Mapeamento entre quatro processadores, com

estrutura para oito processadores

Figura 3.13: Exemplos de diferentes módulos de uma mesma

aplicação na AMM

Figura 3.14: AMM com oito processadores, configurado para

quatro processadores "mestre-escravo"

Figura 3.15: Mapeamento real idealizado para diferentes

configurações de interconexões.

Figura 3.16: Estrutura para detecção de falhas na AMM ................................................. 70

Figura 3.17: Estrutura de log de atividades presente na AMM 
Figura 3.18: Estrutura de depuração da UPEM2 e estrutura de log

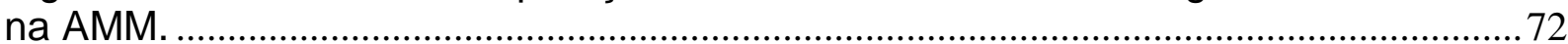

Figura 4.1: Blocos arquiteturais da UPEM, (PENTEADO, 2004). ...................................76

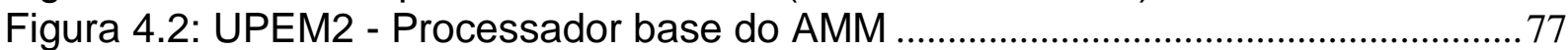

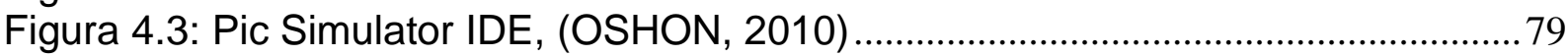

Figura 4.4: Simulação da UPEM2 no software ModelSim, com o

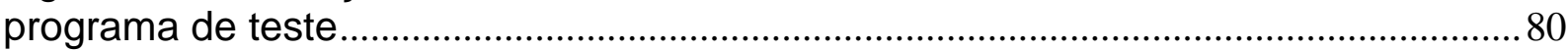

Figura 4.5: UPEM2 executando o programa Tetris (GUNEÉ, 2008),

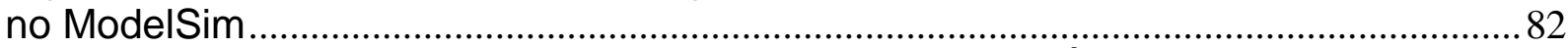

Figura 4.6: UPEM2 executando o programa Tetris (GUNEÉ, 2008),

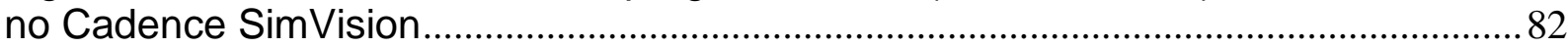

Figura 5.1: Mapa dos controladores e memória para 2, 4, 6 e 8

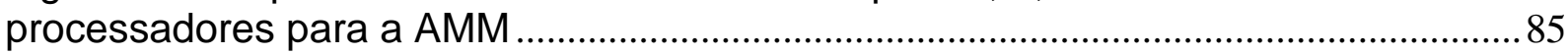

Figura 5.2: Exemplo de código para transmitir uma informação .......................................86

Figura 5.3: Exemplo de trecho de código para recepção de dados................................. 86

Figura 5.4: Exemplo de trecho de código para recepção por

interrupção

Figura 5.5(a): Fluxo para programação e depuração dos programas

na AMM

Figura 5.5(b): Fluxo para programação e depuração dos programas

na AMM

Figura 5.6: Algoritmo de controle PID em blocos, (CASTELAN,

2010)

Figura 5.7: Simulação de um controle PID em um motor:

(CASTELAN, 2010)

Figura 5.8: Aeromodelo, usando 4 ATMEL 8bits para 4 controles

PID (ROBERTS, J., 2007)

Figura 5.9: Programa mestre controla três controles PID

independentes

Figura 5.10: Trecho de código do processador mestre para o

programa de controle PID

Figura 5.11: Trecho do código de controle PID nos processadores

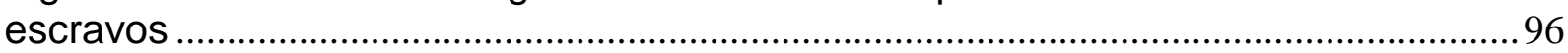

Figura 5.12: Trecho de código para simular conversões A/D ........................................97

Figura 5.13: Processador configurado como mestre enviando três

mensagens aos escravos.

Figura 5.14: Processadores do protótipo da AMM configurados

como escravos, em busca do setpoint

Figura 5.15(a): Vista processamento de controle PID por cada processador escravo

Figura 5.15(b): Vista processamento de controle PID por cada processador escravo

Figura 5.15(c): Vista processamento de controle PID por cada

processador escravo.

Figura 5.16: Processador mestre controla três escravos

redundantes com o controle PID.

Figura 5.17: Trecho do código fonte no processador mestre para o

controle PID redundante

Figura 5.18: Processador configurado como mestre enviando três mensagens síncronas 
Figura 5.19: Processadores do protótipo da AMM configurados como escravos redundantes.

Figura 5.20: Simulação da redundância entre três processadores

eleitos como escravos.

Figura 5.21: Lógica criada para inclusão proposital de falhas

controladas no hardware.

Figura 5.22: Trecho de código incluído na descrição VHDL do

processador para gerar falhas

Figura 5.23: Metodologia para criar uma falha em um processador

executando controle PID

Figura 5.24: Simulação de uma falha controlada em um

processador da AMM.

Figura 5.25: Visualização da simulação da hierarquia da estrutura

de $\log$ da AMM.

Figura 5.26: Simulação mostra que a estrutura de log armazenou a

ocorrência da falha

Figura 5.27: Simulação mostra que a estrutura de log armazenou a

propagação da falha

Figura 5.28: Suspensão da cpu3 após detecção da falha, enquanto

cpu2 continua

Figura 5.29: Algoritmo de criptografia AES, em blocos, (KAMAL, A.

A.; YOUSSEF, A. M., 2009)

Figura 5.30: Texto cifrado pelo AES 128 bits

Figura 5.31: Cifra no programa AES Block Cipher Calculator,

(BROWN L, 2005).

Figura 5.32: Processo para validação da cifra AES no processador

da AMM

Figura 5.33: Resultado da simulação da cifra AES 128 bits no

processador do AMM

Figura 5.34: Texto decifrado pelo AES 128 bits

Figura 5.35: Decifra no programa AES Block Cipher Calculator,

(BROWN L, 2005)

Figura 5.36: Processo para validação da decifra AES no

processador do AMM

Figura 5.37: Resultado da simulação da decifra AES 128 bits no

processador do AMM

Figura 5.38: Saída do AES Block Cipher Calculator, com os valores

testados no protótipo da AMM

Figura 5.39: Organização do teste para troca de texto a ser cifrado

Figura 5.40: Mensagens sendo depositadas no transmissor do

processador eleito como mestre.

Figura 5.41: Resultados da troca de mensagens e algoritmo de

cifra AES no protótipo da AMM.

Figura 5.42: Teste real em FPGA da UPEM2: Os jogos Tetris e

Pong (GUNEÉ, 2008), na TV.

Figura 5.43: Layout preliminar do processador UPEM2, utilizado na

AMM

Figura 5.44: Layout preliminar da memória RAM do processador

UPEM2 
Figura 5.45: Estimativa de área em silício para a UPEM2: 3mm x $4,5 \mathrm{~mm}$ em tecnologia $0,6 \mu$

Figura 5.46: Protótipo AMM 4 processadores, estimado em 9x6mm em tecnologia $0,6 \mu$ 


\section{LISTA DE TABELAS}

Tabela 3.1: Requisitos para o RTOS VELLOS, para CPUs PIC

(HUTORNY, 2010).

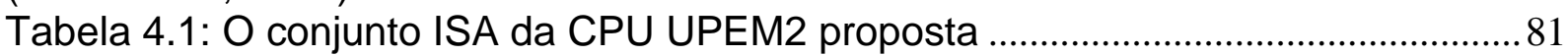

Tabela 5.1: Recursos utilizados entre UPEM e UPEM2 no FPGA

Xilinx XC2S200E

Tabela 5.2: Recursos utilizados entre a RAM da UPEM e a RAM da

UPEM2 no FPGA Xilinx XC2S200E

Tabela 5.3: Comparação de área utilizada entre UPEM2, AEMB e

PICOBLAZE

Tabela 5.4: Ocupação de diferentes versões do protótipo da AMM no XC2VP30

Tabela 5.5: AMM versus PicoBlaze e Leon3

Tabela 5.6: Desempenho da comunicação 


\section{LISTA DE ABREVIATURAS E SIGLAS}

AMM
AMP
ASIC
CMP
EDA
GNU GPL
IPC
ISA
MCAPI
MPI
NOC
PID
RTOS
SCF
SMP

Arquitetura Modular Multicore

Asymmetric Multiprocessing

Application-Specific Integrated Circuit

Chip Multiprocessing

Electronic Design Automation

General Public License

Instructions Per Clock

Instruction Set Architecture

Multicore Communication Application Programming Interface

Message Passing Interface

Network-on-Chip

Proporcional Integral Diferencial

Run Time Operational System

Sistemas Ciberfísicos

Symmetric Multiprocessing 


\section{SUMÁRIO}

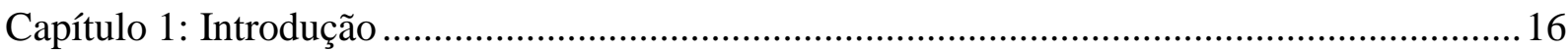

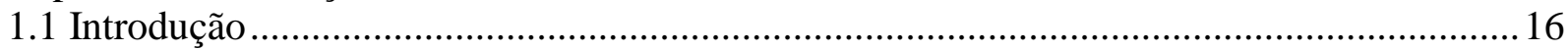

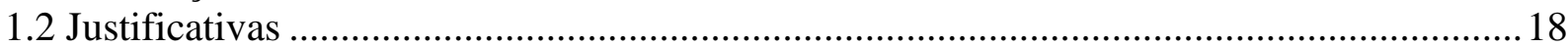

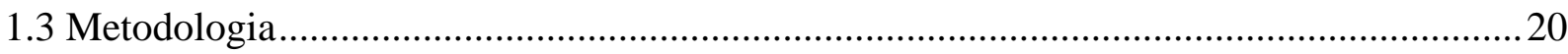

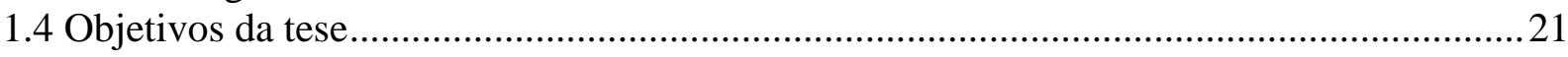

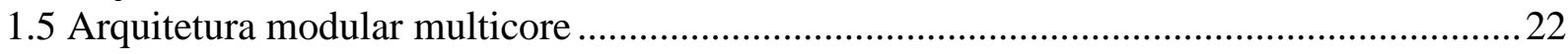

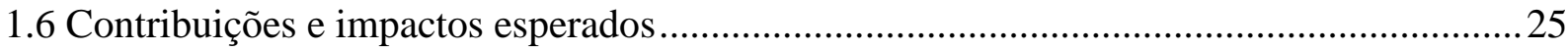

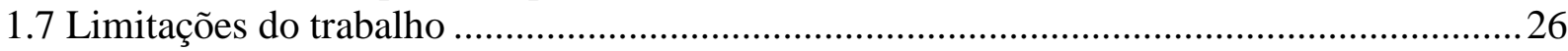

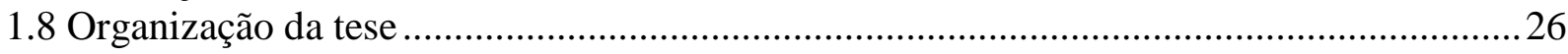

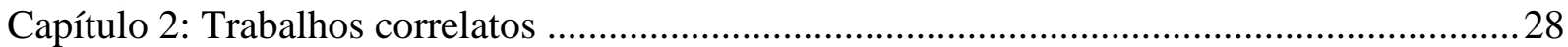

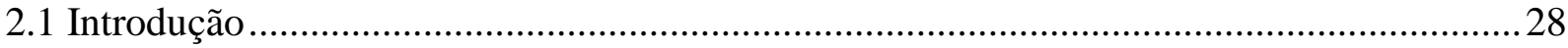

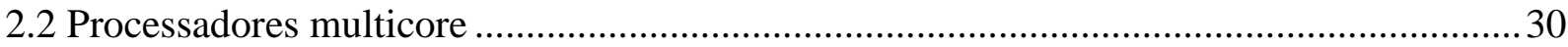

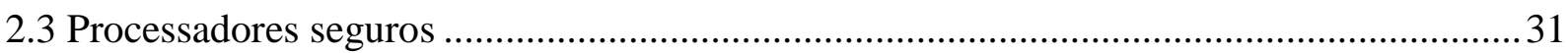

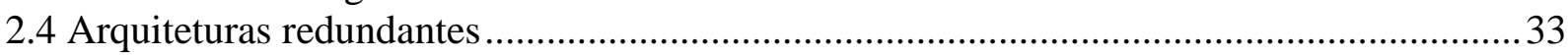

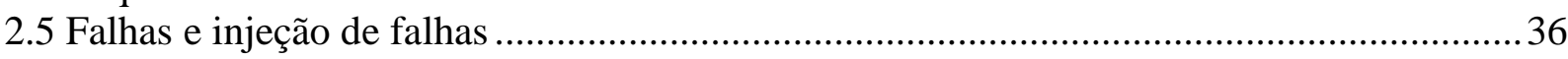

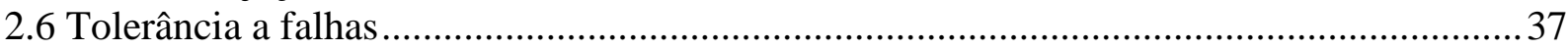

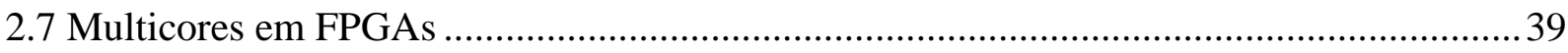

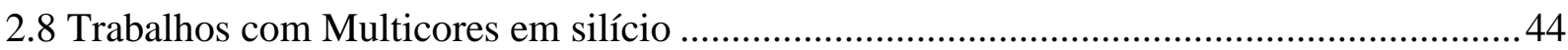

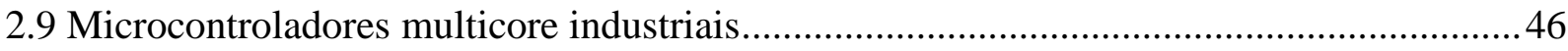

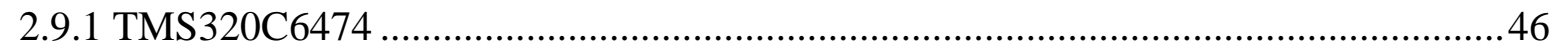

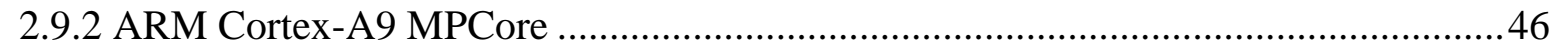

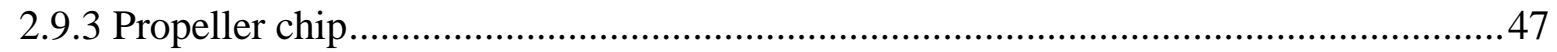

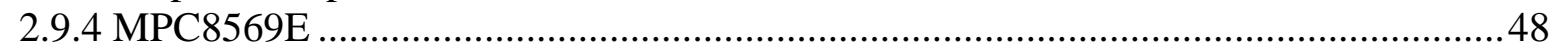

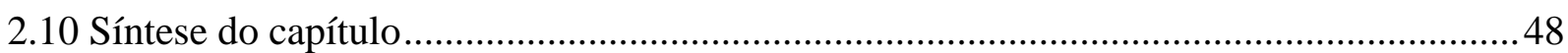

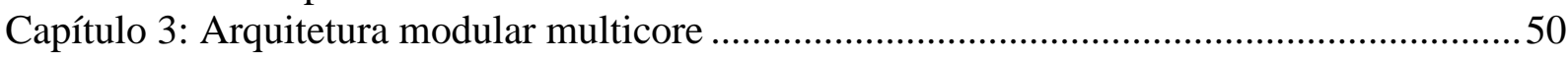

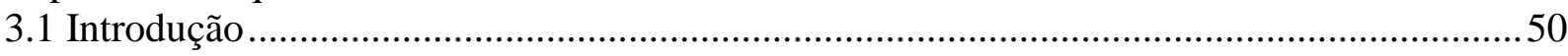

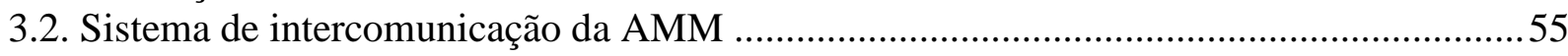

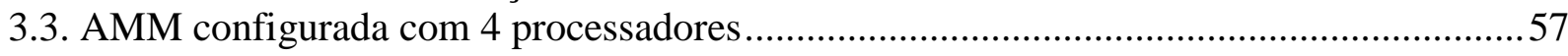

3.4. AMM: Interconexão entre quatro processadores...........................................................59

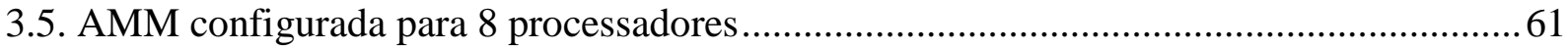

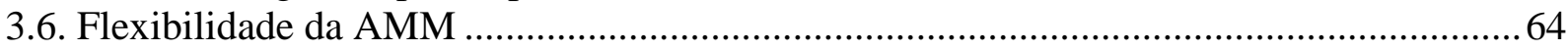

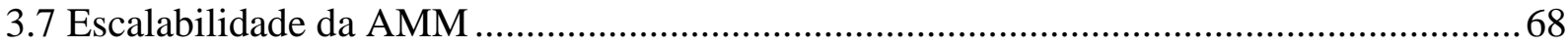

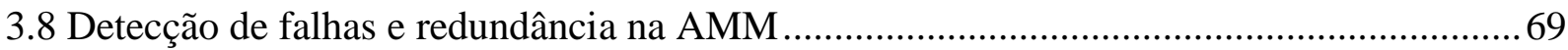

3.9 Utilização de RTOS e passagem de mensagens na AMM .............................................. 72

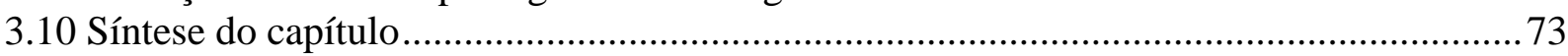

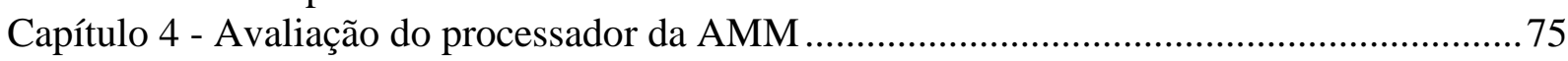

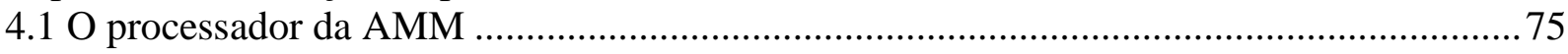

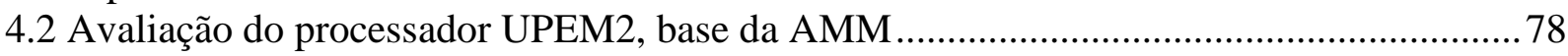

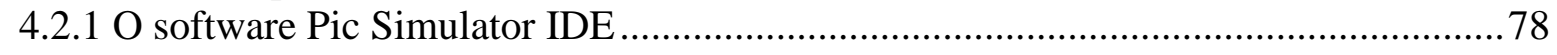

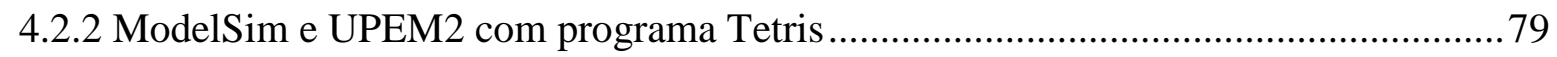

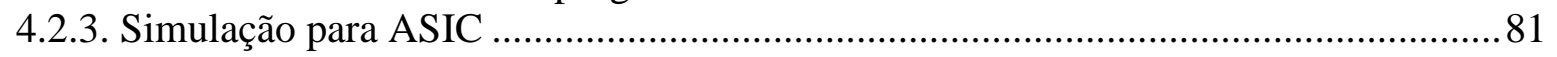

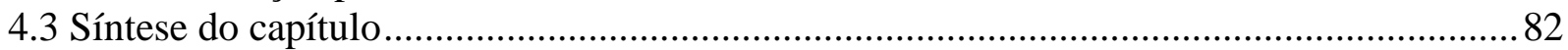

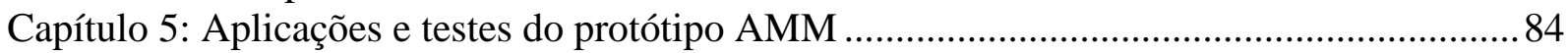

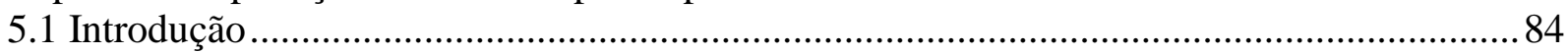

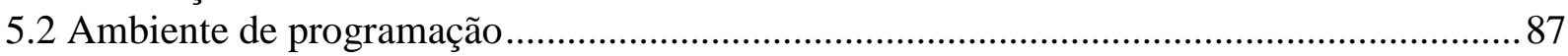

5.3 Controle proporcional integral diferencial (PID), na AMM.......................................... 92

5.4 Controle proporcional integral diferencial redundante, na AMM .................................. 101 


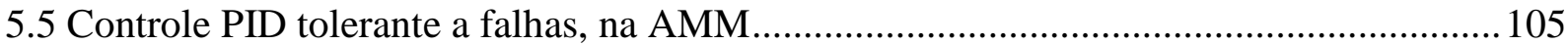

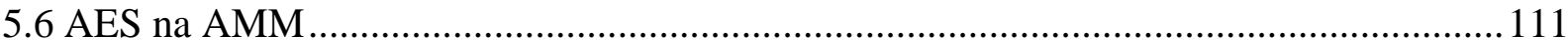

5.7 Envio de texto a ser cifrado em um processador executando o

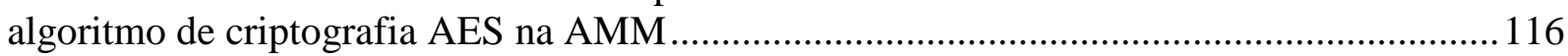

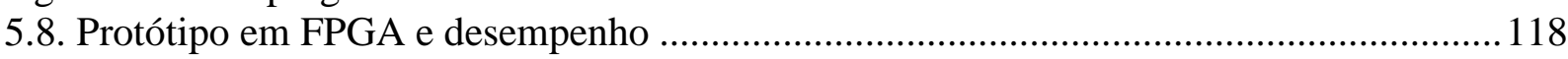

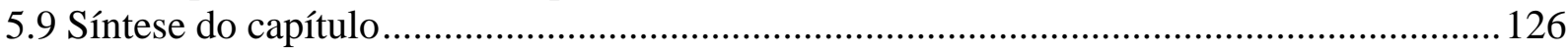

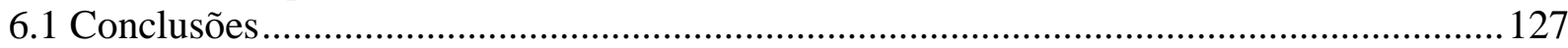

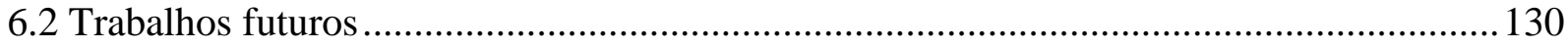

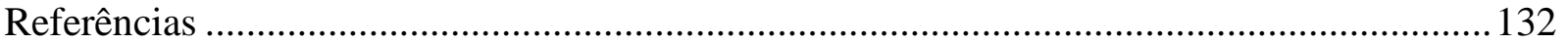




\section{Capítulo 1: Introdução}

\subsection{Introdução}

Nas décadas de 1960-1970 a computação era direcionada a mainframe, onde grandes computadores executavam, de forma centralizada, o processamento de aplicações de grande volume de dados para a época. Nas décadas de 1980-1990 a computação era direcionada à computação desktop e internet, onde um computador no escritório era utilizado para negócios e atividades pessoais. A década de 2000 foi a chamada era da computação ubíqua, na qual vários dispositivos computacionais estão ao redor de cada pessoa e em todo lugar, sendo milhões de computadores para desktop e bilhões de processadores embarcados. A década atual de 2010 está direcionada aos Sistemas Ciberfísicos ${ }^{1}$ (SCF), sistemas onde existe uma união entre computação e física. Os SCF serão utilizados nas mais diversas áreas, formando uma nova era de produtos que realizam computação sobre sensores e atuadores e se intercomunicam (LEE, I., 2008).

Sistemas Ciberfísicos estarão em qualquer lugar, serão utilizados por qualquer um e para qualquer coisa. A expectativa é disponibilidade 24h/dia e 7 dias/semana, $100 \%$ de confiança, $100 \%$ de conectividade, resposta instantânea e armazenar qualquer coisa para sempre (WING, J. M., 2008).

Aplicações para SCF incluem sistemas e dispositivos médicos altamente confiáveis, controle de trafego e segurança, sistemas automotivos avançados, controle de processos, conservação de energia, controle ambiental, aviação, instrumentação, controle de infra estrutura crítica - energia elétrica, abastecimento de água, e sistemas de comunicação -, tele presença, tele medicina, sistemas de defesa, fabricação e estruturas inteligentes.

$\mathrm{Na}$ área da medicina, SCF auxilia na concepção e utilização de marcapassos, injeção automática de medicamentos, tecnologias de scanners como a ressonância magnética, dentre outras. Na engenharia civil, a concepção "sensores 
em qualquer lugar" auxilia no monitoramento de construções inteligentes, como pontes e prédios, para prevenção de catástrofes naturais ou mesmo apenas para comodidade.

Sistemas Ciberfísicos são sistemas que unem física e engenharia, nos quais operações são monitoradas, coordenadas, controladas e integradas por um núcleo que realiza computação e comunicação. Integra computação, comunicação e capacidade de armazenamento com o monitoramento e/ou controle de entidades no mundo físico. (RAJKUMAR et al. 2010).

Sistemas Ciberfísicos integram computação e comunicação com monitoramento e controle de entidades do mundo físico. Estes sistemas são usualmente compostos de um conjunto de agentes unidos por uma rede de trabalho, incluindo sensores, atuadores, unidades de controle de processamento e dispositivos de comunicação. Enquanto algumas formas de SCF já estão em uso, o grande aumento dos sensores e atuadores embarcados sem fio, está criando muitas novas aplicações. Por exemplo, dispositivos médicos, veículos autônomos e estruturas inteligentes. (CARDENAS, 2008)

Dado o avanço acelerado dos SCF, existem lacunas de projeto e capacidade de implementação para alcançar confiança, privacidade, personalização, menor custo, etc. A Figura 1.1 ilustra o cenário atual dos SCF e contextualiza algumas lacunas para pesquisa.

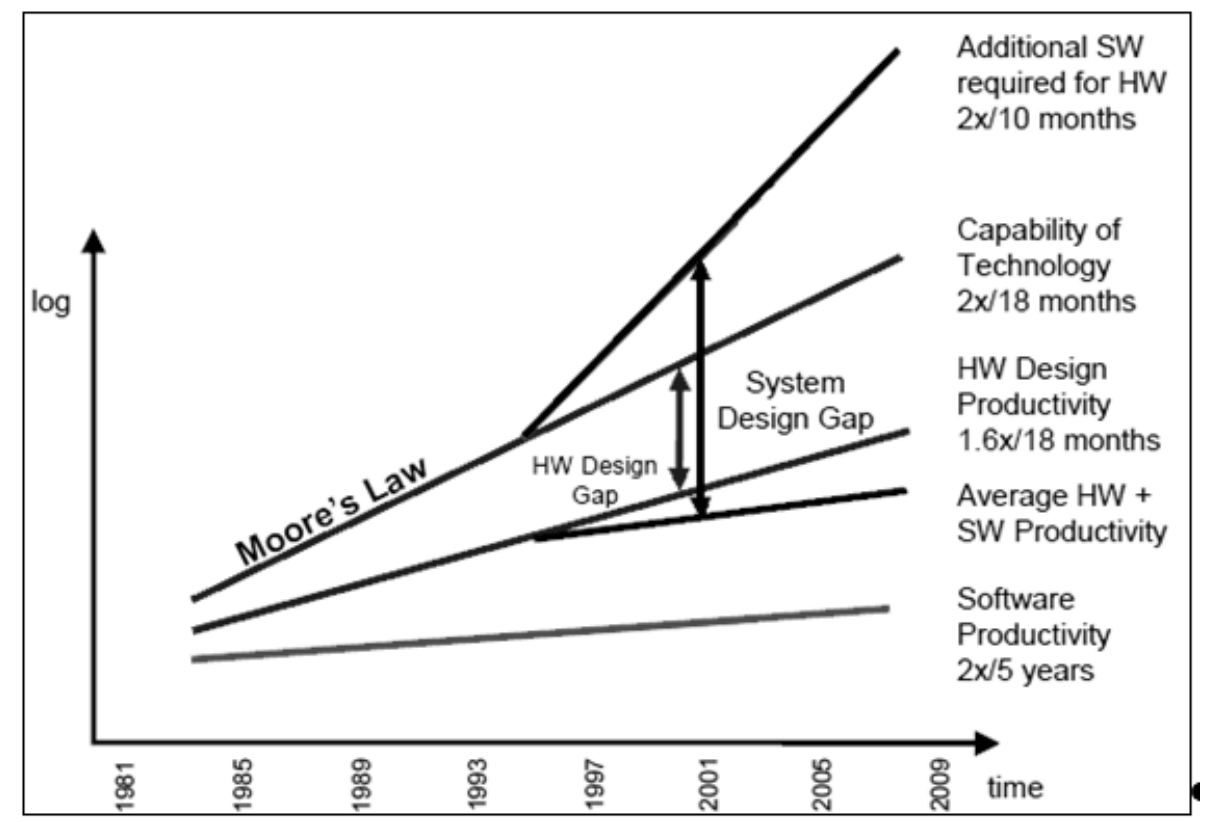

Figura 1.1: Lacunas para novas pesquisas em SCF (ECKER, 2009) 
Em um SCF para sistemas de geração e distribuição de energia elétrica, um grande número de dispositivos de potencia, sob um controle distribuído, gerenciam o fluxo da energia elétrica. Isto introduz muitos pontos de acesso que podem ser explorados por um atacante. O fluxo de informação deste sistema pode divulgar informações sobre o estado do sistema o que pode expor suas vulneralibidades. $O$ North American Electric Regulatory Commission (NERC) enfatiza a necessidade de proteger a infra estrutura de energia contra ciber ataques. (MCMILLIN, 2009)

Em SCF aplicados à linha automotiva, microcontroladores podem ser empregados, por exemplo na autenticação da chave de ignição, controle do motor, sistema de freios, monitoramento de air bag, travas das portas, vidros automáticos, sistemas de entretenimento, etc. Em 2005, um BMW 745i já possuía 60 microcontroladores em seu sistema. (RAJKUMAR et al., 2010).

Alguns problemas que precisam de soluções podem ser citados, como por exemplo, a tolerância a falha, segurança da rede, códigos intrusos, propriedades críticas em dispositivos médicos, etc. Assim, algumas soluções existem, porém, cobrem parcialmente os diversos problemas a serem enfrentados na concepção dos SCF.

\subsection{Justificativas}

Muitos desafios deverão ser enfrentados por SCF, dentre eles pode-se citar: (i) integridade - refere-se à veracidade dos dados ou recursos, quando por exemplo, uma parte autorizada recebe dados falsos e os tomam como verdadeiros; (ii) disponibilidade - refere-se à habilidade do sistema ser acessível e usável, mesmo sob demanda; (iii) confidencialidade - refere-se à característica do sistema em manter informações secretas à usuários não autorizados; (iv) escalabilidade precisa ser escalável para sistemas compostos por vários componentes para permitir a construção de sistemas complexos; (v) nível de abstração razoável - a noção de sistema deve ser mantida, ao invés de focar-se em comunicações nó-a-nó entre dispositivos; (vi) multi tolerância - níveis de tolerância a falhas podem especificar a satisfação em segurança, tempo de vida e restrições de temporização, na presença 
de falhas e; (vii) os sistemas devem suportar múltiplos sistemas híbridos que compõem os SCF. (BONAKDARPOUR, 2008).

Com a proliferação dos sistemas embarcados, um outro paradigma está se consolidando: sistemas embarcados abertos. Enquanto sistemas embarcados tradicionais provêem somente aplicações fechadas aos usuários, tais como email e navegador em telefones celulares, sistemas embarcados abertos permitem que usuários executem livremente aplicações abertas. Estas podem ser copiadas a partir de qualquer web site para adicionar muitas funcionalidades aos sistemas embarcados. (INOUE, 2009)

A flexibilidade dos sistemas embarcados abertos resulta em um novo grupo de aplicações abertas que podem conter bugs ou vírus. Isto significa que as aplicações base precisam ser protegidas de aplicações abertas escritas com códigos maliciosos.

Segurança computacional é um campo amplo e dinâmico. Sistemas computacionais são sujeitos a uma vasta gama de ataques e sofrem de muitas vulnerabilidades. Segundo (ROGERS, 2010), a pirataria de software produziu um impacto de 53 bilhões de dólares, visto que foi estimado em $41 \%$ do software em uso ao redor do mundo em 2008. Além disso, segundo o mesmo autor, a grande maioria (98\%) dos microprocessadores são produzidos e vendidos para uso em sistemas embarcados. Estes também evoluem e são agora capazes de se conectarem em redes e na própria internet, expondo os sistemas embarcados a muitos dos mesmos ataques que sistemas computacionais tradicionais e de propósito geral apresentam.

A segurança em sistemas embarcados pode ser classificada em segurança de dados e segurança de programa. O objetivo da segurança de dados é a proteção da integridade e privacidade de dados confidenciais. O objetivo da segurança de programa é a garantia da correta execução dos programas, que resulta na correta seqüência de ações.

Outra barreira a ser vencida por SCF é a tolerância a falhas por mudanças de estados de bits provocadas por fenômenos naturais conhecidos como total ionizing dose (TID), single event latchups (SELs) e single event upset (SEUs), se o ambiente de funcionamento for hostil ou ruidoso.

Estes fenômenos, detalhados no capítulo 2 desta tese, podem ser "catastróficos" em um circuito digital mapeado em FPGA se ocorrem na memória de 
configuração, gerando circuitos com lógica digital diferente da especificada inicialmente.

O cenário de sistemas ciberfísicos exigirá dos processadores de sistemas embarcados melhorias em características além de processamento de $\mathrm{I} / \mathrm{O}$, consumo de energia, e comunicação, ou seja, as futuras arquiteturas de processadores deverão possuir também características de segurança, tolerância a falhas e flexibilidade arquitetural para adequação à várias aplicações.

Neste contexto, algumas perguntas podem ser levantadas:

Os processadores estão suficientemente robustos, considerando os aspectos de segurança, privacidade de dados, tolerância a falhas e flexibilidade de adequação, para suprir às futuras necessidades dos sistemas ciberfísicos ?

Existem ambientes consolidados que integram várias ferramentas envolvidas no projeto de hardware/software, tais como, síntese, compilação, simulação, depuração, co-design, verificação e injeção de falhas ?

Como conceber novos processadores que possam garantir segurança, privacidade de dados, tolerância a falhas, flexibilidade de adequação, dentre outros requisitos de SCF, sem aumentar exponencialmente a área de lógica necessária?

Certamente não existe uma única forma ou um único sistema capaz de oferecer o devido suporte para responder estas perguntas. Além disso, a cada dia, novos requisitos são necessários, tornando a pesquisa e o desenvolvimento, um processo contínuo.

Porém, é possível apontar algumas soluções que, unidas a outras e à constante pesquisa, podem auxiliar o desenvolvimento de novos sistemas e produtos.

\subsection{Metodologia}

Verificar e identificar alguns dos principais problemas envolvidos em sistemas embarcados ciberfísicos e propor uma solução em hardware para alguns destes problemas;

Idealizar cenários para aplicações voltadas à SCF e seu possível mapeamento em um ambiente composto por ferramentas de hardware e software; 
Projetar um protótipo em FPGA para um sistema composto por vários processadores que contempla flexibilidade, segurança e tolerância a falhas;

Descrever em detalhes a arquitetura completa do protótipo;

Obter uma descrição VHDL sintetizável de um processador compatível com compiladores comerciais existentes;

Implementar e testar o protótipo em FPGA;

Avaliar a funcionalidade e o desempenho do protótipo, com 0 desenvolvimento de programas especificamente escritos para o protótipo.

\subsection{Objetivos da tese}

Propor uma arquitetura modular multicore (AMM) inserida em uma linha evolucionária de hardware e suas respectivas ferramentas de software, para uso em sistemas embarcados ciberfísicos, com características de flexibilidade, segurança e tolerância a falhas.

Os objetivos secundários são:

(i) Demonstrar um protótipo funcional, de uma arquitetura com flexibilidade de adequação à diversos projetos, configurável para executar códigos redundantes e tolerante à falhas e com características de segurança de dados e contra clonagem;

(ii) Comprovar a flexibilidade da arquitetura e indicar algumas aplicações;

(iii) Obter um protótipo com redundância de processamento;

(iv) Comprovar a segurança de dados da arquitetura, em relação a privacidade de dados;

(v) Comprovar a tolerância à falhas e geração de logs do protótipo e

(vi) Obter uma versão preliminar funcional da AMM. 


\subsection{Arquitetura modular multicore}

O avanço da pesquisa e da tecnologia em sistemas digitais possibilitou a união do poder computacional de muitos processadores inter-comunicantes em um mesmo encapsulamento. Surge assim o conceito de multicore, um processador composto por réplicas idênticas e funcionais de um processador ou várias unidades funcionais distintas (DOMEIKA, 2008). Um multicore agrega muita flexibilidade, em termos da distribuição da aplicação.

Neste contexto, idealizou-se uma arquitetura mapeável em FPGA para um multicore voltado à SCF, compondo uma arquitetura flexível, tolerante a falhas e com características de segurança de dados e contra clonagem.

A arquitetura idealizada é homogênea composta por processadores idênticos, ou heterogênea, composta por processadores distintos, capazes de serem configurados sob diversas formas de interconexão.

Assim, pode-se obter redundância de processamento, empregar técnicas de tolerância a falhas, proteger os dados com algoritmos de criptografia, ou ainda, manter todos os processadores executando códigos e funções distintas.

A arquitetura proposta neste trabalho é chamada por Arquitetura Modular Multicore - AMM. É composta por $n$ processadores inter-comunicantes e provê características importantes de um sistema robusto, tais como multitask real, redundância, detecção de falhas e geração de logs, caso sejam necessárias.

A Figura 1.2 mostra que a AMM pode ser caracterizada como: (A) de 2 a $n$ processadores; (B) configuração $n$ - $n$ processadores fracamente acoplados; (C) $n$ $n$, fortemente acoplados ou; (D) 1- $n$, "mestres" - $n$ escravos". 


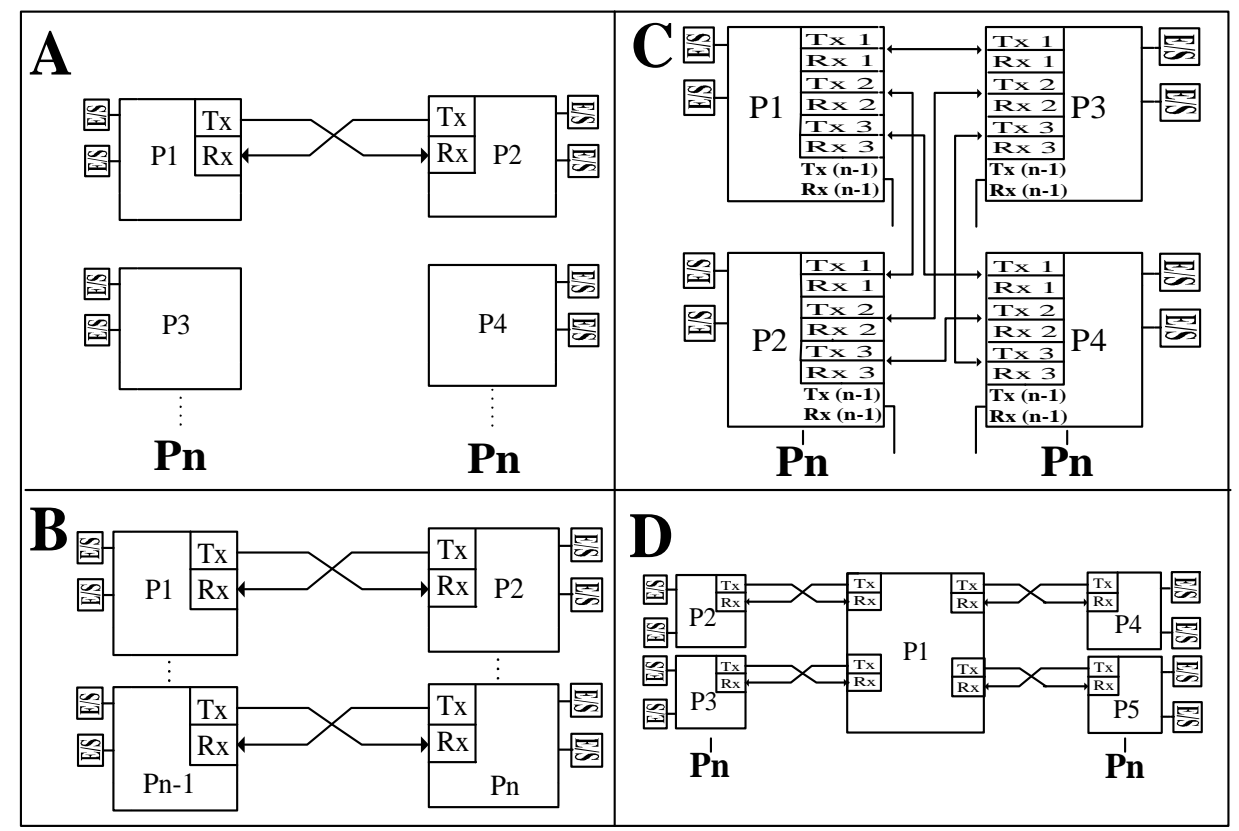

Figura 1.2: Configurações para a AMM

A flexibilidade é alcançada por meio de programas e pela possibilidade de agrupar os processadores sob diversas configurações de interconexão. A redundância é alcançada por meio da replicação de um mesmo programa em mais de um processador e técnicas para sincronismo na execução. A tolerância a falhas é alcançada por meio de um hardware de detecção de falhas e mecanismos de votação entre processadores. A segurança é alcançada destinando-se um dos processadores para executar operações de cifra e decifra de dados e pelo uso de memórias internas ao multicore.

Neste contexto, a aplicação pode ser distribuída entre os processadores: (i) um ou vários processadores podem estar dedicados à processamento dos dados; (ii) alguns processadores podem estar dedicados à recepção e processamento prévio local de sinais; (iii) outros processadores podem ser dedicados a geração de estímulos e comunicação com outros dispositivos externos ao chip; (iv) processadores podem trocar informações e dados; $(v)$ pode-se eleger um processador central para processamento "global", se houver necessidade e; (vi) pode-se definir núcleos para tarefas idênticas, obtendo-se assim, redundância.

Por exemplo, cada processador pode ser utilizado de forma independente para diversas funções, executando processamento local de dados para uma ou mais tarefas distintas, programadas em suas respectivas memórias de programa e selecionadas de acordo com a necessidade da aplicação. 
A seleção destas funções é feita com o uso de troca de informações entre os processadores, podendo ser centralizada em um único processador ou coordenada por todos os processadores do sistema.

É possível desenvolver a aplicação em uma versão AMM que possua mais processadores que o necessário, buscando-se conduzir a aplicação com o número mínimo de processadores. É possível desenvolver o sistema em uma versão que possui processadores agrupados e, após comprovar o funcionamento, se for o caso, distribuir fisicamente os processadores de forma transparente para o software anteriormente desenvolvido.

As características da AMM consideradas mais importantes são:

(i) Arquitetura pode ser composta por $n$ processadores, hardware dedicado ou uma união ambos;

(ii) Flexibilidade: permite que engenheiros e programadores encontrem por meio de software, de forma simples, a melhor forma para interconectar os processadores e desenvolver rotinas de software dedicadas em cada processador;

(iii) Redundância de processamento, caso seja necessária e útil para sistemas considerados críticos;

(iv) Tolerância à falhas: possui hardware simples para detecção de falhas, para ser utilizado em conjunto com códigos redundantes;

(v) Escalabilidade: Utiliza o mesmo conceito de comunicação para processadores locais ou fisicamente distribuídos;

(vi) Conceito adaptável à outros processadores, formando outras versões para a AMM para compatibilidade com outros compiladores e ferramentas EDA;

(vii) Sistema de comunicação simples, composto por apenas duas linhas de dados seriais entre dois processadores. Permite também comunicação assíncrona independente entre processadores;

(viii) Geração de log para rollback de processamento em caso de falhas detectadas e;

(ix) Periféricos: diminui a necessidade de periféricos específicos para funções digitais como contagem de pulso, geração de pulsos, PWM, UART, I2C, CanBus etc, pois podem ser realizadas em software nos próprios processadores; 
Algumas áreas de emprego da AMM são: (i) Sistemas Ciberfísicos; (ii) Robótica; (iii) Automotiva; (iv) Mecatrônica; (v) Controle em geral; (vi) Aplicações típicas de microcontroladores e sistemas embarcados; etc.

Aplicações voltadas à controlador lógico programável (CLP), braços robóticos, veículos, fresas, impressoras, sensores, atuadores, controle digital, controle de motores, temperatura, etc.

\subsection{Contribuições e impactos esperados}

Uma arquitetura flexível, composta por processadores minimalistas, módulos de hardware dedicado ou sistemas híbridos. A arquitetura provê características de segurança, tolerância a falhas e flexibilidade de adequação a diversas aplicações.

Com a evolução da AMM proposta, espera-se obter:

Uma forma de conceber processadores de modo que estes já possuam atributos como tolerância à falha, segurança e flexibilidade de adequação.

Um ambiente de desenvolvimento unificado para a AMM, com ferramentas de compilação de programas, simulação, depuração e hardware/software co-design;

Outras versões da AMM, composta por núcleos diferentes do processador base utilizado no protótipo do sistema atual. Assim, será possível obter outros dados referentes à àrea de lógica ocupada pelos novos sistemas, performance obtida e ser destinada à várias aplicações com diferentes requisitos.

Macros para compiladores compatíveis com o processador atual, para facilitar a programação e diminuir as limitações de uso atual;

IP's AMM compostos por diferentes quantidades de processadores compatíveis com o ambiente de desenvolvimento, para utilização direta em dispositivos FPGA;

Diferentes versões AMM completas em ASIC, incluindo oscilador analógico para fonte de clock, memória RAM de trabalho, memória FLASH de programa e respectivo mecanismo para gravação externa de dados, e blocos analógicos comuns em microcontroladores tais como power-on-reset, $A / D$ e $D / A$, dentre outros.

Modelos para verificação formal e vetores de teste completo para a AMM, compatíveis com as diferentes versões obtidas; 


\subsection{Limitações do trabalho}

Alguns pontos são relevantes, porém, não são explorados neste trabalho e são listados a seguir:

Verificação formal do processador e do sistema multicore como um todo;

Análise do consumo de energia do sistema proposto;

Ambiente de desenvolvimento integrado;

Técnicas de invasão do conteúdo de processadores - dados e do circuito físico;

Técnicas de injeção de falhas;

\subsection{Organização da tese}

Os demais capítulos estão organizados conforme descritos a seguir:

O Capítulo 2 - Trabalhos correlatos - apresenta alguns processadores e microcontroladores multicore da academia e do mercado. Comenta trabalhos com multicores em FPGA, características de processadores seguros e tolerante a falhas.

O Capítulo 3 - Arquitetura Modular Multicore - descreve em detalhes a AMM. Detalha a configuração para o sistema, fornecendo dados para configurações com 2 , 4, 8 ou mais processadores no sistema. O sistema de interconexão entre processadores é apresentado, todos os seus componentes e interligações são detalhados. Descreve a estrutura de detecção de falhas e geração de logs. Por fim, indica alguns RTOS candidatos de uso na arquitetura e algumas formas para a troca de mensagens.

O Capítulo 4 - Concepção do processador da AMM, descreve os métodos para avaliar a execução correta das instruções do processador da AMM. Descreve detalhes de programas reais em um simulador comercial, compatível com 0 processador desenvolvido. Ao final, compara os resultados deste simulador com softwares específicos para simuladores de lógica digital e projeto de ASIC.

No Capítulo 5 - Programas para a AMM - são apresentados alguns programas completos desenvolvidos para uso na $A M M$, os quais foram testados via simulação, verificando sua correta execução. A organização geral dos registradores e rotinas de software são apresentadas para obter-se a flexibilidade, redundância e tolerância a 
falhas da arquitetura proposta. São também apresentados dados de ocupação em dispositivos FPGA de um protótipo funcional da AMM e testes físicos.

Finalmente, o Capítulo 6 apresenta as conclusões da tese, e finaliza discutindo alguns assuntos de interesse futuro, visando melhorias e continuidade do uso e projeto da AMM. 


\title{
Capítulo 2: Trabalhos correlatos
}

\begin{abstract}
Neste capítulo é feita uma revisão de trabalhos acadêmicos e alguns produtos comerciais que podem ser empregados em sistemas ciberfísicos. Uma breve descrição de cada trabalho é realizada e ressalta-se a correlação com a AMM proposta. Comenta-se algumas linhas de pesquisa correlacionadas com sistemas ciberfísicos. Inicia-se por rápidos comentários sobre sistemas embarcados e algumas considerações básicas sobre processadores multicore, os quais estão sendo cada vez mais utilizados para aplicações em diversos segmentos. Na sequência comenta-se sobre processadores seguros, focandose em segurança contra invasão, códigos maliciosos e contra clonagem de dispositivos. Comenta-se também alguns trabalhos sobre arquiteturas redundantes, trabalhos sobre injeção de falhas e métodos para alcançar confiabilidade de execução, utilizando redundância de processamento tripla. Por fim, alguns trabalhos sobre multicore em FPGAs, multicores em silício e alguns microcontroladores multicore industriais são comparados com a AMM proposta, sob diversos aspectos e funcionalidades.
\end{abstract}

\subsection{Introdução}

A crescente demanda por SCF força a busca por novos conceitos e métodos na concepção da futura computação. SCF são integrações da computação com processos físicos. Os alicerces da computação tem base na premissa que a tarefa dos computadores é transformar dados. Sabe-se que a tecnologia é capaz de ricas interações com o mundo físico e que uma nova ciência será a união da física e da computação. (LEE, 2008)

Os desafios técnicos são mais voltados a previsibilidade e robustez que em eficiência. Sistemas de controle de avião, são exemplos típicos onde os fabricantes de software são forçados a uma extrema mentalidade em forma de "caixa lacrada". Em uma linha de fabricação de aviões por 50 anos, o fabricante é forçado a comprar, de uma única vez, microcontroladores necessários para suprir 50 anos de produção. Os sistemas então, não se beneficiarão de 50 anos de melhorias 
tecnológicas sem refazer a extremamente cara certificação e validação do software. Eficiência é quase irrelevante comparada a previsibilidade, e previsibilidade é difícil de se alcançar sem congelar o projeto no nível físico. (LEE, 2008)

Um sistema embarcado é um produto da engenharia que envolve a computação como um meio para às limitações físicas. Estas limitações resultam em dois tipos de interações entre os processos computacionais e o mundo físico: (i) reação à um ambiente físico e; (ii) execução sobre uma plataforma física. Reação às limitações são estudadas em teoria de controle; limitações de execução, em computação. (HENZINGER, 2006)

Sistemas embarcados são constituídos de hardware, software e um ambiente. Envolvem computação, a qual é um meio para as limitações físicas. Isto forma uma clara separação entre a computação - o software -, e o físico - plataforma e ambiente. Sistemas de software são projetados a partir de componentes sequênciais, tais como objetos e threads, sendo que sua estrutura pode mudar dinamicamente - componentes podem ser criados, apagados ou mesmo migrar. Sistemas de hardware são projetados como uma composição de componentes paralelos interconectados, e sua composição é definida especificando-se como os dados fluem através dos múltiplos componentes. Computação e software são partes integrantes de um sistema embarcado. Assim, as deficiências do projeto corrente, validação e processos de manutenção tornam o software a parte mais custosa e importante em sistemas automotivos, aero espaciais, médicos e outras aplicações críticas. (HENZINGER, 2006)

Sistemas embarcados monitoram e controlam os processos físicos, geralmente, com laços de realimentação, nos quais, processos físicos afetam a computação e vice-versa. SCF serão concorrentes por natureza. Processos físicos são concorrentes e sua união com computação requer uma composição concorrente de processos de computação com os processos físicos. Sistemas embarcados precisam reagir a múltiplos estímulos de sensores e controlar múltiplos atuadores concorrentemente. 


\subsection{Processadores multicore}

Um processador multicore consiste em múltiplos processadores dispostos em um mesmo encapsulamento físico e sua respectiva interface com uma placa mãe. Processadores multicore foram introduzidos em vários segmentos da academia e do mercado. A motivação básica é a performance, pois o uso de processadores multicore pode resultar em execução mais rápida, aumento do throughput, e baixo consumo necessário para aplicações embarcadas (DOMEIKA, 2008).

Um sistema multiprocessador consiste de múltiplos processadores interconectados em um único sistema, sendo que cada um destes processadores podem ser core simples ou multicore. A Figura 2.1 mostra três diferentes layouts de sistemas: um mono processador / core simples; um sistema multiprocessador / core simples e um multiprocessador / multicore.

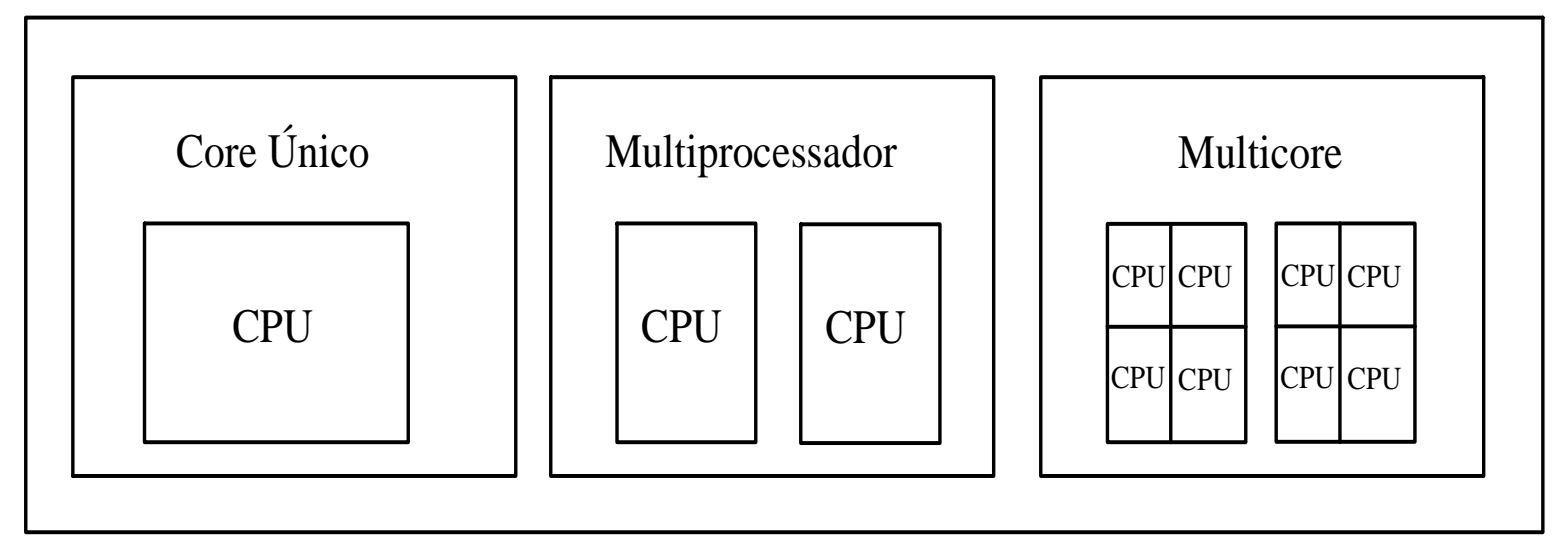

Figura 2.1: Três configurações de sistema (DOMEIKA, 2008)

Um processador multicore possui dois ou mais cores em um único chip. Multicore difere de multiprocessador: (i) latência de comunicação - multicore tipicamente possui latência menor que a latência de um multiprocessador; (ii) largura de banda - tipicamente mais alta que a largura de banda de um multiprocessador, pois os processadores estão fisicamente mais próximos e; (iii) número de processadores - multicore apresenta atualmente menos processadores que um sistema multiprocessador.

Multicore são organizados para compartilhar informação através dos cores utilizando barramentos rápidos ou um network de chaveamento que limita o número de cores que podem ser acomodados (SAVAGE, 2008). 
Um processador multicore é definido como um processador que contém múltiplos processadores em um chip. Chips convencionais de um único processador precisam operar em altas frequências de clock para prover performance suficiente, o que torna mais difícil reduzir a dissipação de energia. Um chip multicore permite o desejado nível de performance ser alcançado com um número maior de processadores que operam à uma frequência de clock moderada, o que auxilia em manter a baixa dissipação de energia (INOUE, 2009).

Uma classificação de processadores multicores é feita com base no tipo do processador presente no mesmo chip. Um multicore homogêneo é formado por dois ou mais processadores de mesmo conjunto de instruções. Um multicore heterogêneo é composto por processadores com conjuntos de instruções diferentes, possuindo a vantagem de empregar um determinado processador na execução de uma determinada tarefa específica. Uma outra classificação de processadores multicore é refere-se à como os processadores dispõem-se em relação ao sistema embarcado como um todo. Existem duas classificações chamadas por simétricas (SMP) e assimétricas (AMP), as quais diferem em termos do acesso a memória e a comunicação entre processos. (DOMEIKA, 2008)

A comunicação entre os processadores em um sistema SMP é realizada por compartilhamento de memória e o sistema operacional que provê funcionalidades de sincronização e exclusividade de acesso a regiões da memória.

Em sistemas AMP com regiões de memória separadas a comunicação é realizada por meio de passagem de mensagens facilitando que servidores empacotem dados e transfira-os de um sistema operacional para outro. Um padrão de comunicação que suporta comunicação entre processadores em um sistema AMP é o Multicore Communication Application Programming Interface (MCAPI) (MEAKIN, 2009).

\subsection{Processadores seguros}

Devido a necessidade de confidencialidade de dados, confiabilidade na integridade dos programas, garantias contra cópias de partes de dispositivos, aparece o conceito de processadores seguros. 
O conceito do que é um processador seguro evoluiu ao longo dos anos. No início da era Desktop, os computadores eram utilizados de forma única, sozinhos e fechados em uma sala. Com a atual e crescente conectividade os computadores e os dispositivos móveis que executam computação embarcada estão cada vez mais vulneráveis a ataques contra sua integridade e confidencialidade.

O princípio básico da confidencialidade é o uso de algoritmos de criptografia considerados seguros, cujas chaves para as operações são mantidas em locais seguros. Para garantir a integridade de um programa, assinaturas são geradas de acordo com a sequencia e os valores de cada instrução em um bloco. Desta forma, procura-se garantir a confidencialidade dos dados criptografando-os e, ao mesmo tempo, gerando assinaturas dos blocos de instruções procurando garantir também a integridade.

Ainda assim, as técnicas de injeção de padrões conhecidos e análise do consumo de energia do processador, podem revelar os processos ocultos que um processador está executando.

Considerando a extrema complexidade dos modernos sistemas operacionais em conjunto com a flexibilidade do software, a probabilidade de erros ou intervenção futura aumenta, eliminando a confiança plena no sistema operacional ou qualquer outro software voltado a segurança. Como resultado, mecanismos de hardware precisam ser utilizados para prover proteção de software confiável. É importante notar que, devido ao fato que nenhum sistema é completamente seguro à todos os ataques, cada sistema precisa ser projetado com um certo conjunto de requisitos de segurança. (EDMISON, 2006)

O fabricante Maxim desenvolveu o microprocessador seguro DS5250, projetado para servir como um co-processador para sistemas embarcados em conjunto com microprocessadores não seguros. O DS5250 contém uma memória não volátil interna, a qual é apagada se uma invasão é detectada. Esta memória é utilizada para armazenar as chaves secretas e também pode ser utilizada para gravar outros dados considerados confidenciais. O DS5250 pode também acessar uma memória externa, utilizando criptografia.

O fabricante Atmel desenvolveu o chip AT91SO, o qual possui compatibilidade com os principais algoritmos conhecidos, tais como RSA, DES e AES, bem como vários periféricos de comunicação. Pode ser utilizado para cifrar/decifrar diretamente os dados de outros dispositivos externos, obtendo-se 
assim um canal de comunicação criptografado, o que aumenta a segurança nas comunicações entre dispositivos.

O mesmo fabricante Atmel desenvolveu o chip AT98SC, o qual permite assinaturas digitais entre dispositivos, além da criptografia. Assim, os chips intercomunicantes trocam informações sobre a autenticidade de ambos, confirmando se os dispositivos são genuínos e confiáveis antes de iniciarem a troca efetiva de dados criptografados.

Bruister (2003) mostra como desenvolver um microcontrolador seguro utilizando o algoritmo de criptografia 3DES e o IP MicroBlaze em um FPGA Virtex da família Xilinx. Os dados são criptografados internamente ao sistema e os dados de entrada e saída são assim também criptografados. O hardware de criptografia é inserido entre o MicroBlaze e sua memória de dados.

Com base no conceito industrial de segurança separação vermelho/preto, onde elementos classificados como vermelhos precisam ser completamente separados dos componentes pretos do sistema,

Hufimire et al. (2007) propõem formas de interconectar os processadores de modo que informações importantes não vazem de um core à outro. Os cores permanecem separados e somente se comunicam por meio de macros com conexões pré-definidas. Assim, garante-se que um core seja fisicamente incapaz de acessar dados não autorizados em um outro core no sistema.

\subsection{Arquiteturas redundantes}

A diminuição física dos transistores a cada nova tecnologia de fabricação e o alto número de transistores em um mesmo chip são fatores que contribuem para o crescimento da taxa de erros. (GOLANDER, A.; WEISS, S.; RONEN, R., 2008) Para garantir a continuidade da evolução, novas soluções precisam ser desenvolvidas.

Golander, A.; Weiss, S.; Ronen, R. (2008) apresentaram um sistema chamado Dynamic Dual Modular Redundancy (DDMR) que utiliza técnicas conhecidas e componentes para produzir uma arquitetura multicore que provê detecção de erros de software e recuperação. O DDMR pode ser facilmente integrado com arquiteturas CMP e substitui links entre pares conectados em tempo 
de fabricação por uma arquitetura em anel. Esta arquitetura permite interligação em tempo de execução entre processadores redundantes.

Propostas de Dual Modular Redundancy (DMR) em chips multiprocessadores, usualmente tem base em processadores vizinhos conectados por meio de links especiais que facilitam sincronização, transferência e comparação dos resultados, além de recuperação em caso de detecção de erros. Porém, utilizar processadores dedicados para redundância possui problemas, pois, adiciona uma limitação sobre como threads podem ser agendadas, reduzindo flexibilidade e performance. Com links dinâmicos: (i) a disponibilidade não é afetada por defeitos em processadores e; (ii) processadores com vazão similar podem ser pareados para executarem duas threads redundantes com a mesma velocidade. (GOLANDER, A.; WEISS, S.; RONEN, R, 2008)

A Figura 2.2 mostra, em (A) processadores interconectados na fábrica, porém, com ligações estáticas e dois processadores com problemas; em (B) uma proposta de interligação dinâmica entre cores e; em (C) a proposta de Golander, A.; Weiss, S.; Ronen, R. (2008), na qual, é utilizado um anel de interconexão com divisão de slots de tempo. Os números nos retângulos em $(A)$ e $(B)$ mostra o IPC normalizado, o qual varia de acordo com o processo de fabricação.

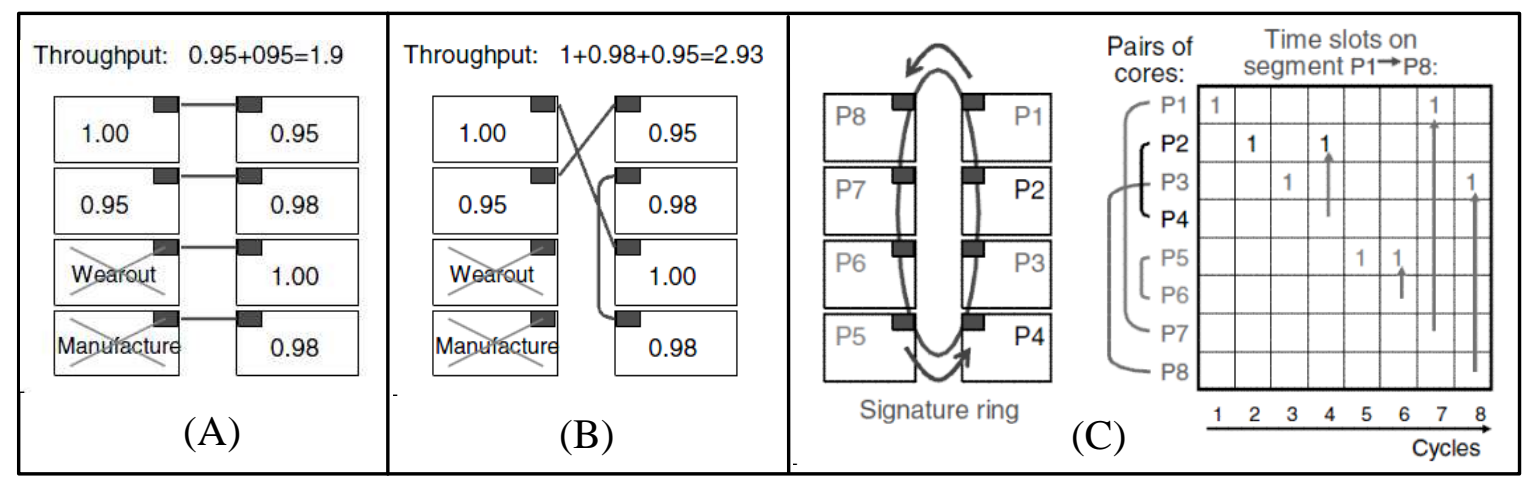

Figura 2.2: Proposta de anel de interconexão, (GOLANDER, A.; WEISS, S.; RONEN, R, 2008)

O trabalho de Golander, A.; Weiss, S.; Ronen, R. (2008) difere da proposta da AMM, pois cada processador é interligado aos demais de forma lógica, ou seja, depende de um sistema operacional para gerenciar as comunicações entre os processadores, enquanto que, na $\mathrm{AMM}$, as interligações são físicas e não dependem de S.O. 
Vadlamani et al. (2010), apresentaram um mecanismo flexível de prevenção de falhas com base em informações de vulnerabilidade arquitetural (AVF) e dois níveis de voltagem dinâmica e escala de frequência (DVFS). Apresentaram um novo algoritmo implementado em tempo real em um multicore, utilizando um NoC monitor dedicado e um controlador que avalia informações térmicas e estatísticas de performance do multicore para permitir seletivamente pequena Dual Modular Redundancy por processador.

O trabalho de Vadlamani et al. (2010) difere da proposta AMM pois utiliza um bloco analógico para voltagem dinâmica e escala de frequência (DVFS) que auxilia os processadores do sistema, monitorando e regulando a temperatura. Este módulo não é previsto na AMM.

Miller et al. (2009) apresentaram uma arquitetura que dinamicamente adapta o nível de proteção às características de cada chip individual e seu comportamento em tempo real. Nesta arquitetura multicore, cada processador pode executar suas computações de forma independente, cada qual executando uma thread separada, ou em união, com ambos executando a mesma thread e checando os resultados ao final de cada estágio do pipeline. A redundância pode ser ativada seletivamente, ao nível de pipeline, para prover proteção contra erros à custos reduzidos.

A Figura 2.3 mostra a implementação de uma arquitetura sequêncial de pares pipelines com base em um MIPS de quatro estágios de pipeline, no qual cada estágio é replicado.Na Figura 2.3, somente os estágios sombreados estão ativos em um dado momento da execução.

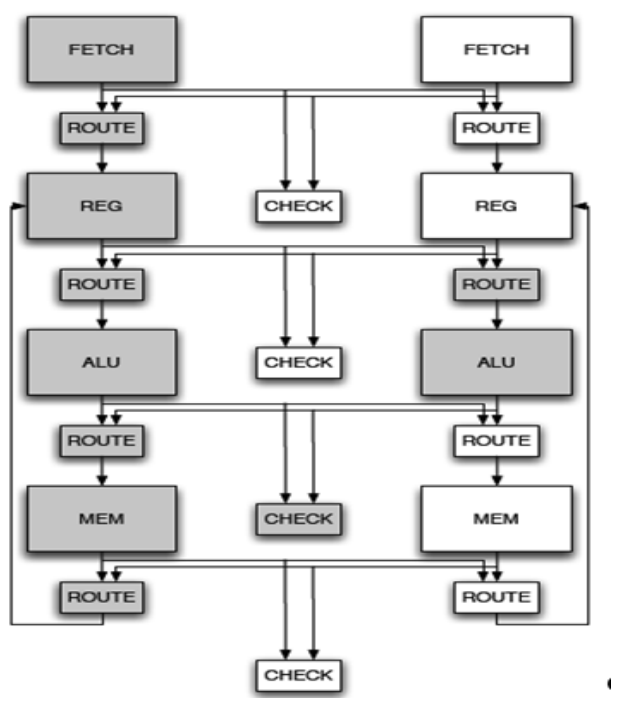

Figura 2.3: Arquitetura sequencial com redundância seletiva, (MILLER et al., 2009) 
O trabalho de Miller et al. (2009) apresenta uma técnica que escalona blocos ativos de pipeline, diferindo da proposta da AMM, onde esta característica não é possível. Na AMM, a redundância, quando solicitada, é realizada com duas ou mais cópias completas do processador base. Além disso, a redundância obtida com apenas dois processadores não é eficiente, pois, não é possível determinar qual processador apresenta a falha.

\subsection{Falhas e injeção de falhas}

Um sistema tolerante a falhas tem a capacidade de fornecer, por redundância, um serviço de acordo com as especificações, independentemente das falhas que ocorrem ou ocorrerão. Esta redundância pode ser em hardware, em software ou em uma combinação de ambos. (BECKER, 2008).

No trabalho de Becker (2008) várias técnicas para detecção de falhas são discutidas, como também, são caracterizadas várias fontes e tipos de falhas.

Eghbal ,A.; Zarandi, H. R.;Yaghini , P. M. (2009) apresentaram um estudo de injeção de falhas em uma descrição VHDL do microcontrolador PIC16C5x e mostram que até $50 \%$ das falhas injetadas em alguns componentes do sistema causam falhas subsequentes em outros componentes, indicando a necessidade de um método de tolerância a falhas para o PIC16C5x. Também concluiu que o contador de programa foi o componente mais significativamente afetado pelas injeções de falha. Alguns métodos para injeção de falhas utilizados neste trabalho foram também aplicados para simular falhas em alguns componentes do processador base da AMM.

Jenn et al. (1994), apresentaram uma ferramenta chamada por MEFISTO, para injeção de falhas em modelos VHDL no processo de desenvolvimento de sistemas tolerantes a falhas.

Para a injeção de falhas por meio de modificações no modelo VHDL, duas técnicas podem ser utilizadas. A primeira tem base na adição de componentes dedicados a injeção de falhas, chamados por sabotadores, no modelo VHDL. A segunda tem base na mutação de componentes existentes no modelo VHDL, os 
quais geram descrições modificadas de componentes chamados por mutantes (JENN et al., 1994).

\subsection{Tolerância a falhas}

Sistemas multicores podem ser destinados a aplicações tolerante a falhas devido ao processamento executado em núcleos distintos. Assim, processadores multicore podem ser a tolerante a falhas por meio de premissas de software ou por meio de hardware dedicado.

Um sistema tolerante a falhas é um sistema que continua funcionando corretamente mesmo na presença de falhas de hardware e/ou erros de software. Injeção de falhas é uma técnica popular na avaliação das dependências de um sistema e pode ser implementado em forma física, por software ou simulação. De acordo às definições genéricas e conceitos de falhas, estas podem ser classificadas em duas classes, propagadas e não propagadas. (EGHBAL, A.; ZARANDI,H .R. ; YAGHINI, P.M., 2009).

Rajest et al. (2009) apresentaram uma unidade de hardware reconfigurável inserida no core, a qual pode detectar e isolar as falhas nas unidades funcionais do core utilizando padrões de testes armazenados.

Segundo Rajest et al. (2009), falhas de hardware permanentes ou intermitentes causadas por defeitos no silício ou no processo de encapsulamento levam a hard faults. Falhas transientes, ou falhas de software, as quais causam mudanças errôneas aleatórias em valores de bits podem ser causadas por ruídos elétricos ou radiação externa. Controlar hard faults é uma tarefa dispendiosa e replicar unidades funcionais não é uma boa solução em termos de custo e espaço. O uso de hardware reconfigurável é uma opção perante soluções somente em hardware e soluções somente em software.

O trabalho de Rajest et al. (2009) difere da proposta AMM, pois, foi desenvolvida uma unidade de hardware reconfígurável específica para uso no processador OpenSparc T1, a qual não é flexível ou adaptável à outros processadores.

Segundo Johnson, J.;Wirthlin, M. (2010), single event upsets (SEUs) são a maior preocupação quando FPGAs, configuráveis com SRAM, são utilizadas em 
ambientes com alto nível de radiação. Assim, um SEU ocorre quando uma célula da memória interna de configuração é modificada por uma partícula de alta energia. Esta memória controla o roteamento, a lógica, flip-flops e outros componentes do FPGA. Sendo assim, sua integridade deve ser mantida. Para isso, o método mais comum é a utilização de Redundância Modular Tripla, do inglês Triple Modular Redundancy (TMR), aliado a uma técnica de correção de erros (memory scrubbing). A Figura 2.4 ilustra um simples exemplo para uma estrutura TMR.

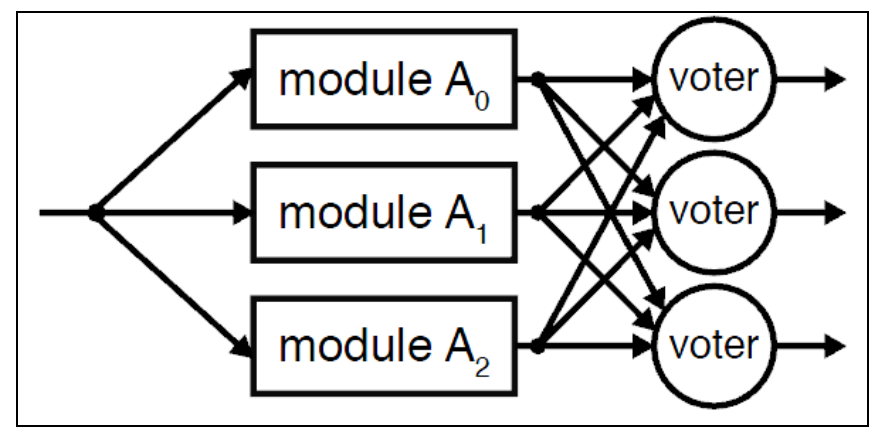

Figura 2.4: Exemplo simples para Redundância Modular Tripla, (JOHNSON, J.;WIRTHLIN, M., 2010)

O trabalho de Johnson, J.;Wirthlin, M. (2010) focou no desenvolvimento de algoritmos e ferramentas para inserção automática das estruturas de votação e seu sincronismo.

O trabalho de Lima et al., (2001) apresenta uma versão com Redundância Modular Tripla de um microcontrolador similar à arquitetura 8051, sintetizável em FPGA. O trabalho apresenta também resultados obtidos com uma ferramenta de geração de falhas e difere da AMM pois foca somente estudos sobre redundância modular tripla.

Tanoue et al. (2009) propõem um esquema para Redundância Modular Tripla acoplada com reconfiguração parcial do FPGA, para remover possíveis ocorrências de SEUs. Assim, a área onde ocorreu uma falha pode ser corrigida.

O trabalho de Tanoue et al. (2009) difere da AMM pois apresenta a vantagem de sincronização de processadores após falhas, característica não obtida na versão atual do protótipo da AMM. Também difere pois utiliza obrigatoriamente um Sistema Operacional. 


\subsection{Multicores em FPGAs}

Nesta seção serão vistos alguns trabalhos acadêmicos direcionados especificamente para prototipação e uso em dispositivos FPGA. Ao final da seção, cada um dos trabalhos acadêmicos são comparados ao AMM.

Um FPGA provê a flexibilidade necessária para a implementação e a verificação funcional de vários projetos de circuitos digitais. (Zemva, A.; Trost, A.; Zajc,B., 1998) ( GONZALEZ, J. A. Q., 2006) (GERICOTA, M. G. O., 2003).

Minhass, W. H.;Öberg, J.;Sander, I. (2009) apresentaram um multicore 4x4 em mesh network direcionado para uso em FPGAs da empresa Altera. Um sistema de interconexão é utilizado para unir 16 processadores Nios II dispostos em 4 chips FPGA Altera Stratix II. Em cada FPGA, são mapeados 4 processadores Nios II conectados por meio de um Address-Mapped Resource Network Interface (RNI). Foi descrita uma hardware abstraction layer (HAL) a qual tem base no padrão message passing interface (MPI) e os aplicativos utilizam a camada HAL para se comunicarem com o RNI. O RNI transfere mensagens com um tamanho máximo de 512 bytes com 32 bits de dados e 20 bits de cabeçalho. Os autores do trabalho afirmam que o MPI é o gargalo do sistema. A Figura 2.5 mostra o diagrama do sistema e a configuração da memória usada para comunicar com o RNI.

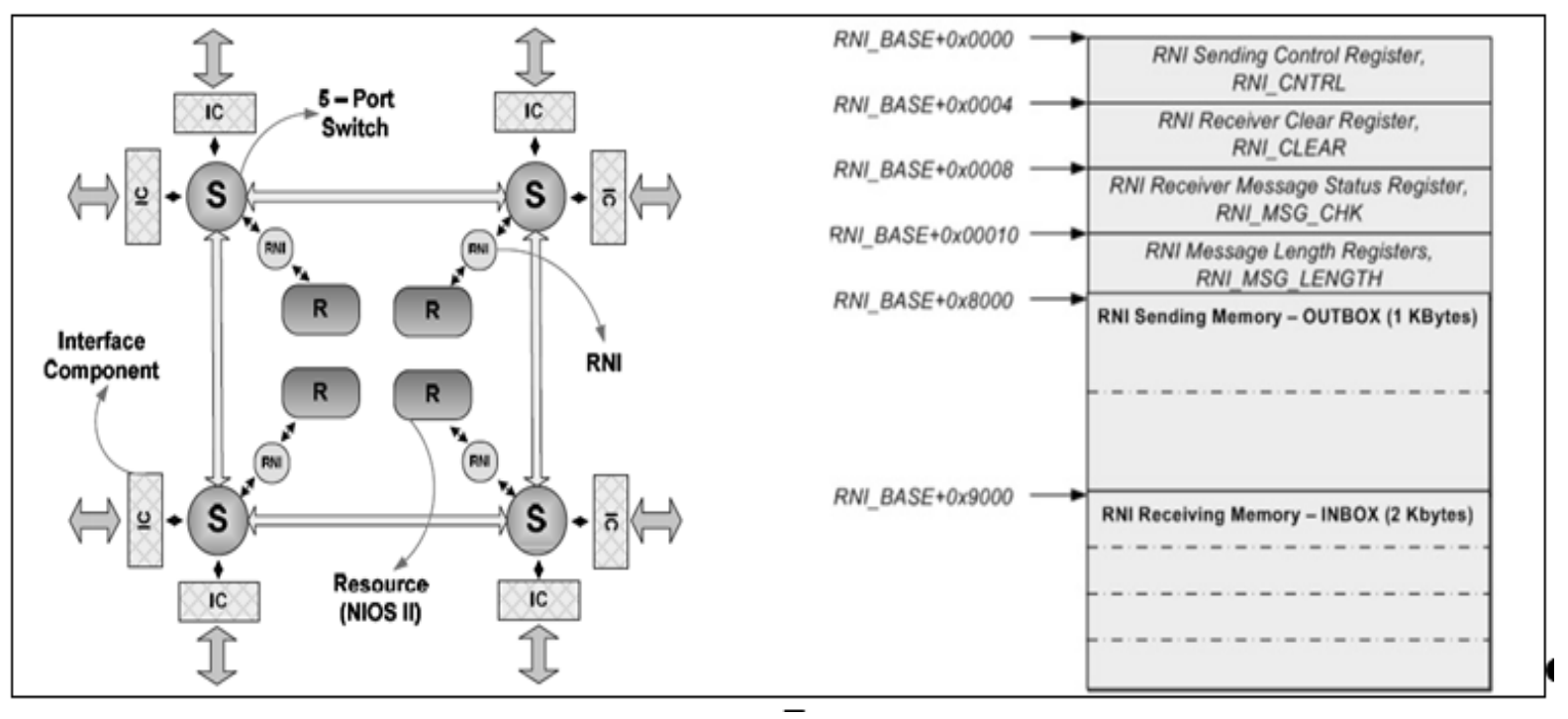

Figura 2.5: Diagrama do multicore Noc e configuração RNI para a RAM, (MINHASS, W. H.; ÖBERG, J.; SANDER, I., 2009) 
O sistema proposto por Minhass, W. H.;Öberg, J.;Sander, I. (2009) é composto por quatro Nios II, o qual é um processador robusto, interligados por meio do barramento Avalon e utiliza premissas de software MPI para implementar a comunicação.

$\mathrm{Na} A M M$, as características das aplicações alvo diferem das aplicações alvo do sistema proposto. Na AMM não são utilizados barramentos proprietários para interligação dos processadores, como o Avalon. Também, a comunicação é realizada em hardware. A organização das mensagens RNI na RAM se assemelha com a organização das mensagens do processador da AMM.

Em outro trabalho, os autores Kavadias et. al. (2010) propõem um sistema composto por quatro processadores Xilinx Microblaze no qual, afirmam que o uso de memórias locais por core permite comunicação direta entre cores, com menor atraso e menor consumo de energia em relação ao uso de comunicação com base em coerência de cache, especialmente com as arquiteturas CMP tornando-se mais difundidas.

O sistema foi implementado em um FPGA Xilinx Virtex5 e quatro Xilinx Microblaze foram integrados no sistema desenvolvido. A Figura 2.6 mostra a arquitetura do sistema desenvolvido.

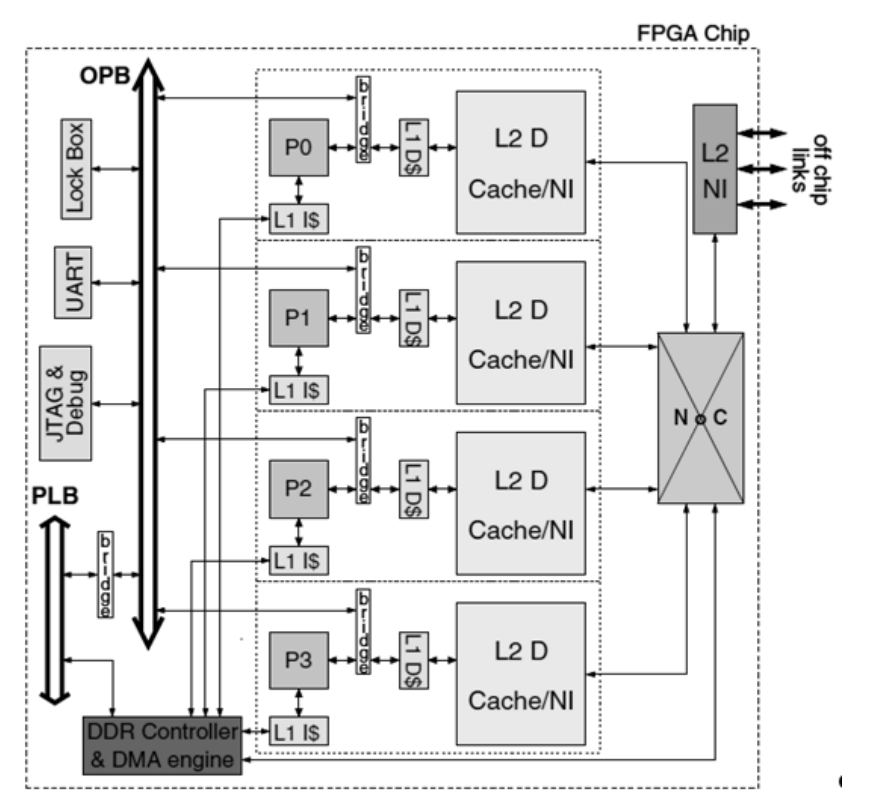

Figura 2.6: Protótipo do sistema com 4 Xilinx Microblaze e um network (Kavadias, et al., 2010) 
Para avaliar a largura de banda do sistema, os autores utilizaram uma adaptação do benchmark STREAM, o qual é destinado a verificar a largura de banda em diferentes níveis de hierarquia de memória, (MCCALPIN, J. D., 1995). O benchmark STREAM copia três arrays de dados de uma memória remota para uma memória local, executa cálculos simples sobre os elementos deste array e envia de volta os resultados destas computações. Outros benchmarks padronizados também foram aplicados para se conhecer a escalabilidade do sistema e a performance.

O sistema apresentado por Kavadias, (2010) é composto por quatro Xilinx Microblaze, processador robusto da empresa Xilinx, e uma rede de interconexão desenvolvida pelos autores do trabalho. Os autores afirmam que o uso de memórias locais por core permite comunicação direta entre cores, com menor atraso e menor consumo de energia. Isto se assemelha com o método de comunicação adotado na AMM, no qual, processadores trocam informações entre si diretamente em suas memórias locais. O método utilizado no sistema, para avaliar a largura de banda com base no benchmark STREAM, inspirou o desenvolvimento de uma aplicação equivalente na AMM (capítulo 5).

Bobda, C.; Haller,T.; Muehlbauer, F. (2007) apresentam uma técnica de projeto para um multiprocessador adaptativo on-chip, especificamente para dispositivos FPGAs. O sistema consiste de um processador PowerPc e dois processadores MicroBlaze em um FPGA Virtex II Pro 30. A largura de banda medida para o sistema foi $36 \mathrm{Mbytes} / \mathrm{s}$ e inclui a transação completa necessária para codificar, enviar e decodificar uma mensagem. A arquitetura conceitual deste sistema é visualizada na Figura 2.7.

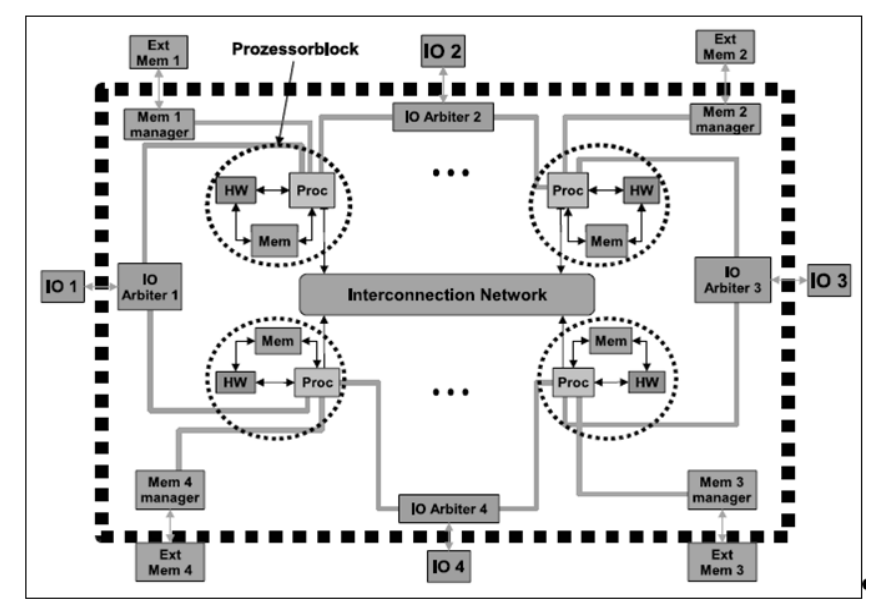

Figura 2.7: Sistema proposto com quatro processadores Xilinx Microblaze, BOBDA,C.;HALLER,T.;MUEHLBAUER,F., 2007) 
Os autores Ihrig, J. C.; Melhem, R.; Jones, A. K. (2010) apresentam uma ferramenta para automação de fluxo de projeto chamada ACME que automaticamente gera um emulador de hardware de ciclos precisos, o qual integra blocos de hardware sintetizados com processadores soft-cores que executam o código C.

A Figura 2.8 mostra o modelo conceitual do ambiente de emulação no qual cada switch é emulado utilizando uma combinação de lógica em FPGA e processadores soft-cores tais como o MicroBlaze, PicoBlaze ou Nios.

A lógica básica, como por exemplo os multiplexers, os pipelines, buffers e controles simples são instanciados diretamente na lógica em FPGA. A lógica mais complexa tal como árbitros para os chaveadores é descrita em $\mathrm{C}$ e executada nos processadores.

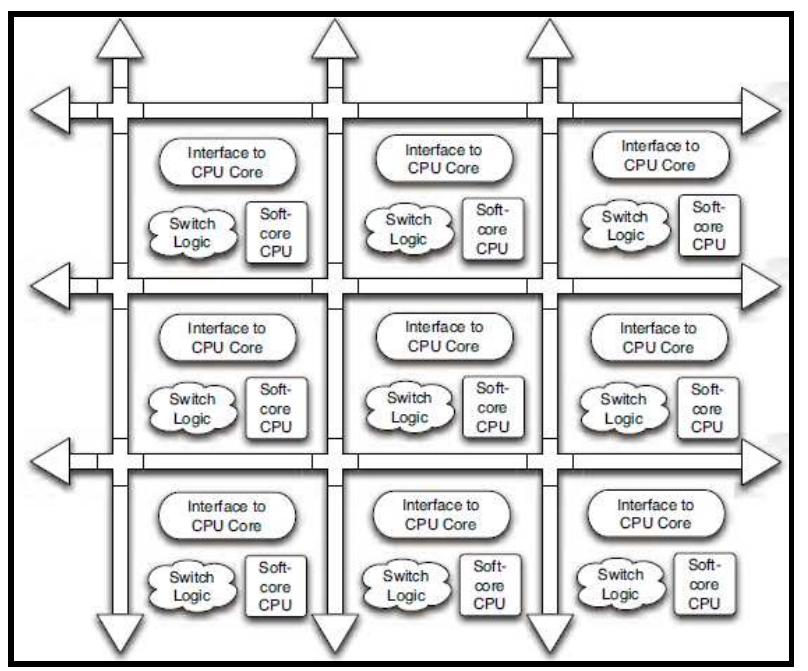

Figura 2.8: Modelo do ambiente de emulação ACME (IHRIG, J. C.; MELHEM, R.; JONES, A.K. 2010)

O trabalho de Ihrig, J. C.; Melhem, R.; Jones, A. K. (2010) apresenta uma ferramenta para automação de fluxo de projeto a qual facilita a emulação do hardware em novos networks de interconexão. Neste trabalho os autores focam em ferramentas para descrição e apenas sugerem algumas futuras utilizações de softcores, e assim, não apresentam resultados em hardware.

O trabalho apresentado por Chun-ming, et al (2009) apresenta uma metodologia de prototipação de silício para um Multi-Project System-on-a-Chip (MPSoC). Uma plataforma chamada CONCORD foi criada, e é uma ferramenta de verificação para emular o hardware do MP-SoC antes do chip ser fabricado. 
A Figura 2.9 apresenta a estrutura CONCORD em blocos.

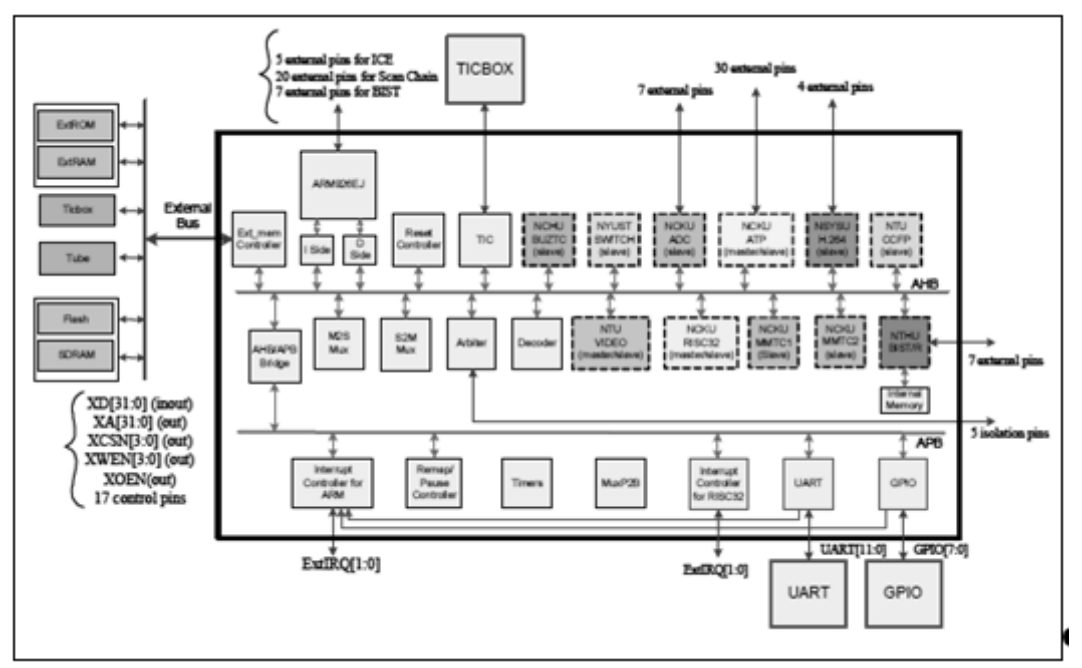

Figura 2.9: Arquitetura do MP-SoC desenvolvido com CONCORD, (CHUN-MING, et al 2009)

A plataforma CONCORD consiste de uma placa de circuito impresso, componentes e diversos soquetes para conectar diversos componentes como módulos periféricos para o sistema $A R M$ Versatile, o qual contém um processador ARM. Assim, os testes são realizados e, em caso de sucesso, a descrição do ARM e a descrição do hardware periférico são unidas em uma única descrição para o chip em silício final. Difere da AMM pois a descrição do sistema deve ser constantemente alterada, ou seja, não há uma única arquitetura padronizada para produção de silício em massa.

A empresa Aeroflex Gaisler desenvolveu o Leon3. O Leon3 é um processador de 32 bits com base na arquitetura SPARC V8 e suporte a configurações de multiprocessamento. O processador é totalmente sintetizável e até 16 processadores podem ser implementados em multiprocessamento assimétrico (AMP) ou multiprocessamento síncrono (SMP). O multiprocessador Leon3 está disponível totalmente em código fonte, sob a licença GNU GPL para avaliação, pesquisa e propósitos educacionais. Para uso comercial, uma licença de baixo custo é disponibilizada. A Figura 2.10 mostra a arquitetura padrão sugerida por Aeroflex Gaisler. 


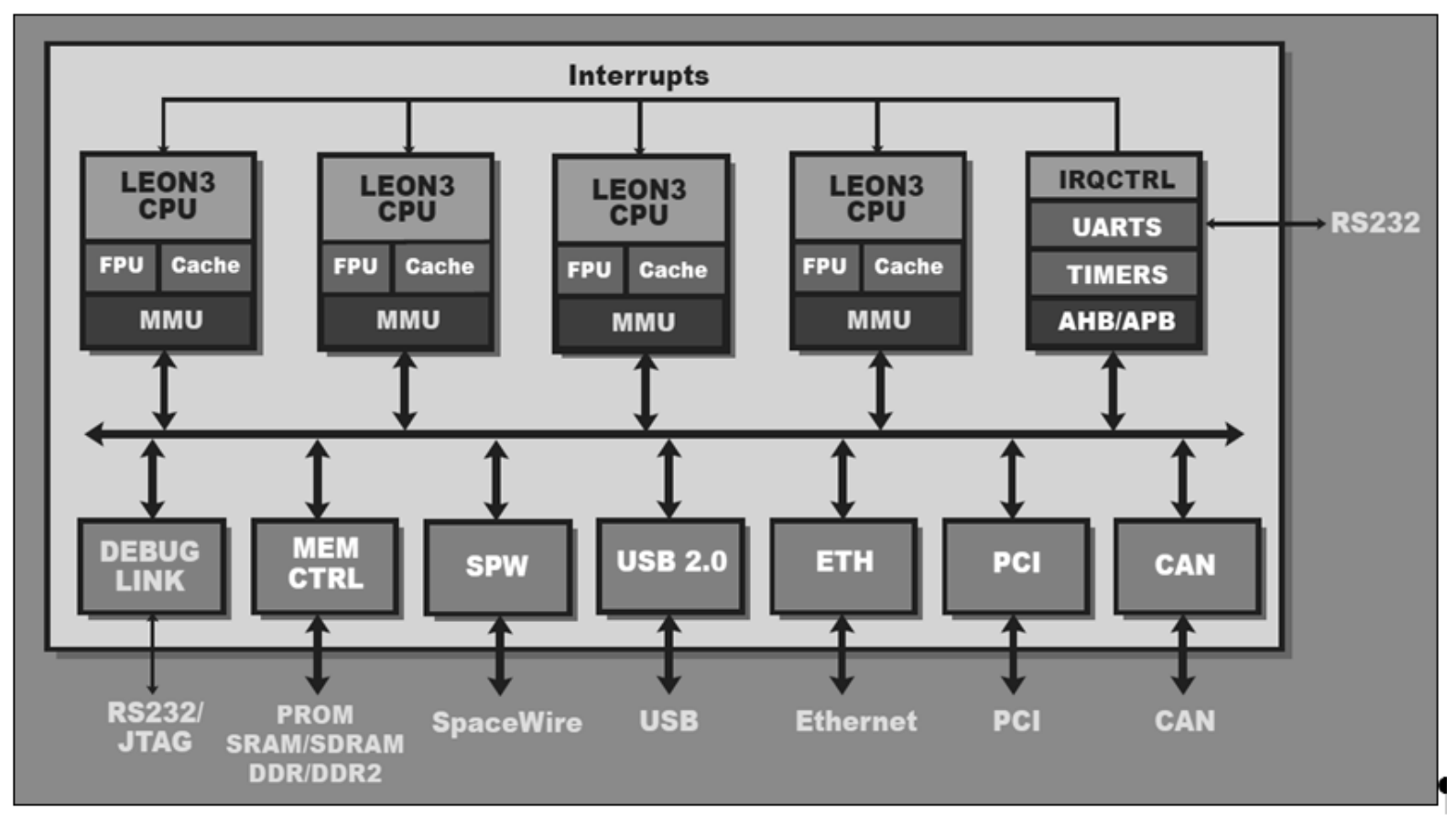

Figura 2.10: Arquitetura interna padrão do Leon3 (Aeroflex Gaisler)

O sistema Leon3 da empresa Aeroflex Gaisler é um sistema composto por até 16 processadores SPARC V8, os quais são processadores robustos, possuem cache de tamanho configurável, unidade de ponto flutuante, $\mathrm{MMU}$, dentre outras. $\mathrm{O}$ Leon3 é destinado a aplicações de alta performance, processamento multimídia e aplicações robustas que exigem sistemas operacionais embutidos.

Processadores soft-cores foram utilizados e comparados também no trabalho de Tong, J.G. A.; Ian, D.L.; Khalid, M.A.S., (2006), no qual vários IP de vários fabricantes são elencados e comparados.

Estes trabalhos contribuíram com alguns conceitos para a concepção da AMM, na qual é possível distribuir tarefas distintas em vários cores presentes em um mesmo chip ou IP.

\subsection{Trabalhos com Multicores em silício}

O microcontrolador SH7211 ou SuperH, da Reneseas Technology, é composto por dois cores distintos e combina funções para controle de motores brushless DC (QIANG, L. et al., 2008) e um processador para execução do 
programa principal. O SuperH é utilizado em uma máquina industrial de lavar roupas, para controle vetorial da velocidade de motor em um core e a interface de usuário no outro core. (JANI, 2007).

O trabalho de Jani (2007) utilizou o microcontrolador SH7211, o qual possui um único processador. Porém, em conjunto com o processador, o SH7211 disponibiliza um hardware dedicado para um módulo de Timer robusto, chamado por MTU2, capaz de gerar um complexo sinal PWM trifásico para controle de motores, além de um segundo módulo Timer mais simples.

No trabalho de Hsiung (2007) foi proposto um conceito para união de vários microcontroladores PIC16F84 interconectados, em forma de link de comunicação serial, para execução de múltiplas tarefas locais e distintas. Um único PIC16F84 principal controla e interliga todas os processadores escravos. Este projeto modulariza o ambiente do processador no qual um único mestre recebe comandos de um usuário e passa as funções aos escravos.Este trabalho contribuiu com importantes conceitos para modularizar e distribuir o código em vários processadores distintas e comunicantes entre si, possibilitando programas locais e melhor flexibilidade do sistema como um todo.

Em Kondo, H. et al. (2008), os autores desenvolveram um SoC multicore para várias aplicações (reconhecimento, medições, controle, e segurança) que requerem processamento de alta performance e baixo consumo. Este SoC integra 3 tipos de processadores sintetizáveis: 8 CPUs (M32R), 2 processadores matriciais multi-bank (MBMX) e um microcontrolador (M32C). Estes processadores operam a $1 \mathrm{GHz}, 500$ $\mathrm{MHz}$ e $500 \mathrm{MHz}$ respectivamente.

Schubert, T.; Becker, B. (2005) apresentaram um sistema multiprocessador chamado de PICHAFF para resolução paralela do problema CHAFF. O CHAFF é utilizado em aviões de guerra e consiste em um radar para contagem de pequenos pontos metálicos em uma nuvem. O PICHAFF é uma adaptação do CHAFF para ser executado no sistema multiprocessador escalável e dinamicamente reconfigurável. É composto por uma placa compatível com barramento PC ISA, nove nós processadores formados com nove microcontroladores Microchip PIC17C43 e um nó de comunicação composto por um processador Motorola MC68340. Os nove Microcontroladores PIC17C43 são interconectados utilizando um canal serial a um barramento PC ISA e o processador Motorola MC68340 é utilizado para controlar o 
canal de comunicação. Alguns conceitos deste trabalho são similares aos conceitos da AMM. Porém, a aplicação alvo difere das aplicações alvo da AMM.

Comparando-se a AMM proposta (capítulo 3) com sistemas multicore em silício citados, o protótipo de Kondo H. et al., (2009) é destinado a aplicações e requisitos de desempenho que exigem alta vazão de dados e diferem das aplicações e requisitos de desempenho alvo da AMM.

A AMM possui mais similaridade com o SuperH e com o sistema proposto em Hsiung, (2007) pois, novamente, considera-se que são destinados à aplicações e desempenho equivalentes.

\subsection{Microcontroladores multicore industriais}

Existem diversos modelos comerciais e pesquisas acadêmicas de microcontroladores multicore e dentre estes pode-se citar: (a) TMS320C6474; (b) Cortex-A9 MPCore; (c) Propeller chip e; (d) MPC8569E.

A seguir, é feito um rápido comentário sobre as principais características dos microcontroladores multicores citados, com base em informações disponibilizadas pelos respectivos fabricantes.

\subsubsection{TMS320C6474}

A Texas Instruments lançou o TMS320C6474, processador multicore de alta performance composto por três cores de $1 \mathrm{GHz}$ em um único encapsulamento, alcançando $3 \mathrm{GHz}$ de processamento DSP, com 1/3 menos consumo e 2/3 mais barato que uma solução discreta composta por um único core (TMS320C6474, 2009).

\subsubsection{ARM Cortex-A9 MPCore}

A ARM lançou o ARM Cortex-A9 MPCore, processador multicore, composto por quatro cores do processador Cortex-A9, cada qual composto por arquitetura Harvard de 64-bit capaz de executar quatro escritas double word a cada cinco ciclos do processador, destinado principalmente a telefones celulares (CORTEXA9, 2008). 


\subsubsection{Propeller chip}

A Parallax lançou o Propeller chip, destinado a prover processamento em alta velocidade para sistemas embarcados, com baixo consumo de energia. O Propeller chip provê flexibilidade e grande capacidade de processamento por meio de seus oito processadores, chamados cogs, que podem executar tarefas simultâneas e independentes ou cooperativas, enquanto mantém uma arquitetura relativamente simples de aprender e utilizar. A arquitetura do Propeller chip pode ser visualizada na Figura 2.11.

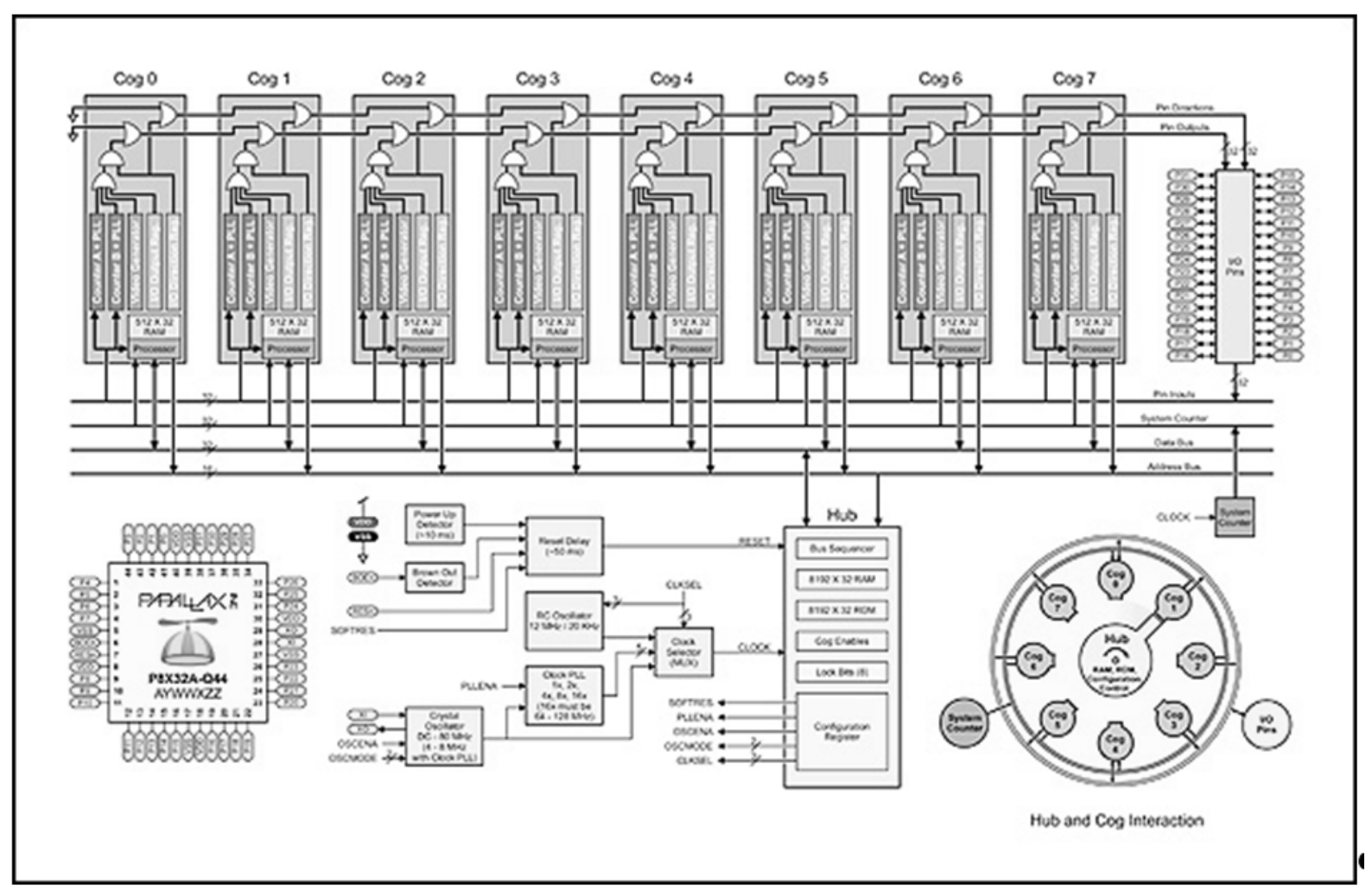

Figura 2.11: Arquitetura interna do Propeller chip, da Parallax (MARTIN, 2009)

Cada um dos oito cogs, ou processadores, contém os mesmos componentes: um bloco processador, $2 \mathrm{~Kb}$ de memória RAM, dois módulos contadores, um gerador de vídeo, registradores de $\mathrm{E} / \mathrm{S}$, registradores de direção de $\mathrm{E} / \mathrm{S}$, e demais registradores. Cada cog é projetado exatamente igual e podem exercer tarefas independentemente dos outros. Todos os oitos cogs possuem a mesma fonte de clock e, assim todos os cogs ativos executam instruções simultaneamente. Todos os cogs também possuem acessos aos mesmos recursos compartilhados, tal como 
pinos de E/S, memória principal e o System Counter. Os cogs podem ser iniciados e suspensos para executarem tarefas simultaneamente, de forma independente ou sob coordenação de outro cog por meio da memória principal. (MARTIN, 2009)

\subsubsection{MPC8569E}

A Freescale lançou o MPC8569E PowerQUICC® III desenvolvido para alcançar os requisitos de performance de equipamentos broadband incluindo estações 3G/WiMAX/LTE, controladores de rede via rádio, gateways e equipamentos ATM/TDM/IP. O MPC8569E combina quatro cores do processador de alta performance e500 alcançando até $1.33 \mathrm{GHz}$, e 2799 MIPS. O dispositivo possibilita gerenciar muitas funções em um único chip enquanto que outras soluções requerem muitos componentes (MPC8569E, 2009).

Confrontando-se a arquitetura AMM proposta com os microcontroladores multicore e aqueles citados em aplicações industriais, o TMS320C6474, o Cortex-A9 e o MPC8569E são destinados a aplicações e requisitos de desempenho que exigem alta vazão de dados e diferem das aplicações e requisitos de desempenho alvo da AMM. A AMM possui mais similaridade com o Propeller chip pois considerase que são destinados à aplicações e desempenho equivalentes.

\subsection{Síntese do capítulo}

Visto que sistemas embarcados precisam reagir a múltiplos estímulos de sensores e controlar múltiplos atuadores concorrentemente, apresentou-se alguns conceitos sobre processadores multicore, os quais podem executar diversos programas independentemente.

Ressaltou-se as diferenças identificadas entre trabalhos acadêmicos e a AMM, nos quais foram utilizados agrupamentos sob diferentes configurações de interconexão para os IPs NIOS II e Microblaze.

Verificou-se que Leon3 é altamente configurável, porém, características de redundância e tolerância a falhas são tratadas somente em versões específicas do Leon3.

Também, apresentou-se alguns microcontroladores multicore comercias e alguns trabalhos acadêmicos que os utilizam. Dentre estes, o Propeller chip foi 
identificado como o multicore de arquitetura mais próxima do protótipo proposto nesta tese para a AMM. Ainda assim, o Propeller chip não é voltado às características de segurança e tolerância a falhas.

No próximo capítulo, a Arquitetura Modular Multicore é apresentada, contextualizada em um ambiente de desenvolvimento, linha de dispositivos e detalhes de funcionamento. 


\section{Capítulo 3: Arquitetura modular multicore}

Neste capítulo a AMM é detalhada. Procura-se contextualizar a arquitetura em um ambiente de desenvolvimento, ferramentas de síntese e depuração. São mostradas e comentadas características do sistema de interconexão desenvolvido, mapeamento da memória para o respectivo acesso por software, estrutura do mecanismo de comunicação, visão global de 4 e 8 processadores totalmente interconectados e exemplos em software para acesso ao sistema de intercomunicação.

\subsection{Introdução}

Em um trabalho anterior apresentou-se um processador, chamado Unidade de Processamento Específica para Microcontroladores (UPEM). (PENTEADO, C. G.; MORENO, E. D., 2009), (PENTEADO, 2004). Um dos objetivos do trabalho foi obter um processador para flexibilizar as funções e o uso de alguns periféricos selecionados. O processador UPEM foi ampliado recentemente, obtendo-se 0 processador UPEM2.

O processador UPEM2 é utilizado como base de um protótipo para a AMM (capítulo 4). Desta forma, os exemplos e os detalhes arquiteturais do conceito da AMM aqui apresentados focam endereços de memória, registradores internos e outras características referentes ao processador UPEM2.

Porém, não há impedimentos para que estes conceitos sejam adaptados à outros processadores de interesse futuro. Para isso, pequenas alterações seriam necessárias, as quais são comentadas no decorrer deste capítulo.

Assim, apresenta-se nesta tese a Arquitetura Modular Multicore e uma prototipação em FPGAs, idealizada para prover a flexibilidade, segurança e tolerância a falhas, e auxiliar no desenvolvimento de futuras aplicações.

Para assegurar as questões de segurança idealizou-se que cada processador execute tarefas e programas presentes em memórias de programa independentes e memórias de trabalho também independentes. 
Programas distintos, coordenados por um processador eleito como central, podem assumir vários comportamentos distintos, os quais podem ser destinados às funções de geração ou recepção de sinais, ou ambas, dependendo da aplicação e a performance requisitada.

A Figura 3.1 mostra o conceito do sistema multicore proposto: $n$ processadores totalmente interconectados, com alguns periféricos em cada processador.

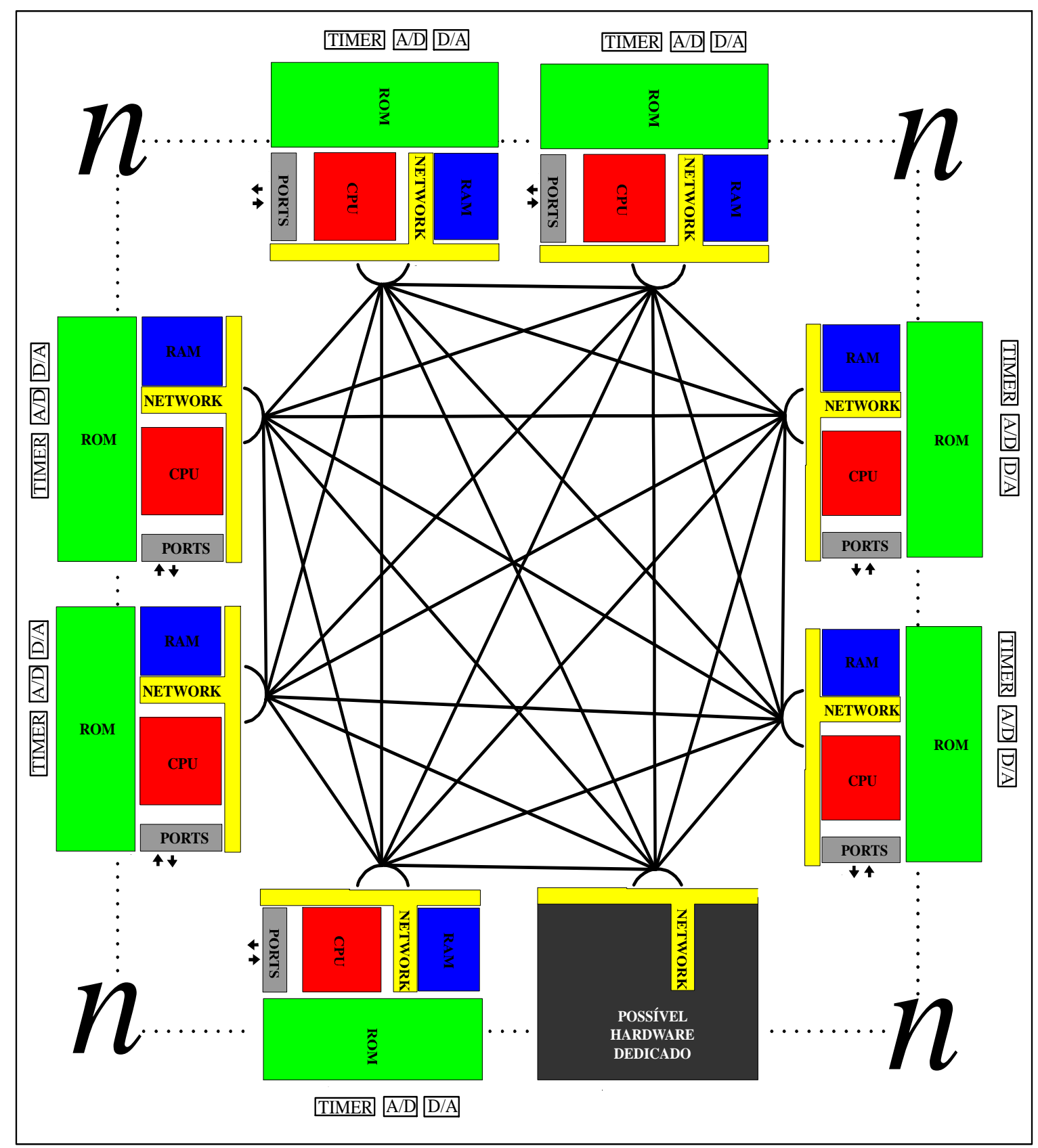

Figura 3.1: Conceito da AMM proposta 
Os principais componentes mostrados na Figura 3.1 são:

(i) sistema de interconexão fully meshed network, o qual permite que cada processador se comunique diretamente com os demais. Foi adotado pois evita pontos únicos de falha garantindo maior disponibilidade, em que pese seu custo. Outras soluções podem ser utilizadas em futuras novas versões da AMM, como barramentos, anel ou mesh.

(ii) $n$ processadores compostos por uma memória RAM local, ROMs locais para armazenar programas, Unidade de Controle, Unidade Lógica e Aritmética, registradores, pilha, buffer de comunicação local, ports bidirecionais para E/S, $n-1$ buffers para comunicação interna entre processadores e demais componentes comuns a todos os processadores e;

(iii) sugestão de periféricos simples como Timer e A/D e D/A.

Como já comentado no capítulo 1 desta tese, a AMM pode ser composta por $n$ processadores. Cada processador é composto por uma memória RAM, uma memória ROM de programa, um processador e n-1 componente de comunicação. Cada processador pode ser auxiliado por alguns periféricos simples. Para simplificar a descrição, assume-se neste capítulo que o sistema base é composto por 4 processadores, os quais são totalmente interconectados. Assim neste capítulo a arquitetura é detalhada para utilização com quatro processadores, sendo que todos os conceitos podem ser facilmente ajustados para mais ou menos processadores. Ressalta-se aqui, que a AMM é apresentada com apenas quatro processadores apenas por questões de simplificação das Figuras e dos exemplos de interconexões.

A rede de interconexão da AMM permite que informações possam ser enviadas ou recebidas, a qualquer instante e de forma independente, por qualquer um dos processadores. Isto forma um sistema assíncrono para troca de mensagens entre os processadores.

Esta rede de interconexão é composta por vias de dados seriais as quais interconectam dois processadores. Cada processador possui $n-1$ componentes transmissores dedicados que possibilitam o envio de informações a cada outro processador na AMM. De forma similar, cada processador possui $n-1$ componentes receptores dedicados que possibilitam receber informações provenientes de cada outro processador. 
Cada transmissor $(\mathrm{Tx})$ ou receptor $(\mathrm{Rx})$ possui seu próprio registrador de controle e são acessados por software e hardware. Cada registrador de controle do Tx ou Rx fornece informações do "status" de seu Tx ou Rx correspondente ao processador, auxiliando as tarefas do software presente em qualquer processador. Estes registradores são mapeados consecutivamente na memória RAM do processador em endereços fixos pré-determinados.

Cada Tx e cada Rx possui um buffer para armazenar temporariamente a informação. Cada buffer é interconectado à memória RAM de cada processador, formando na memória RAM, um arranjo consecutivo de buffers e áreas de escrita ou leitura de dados.

Cada Tx e Rx utiliza uma única linha de dados (1 bit) para enviar ou receber dados serialmente. Enviando-se dados seriais, evita-se muitas linhas de interconexão entre processadores. Assim, supondo uma configuração com $n$ processadores totalmente interconectados, são necessárias $n(n-1)$ linhas de interconexão.

Assim, em cada ponta do barramento de interconexão existe um buffer de 8 bytes, necessário para sincronizar a transferência final dos dados entre 0 mecanismo de interconexão e a RAM do processador, o que garante: (a) no caso de um envio de dados, os dados possam ser enviados independentemente de alterações nos dados da RAM e; (b) no caso de uma recepção, os 64 bits recebidos sejam atualizados simultaneamente e uma interrupção possa ser gerada ao processador, indicando a recepção de 64 bits atualizados na RAM. Objetivando menor área de utilização em silício, estes buffers podem ser excluídos, porém, neste caso novas estratégias de comunicação são necessárias.

O sistema de comunicação desenvolvido e utilizado na AMM pode ser adaptado a outras implementações que utilizam outros processadores. Para esta adaptação, basta vincular o hardware transmissor, o hardware receptor e os buffers à memória dos processadores de interesse. E então, adaptar o software presente no sistema para acessar corretamente os registradores de controle do transmissor e receptor, podendo ser registradores endereçáveis ou físicos.

Desta forma não há necessidade de instruções especiais para controlar a escrita ou recepção de mensagens. Para isso, basta executar escritas ou leituras em posições específicas da memória RAM, vinculadas aos buffers e controladores. 
A Figura 3.2 ilustra um exemplo de mapeamento na memória RAM dos registradores de controle e as respectivas áreas de comunicação com os buffers.

Na Figura 3.2, em (A), é representado todo o espaço de memória RAM de propósito geral disponível para uso no processador utilizado no protótipo atual da AMM, ou seja, 224 bytes; em (B) representa-se um exemplo para o mapeamento necessário para dois processadores interconectados - utilizando 18 posições de memória RAM, mapeia-se consecutivamente os controladores do receptor e do transmissor, bem como as áreas para troca de informações com os buffers; em $(C)$, (D) e (E), mostra-se o mapeamento para quatro, seis e oito processadores, respectivamente.

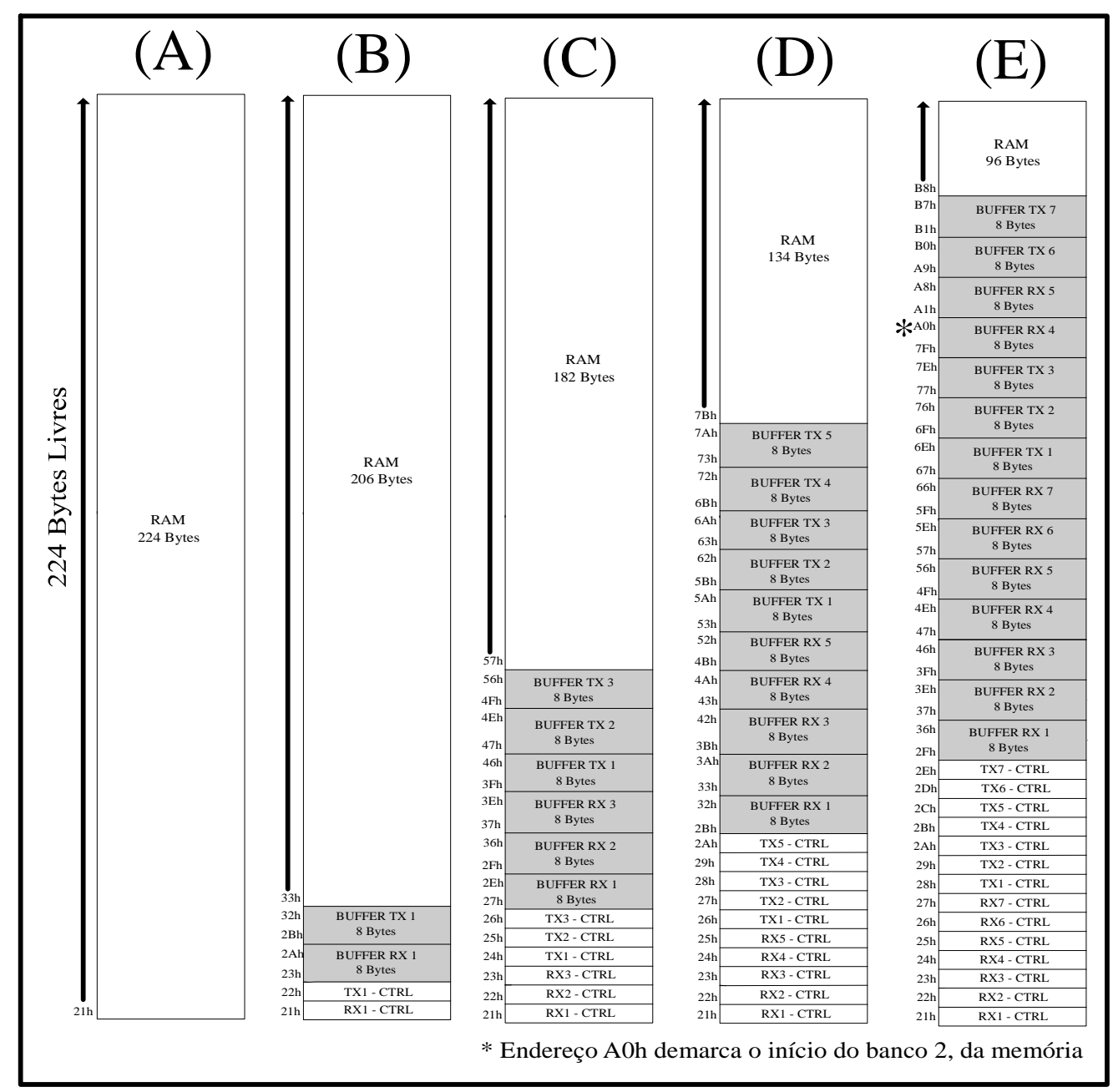

Figura 3.2: Mapeamento da estrutura de intercomunicação para configurações da AMM

Nas próximas seções deste capítulo, o sistema de interconexão, o hardware de suporte e premissas em software para a utilização do sistema, são detalhados. 


\subsection{Sistema de intercomunicação da AMM}

A comunicação entre processadores tem base em 128 bits (16 bytes) sendo que 64 bits ( 8 bytes) originam-se em cada processador. Foram desenvolvidos um transmissor e um receptor, independentes, o que permite iniciar uma transmissão ou recepção a qualquer momento.

A comunicação full-duplex é realizada com apenas duas linhas de transmissão de dados entre processadores e tem funcionamento similar à comunicação Serial Peripheral Interface (SPI), conforme mostra a Figura 3.3.

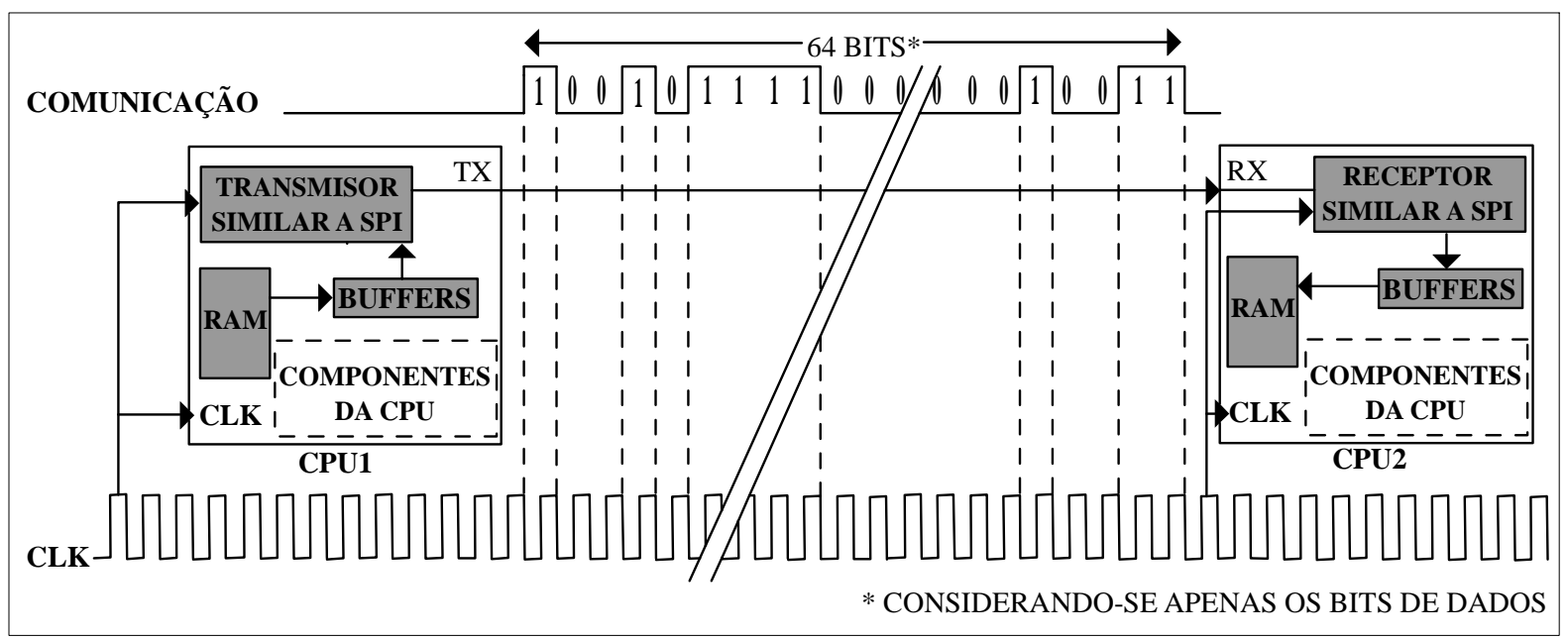

Figura 3.3: Comunicação entre processadores da AMM

A Figura 3.3, mostra que o clock principal, utilizado para estimular os próprios processadores é também utilizado como referencia de tempo e sincronização entre o transmissor e receptor do sistema de comunicação. Desta forma, com duas únicas linhas de dados é possível enviar ou receber dados entre dois processadores. Para a transmissão, os dados são depositados em um buffer de transmissão e, da mesma forma, no receptor os dados são disponibilizados em um segundo buffer para a leitura. Assim, TX é o nome dado à porta de saída do transmissor e RX é o nome dado à uma porta de entrada no receptor.

Um hardware desenvolvido e acoplado à memória RAM, presente no processador, disponibiliza os dados para o buffer. Como mostrado na Figura 3.3, alguns endereços na memória RAM são reservados ao controle da transmissão e ao controle da recepção dos dados. 
A comunicação é sincronizada pelo clock presente nos próprios processadores. Assim, no transmissor, os dados são gerados com base na borda de subida do clock. No receptor, os dados são recebidos com base na borda de descida do clock. Isso garante estabilidade do dado no instante exato da recepção.

Para sincronizar a transferência dos dados, uma marca de início é inserida antes do byte a ser transmitido. Esta marca consiste em uma sequência "10". Para finalizar o envio do byte, uma marca de término é transmitida após o byte. Esta marca consiste de uma sequência "00". A Figura 3.4 ilustra estes detalhes.

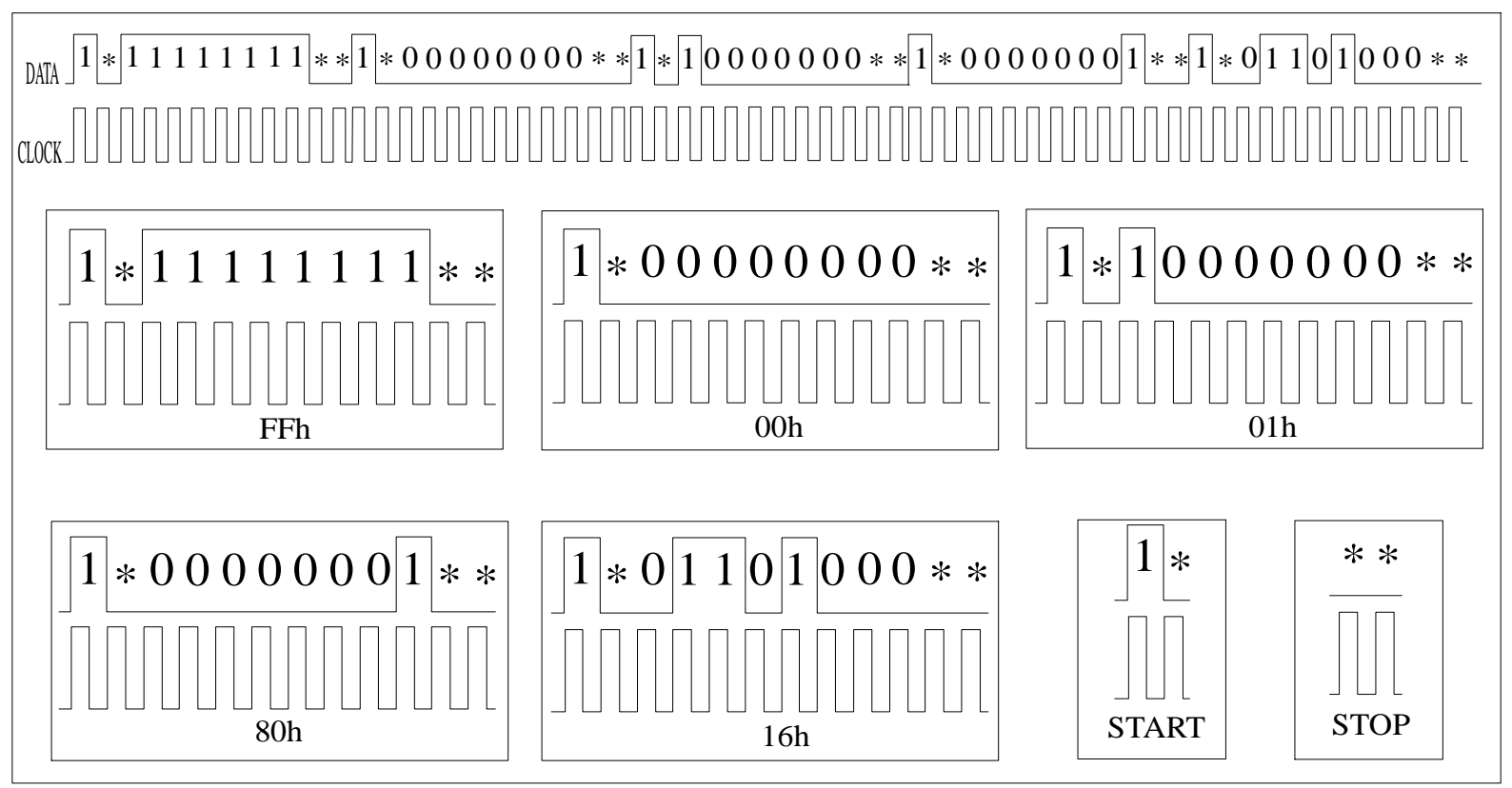

Figura 3.4: Detalhes da comunicação desenvolvida entre processadores na AMM

A Figura 3.4 mostra detalhes da comunicação desenvolvida e utilizada entre processadores na AMM. Assim, o envio dos valores hexadecimais FFh, 00h, 01h, $80 \mathrm{~h}$ e $16 \mathrm{~h}$ é mostrado no exemplo.

A comunicação é realizada em pacotes fixos de "64 bits válidos", ou seja, 8 palavras de 8 bytes, desconsiderando-se os bits de controle. O receptor aguarda estes 64 bits e os organizam para disponibilizá-los para a memória RAM.

Após receber estes 64 bits, o receptor automaticamente entra em espera por novos 64 bits. Estes bits de controle foram incluídos em todos os dados para possibilitar futuras melhorias no sistema de comunicação, como por exemplo, definirse previamente a quantidade de palavras a ser transmitida e recebida. 


\subsection{AMM configurada com 4 processadores}

A Figura 3.5 mostra detalhes de um componente de recepção. Na Figura 3.5 considera-se a AMM composta por quatro processadores, assim os endereços $26 \mathrm{~h}$ 2Dh são reservados à leitura dos dados recebidos pelo hardware receptor RX1. O endereço 20h é reservado ao controle da recepção (RX1 - CTRL), sendo que seus bits são controlados pelo mecanismo de recepção para posterior leitura por software.

O endereço 20h está assim organizado: (i) o bit 0 (menos significativo) indica que uma recepção completa ocorreu e gera uma interrupção ao processador, se habilitada; (ii) o bit 1 é setado no inicio de uma recepção e limpo no fim, indicando recepção em andamento e; (iii) o bit 2 indica ao software que os endereços $26 \mathrm{~h}$ 2Dh contém dados atualizados. Os bits restantes do RX1 - CTRL não são utilizados e, assim, estão disponíveis para uso futuro.

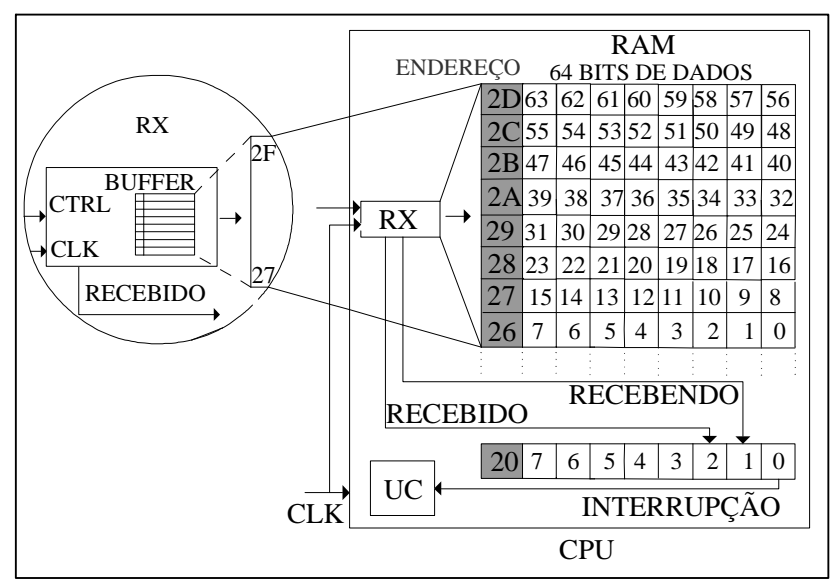

Figura 3.5: Detalhes de um canal de recepção da AMM

A Figura 3.6 mostra detalhes de um componente de transmissão. Na Figura 3.6 também é assumido que a AMM possua quatro processadores e assim os endereços 3E-45h da memória RAM são reservados à escrita de dados no hardware TX1 e a futura transmissão.

O endereço 23h é reservado ao controle da transmissão (TX1 - CTRL), sendo controlado por software. Está organizado: (i) o bit 0 (menos significativo) autoriza o transmissor iniciar o envio; (ii) o bit 1 é setado pelo transmissor e indica transmissão em andamento, sendo zerado no final; (iii) o bit 2 é setado no fim da transmissão e; 
(iv) o bit 3, quando setado, indica para o controlador que deve aguardar todos os outros transmissores estiverem prontos e, assim, iniciar transmissões simultâneas para vários processadores (maiores detalhes no Capítulo 5), se for necessário na aplicação. Os bits restantes do TX1 - CTRL não são utilizados e, assim, estão disponíveis para uso futuro.

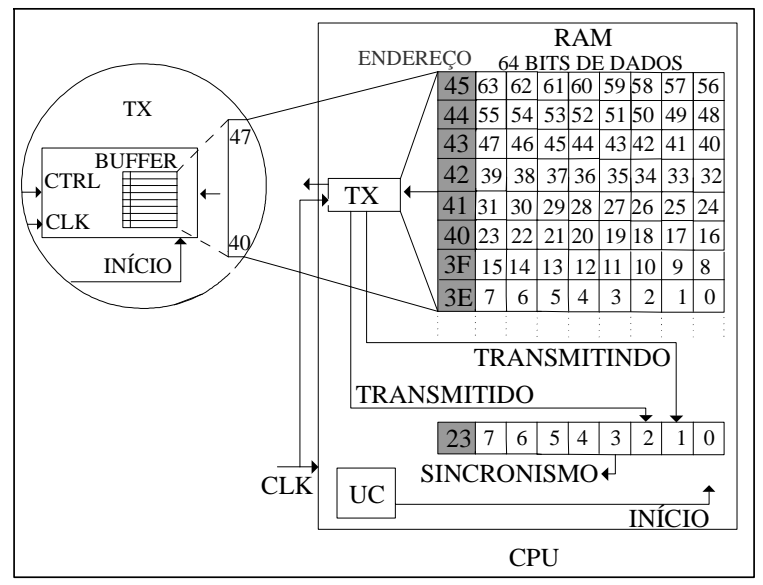

Figura 3.6: Detalhes de um canal de transmissão da AMM

Os 64 bits enviados e recebidos são livres para cada programador definir sua função e uso. É possível vincular bits específicos a determinadas funções de software, autorizar ou suspender ações no processador destino ou simplesmente serem lidos como 8 words de 8 bits.

Atualmente, o número de bits transmitidos ou recebidos é fixo em pacotes de 64 bits. Aumentar este número é uma tarefa simples, bastando especificar na descrição VHDL do sistema quantos bits são desejados e alterar os endereços de controle. Porém, uma vez definido, este número é fixo. Melhorias podem ser introduzidas para tornar este número variável, e tornar assim, a comunicação mais flexível.

Na Figura 3.7, uma configuração para a memória RAM com os registradores de controle e os espaços reservados para a troca de informações dos quatro processadores.

A Figura 3.7 ilustra a estrutura para os componentes de comunicação desenvolvidos, seus respectivos registradores de controle e espaços reservados na memória RAM. Os registradores de controle de cada componente receptor, transmissor e as áreas de acesso ao envio e recepção dos dados são mapeados consecutivamente na memória RAM. Cada transmissor e receptor possui seu respectivo buffer de 64 bits de dados. São necessários barramentos de 64 bits para 
transferir todos os dados simultaneamente de um buffer para a área de memória RAM. Cada transmissor e receptor recebe dados serialmente e deposita em seu respectivo buffer, podendo gerar interrupções individuais no processador.

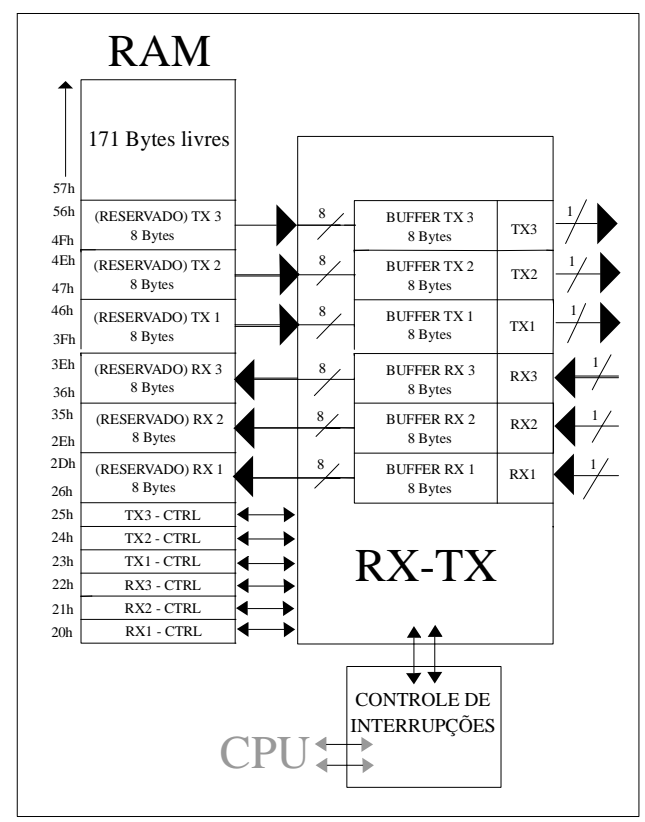

Figura 3.7: Componentes de comunicação desenvolvidos e respectivos registradores

\subsection{AMM: Interconexão entre quatro processadores}

Para viabilizar a comunicação com rede de processadores totalmente interconectados, na qual todos os processadores do sistema se comunicam diretamente com os demais, cada componente de transmissão de um processador é interligado ao componente de recepção de um segundo processador. A Figura 3.8 mostra um exemplo onde quatro processadores estão totalmente interconectados e assim, as ligações físicas entre estes processadores aparecem indicadas de forma explicita na Figura 3.9.

Na Figura 3.8, em cada um dos quatro processadores da AMM existem três componentes transmissores e três componentes receptores. Cada transmissor possui um canal que interliga o processador a um nó vizinho, o qual contém um componente receptor.

Assim, na Figura 3.9 é feita uma relação de interconexão entre os transmissores (TX) e os receptores (RX) para o exemplo de quatro processadores. Para facilitar a compreensão, ordenou-se em (A) pelos transmissores de cada 
processador e em (B) pelos receptores de cada processador. As interligações iniciam sempre a partir do processador 1 , utilizando todos os seus transmissores ligados a cada primeiro receptor dos demais processadores. O segundo processador utiliza todos seus transmissores para se interligar aos demais, utilizando os próximos receptores disponíveis. Assim, o ciclo se fecha quando o último processador também é interligado ao primeiro.

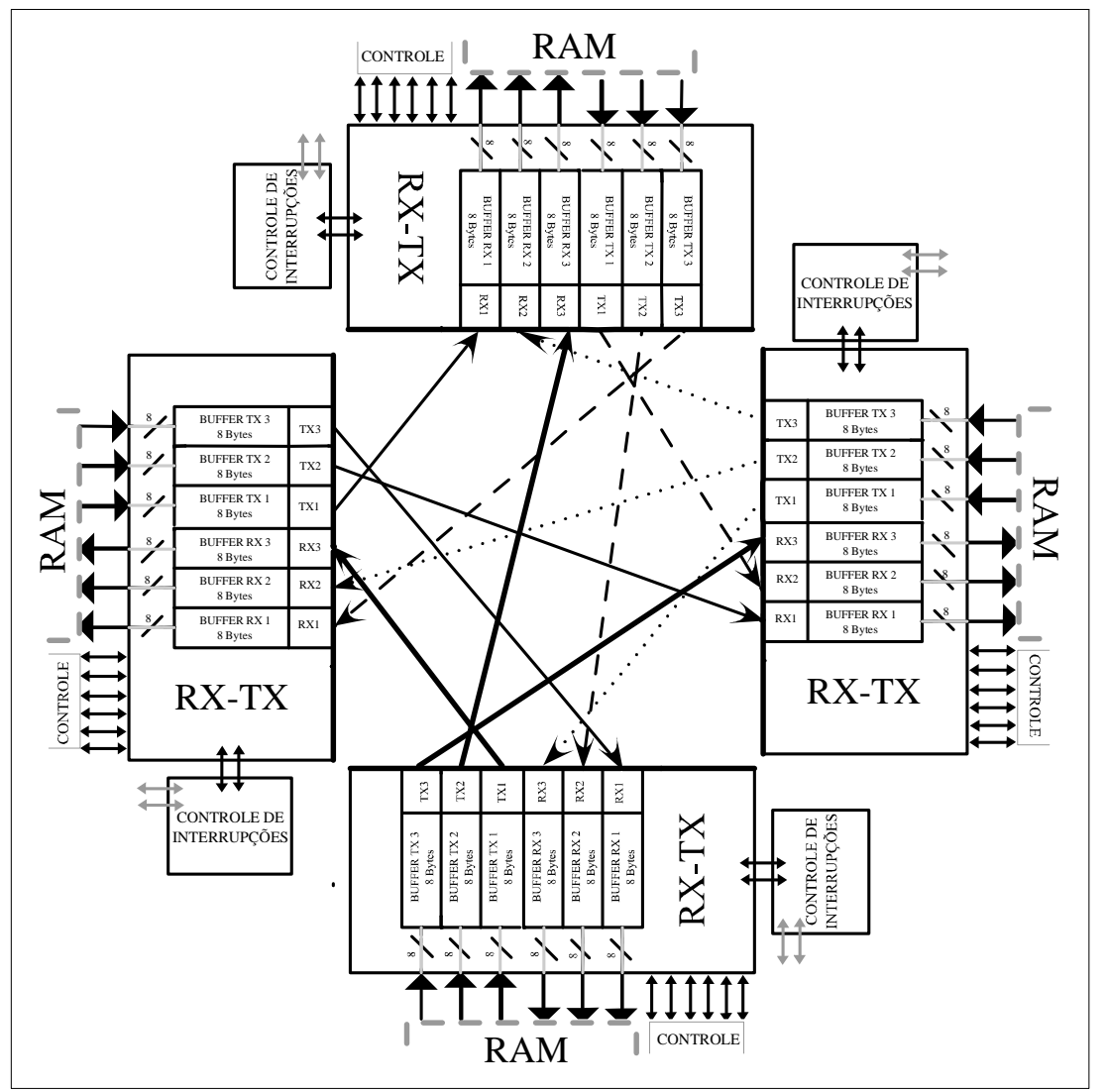

Figura 3.8: Quatro processadores totalmente interconectados

\begin{tabular}{|c|c|}
\hline 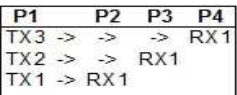 & $\begin{array}{|lllll|}\text { P1 } & \text { P2 } & \text { P3 } & \text { P4 } \\
\text { RX3 } & <- & <- & <- & \text { TX1 } \\
\text { RX2 } & <- & < & \text { TX3 } \\
\text { RX1 } & <- & \text { TX3 } & & \\
\end{array}$ \\
\hline $\begin{array}{|lllll|}\text { P2 } & \text { P3 } & \text { P4 } & \text { P1 } \\
T X 3 & \rightarrow & \rightarrow & \rightarrow & \text { RX1 } \\
\text { TX2 } & \rightarrow & \vec{R} & \text { RX2 } & \\
\text { TX1 } & \rightarrow & \text { RX2 } & & \\
\end{array}$ & \begin{tabular}{|lllll} 
P2 & P1 & P3 & P4 \\
RX3 & $<-$ & $<-$ & $<-$ & TX2 \\
RX2 & $<-$ & $<$ & TX2 & \\
RX1 & $<-$ & TX1 & & \\
\end{tabular} \\
\hline 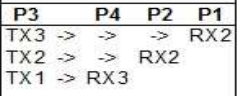 & \begin{tabular}{|lllll} 
P3 & P1 & P2 & P1 \\
$R X 3$ & $<-$ & $<-$ & $<X 3$ \\
$R X 2$ & $<-$ & $<$ & $T X 1$ \\
$R X 1$ & $<-T X 2$ & & \\
$R$ & \\
$R$
\end{tabular} \\
\hline 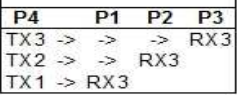 & $\begin{array}{|lllll|}\text { P4 } & \text { P1 } & \text { P2 } & \text { P3 } \\
\text { RX3 } & <- & <- & <- & \text { TX1 } \\
\text { RX2 } & <- & < & \text { TX2 } & \\
\text { RX1 } & <-T X 3 & & \\
\end{array}$ \\
\hline (A) & ( \\
\hline
\end{tabular}

Figura 3.9: Interconexão entre TX e RX para quatro processadores 
A Figura 3.10 ilustra a AMM completa, composta por quatro processadores. Ressalta-se novamente que a arquitetura mostrada nas figuras e nos exemplos, possui somente quatro processadores apenas por questões de simplificação.

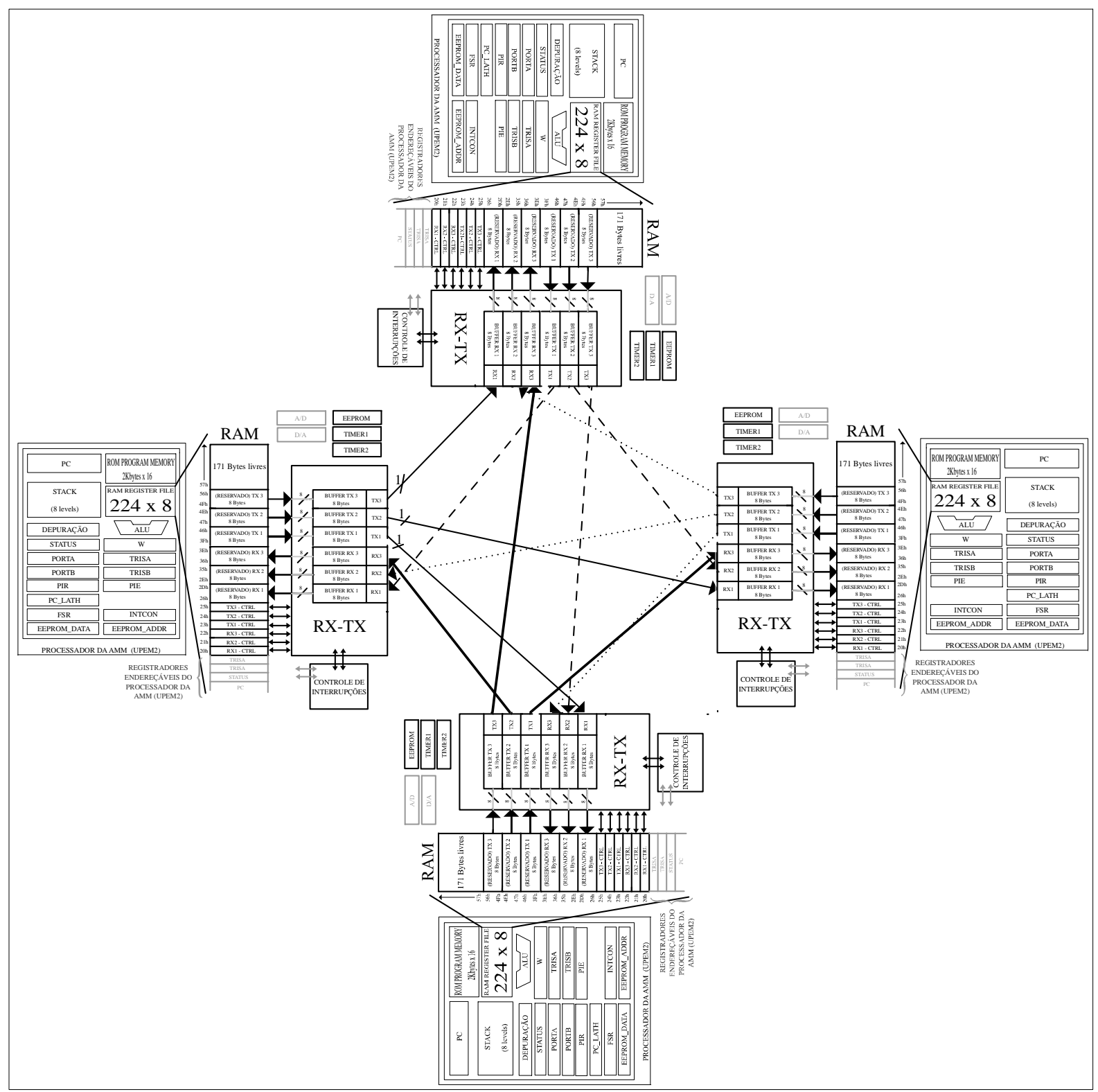

Figura 3.10: Arquitetura da AMM configurada com quatro processadores

\subsection{AMM configurada para 8 processadores}

Na Figura 3.11 mostra-se a AMM com estrutura para oito processadores totalmente interconectados. Assim, existem sete receptores e sete transmissores em cada processador mapeados conforme foi indicado na Figura $3.2(E)$. 
Cada um dos sete transmissores de cada processador são conectados, por meio de uma única linha serial de dados, conforme foi descrito na seção 3.2 deste capítulo, com cada um dos sete receptores presente nos outros processadores.

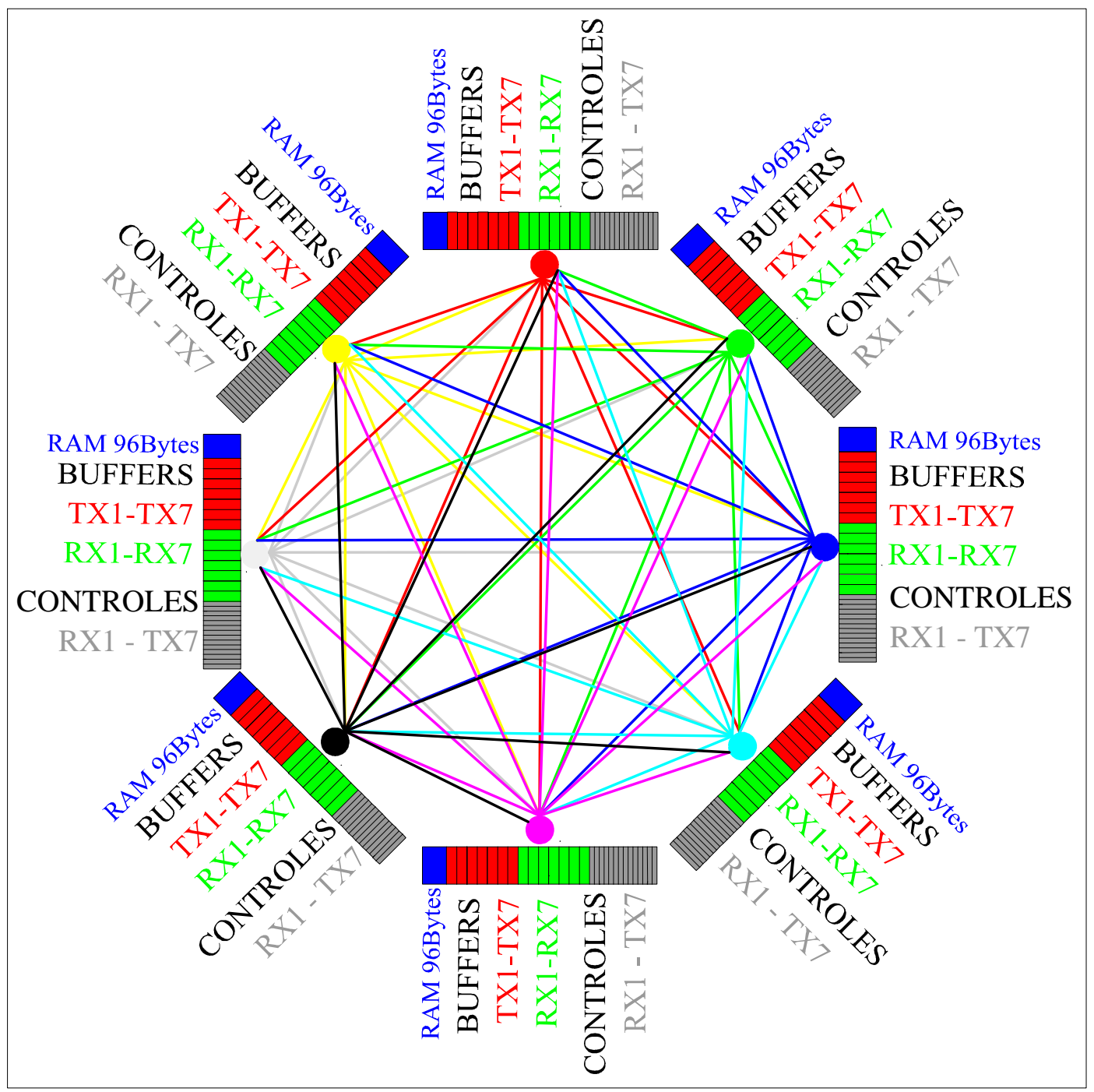

Figura 3.11: AMM composta com 8 processadores totalmente interconectados.

$\mathrm{Na}$ Figura 3.12 considerou-se que, mesmo existindo a estrutura para oito processadores serem totalmente interconectados, considerou-se apenas quatro processadores. Desta forma, os receptores $R X 1, R X 2$ e $R X 3$ e os transmissores TX1, TX2 e TX3 estão em uso e, consequentemente, suas respectivas áreas de memória devem ficar reservadas para comunicação com seus respectivos buffers.

$\mathrm{Na}$ mesma figura, se observa que as áreas de memória reservadas para a comunicação com os buffers dos receptores $\mathrm{RX} 4, \mathrm{RX} 5, \mathrm{RX} 6$ e $\mathrm{RX7}$, bem como as áreas de memória reservadas para a comunicação com os buffers dos 
transmissores TX4, TX5, TX6 e TX7, ficam livres para serem utilizadas como área comum de memória RAM.

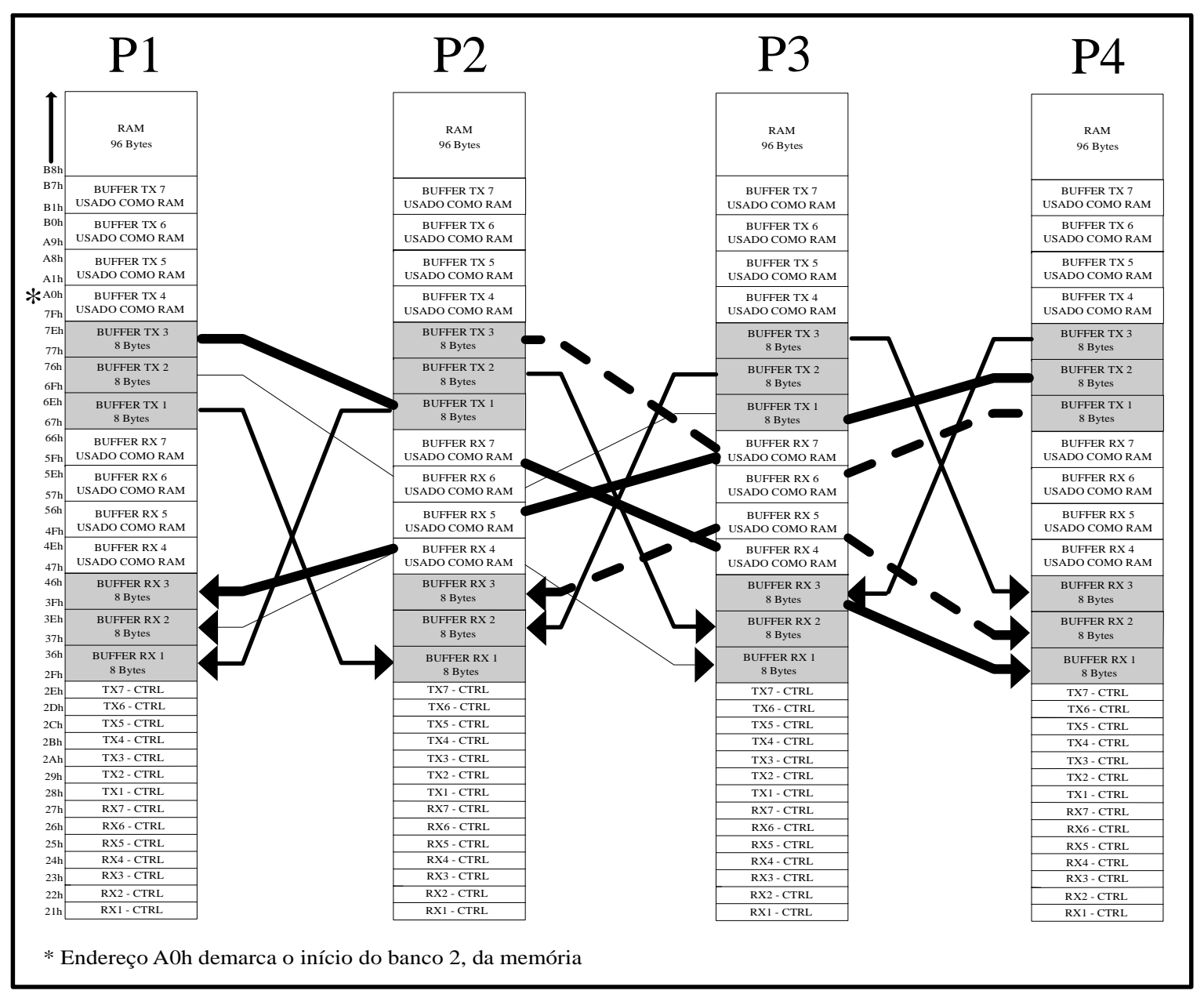

Figura 3.12: Mapeamento entre quatro processadores, com estrutura para oito processadores

Neste sentido, mesmo com toda a estrutura implementada para oito processadores é possível optar-se por utilizar ou não utilizar cada canal de interconexão individualmente. Os canais não utilizados ficam disponíveis para um futuro uso, se necessário, e suas respectivas áreas de memória ficam livres para serem utilizadas como espaço de uma RAM comum. Neste caso, os componentes de interconexão não utilizados tornam-se componentes subutilizado, ou seja, área de lógica disponível, mas não utilizada.

Para tratar a questão dos canais de comunicação não utilizados e, consequentemente, o respectivo componente de comunicação subutilizado:

(i) A Arquitetura Modular Multicore permite que uma aplicação desenvolvida em uma versão $A M M$ com vários processadores seja portada para uma versão $A M M$ 
com menor quantidade de processadores e menor quantidade de componentes de comunicação;

(ii) A aplicação pode ser portada de uma versão da AMM para outra, apenas alterando-se os endereços de acesso do(s) componente(s) de comunicação e buffer(s) utilizado(s);

(iii) Versões com diferentes quantidades de processadores podem ser fabricadas. Assim, pode-se optar por uma versão composta por menos processadores e evitar subutilização de recursos.

O componente de comunicação que possa ser subutilizado na AMM ocupa uma área de lógica importante. Porém, é um overhead justificável pela flexibilidade que a arquitetura pode proporcionar:

(i) Um componente de comunicação permite que outro processador seja interconectado ao sistema. Este outro processador pode executar muitas funções distintas, diferindo de um periférico não utilizado, dedicado e fixo, como em um microcontrolador;

(ii) Um componente de comunicação não utilizado em uma aplicação final pode ser aproveitado em um possível futuro upgrade de software, no qual nova comunicação entre processadores pode ser idealizada e;

(iii) Podem ser fabricadas diferentes versões da AMM em silício, as quais contém diferentes quantidades de processadores e configurações de interconexão.

\subsection{Flexibilidade da AMM}

A AMM é idealizada para prover flexibilidade de recursos, apesar de sua arquitetura fixa. A flexibilidade é alcançada por meio da utilização de microprocessadores e programas carregados em suas memórias. Estes programas podem também emular funções de diversos periféricos digitais, bem como executar outras funções de interesse.

Assim, além das funções de periféricos que podem ser emuladas, os processadores da AMM podem também executar funções da aplicação principal. A aplicação principal pode ser idealizada e escrita em módulos, subdividindo-se as atribuições e funções de cada processador.

É importante ressaltar que paralelização de código não é objetivo da proposta da AMM. Assim, não objetiva-se distribuição de instruções de um único programa 
entre vários processadores como é o foco da computação de alto desempenho. Neste sentido, a distribuição das funções da aplicação é realizada em tempo de desenvolvimento da aplicação, sendo que cada processador é responsável por tratar localmente seu programa e dados, recebendo e/ou enviando mensagens de/para outros processadores.

Na Figura 3.13 exemplo de duas configurações para possíveis aplicações distintas na $A M M:$ em $(A)$, a aplicação requer geração de quatro pulsos PWM, escrita em display LCD, comunicação serial e outras funções; em (B) a aplicação requer dois canais de comunicação serial, processamento integral diferencial para controle de dois motores, contagem de pulsos de sensores de posição, diferentes temporizadores e outras funções.

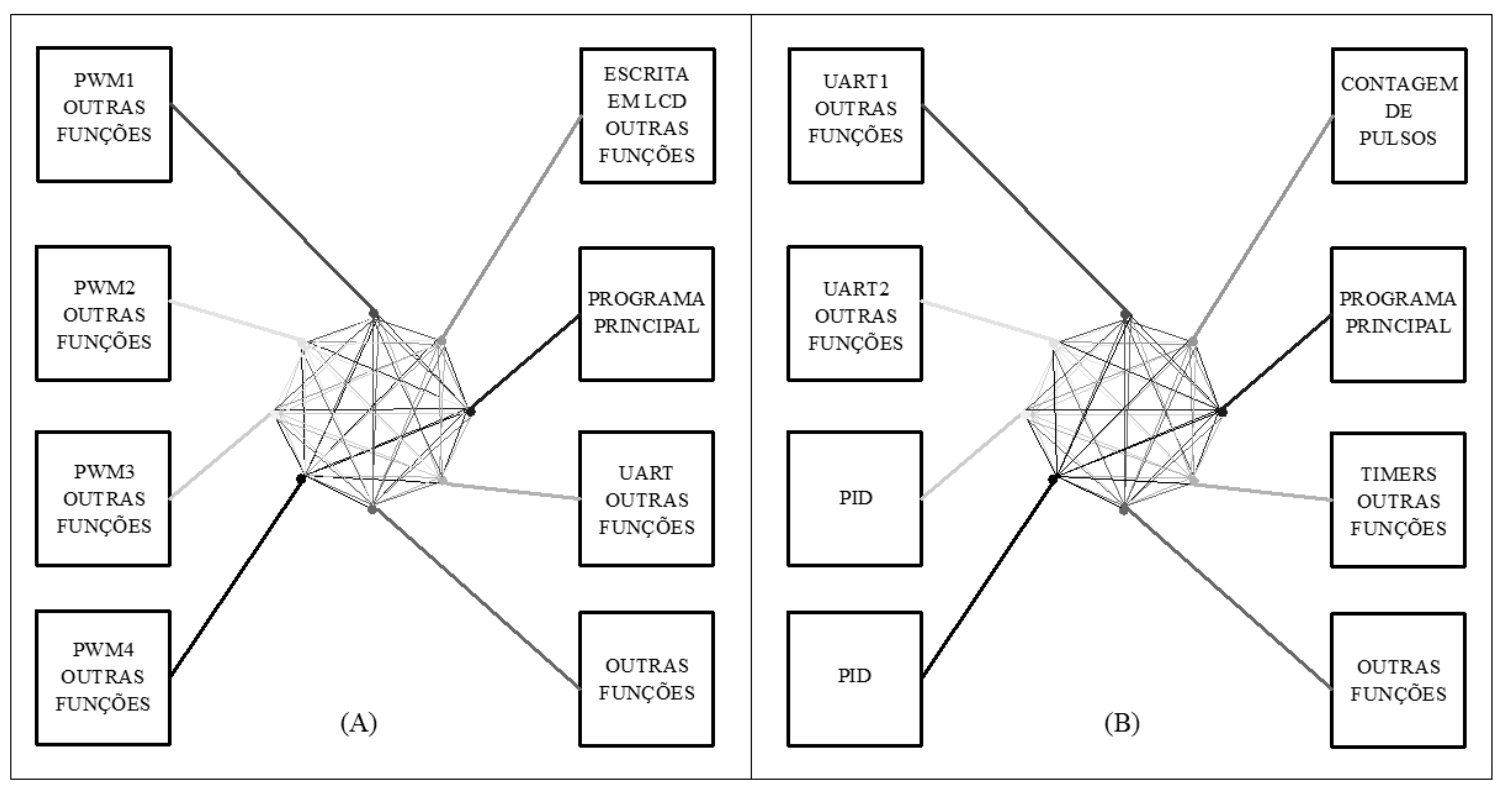

Figura 3.13: Exemplos de diferentes módulos de uma mesma aplicação na AMM

Nos dois exemplos da Figura 3.13, ao redor do processador que pode conter o código principal da aplicação, os outros processadores executam funções variadas de acordo com os requisitos das aplicações solicitadas.

É possível criar funções específicas para cada processador, direcionadas a cada aplicação em particular. Por exemplo, é possível que um ou mais processadores estejam dedicados a receber e tratar estímulos de entrada, realizando computações em seus dados locais e enviando resultados ao processador eleito como central. Este por sua vez pode direcionar as tarefas de processadores dedicados à geração de dados de saída. Ou ainda, funções de 
entrada e saída podem ser balanceadas em um mesmo processador, de acordo com sua complexidade. Desta forma, a flexibilidade para funções digitais é alcançada.

A AMM permite que uma aplicação seja desenvolvida em uma versão com mais processadores e que esta aplicação seja portada para uma versão com menos processadores.

Assim, como exemplificado anteriormente na Figura 3.12, o desenvolvimento da aplicação pode ser testado em uma versão com mais processadores e, após concluída, a aplicação pode ser portada para uma versão AMM com o número mínimo de processadores necessários para executá-la, bastando alterar os endereços dos respectivos componentes de comunicação utilizados.

A Figura 3.14 mostra uma aplicação em configuração "mestre-escravo", mapeada em uma versão AMM de oito processadores, porém, utilizando-se apenas quatro processadores.

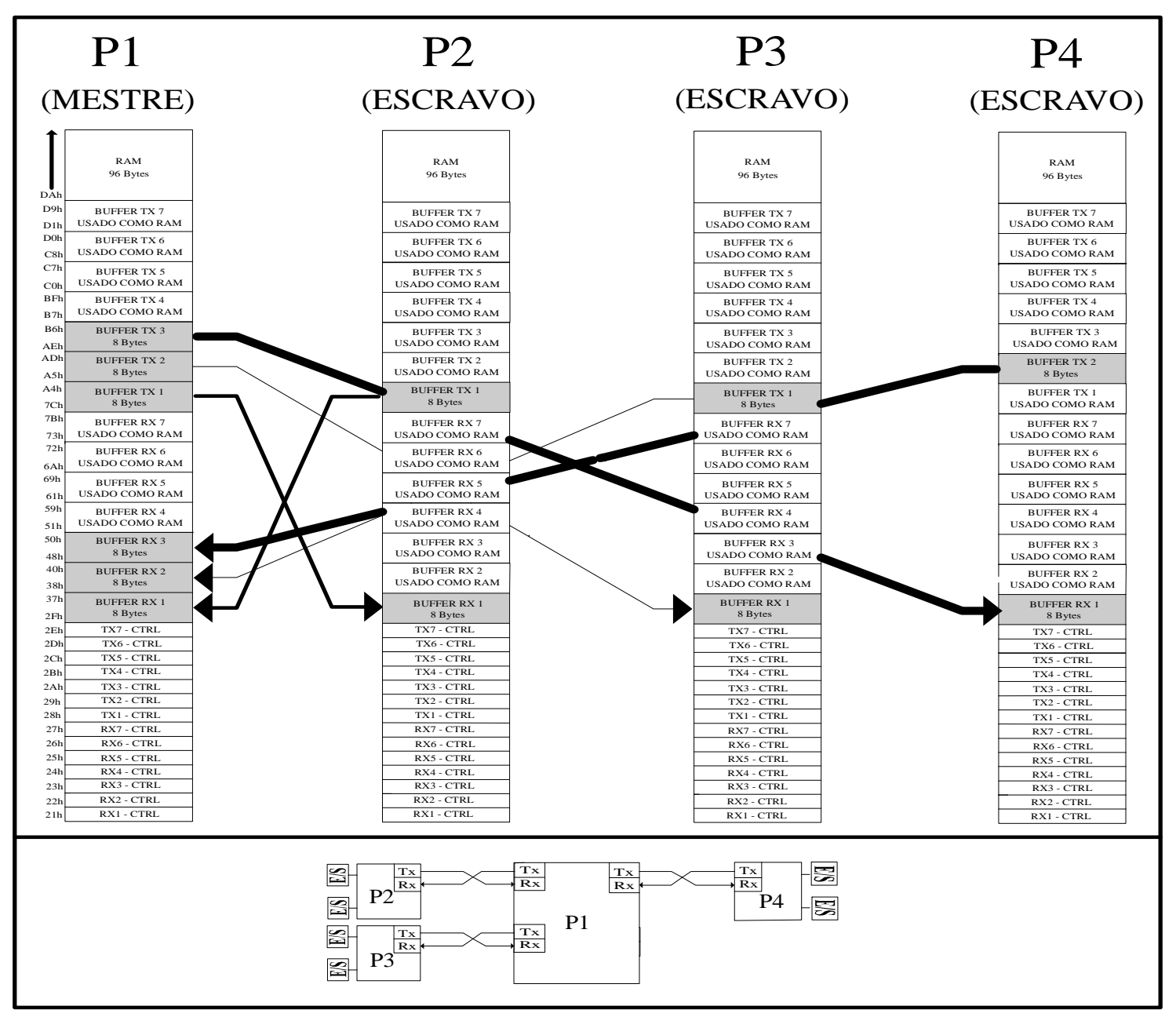

Figura 3.14: AMM com oito processadores, configurado para quatro processadores "mestre-escravo" 
Algumas áreas de memórias reservadas para comunicação com os buffers não são utilizadas no exemplo. Assim, podem ser utilizadas como área comum de memória RAM.

Esta aplicação pode ser portada para uma versão AMM composta por quatro processadores, como por exemplo a versão mostrada na Figura 3.10. O mapeamento de memória para esta versão AMM com quatro processadores é o mesmo visualizado na Figura 3.2(C).

$\mathrm{Na}$ Figura 3.15 diferentes versões $\mathrm{AMM}$ são configuradas para quatro processadores, a partir de uma versão AMM composta por oito processadores. Utilizando os componentes de transmissão e recepção endereçáveis pode ser possível definir a configuração final dos processadores, necessária para a aplicação.

A Figura 3.15 mostra o mapeamento real para as versões de configuração conceituais da Figura 1.2 (A), (B), (C) e (D) (Capítulo 1).

Neste contexto, a forma como os processadores são interconectados pode ser definida por meio do acesso a cada registrador de configuração de cada controlador de transmissão ou de recepção, definindo se a área de acesso ao respectivo buffer será utilizada como área de comunicação ou como área de memória RAM comum.

Conexões adicionais entre processadores, se necessárias para a aplicação sendo desenvolvida, podem ser realizadas por meio de interligações externas ao chip final; caminhos adicionais de comunicação entre processadores podem ser realizados por meio do uso de trilhas na placa de circuito impresso final, podendo interligar processadores diretamente entre PORTs, configurados como entrada ou saída.

Assim, obtém-se flexibilidade de adequação do chip aos requisitos da aplicação, mesmo durante seu desenvolvimento. 


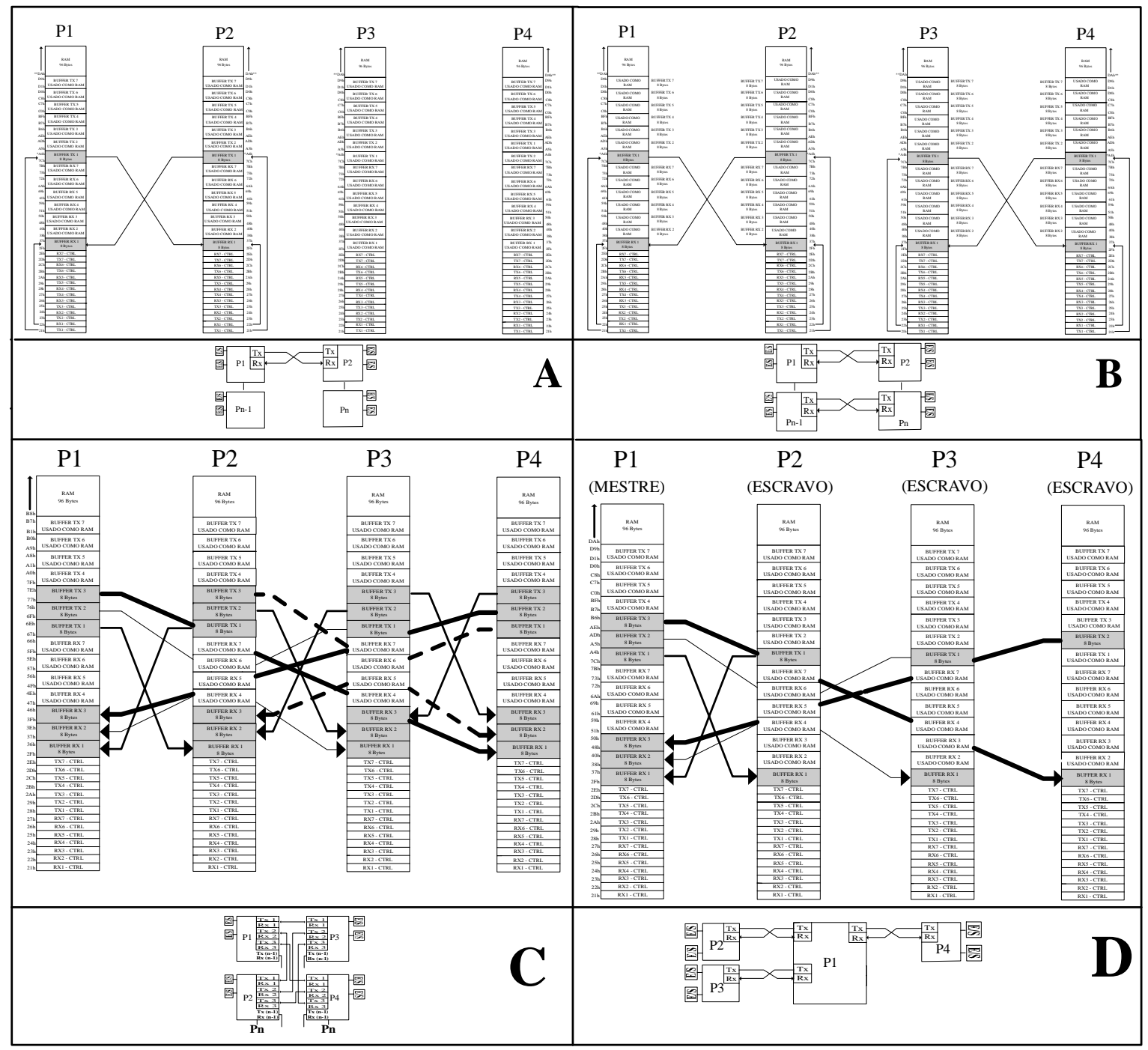

Figura 3.15: Mapeamento real idealizado para diferentes configurações de interconexões

\subsection{Escalabilidade da AMM}

A AMM é escalável e, teoricamente, é possível incluir um número ilimitado de processadores no sistema. Porém, isso não é praticável devido ao sistema de interconexão adotado.

Manter os processadores totalmente interconectados permite todos os caminhos físicos e independentes para a comunicação entre cores. Assim, diferentes configurações podem ser assumidas, bastando configurar o software presente em cada processador para assumir a configuração lógica desejada. 
Em um hipotético AMM composto por 100 processadores, para manter os processadores totalmente interconectados, o número de interconexões seria 100(100-1)/2 ou seja 4950 linhas de interconexão e 99 componentes de transmissão e 99 componentes de recepção em cada processador. Isto inviabilizaria muitos processadores no sistema pois as interconexões e os componentes de comunicação exigiriam área significativa do chip.

Estima-se que entre 15 à 20 processadores na $\mathrm{AMM}$ é uma configuração praticável e está nos limites da escalabilidade, em um único agrupamento de processadores. Assim, com 20 processadores, para manter os processadores totalmente conectados, o número de interconexões seria 20(20-1)/2, ou seja, 190 linhas de interconexão entre processadores, bem como 19 componentes de transmissão e recepção, seria uma configuração limite praticável estimada.

Com o processador atual da AMM, UPEM2, é possível endereçar somente 224 endereços da memória RAM e mapear-se até 23 buffers de comunicação e, portanto, o máximo de 24 processadores. Porém, isso consumiria quase toda a área de memória RAM, vinculando-a aos 23 buffers de 8 bytes cada. Isto seria impraticável pois não existiria área de memória RAM disponível para variáveis do próprio programa executando nos processadores.

\subsection{Detecção de falhas e redundância na AMM}

A tolerância a falhas em sistemas multicores tem sido amplamente investigada por vários autores, devido a sua importância principalmente na utilização de sistemas críticos. A tolerância a falhas se inicia na detecção da falha.

A detecção da falha na AMM é implementada por meio de uma lógica de depuração inserida no processador UPEM2, base da AMM, auxiliado por uma lógica de sincronização para comparação de resultados.

Assim, um mecanismo de detecção de falhas é também proposto, com base na estrutura desenvolvida para avaliação da UPEM2, na qual os valores de alguns registradores e componentes internos são também disponibilizados externamente por meio de portas de saída (capítulo 4).

Este mecanismo consiste em uma lógica de sincronização entre os resultados dos cálculos de dois processadores UPEM2. Por sua vez, os processadores são sincronizados com o uso de transmissões simultâneas para vários processadores, 
discutidas na seção 3.3 deste capítulo, e redundância de software em suas memórias de programa. A Figura 3.16 ilustra a estrutura em blocos para a detecção de falhas na AMM.

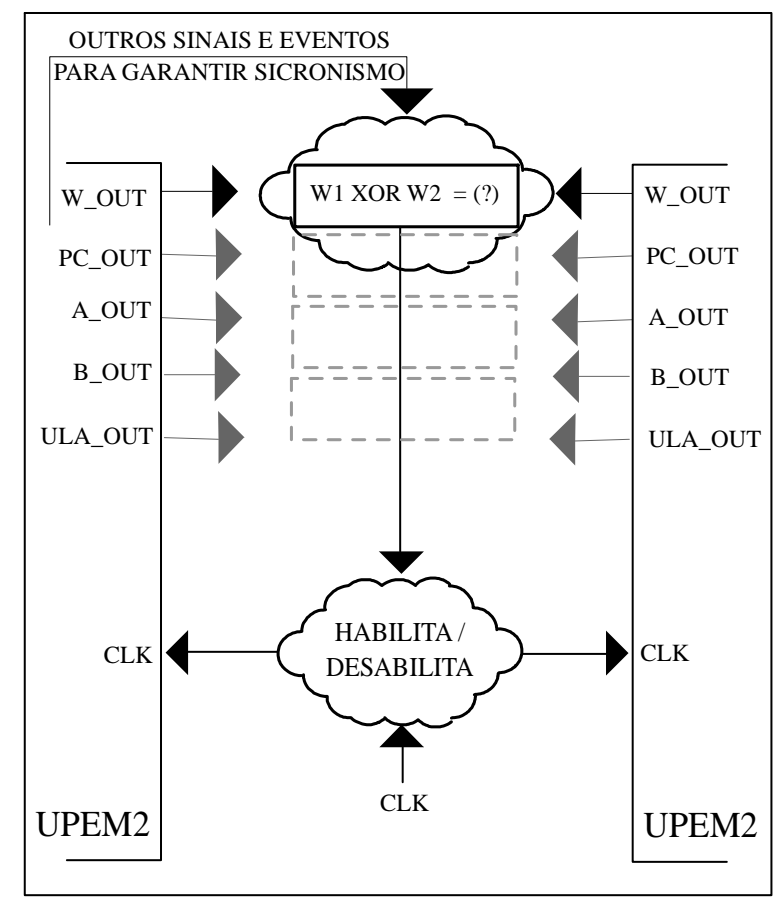

Figura 3.16: Estrutura para detecção de falhas na AMM

A Figura 3.16 mostra que os registradores de trabalho "W" de dois processadores da AMM são comparados em uma lógica que sincroniza o instante exato para a comparação. Caso os valores presentes nos registradores apresentem qualquer diferença, uma lógica para interromper o clock de ambos processadores é acionada, cessando qualquer atividades em ambos e garantindo que futuros problemas não aconteçam.

É possível alterar facilmente o registrador de interesse para ser comparado entre os processadores monitorados. Ou ainda, incluir mais de um registrador na comparação, se for de interesse aumentar a confiabilidade da detecção.

É possível ainda, adaptar a estrutura de detecção de falhas apresentada para outras descrições VHDL de outros processadores de interesse, bastando verificar quais registradores devem ser monitorados, bem como sua quantidade de bits

Ao detectar-se a falha é importante realizar também um estudo sobre as causas da falha, verificando-se um histórico de ocorrências. Para isso, a AMM 
possui uma estrutura interna que gera logs de suas atividades monitoradas. Esta estrutura de log é visualizada na Figura 3.17.

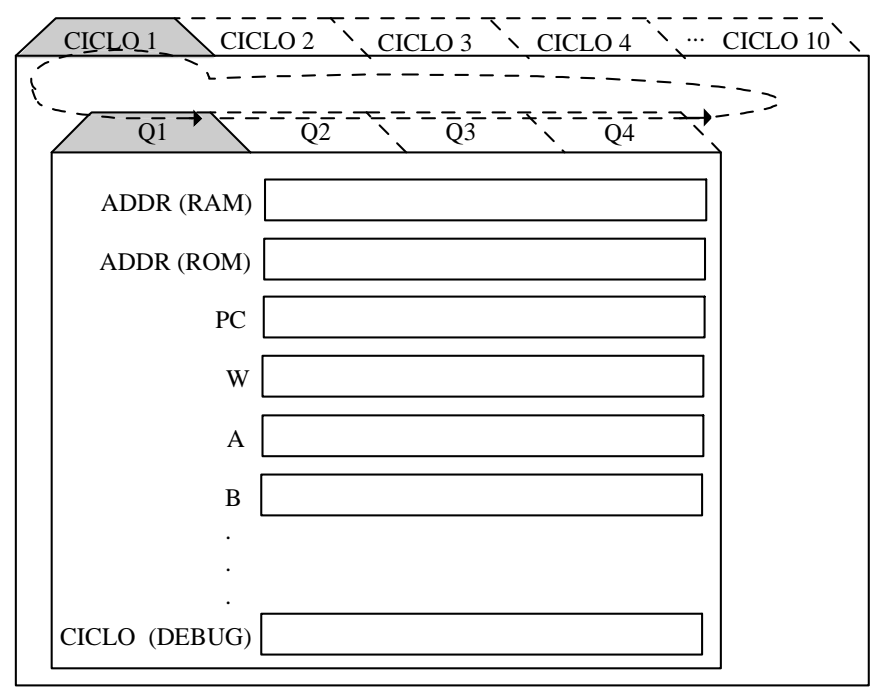

Figura 3.17: Estrutura de log de atividades presente na AMM

A estrutura é composta basicamente por uma memória finita separada da memória dos processadores, cujos dados são armazenados continuamente, retornando ao início e sobrescrevendo os dados mais antigos com dados mais atualizados.

Assim, a ocorrência de eventos em dez ciclos de um processador, configurado para ser monitorado, são armazenados até o instante da falha detectada. Por sua vez, em cada ciclo, os quatro estados principais do processador, Q1, Q2, Q3 e Q4 são armazenados de forma independente. No fim de cada ciclo são armazenados todos os valores correntes de cada registrador e componente de interesse para ser salvo. O último dado importante que deve ser armazenado nesta estrutura de log é o contador de ciclos do processador, para propósitos de melhor interpretação dos dados lidos em uma possível análise.

O número de ciclos, bem como quais componentes devem ter seus valores registrados é facilmente configurável na lógica de controle do sistema de log. Novamente, com o uso da estrutura de depuração da UPEM2, os dados podem ser disponibilizados e armazenados, conforme ilustra a Figura 3.18. 


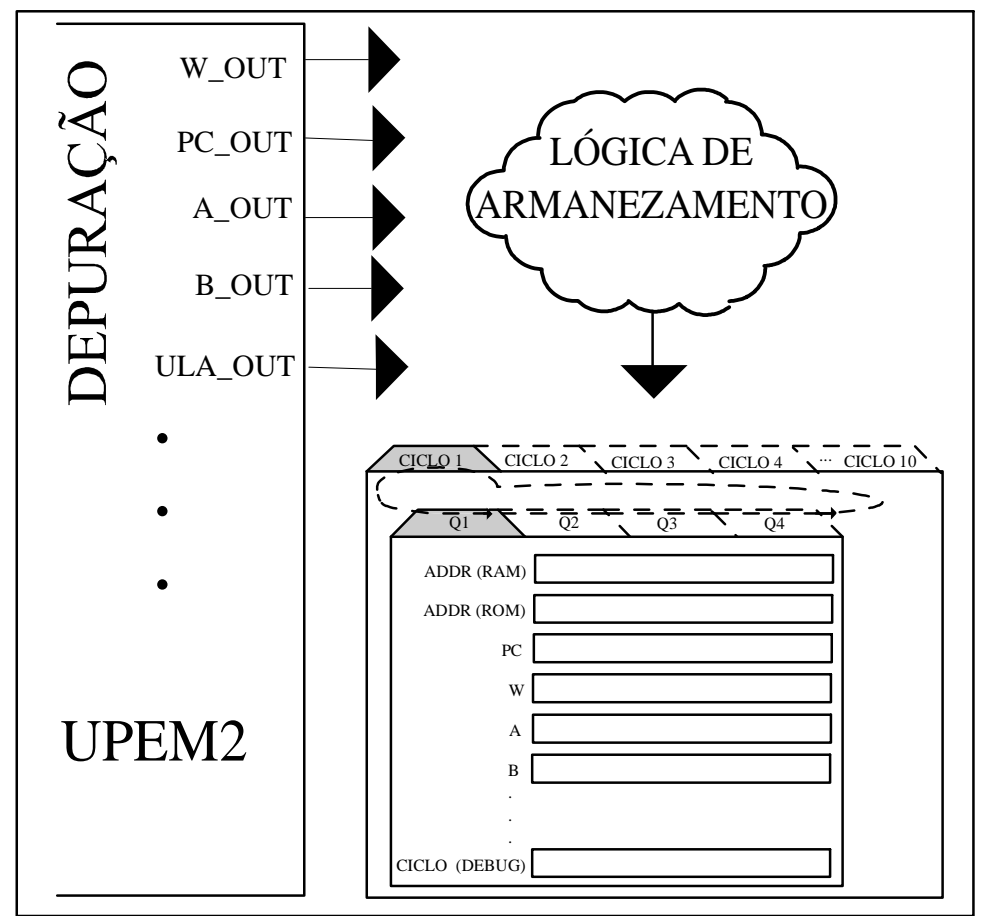

Figura 3.18: Estrutura de depuração da UPEM2 e estrutura de log na AMM.

Os resultados simulados para a detecção da falha, redundância e geração do log de ocorrências são comentados no capítulo 5 desta tese, o qual trata questões de aplicações e testes da AMM.

\subsection{Utilização de RTOS e passagem de mensagens na AMM}

Alguns sistemas operacionais de tempo real (RTOS) minimalistas para sistemas embarcados são disponibilizados, e podem ser candidatos para uso na versão atual da AMM, bem como para futuras versões com base em outros processadores. Como por exemplo o SALVO (PUMPKIN, 2004) e o Novo RTOS (NOVO, 2008), e versões acadêmicas, ou projetos em desenvolvimento como o FreeRTOS (FREERTOS, 2010), VELLOS (HUTORNY, 2010), uGNU/RTOS Homepage - escrito especialmente para PIC16 - (PLATONE, I. 2008), OSA RTOS (TIMOFEEV, V. 2010), Simple RTOS (BAVARESCO, 2010), etc.

Estes RTOS são voltados à sistemas embarcados e microcontroladores, requisitando área mínima de programa e memória RAM, como mostra a tabela 3.1. Vários modelos de microcontroladores de vários fabricantes são suportados por estes RTOS. 
Tabela 3.1: Requisitos para o RTOS VELLOS, para CPUs PIC (HUTORNY, 2010)

\begin{tabular}{|l|c|c|c|}
\hline $\begin{array}{l}\text { PIC family } \\
\text { Feature }\end{array}$ & $\begin{array}{c}\text { PIC12F675 } \\
\text { Flash/RAM }\end{array}$ & $\begin{array}{c}\text { PIC16F690 } \\
\text { Flash/RAM }\end{array}$ & $\begin{array}{c}\text { PIC18F } \\
\text { Flash/RAM }\end{array}$ \\
\hline Bare operating system & $195 / 20$ & $220 / 20$ & $210 / 20$ \\
\hline Heartbeat Timer (1ms, 1s) & $75 / 7$ & $85 / 7$ & $70 / 7$ \\
\hline A definition of class (per class) & $2 / 0$ & $2 / 0$ & $2 / 0$ \\
\hline An object instance (per object) & $2 / 0$ & $2 / 0$ & $2 / 0$ \\
\hline
\end{tabular}

A Tabela 3.1 apresenta informações do desenvolvedor do RTOS VELLOS e mostra que, para três modelos de microcontrolador PIC distintos, o RTOS VELLOS requer diferentes quantidades de bytes na memória de programa (FLASH) e na memória de dados (RAM) para correta operação. Por exemplo, para o PIC16F690, o "corpo" principal do RTOS VELLOS requer 220 bytes de espaço na memória de programa e 20 bytes na memória de dados.

A comunicação entre os programas dos diversos núcleos presentes na AMM e entre núcleos de uniões de AMMs, podem ser realizadas em três meios: (i) via chamadas via hardware de interconexão desenvolvido; (ii) chamadas de sistema operacional ou; (iii) via middleware de comunicação.

Pode-se citar bibliotecas de software como o padrão MCAPI em desenvolvimento ou como a The Multiprocessor Communications Interface Layer (MPCl) e o middleware OSA+, o qual é um middleware escalável para sistemas de tempo real.

A comunicação entre núcleos deve ser realizada com técnicas avançadas de software para garantir-se a preditibilidade e segurança em sistemas ciber-físicos. Assim, evita-se estados de deadlock do sistema causados por perdas de mensagens, time-out de mensagens, mensagens corrompidas ou duplicadas, e outros diversos problemas envolvidos na troca de mensagens.

\subsection{Síntese do capítulo}

$\mathrm{Na} A M M$, informações podem ser enviadas ou recebidas, a qualquer instante e de forma independente, por qualquer um dos processadores, e não existe necessidade de instruções especiais no processador para controlar a escrita ou recepção de mensagens. A comunicação full-duplex é realizada com apenas duas 
linhas de transmissão e são disponibilizados 64 bits para envio e 64 bits para recepção, livres para cada programador definir sua função e uso.

A AMM é idealizada para prover flexibilidade de recursos, apesar de sua arquitetura fixa. A configuração final dos processadores - Figura 1.2 (capítulo 1) necessária para a aplicação pode ser definida em software. A flexibilidade é alcançada por meio da utilização de microprocessadores e programas carregados em suas memórias.

A AMM permite que aplicações concluídas em uma versão que não utilize todos os processadores possa ser portada para uma versão com o número mínimo de processadores exigidos. Algumas áreas de memórias reservadas para comunicação com os buffers que não sejam utilizadas podem servir como área comum de memória RAM.

Estima-se que entre 15 à 20 processadores na $A M M$ é uma configuração praticável e está nos limites da escalabilidade, para um único agrupamento de processadores.

A detecção da falha na $A M M$ é realizada por meio de uma lógica de depuração acoplada ao processador UPEM2, base da AMM, auxiliado por uma lógica de sincronização para comparação de resultados. É possível adaptar facilmente toda a estrutura de detecção de falhas apresentada para outros processadores de interesse, bastando verificar quais registradores devem ser monitorados, bem como sua quantidade de bits

A AMM possui uma estrutura interna que gera logs de suas atividades. Esta estrutura de log sugerida também pode ser adaptada para uso de outros processadores de interesse.

Por fim, sugere-se alguns RTOS para serem utilizados na AMM, caso o desenvolvedor do sistema julgue necessário utilizá-los.

O próximo capítulo apresenta uma metodologia, desenvolvida neste trabalho, para avaliação de processadores e circuitos digitais. A metodologia resultou no processador utilizado como sendo base do processador da AMM, e comprovou a correta execução dos programas testados. 


\title{
Capítulo 4 - Avaliação do processador da AMM
}

\author{
Neste capítulo apresenta-se em detalhes a metodologia para avaliação do \\ processador base do AMM. Partindo-se de um processador anteriormente descrito \\ em VHDL, foi necessário ampliá-lo para ser inserido na AMM. Foram realizadas \\ simulações com base em um simulador comercial e comparadas com simulações no \\ software Modelsim e ferramentas de simulação de circuitos integrados. Os \\ resultados obtidos indicam funcionamento correto para os programas testados e \\ estimulam a utilização do processador ampliado servir como base da AMM.
}

\subsection{O processador da AMM}

O processador base utilizada na concepção e implementação da AMM, chamado aqui por UPEM2, foi desenvolvido como uma evolução do processador UPEM. A seguir, um breve comentário sobre a UPEM, para embasar o surgimento e utilização da UPEM2.

A UPEM foi descrita especificamente para emular o comportamento de alguns periféricos alvo identificados em (PENTEADO, 2004), e foi modificada para os interesses do estudo a partir de uma versão VHDL do PIC, o CQPIC (MORIOKA, 2004). O CQPIC é uma descrição completa Verilog e VHDL do microcontrolador PIC16F84 e seus periféricos. Apesar deste microcontrolador ser obsoleto e sua produção ter sido descontinuada pelo fabricante Microchip, a CPU base deste microcontrolador foi descrita em VHDL e utilizada no trabalho de Yuan,S.; Chang, P.; Liao, S. (2010).

Em 2004, este processador modificado foi chamado por UPEM - Unidade de Processamento de Periféricos Específica para Microcontroladores - e foi concebido para executar códigos compatíveis com o microcontrolador PIC, linha PIC16F, da Microchip. A UPEM executa diretamente, com limitações de uso, programas gerados por compiladores direcionados a esta linha de microcontroladores, (PENTEADO, 2004).

Os blocos finais que compõem a UPEM podem ser visualizados na Figura 4.1. 


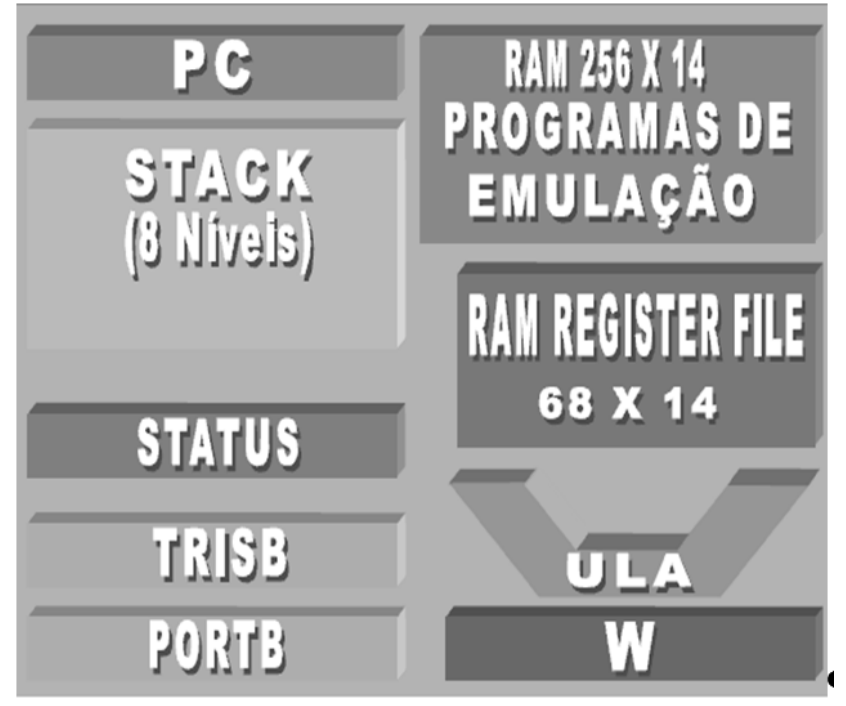

Figura 4.1: Blocos arquiteturais da UPEM, (PENTEADO, 2004).

A arquitetura final da UPEM é parcialmente compatível com programas gerados para o microcontrolador PIC16F84, pois, a UPEM não possui periféricos e possui recursos limitados para acesso aos registradores endereçáveis.

Por motivos de redução máxima de área de utilização em FPGA, em relação ao PIC16F84 a UPEM não possui: (i) o PORT A; (ii) diversos registradores disponíveis no PIC16F84; (iii) acesso à todos os registradores endereçáveis; (iv) controle de interrupção e; (v) nenhum periférico extra.

A UPEM foi escolhida para utilização na AMM por questões de ser um processador não pipeline, não superescalar e estágios contínuos de processamento, o que facilita a previsibilidade de operações, característica importante em sistemas de tempo real e ciberfísicos.

Porém, para utilizar a UPEM na AMM foi necessário evoluí-la, pois é um processador de usabilidade limitada. A UPEM acessa somente 64 bytes de memória RAM, uma quantidade insuficiente para mapear a estrutura de comunicação idealizada para a AMM. Além disso, a UPEM não possui estrutura de interrupção, o que dificulta a sincronização de eventos e torna a programação mais limitada.

A UPEM foi reestruturada para poder servir como base da AMM, surgindo assim a UPEM2. A UPEM2, por sua vez, é compatível com a CPU presente no microcontrolador PIC16F628, mais evoluído que o descontinuado PIC16F84, ambos da Microchip. A arquitetura final simplificada da UPEM2 é ilustrada na Figura 4.2. Ambos, PORTA e PORTB são bidirecionais. 


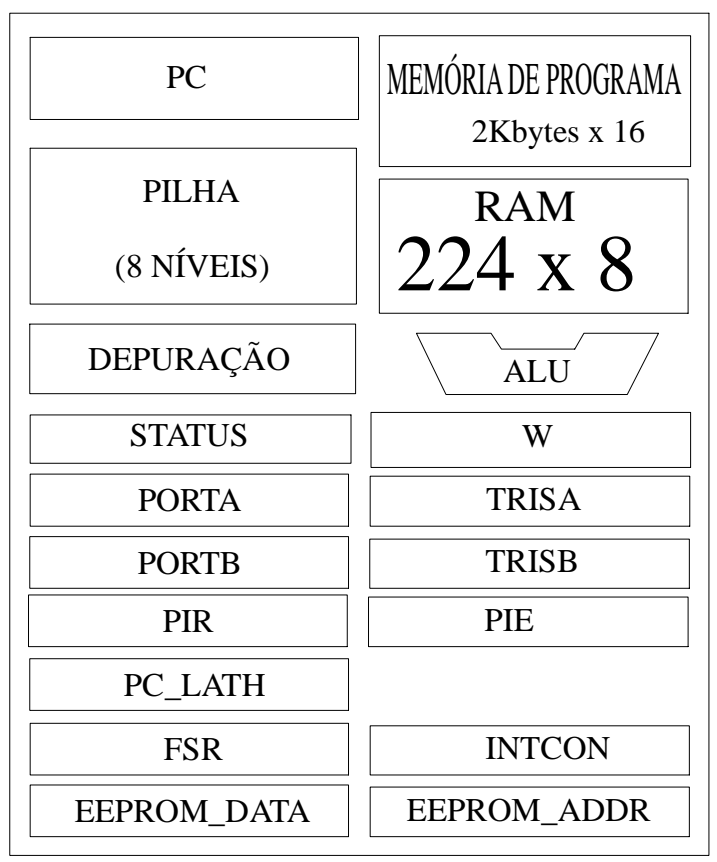

Figura 4.2: UPEM2 - Processador base do AMM

Comparando-se a UPEM com a UPEM2, a UPEM2 possui mais registradores de controle interno, é capaz de endereçar mais memória RAM interna - os quatro bancos disponíveis no processador do PIC16F628 - 224x8bits -, possui PORT A e PORT B cada qual com 8 bits totalizando então $16 \mathrm{E} / \mathrm{S}$ bidirecionais. Foi implementado um controle de interrupção e 2 Timers para auxiliar o processador UPEM2. Adicionou-se também um hardware de depuração o qual permite acesso direto à registradores internos e outros pontos de interesse. Este hardware de depuração permite a geração de logs, salvando dados numa estrutura separada do processador UPEM2 (Capítulo 3).

Para evoluir o processador UPEM ao processador UPEM2, foi proposta uma metodologia para avaliação de processadores e aplicada no desenvolvimento de uma versão VHDL de uma CPU compatível com a CPU presente no microcontrolador PIC16F628

Esta metodologia permitiu avaliar aproximadamente 150 testes nas 34 instruções descritas. Os testes de instruções foram considerados suficientes, e iniciou-se então a etapa final de testes do processador UPEM2, com programas reais. 


\subsection{Avaliação do processador UPEM2, base da AMM}

Para a avaliação do processador UPEM2 objetivando a total compatibilidade entre a UPEM2 e os compiladores existentes para o PIC16F628:

(i) Para comprovar a compatibilidade entre a UPEM2 e programas reais para PIC16F existentes no mercado, vários simuladores e programas reais foram estudados e escolheu-se simuladores de fácil interação para funções step-by-step na execução do código;

(ii) O simulador escolhido foi o Pic Simulator IDE, desenvolvido por Vladimir Soso, da empresa OshonsSoft (OSHON, 2010);

(iii) Com o Pic Simulador IDE, comparou-se o número de ciclos e os efeitos da execução de cada instrução isolada com os resultados obtidos com a UPEM2 no software de simulação de lógica digital ModelSim;

(iv) Procurou-se, programas reais que utilizam o maior número de instruções do PIC e que executem corretamente com o mínimo hardware externo possível;

(v) Os programas reais escolhidos foram dois jogos, Tetris e Pong, (GUNÉE, 2008), os quais são programas complexos que geram sinal de vídeo composto NTSC e utilizam cerca de $90 \%$ das instruções disponibilizadas no PIC. Optou-se pelo uso dos jogos para facilitar a visualização dos resultados físicos em FPGA, não dependendo de outros equipamentos ou componentes externos ao kit do FPGA utilizado.

\subsubsection{O software Pic Simulator IDE}

O software PIC Simulator IDE é uma ferramenta para debug e depuração do funcionamento de programas desenvolvidos para Microcontroladores PIC.

As funcionalidades consideradas mais importantes para auxiliar no desenvolvimento da UPEM2 foram sua contagem de ciclos, depuração do próximo e do ultimo opcode executado, inclusão de breakpoints, bem como a visualização de todos os valores dos registradores, RAM, ROM e portas de E/S. O programa Tetris foi carregado no software Pic Simulator IDE e sua execução foi comparada com a execução do mesmo programa no software ModelSim, o qual simula a UPEM2 real descrita em VHDL. Os detalhes do PIC Simulator IDE relevantes para este estudo são ilustrados em destaque na Figura 4.3. 


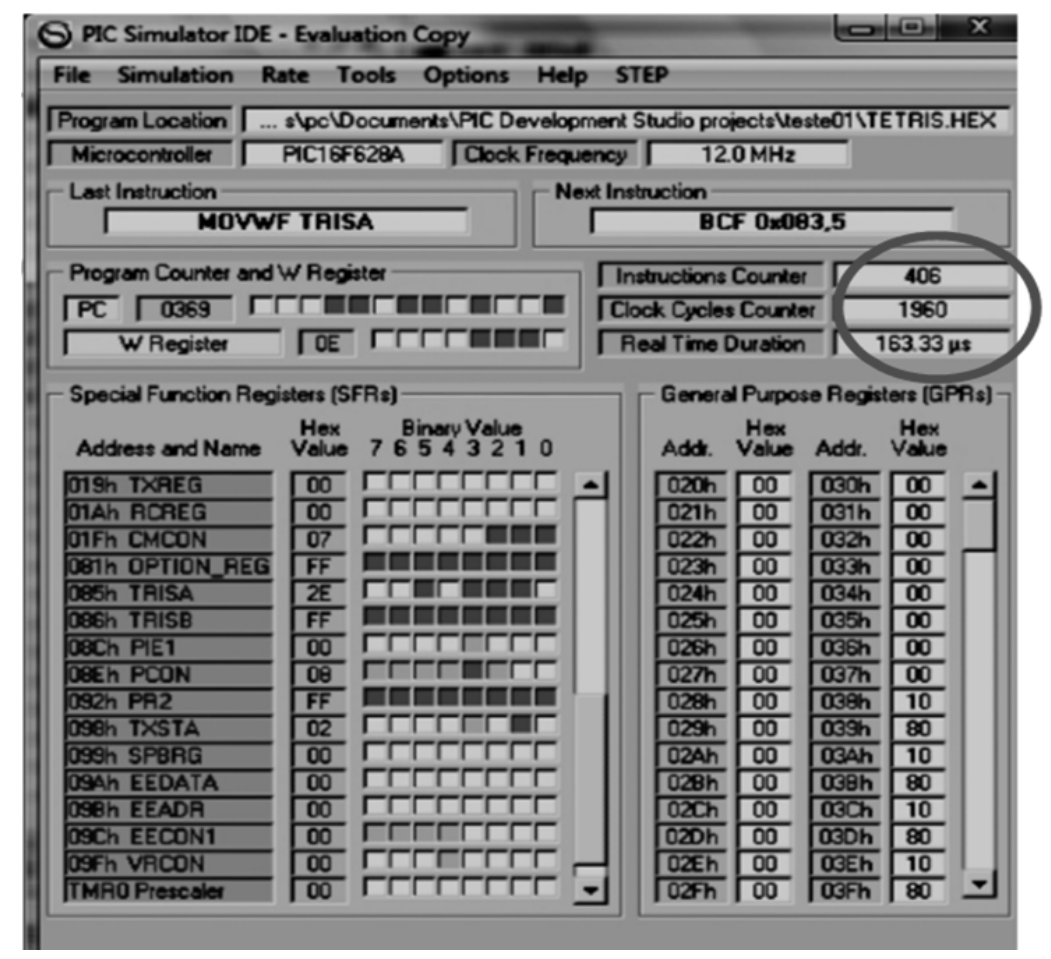

Figura 4.3: Pic Simulator IDE, (OSHON, 2010)

Na Figura 4.3, os campos Instructions Counter e Clock Cycles Counter são úteis na depuração de qualquer software de interesse. Na simulação do jogo Tetris, 406 instruções foram executadas em 1960 ciclos de clock. Tomou-se aleatóriamente um estado da simulação, em destaque na Figura 4.3. Estes dados, 406 instruções e 1960 ciclos de clock são os mesmos mostrados na Figura 4.4, em que o programa foi carregado e executado na UPEM2, com o software Modelsim.

\subsubsection{ModelSim e UPEM2 com programa Tetris}

Para a continuar a avaliação da UPEM2, sua memória de programa foi carregada com o programa Tetris, compilado para o PIC16F628. Para isso, o programa tetris.asm, (GUNEÉ, 2008), foi traduzido diretamente para uma descrição VHDL que representa a memória de programa do PIC, por meio do programa hex2vhd, integrante do projeto CQPIC, (MORIOKA, 2004). Foram necessárias algumas modificações na descrição vhdl gerada pelo programa hex2vhd para adequá-lo à UPEM2. Assim, foi possível simular a execução do programa real Tetris na UPEM2 simulada no ambiente Modelsim.

O principal objetivo desta comparação foi verificar a contagem de ciclos gastos para executar os programas e compará-los com a contagem de ciclos da 
UPEM2 sendo simulada no software ModelSim, além de verificar o comportamento final do programa real testado. Na Figura 4.4, visualiza-se a simulação da UPEM2 no software ModelSim com o mesmo programa que foi carregado no software Pic Simulator IDE, na Figura 4.3.

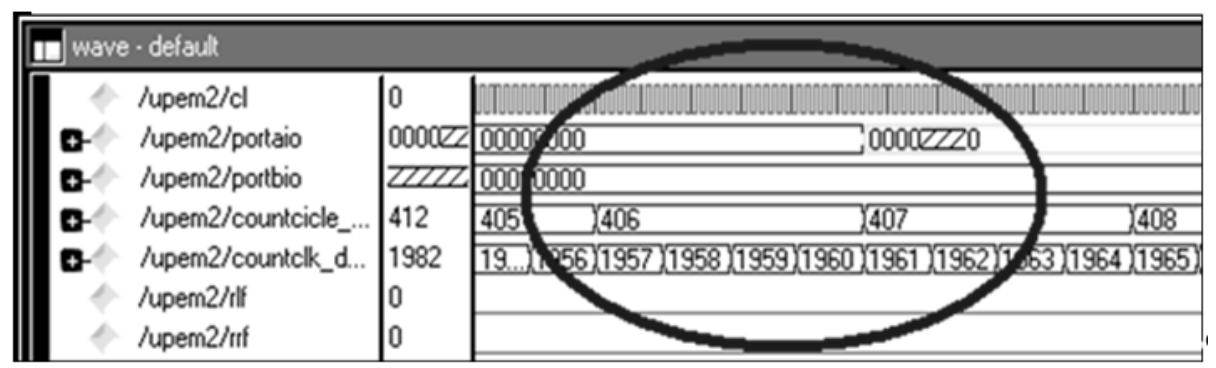

Figura 4.4: Simulação da UPEM2 no software ModelSim, com o programa de teste

Um ponto positivo no desenvolvimento da UPEM2 foi que, na área em destaque na Figura 4.4, o número de ciclos e de clocks estavam idênticos nas duas simulações, Figura 4.3 e Figura 4.4. Na Figura 4.3, Instructions Counter e Clock Cycles Counter, possuem exatamente o mesmo valor que countcycle e countclk_d, na Figura 4.4, sinais incluídos na descrição VHDL para depuração e testes de programas que executem na UPEM2.

Após esta confirmação otimista do possível funcionamento correto da UPEM2, ambos simuladores, ModelSim e Pic Simulator IDE, foram deixados em funcionamento contínuo e os resultados foram comparados manualmente em diversos pontos aleatórios. Em todos os pontos de comparação os resultados entre a execução da UPEM2 e a execução no Pic Simulator IDE foram idênticos. Decidiuse então parar estes testes após o ModelSim simular por mais de 7 horas, em um Intel Core2Duo 4G RAM, alcançando pouco mais de 50 mil instruções executadas corretamente em relação ao Pic Simulator IDE. A UPEM2 foi mapeada em FPGA e executou corretamente os programas, conforme é detalhado no capítulo 5 desta tese.

Na tabela 4.1 aparece o conjunto ISA final da UPEM2. O conjunto ISA da CPU presente no microcontrolador PIC possui 35 instruções, enquanto a UPEM2 proposta utilizou 32 destas instruções. Não há modo de baixo consumo ativado por instruções, descartando-se a instrução SLEEP. Por fim, não foi implementado o periférico watchdogtimer e, sendo assim, descartou-se a instrução CLRWDT. Para a correta execução dos programas reais testados, implementou-se 
também duas instruções obsoletas no PIC, as instruções TRISA e TRISB, que atribuem valores aos registradores de controle das portas em apenas um ciclo de máquina. Totalizou-se assim 34 instruções.

Tabela 4.1: O conjunto ISA da CPU UPEM2 proposta

\begin{tabular}{|c|c|c|c|c|c|c|c|}
\hline 1 & addlw & 10 & clrf & 19 & iorwf & 28 & sublw \\
\hline 2 & addwf & 11 & clrw & 20 & movf & 29 & subwf \\
\hline 3 & andlw & 12 & comf & 21 & movlw & 30 & swapf \\
\hline 4 & andwf & 13 & decf & 22 & movwf & 31 & xorlw \\
\hline 5 & bcf & 14 & decfsz & 23 & nop & 32 & xorwf \\
\hline 6 & bsf & 15 & goto & 24 & retlw & 33 & trisa \\
\hline 7 & btfsc & 16 & incf & 25 & return & 34 & trisb \\
\hline 8 & btfss & 17 & incfsz & 26 & rlf & & \\
\hline 9 & call & 18 & iorlw & 27 & $\operatorname{rrf}$ & & \\
\hline
\end{tabular}

\subsubsection{Simulação para ASIC}

Após o sucesso da descrição e implementação em FPGA do processador UPEM2, foi iniciado 0 projeto UPEM2 nas ferramentas Cadence para desenvolvimento de circuitos integrados. Com a ferramenta First Encounter, a descrição VHDL da UPEM2 e as memórias mapeadas com o programa Tetris foram sintetizadas para uma descrição Verilog com as células da tecnologia adotada.

Com o processador UPEM2 no Cadence, a descrição foi simulada no software Cadence Ncsim e os resultados visualizados na ferramenta Cadence SimVision e os resultados foram comparados com a simulação no software ModelSim. Os resultados foram positivos, pois, as duas simulações se comportaram da forma correta e esperada: as simulações se mostraram idênticas. As Figuras 4.5 e 4.6 ilustram as duas simulações, no ModelSim e no Cadence SimVision, respectivamente. Nota-se na parte inferior em destaque de ambas Figuras, que a sequência de valores na porta de saída PORTB são idênticas: valores intermitentes de 00h e mudança para FEh. Isso indica que a UPEM2 poderá funcionar corretamente em silício. 


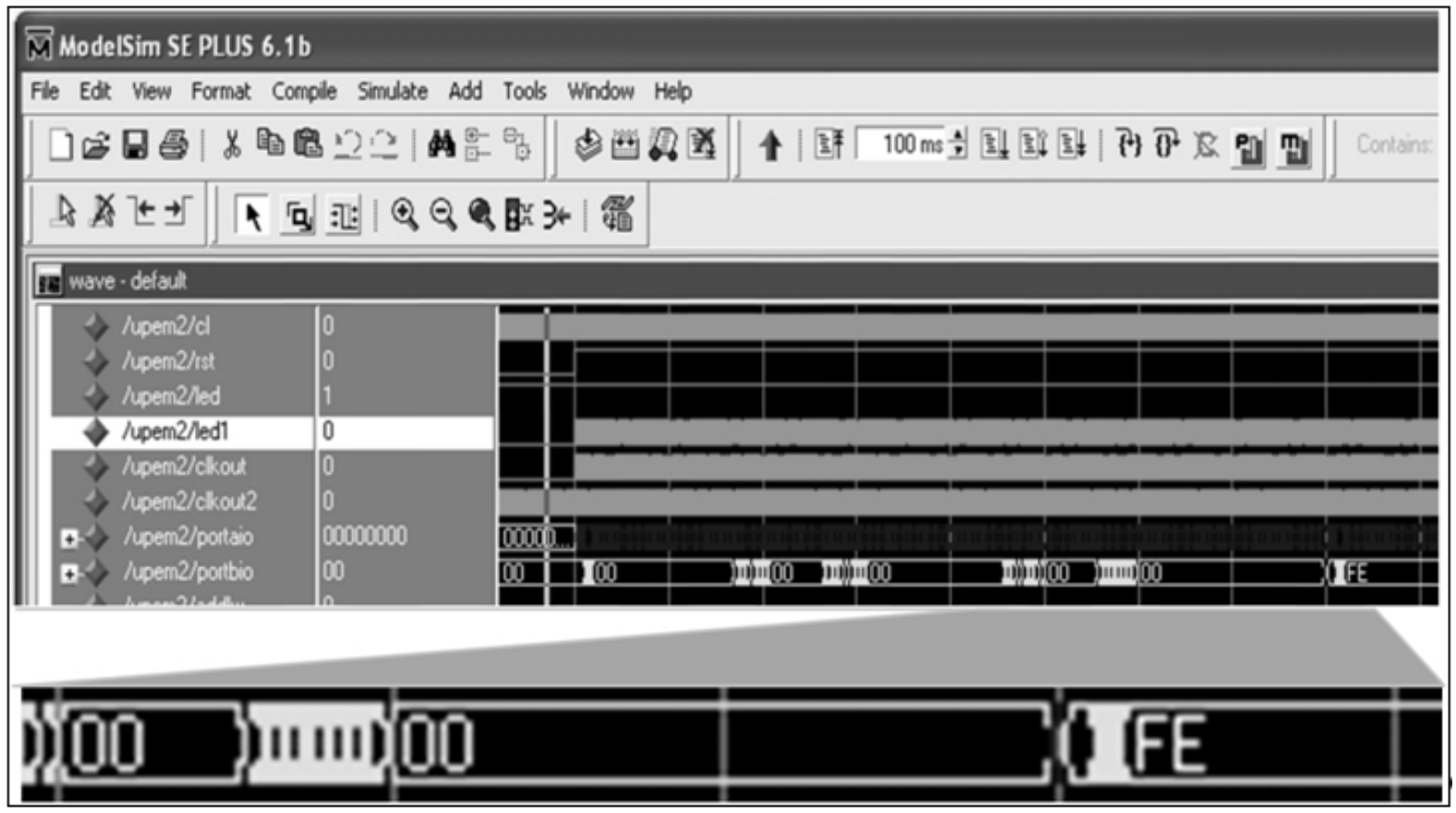

Figura 4.5: UPEM2 executando o programa Tetris (GUNEÉ, 2008), no ModelSim

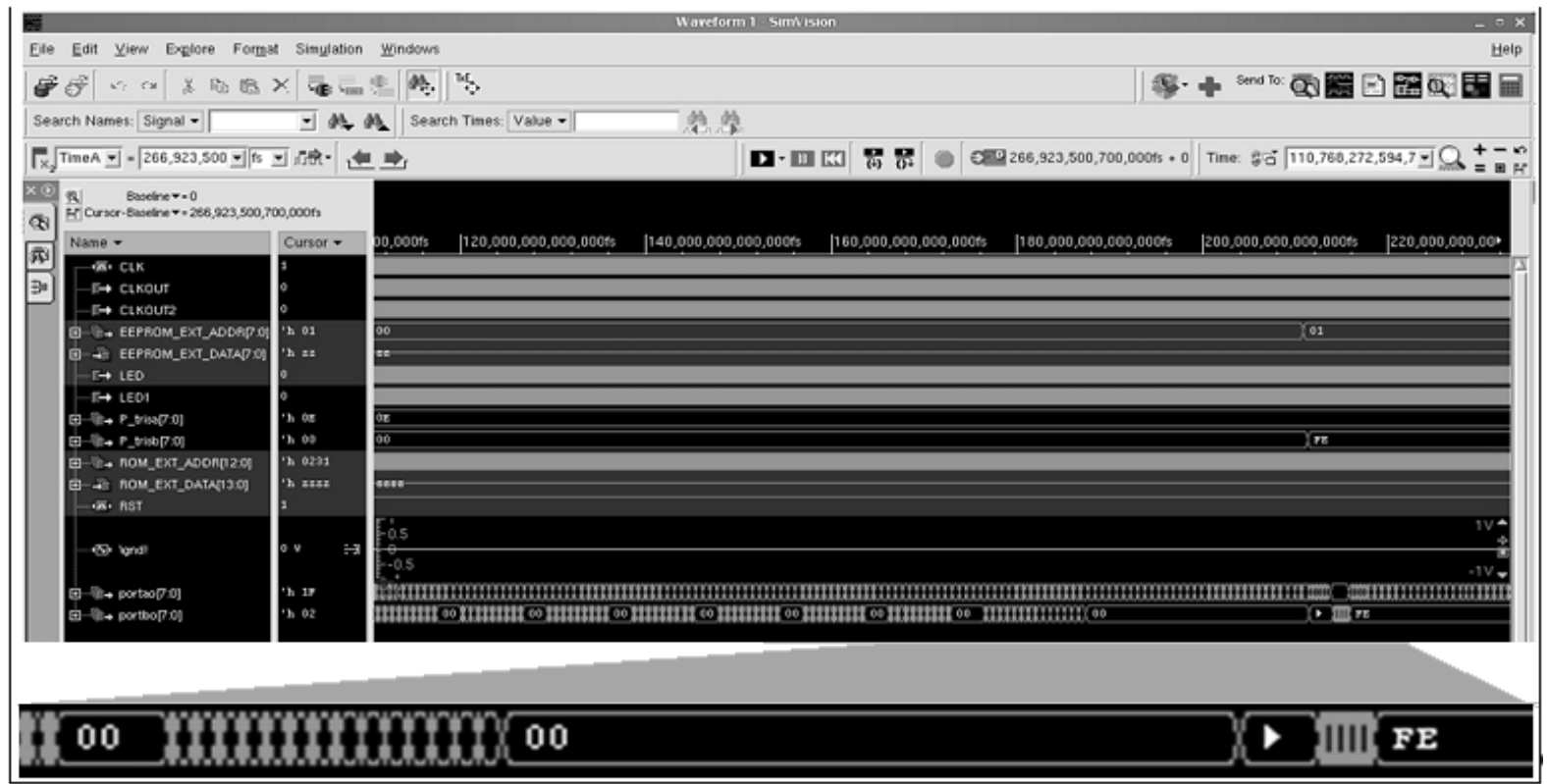

Figura 4.6: UPEM2 executando o programa Tetris (GUNEÉ, 2008), no Cadence SimVision

\subsection{Síntese do capítulo}

O processador base utilizado em um protótipo da AMM, a UPEM2, foi desenvolvido como uma evolução de um processador anteriormente descrito, a UPEM. Desenvolveu-se uma versão VHDL de uma CPU compatível com a CPU 
presente no microcontrolador PIC16F628, e iniciou-se a etapa de avaliação final da UPEM2, com programas reais.

Com o uso do software comercial de simulação para o microcontrolador PIC, PIC Simulator IDE, comparou-se a execução de dois programas reais com dados de execução do mesmo programa na UPEM2 carregada no software de simulação Modelsim. Comprovou-se total compatibilidade entre as simulações.

Com estes resultados positivos, o processador da AMM foi simulado no software Cadence NcSim e visualizados no software Cadence SimVision. Os resultados foram comparados com a simulação no software ModelSim. Os resultados foram positivos, pois, as duas simulações se comportaram de forma idêntica, sendo um bom indicativo de que o processador da AMM poderá funcionar corretamente também em silício.

O próximo capítulo, apresenta testes e aplicações do processador UPEM2 inserido na $A M M$ e os respectivos testes do protótipo AMM. São mostradas várias simulações da AMM, protótipo em FPGA e um protótipo do processador UPEM2 e da AMM em silício. 


\title{
Capítulo 5: Aplicações e testes do protótipo AMM
}

\begin{abstract}
Este capítulo descreve os testes realizados para a avaliação do protótipo AMM desenvolvido. Detalha alguns programas especificamente escritos para serem utilizados na $A M M$, visando comprovar suas principais características. Descreve também o fluxo manual de concepção, programação e depuração dos resultados. Este fluxo utiliza compiladores e ferramentas comerciais em conjunto com uma sequência de ações manuais adotadas. Comprova, por meio de simulações, o correto funcionamento do protótipo AMM para os programas testados. Apresenta testes funcionais em FPGA para o processador base do protótipo AMM, dados de utilização do protótipo em FPGA e um protótipo do processador da AMM em silício. Para finalizar, apresenta uma estimativa de área em silício para a algumas versões $A M M$ idealizadas.
\end{abstract}

\subsection{Introdução}

No decorrer deste capítulo são apresentados e comentados os programas desenvolvidos para testar a funcionalidade e emprego dos conceitos de flexibilidade, redundância, tolerância à falhas na AMM.

Considerando-se que o processador utilizado no protótipo da $\mathrm{AMM}$ é compatível com o processador utilizado no microcontrolador PIC da empresa Microchip, família PIC16F, então o processador da AMM pode ser programado com o uso de qualquer compilador voltado a microcontroladores PIC da empresa Microchip. Assim, o compilador PicBasic Pro foi utilizado nos testes de programação da AMM.

A sintaxe para declaração de variáveis no compilador PicBasic é definida por:

$$
\text { <nome } \quad \text { VAR }<\text { tamanho>\{.modificadores\}\{\$localização\} }
$$

Onde:

nome identifica a variável e sua função; 
$V A R$ indica ao compilador que uma variável está sendo declarada;

tamanho indica ao compilador quantos bits na memória RAM são necessários para conter a variável, o qual pode ser do tipo BIT (1 Bit) BYTE (8 Bits) e Word (tamanho variável conforme definido pelo programador);

modificadores, parâmetro opcional para restringir-se a bits específicos e;

\$localização, parâmetro opcional que define a localização exata da variável na memória RAM.

Desta forma é possível mapear todos os controladores de transmissão e recepção e suas respectivas áreas de memória reservadas para a comunicação, como visualizado na Figura $5.1 \mathrm{em}(\mathrm{A}),(\mathrm{B}),(\mathrm{C})$ e (D) para 2, 4, 6 ou 8 processadores respectivamente.

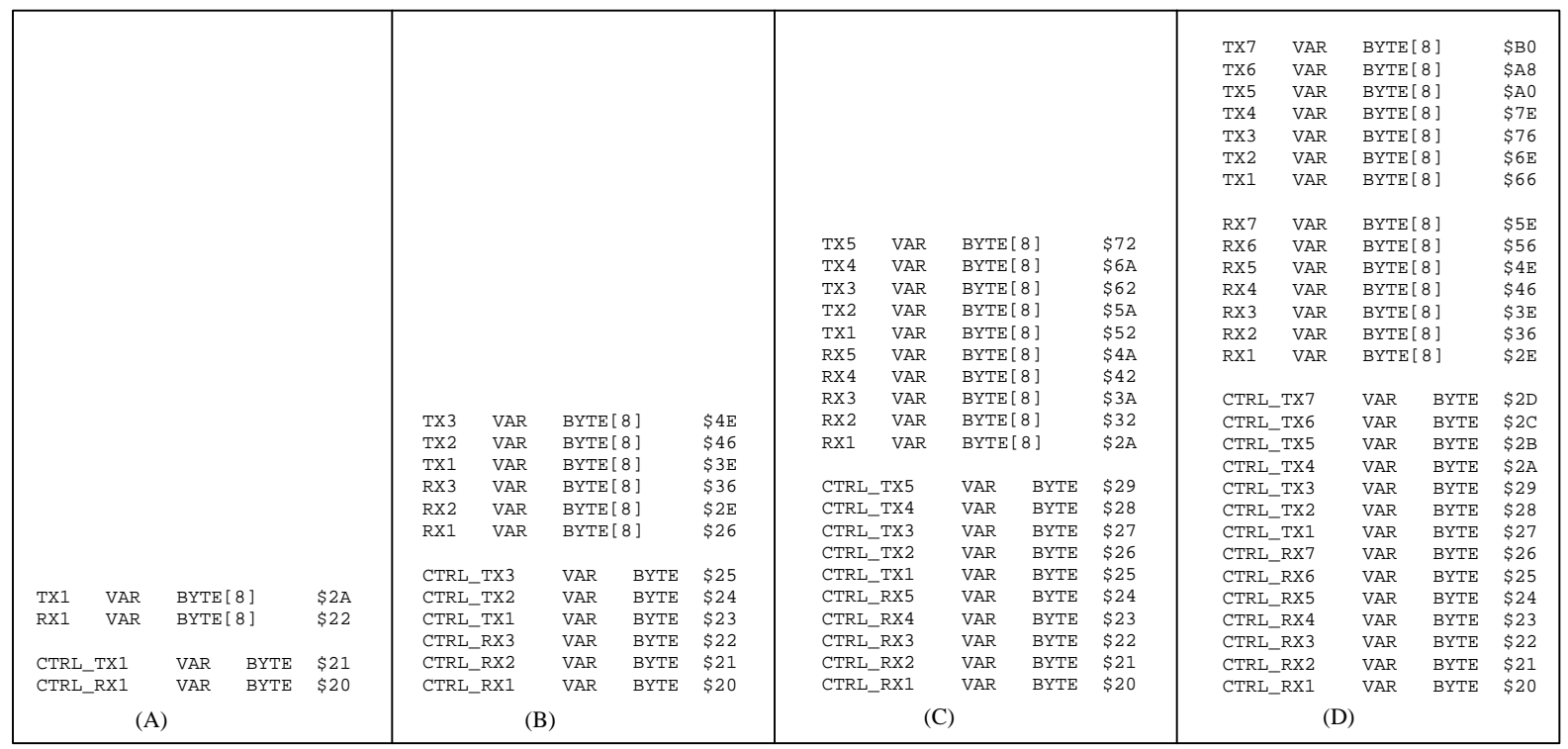

Figura 5.1: Mapa dos controladores e memória para 2, 4, 6 e 8 processadores para a AMM

Com este mapeamento, para transmitir uma informação entre processadores basta atribuir valores à área de escrita correspondente a cada processador(es) e alterar o valor da variável de controle do respectivo transmissor. Por exemplo, para gerar dados para o componente de transmissão 1, os dados devem ser divididos em 8 bytes individuais e depositados na área de memória reservada ao transmissor 1 . Como a comunicação atual é formada por um pacote de 64 bits, é recomentado zerar os bits não utilizados no pacote transmitido. Após as atribuições de valores forem concluídas na memória RAM, basta acessar a variável correspondente ao 
controle do transmissor e liberar a transmissão. A Figura 5.2 ilustra um exemplo deste trecho de código.

\begin{tabular}{|c|c|c|}
\hline TX1 [0] & $=O A$ & 'Valor para controle de função no processador destino \\
\hline TX1 [ 1] & $=01$ & 'Valor para controle de função no processador destino \\
\hline TX1 [2] & $=$ VAR_TEMP & 'Valor para VAR_TEMP, declarada no processador destino \\
\hline TX1 [3] & $=\mathrm{CONT} 1$ & 'Valor para CONT1, declarada no processador destino \\
\hline TX1 [ 4$]$ & $=\mathrm{CONT} 2$ & 'Valor para CONT2, declarada no processador destino \\
\hline TX1 [ 5 ] & $=00$ & 'Não utilizado \\
\hline TX1 [ 6 ] & $=00$ & 'Não utilizado \\
\hline TX1 [ 7 ] & $=00$ & 'Não utilizado \\
\hline CTRL_T & bit0 $=1$ & Libera transmissão \\
\hline
\end{tabular}

Figura 5.2: Exemplo de código para transmitir uma informação

De forma similar, para receber informações provenientes de outro processador deve-se monitorar a variável correspondente ao controle de recepção e ler as informações normalmente a partir da variável correspondente à área de memória de um componente de recepção. Assim, um exemplo de código para receber e atualizar valores é mostrado na Figura 5.3. Neste exemplo, considera-se que as interrupções de recepção estão desabilitadas e, sendo assim, é necessário monitorar constantemente o valor de CTRL_RX1 (bit0).

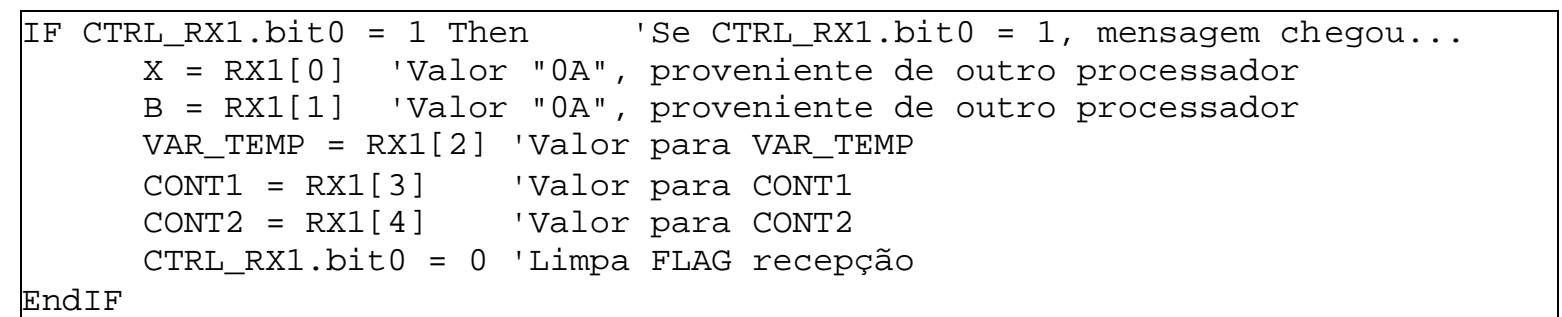

Figura 5.3: Exemplo de trecho de código para recepção de dados.

Na Figura 5.4, é ilustrado um código no qual a recepção é vinculada ao mecanismo de interrupção. Sendo assim, quando uma mensagem é recebida, automaticamente é gerada uma interrupção que desvia o processamento para o trecho de código correspondente ao tratamento dos sinais recebidos. Neste caso, não é necessário monitorar o CTRL_RX1 (bit0).

Demais variáveis de cada programa, presente em cada memória de cada processador, podem ser declaradas normalmente sem a opção \$localização, deixando a cargo do compilador definir a melhor posição para as demais variáveis. 


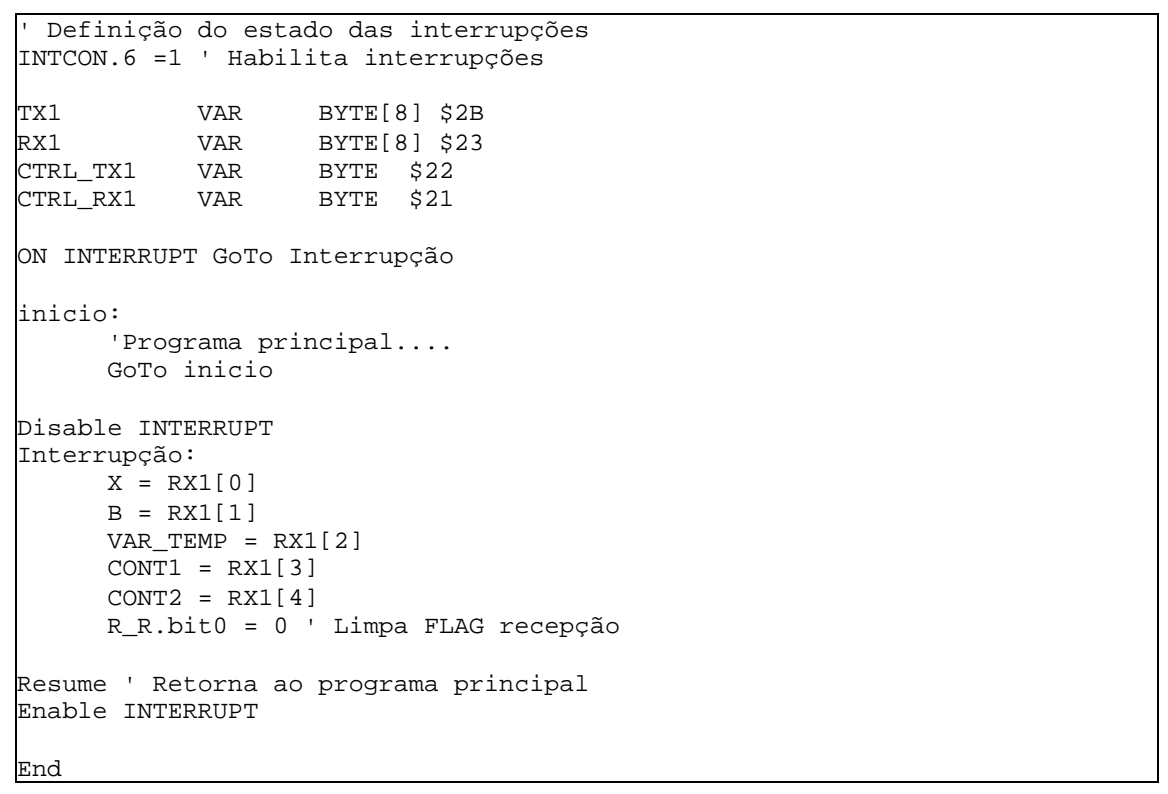

Figura 5.4: Exemplo de trecho de código para recepção por interrupção

\subsection{Ambiente de programação}

Como o processador utilizado no protótipo da AMM é compatível com o processador presente nos microcontroladores PIC do fabricante Microchip, qualquer software comercial destinado à estes microcontroladores pode ser utilizado. Assim, para o desenvolvimento e depuração dos programas desenvolvidos para o protótipo da AMM, foram utilizados os seguintes softwares:

(i) Microchip MPLAB 8.53 - Ambiente de desenvolvimento e depuração de microcontroladores PIC da Microchip. O MPLAB é interligado a diversos compiladores, sendo possível escrever códigos na linguagem C, Assembly para o PIC e outras. Para isso basta configurar o compilador de interesse. Para a escrita dos códigos deste capítulo, utilizou-se o MPLAB especificamente para o desenvolvimento de códigos na linguagem Assembly;

(ii) CDLite e PicBasic Pro - O ambiente CDLite é fornecido pela empresa Rentron Software e contém muitas funcionalidades para programação, depuração e gravação do código na memória FLASH do chip. O CDLite também pode ser interligado à vários compiladores. Para o desenvolvimento dos códigos utilizados neste capítulo, o CDLite foi interligado ao PicBasic Pro, compilador em linguagem Basic, especificamente desenvolvido para microcontroladores PIC da Microchip;

(iii) Pic Simulator IDE - Simulador de microcontroladores PIC, já apresentado no capítulo 3 desta tese; 
(iv) Programa HEX2VHD - Programa para conversão de arquivos hexadecimais em sua respectiva representação VHDL sob a forma de uma memória ROM;

(v) Modelsim - Software de simulação do comportamento de lógica digital descrita em linguagem Verilog ou VHDL. Como a AMM é descrita em VHDL, utilizouse o Modelsim compatível para simulações VHDL e;

(vi) Xilinx ISE 9.1 - Ambiente de síntese de arquivos em linguagem de descrição de hardware e mapeamento de FPGAs Xilinx.

Assim foi possível idealizar programas e, com estes softwares, escrevê-los, depurar, simular e comparar os resultados obtidos nos softwares comerciais para o PIC e os resultados obtidos no software Modelsim, no qual a descrição VHDL da AMM completa é carregada. Após obter a correta execução de alguns programas, os quais são comentados neste capítulo, estes programas foram mapeados nas memórias de programas das UPEM2s e em FPGA para comprovação física do funcionamento do sistema AMM proposto.

A Figura 5.5 ilustra o fluxo de criação de programas para a AMM composta por quatro processadores, partindo-se da concepção do programa, sua compilação, depuração e mapeamento em FPGA. O fluxo para uma composição com mais de quatro processadores se mantém igual. Assim:

(i) na parte superior da Figura 5.5(a), o fluxo inicia com a definição do problema a ser trabalhado e os programas fonte para cada processador na AMM são compilados individualmente, por meio de qualquer compilador compatível com microcontroladores PIC, linha PIC16FXX;

(ii) com o programa fonte escrito com base na linguagem aceita pelo compilador utilizado, no caso ".bas" para o compilador Picbasic Pro e ".asm" para o MPASM, obtém-se o arquivo ".hex" utilizado para a programação da UPEM2, processador base da AMM;

(iii) o arquivo ".hex" é carregado em qualquer software de simulação compatível com o microcontrolador PIC. Como já comentado, utilizou-se o Pic Simulator IDE para a depuração e verificação do correto funcionamento do programa no formato ".hex";

(iv) ainda na Figura 5.5(a), a simulação dos programas é iniciada e é necessário entrar manualmente com possíveis estímulos nos endereços específicos de recepção de cada processador, pois, neste ponto, não há qualquer interligação 
entre os programas - não há integração entre várias instâncias do PIC Simulator IDE abertas simultaneamente no computador pessoal sendo utilizado;

(v) os resultados das computações de cada programa são mostrados no mapeamento da memória e registradores internos do simulador PIC Simulator IDE;

(vi) no caso de sucesso na execução dos programas por simulação, o fluxo continua na parte superior da Figura 5.5(b), onde cada arquivo ".hex" é convertido, por meio do programa HEX2VHD, para uma descrição VHDL que representará uma memória ROM de programa. Esta será parte integrante do processador presente na descrição da AMM. Assim, cada arquivo ".hex" é convertido para uma memória ROM distinta;

(vii) com o correto programa em forma de memória ROM VHDL, o mesmo é carregado no software Modelsim, o qual contém toda a descrição VHDL funcional da AMM, com processadores e a estrutura de interconexão (capítulo 3);

(viii) neste ponto a simulação é totalmente automática, pois, os estímulos e troca de informações entre os processadores são realizados por meio da estrutura física de interconexão existente na descrição;

(ix) se a simulação no software Modelsim indica o correto funcionamento lógico, a descrição VHDL da AMM está pronta para ser mapeada e testada em um FPGA ou servir como base para um possível projeto de um ASIC.

Na Figura 5.5 (a), os dados para simulação da rede de interconexão são escritos manualmente diretamente nas caixas de texto do simulador PIC Simulator IDE, as quais representam a memória RAM de cada processador. Assim, valores hexadecimais são depositados no simulador, no decorrer da execução do programa, a qual é pausada automaticamente durante o depósito manual.

Na Figura 5.5 (b), no centro da Figura encontram-se os componentes de transmissão e recepção, as respectivos áreas de dados pertencentes a cada processador e uma representação da rede de interconexão, já comentados no capítulo 4 desta tese. Com este fluxo de criação, compilação e depuração foi possível conceber os seguintes programas na AMM: (i) Proporcional Integral Diferencial; (ii) Proporcional Integral Diferencial redundante e; (iii) AES para cifra e decifra. Utilizou-se também o mesmo fluxo para o teste de um Proporcional Integral Diferencial com detecção de falhas e teste para geração de logs de eventos.

Cada um destes programas e testes são comentados e seus resultados apresentados a seguir: 


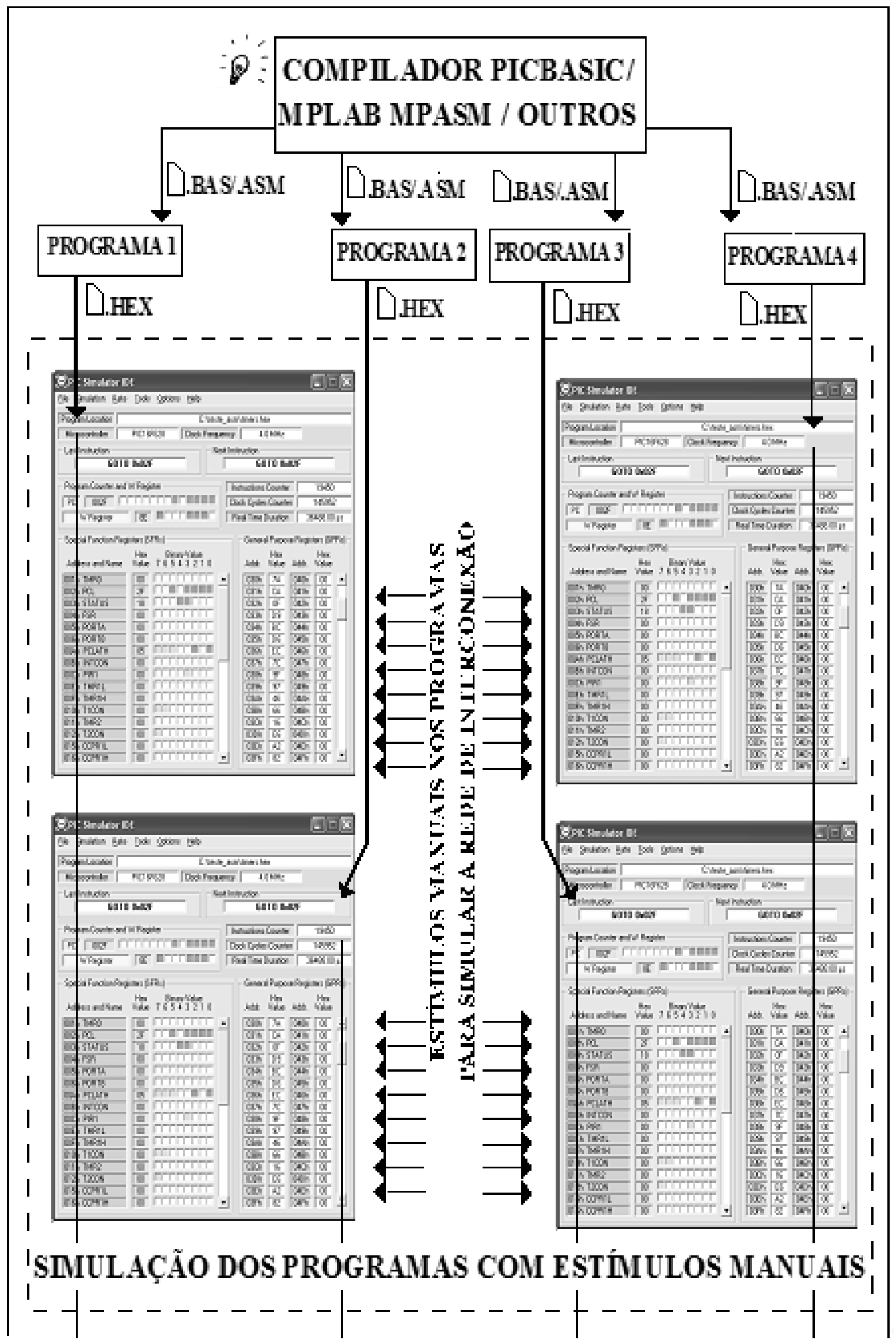

Figura 5.5(a): Fluxo para programação e depuração dos programas na AMM 


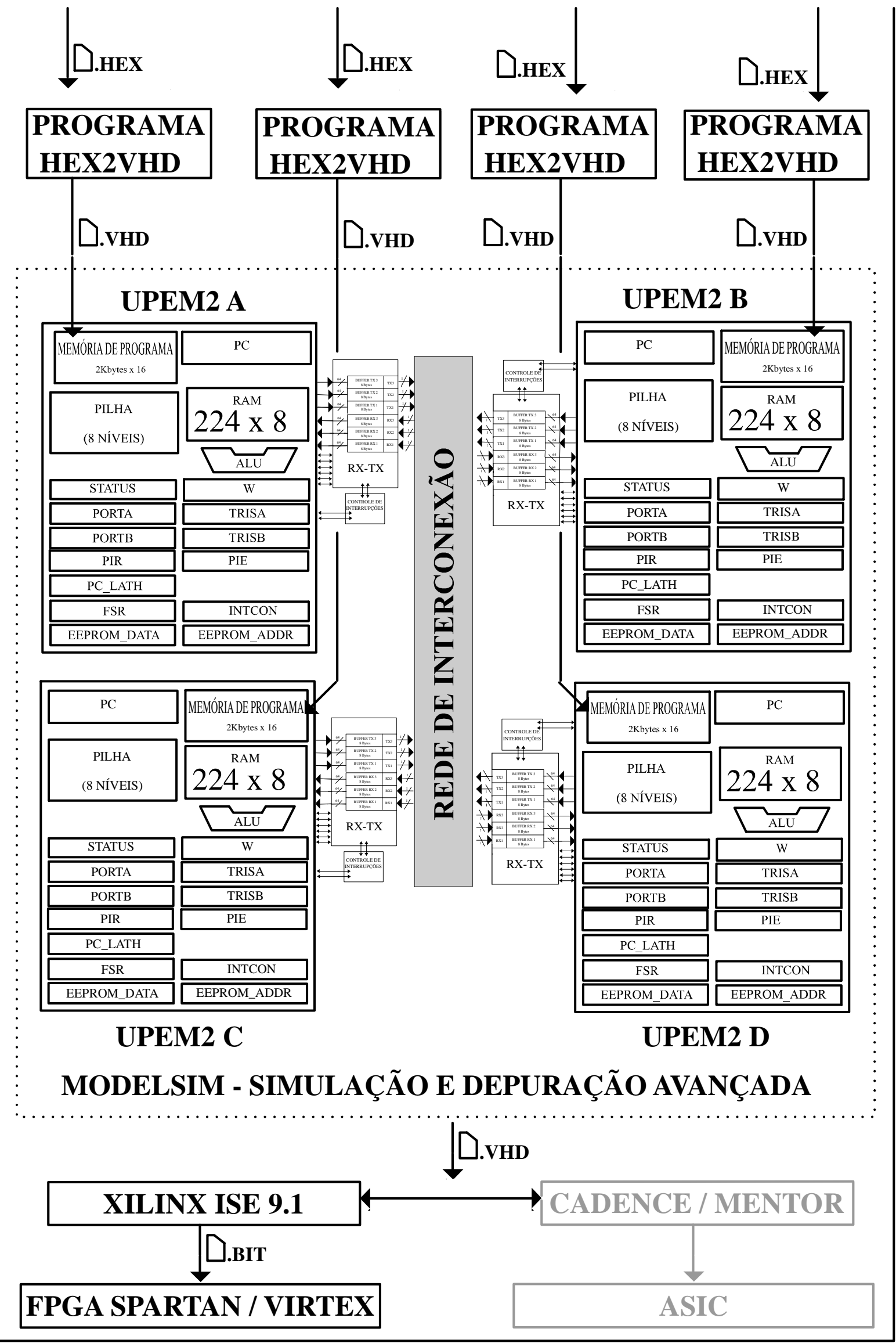

Figura 5.5(b): Fluxo para programação e depuração dos programas na AMM 


\subsection{Controle proporcional integral diferencial (PID), na AMM}

O controle Proporcional Integral Diferencial é uma forma genérica de controle realimentado amplamente utilizado em sistemas de controle industriais. Um controlador PID calcula um valor de erro como a diferença entre o valor de uma variável em processo lido e um novo valor, chamado setpoint. O controle tenta minimizar o erro, ajustando as entradas do processo de controle. Os parâmetros do controle PID devem ser ajustados de acordo com a natureza do sistema a ser controlado. O algoritmo de controle PID envolve três parâmetros separados: o proporcional, o qual determina a reação perante ao erro atual; o integral, o qual determina a reação com base na soma dos erros recentes e; o diferencial, o qual determina a reação com base na taxa de mudança do erro. A Figura 5.6 ilustra o algoritmo de controle PID sob forma de blocos.

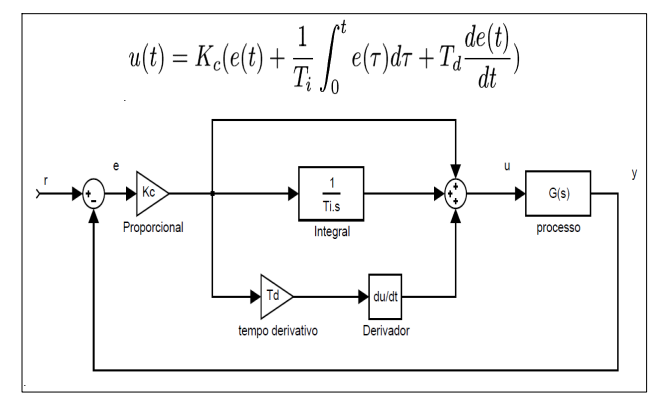

Figura 5.6: Algoritmo de controle PID em blocos, (CASTELAN, 2010)

Assim, o controle PID pode ser aplicado em vários sistemas de controle, incluindo controle de motores, no qual, o controlador PID obtém a posição atual do motor (Actual) e indica nova posição (Setpoint). O controle PID é utilizado então para que o motor movimente-se até a posição desejada, respeitando valores limites como velocidade, torque, erro desejado, dentre outros.

Para o correto funcionamento do controle PID é necessário então um processador capaz de fornecer a correta vazão dos dados de saída, com base nos parâmetros que entram como retorno de suas próprias computações anteriores.

Existe muita documentação sobre o controle PID disponível na literatura e não é objetivo aqui descrever as particularidades do controle PID. A Figura 5.7 ilustra um exemplo de atuação do controle PID. 


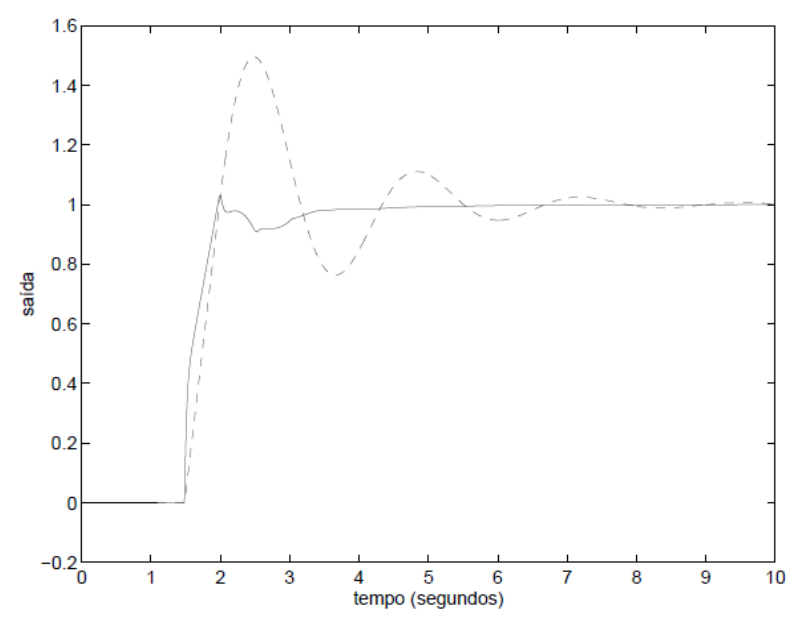

Figura 5.7: Simulação de um controle PID em um motor: (CASTELAN, 2010)

O trabalho de Roberts, J. (2007) apresenta um aeromodelo de um helicóptero, no qual, quatro microcontroladores executam quatro algoritmos de controle PID independentes para controlar quatro motores DC, correspondente a cada hélice. O modelo é visualizado na parte superior da Figura 5.8 e os quatro microcontroladores na parte inferior da mesma Figura.

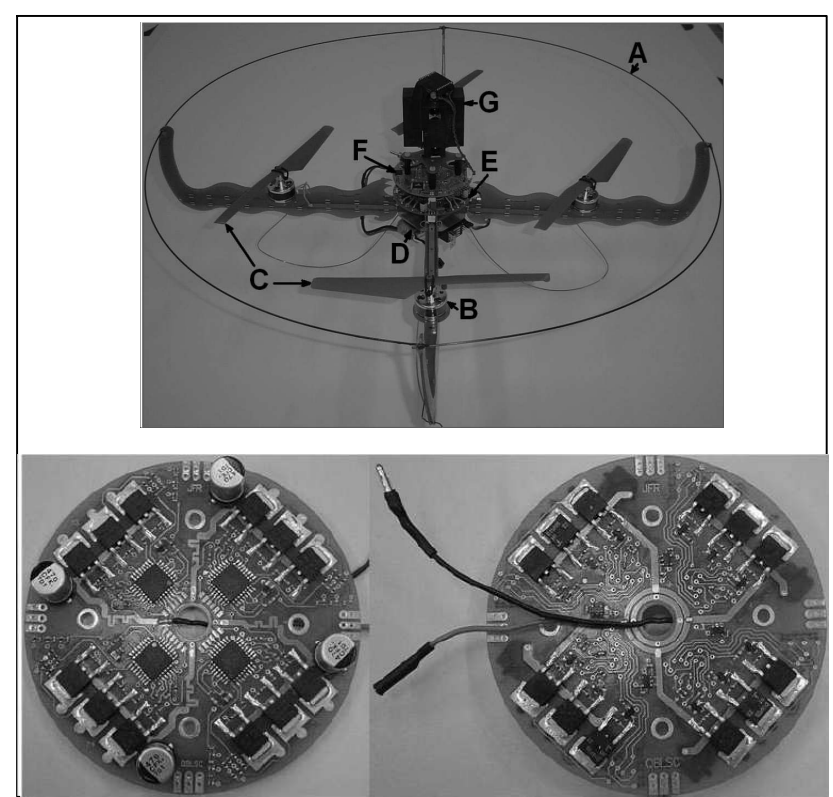

Figura 5.8: Aeromodelo, usando 4 ATMEL 8bits para 4 controles PID (ROBERTS, J., 2007)

Idealizou-se assim uma aplicação na AMM composta por quatro processadores e três motores, sendo um eleito como o processador principal e três processadores escravos. O processador principal envia setpoints para cada processador escravo iniciar seu processamento para seu motor atingir o setpoint 
solicitado. O processador principal pode se comunicar à um dispositivo externo e obter parâmetros para setpoints ou pode conter todos os parâmetros pré-definidos em sua memória. A Figura 5.9 ilustra a configuração desta aplicação idealizada.

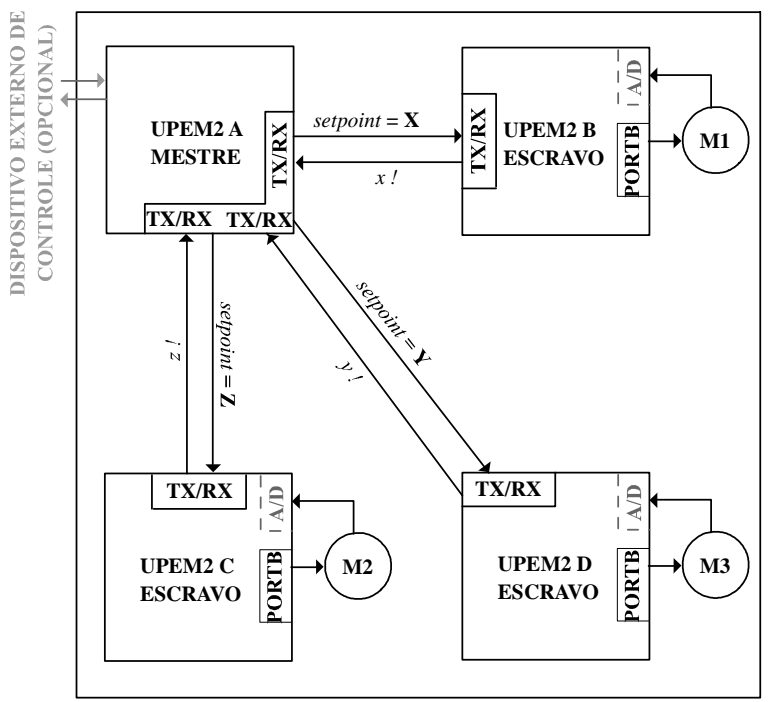

Figura 5.9: Programa mestre controla três controles PID independentes

Por questões de simplificação das simulações não foram utilizados modelos de motores reais. Os dados referentes ao retorno do motor são simulados no próprio programa de controle, desconsiderando valores físicos de inércia, carga ou outros fatores típicos do movimento de um motor, ou seja admite-se por simplicidade que a saída retorna por realimentação sem qualquer distorção.

Assim, após receber seu respectivo setpoint, cada processador escravo inicia seu processamento de forma independente até atingi-lo ou verificar que o mesmo não é alcançável. A Figura 5.10 mostra um trecho do código do processador mestre.

No trecho de código da Figura 5.10 é possível ver que as variáveis CTRL_RX1, CTRL_RX2, CTRL_RX3, CTRL_TX1, CTRL_TX2 e CTRL_TX3 foram fixadas para acessar os endereços \$20, \$21, \$22, \$23, \$24 e \$25 correspondentes aos controladores na arquitetura descrita em VHDL. Da mesma forma as variáveis que acessam as áreas de memória de comunicação também são fixas nos endereços correspondentes.

Neste programa idealizado, o primeiro processador escravo recebe o setpoint 25, definido na primeira posição da área de transmissão TX1. O segundo processador escravo recebe o setpoint 70 , definido na primeira posição da área de 
transmissão TX2. O terceiro processador escravo recebe o setpoint 150, definido na primeira posição da área de memória do TX3. Atuando-se nos respectivos controladores de comunicação, os setpoints são enviados. Os parâmetros de controle PID, Kp (proporcional), Ki (integral) e Kd (derivativo) foram mantidos em $\mathrm{Kp}=200, \mathrm{Ki}=3$ e $\mathrm{Kd}=0$, para todos os programas aqui apresentados.

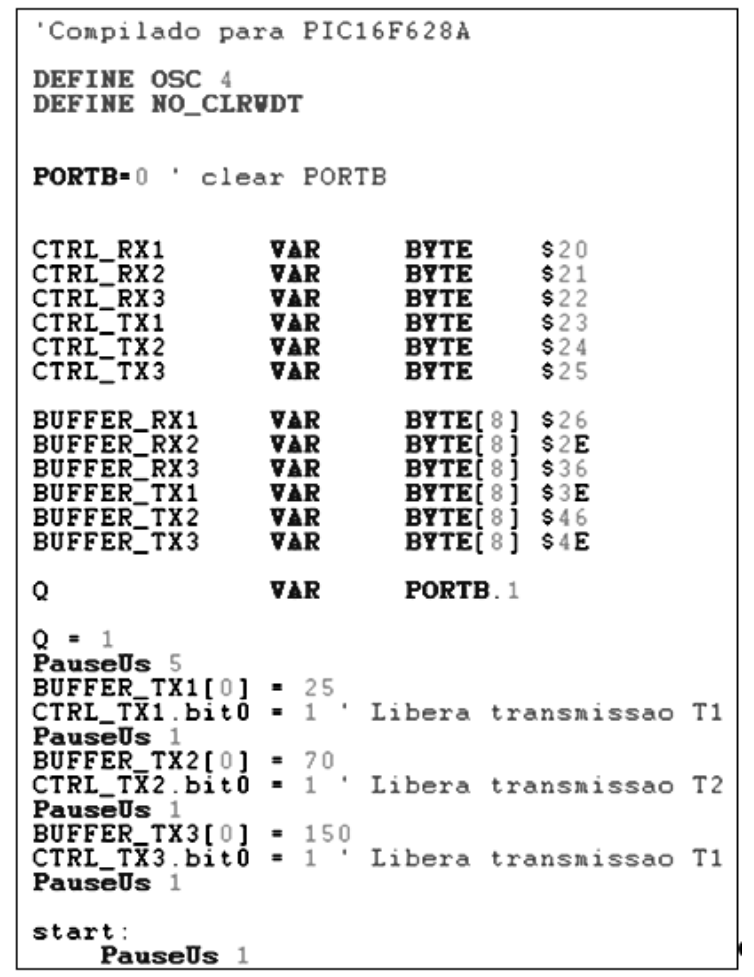

Figura 5.10: Trecho de código do processador mestre para o programa de controle PID

A Figura 5.11 ilustra um trecho do código escrito para executar nos processadores escravos. De forma similar ao programa escrito para o mestre, 0 programa escravo segue a mesma organização de endereços correspondentes aos controladores e áreas de memórias reservadas para comunicação.

Este código é uma adaptação do programa original desenvolvido por (ROBERTS, 2010) no qual o controle PID é executado em microcontroladores PIC.

Este programa de controle PID é executado por meio de várias iterações controladas em um laço principal de programa. A cada iteração o programa adquire dados de um conversor A/D para determinar a posição atual do motor sendo controlado e executa o cálculo de controle PID para controlar o movimento do motor, por meio de Modulação por Largura de Pulso (PWM) e tentar alcançar o setpoint solicitado, o qual é comparado com valor obtido do conversor A/D. 


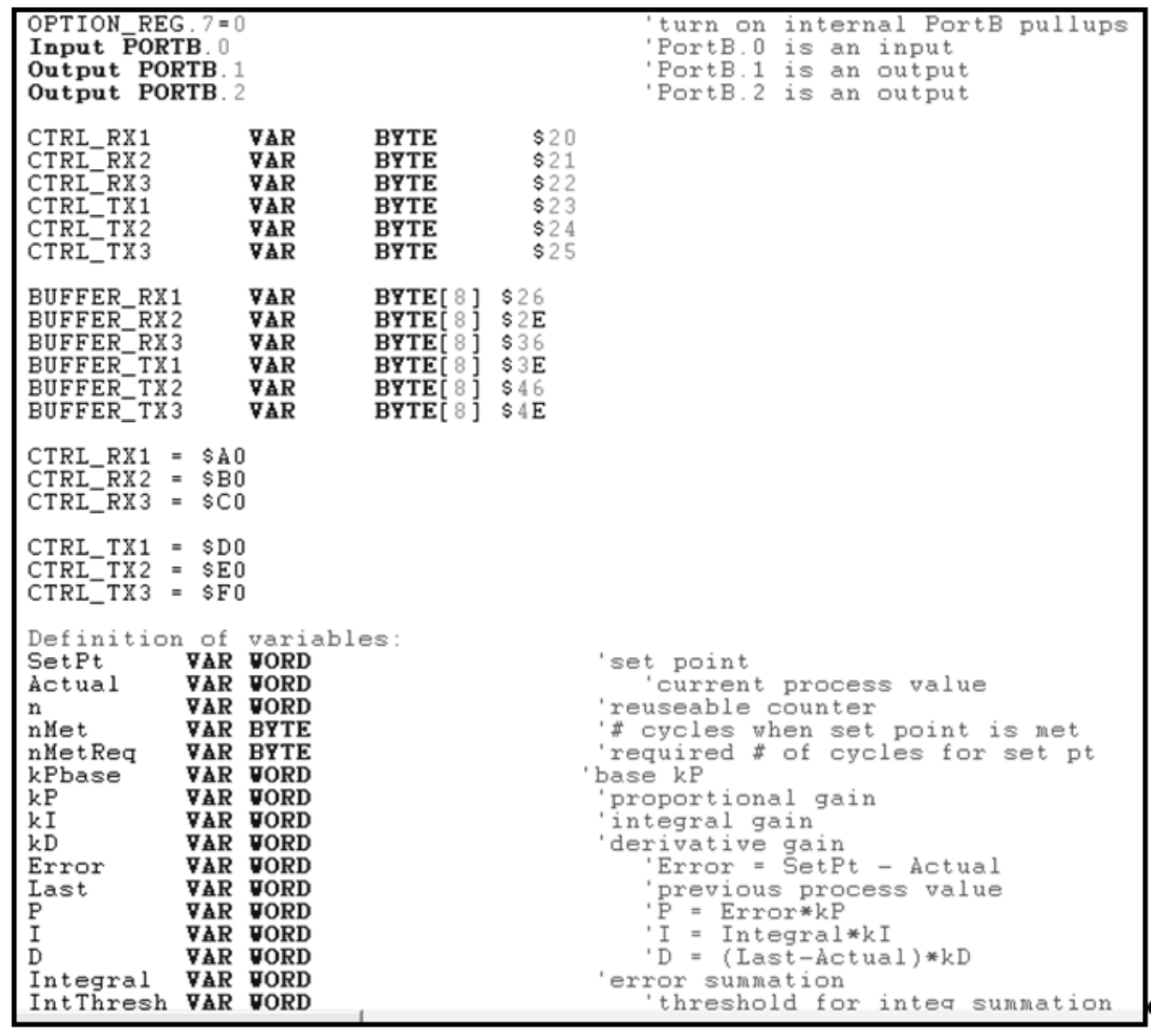

Figura 5.11: Trecho do código de controle PID nos processadores escravos

É possível determinar vários parâmetros de entrada neste programa para configurar, por exemplo, a velocidade máxima permitida, a aceleração máxima, o erro máximo tolerável entre o setpoint e a posição efetivamente alcançada, 0 número máximo de interações até decidir-se se o setpoint é alcançável ou não, dentre outros parâmetros possíveis.

No programa modificado e utilizado nos processadores escravos, somente o setpoint é recebido externamente, pois, considerou-se que os demais parâmetros não são foco para serem explorados nesta tese, sendo mantidos como constantes no programa. Porém, não há impedimentos para que futuras implementações utilizem todos os parâmetros permitidos.

Outra limitação nos testes do protótipo da AMM é a inexistência física do conversor $A / D$, sendo então necessário simular conversões $A / D$ sucessivas. $\mathrm{Na}$ prática, a conversão A/D retorna um valor binário em uma variável que é manipulada no programa. 
Assim, a variável Actual no programa original contém o valor obtido da conversão $A / D$. No programa modificado, simula-se diferentes valores para a variável Actual, com base em $n$ iterações do programa, conforme ilustra outro trecho de código do programa para os processadores escravos na Figura 5.12.

Por fim, ressalta-se que os três programas carregados nas memórias de programa dos processadores escravos são idênticos.

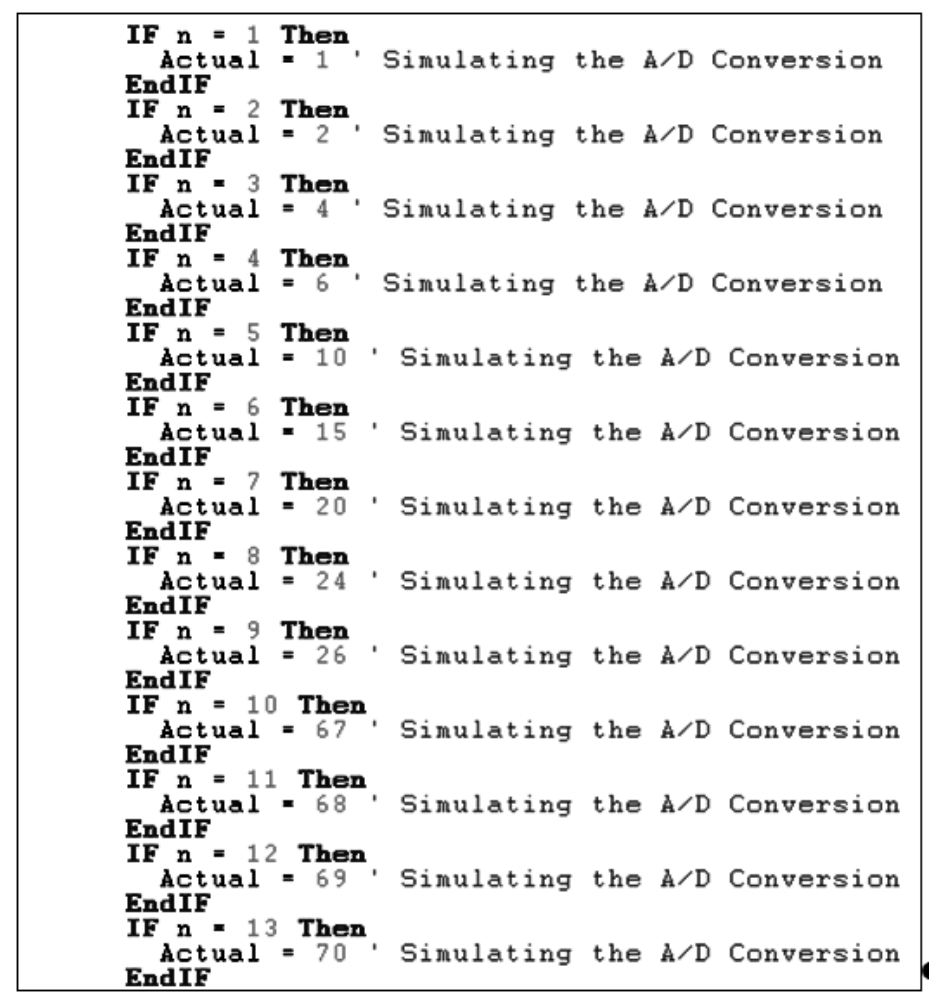

Figura 5.12: Trecho de código para simular conversões A/D

Seguindo o fluxo apresentado na Figura 5.5, os programas foram simulados no PIC Simulator IDE, apresentaram resultados positivos, foram então convertidos para memória ROM de programa por meio do programa HEX2VHD e carregados no software de simulação Modelsim junto com seus respectivos processadores.

Os resultados da simulação com o software ModelSim do protótipo da AMM executando os programas que compõe a aplicação do controle PID são visualizados nas Figuras 5.13 e 5.14. A Figura 5.12 mostra o processador eleito como mestre enviando três mensagens aos processadores escravos. As mensagens, indicadas pelas três setas, contém informações dos três setpoints, 25, 70 e 150.

A Figura 5.14 mostra a simulação no software ModelSim dos processadores escravos executando o controle PID para os setpoints recebidos. 


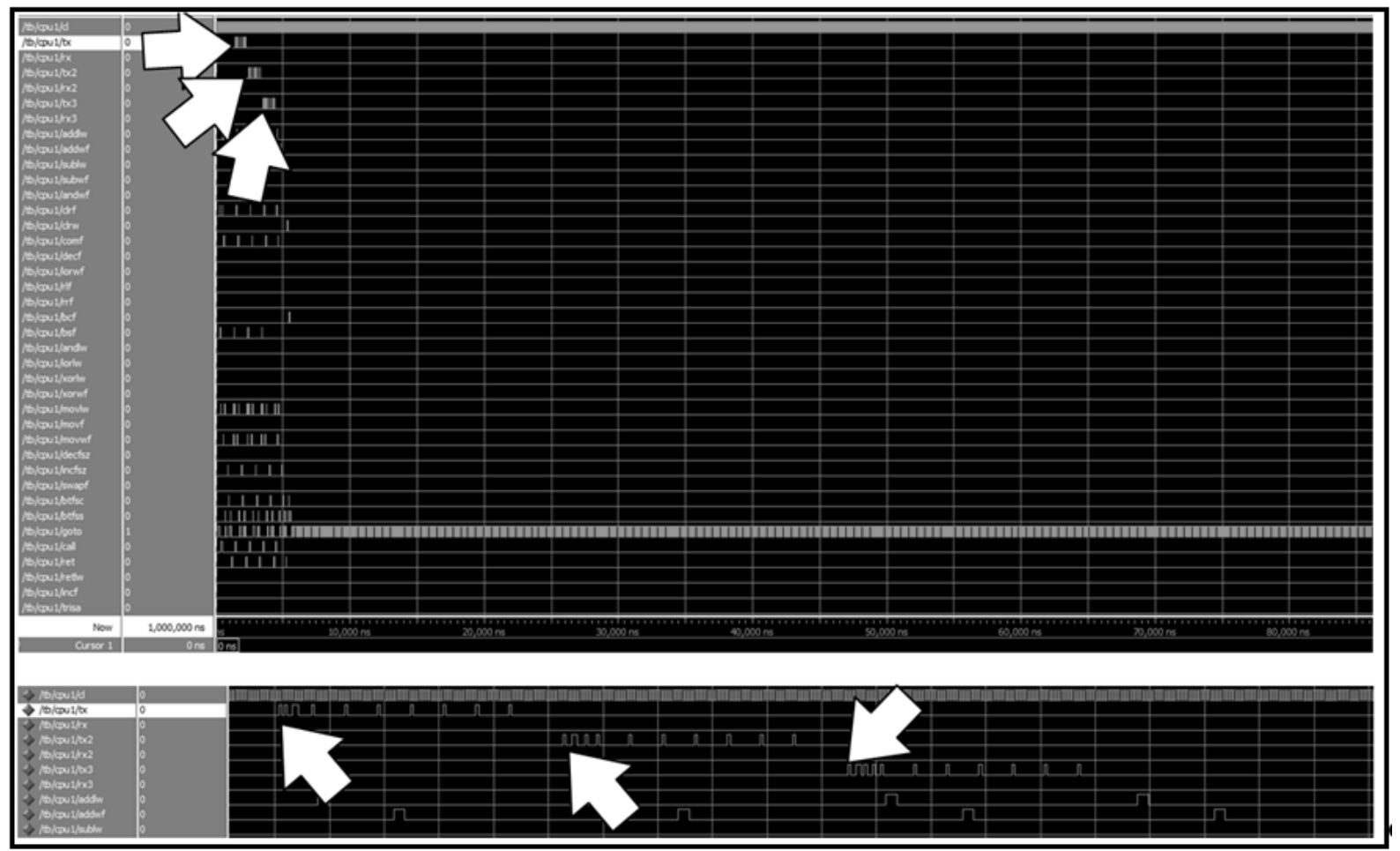

Figura 5.13: Processador configurado como mestre enviando três mensagens aos escravos

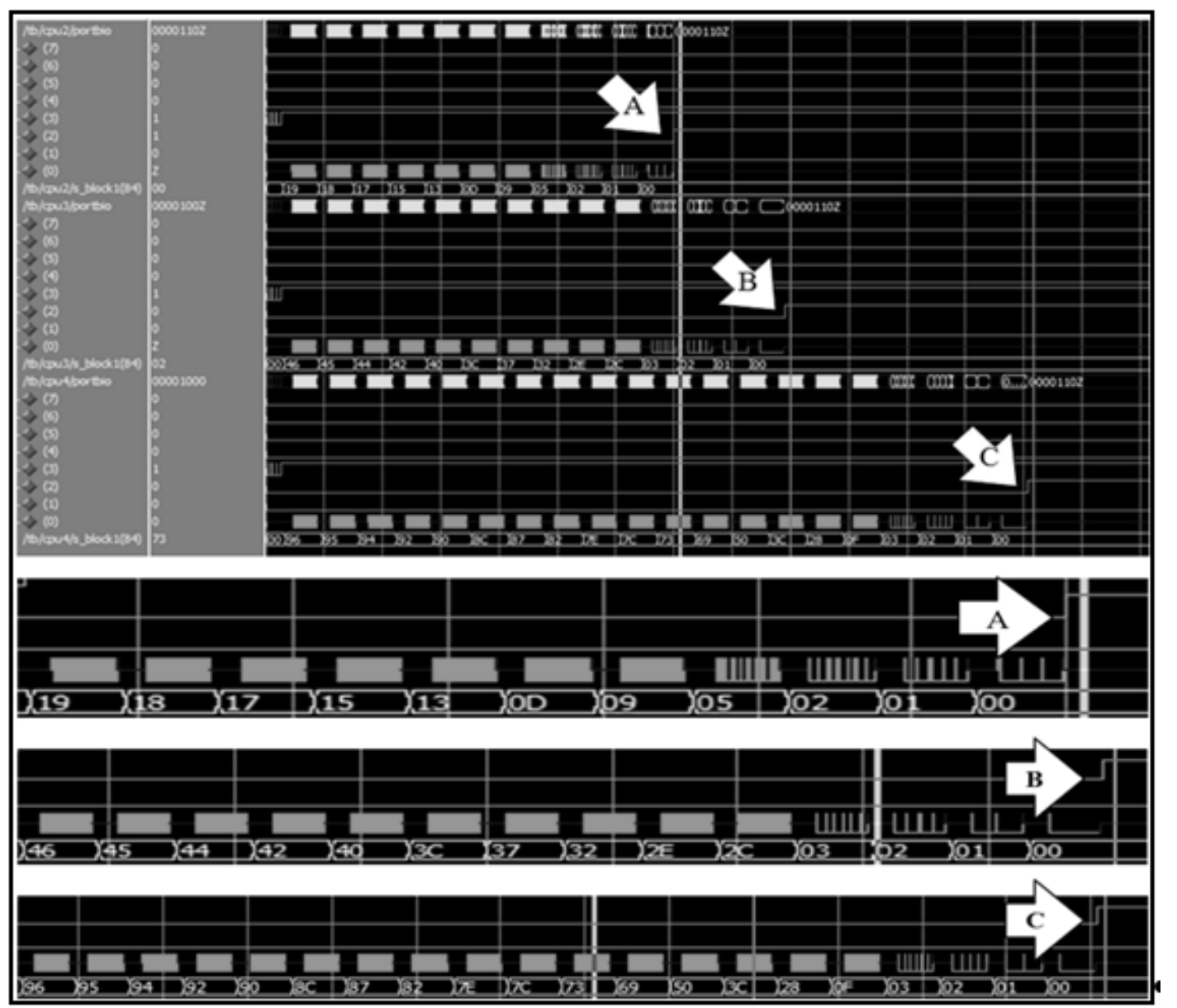

Figura 5.14: Processadores do protótipo da AMM configurados como escravos, em busca do setpoint 
$\mathrm{Na}$ parte superior da Figura 5.14, a simulação dos três processadores escravos foi organizada para mostrar os PORTB de cada processador escravo. Assim, cpu2/portbio corresponde ao PORTB do processador escravo 1; cpu3/portbio corresponde ao PORTB do processador escravo 2 e; cpu4/portbio corresponde ao PORTB do processador escravo 3.

O PORTB é composto por 8 bits e, nesta aplicação, o PORTB.0, ou seja, o bit menos significativo, é usado como porta de saída para geração de um pulso PWM. O PORTB.2 foi utilizado como um indicativo se o setpoint foi encontrado, indicado pelas setas $A$, B e $C$.

O PWM é gerado em software pelo próprio processador, tendo por base o valor final obtido pelos cálculos realizados do controle PID. Assim, na Figura 5.14 os valores hexadecimais $19,18,17 . . .0$ são utilizados como referência para geração da largura do pulso, onde FF representa $100 \%$ e 00 representa $0 \%$.

Considerou-se que os três processadores escravos iniciam o motor na posição 0 e cada processador procura de forma independente por seu setpoint recebido. Foi possível verificar que quando maior o valor do setpoint recebido, maior é o valor gerado para ser produzido o PWM. Assim, com o valor setpoint igual a 25, o PWM inicia com valores 19,18,17..., resultando em pouca aceleração; já com o valor setpoint igual a 150, o PWM inicia com valores 96, 95, 94..., resultando em aceleração maior em relação ao valor 25 . Isto é devido ao fato de que a diferença de valores entre a posição inicial 0 e a posição final solicitada 25 é menor que a diferença de valores entre posição inicial 0 e a posição final solicitada 150.

Neste sentido, mesmo mantendo fixo o parâmetro de aceleração máxima, o programa de controle PID se comporta de formas distintas de acordo com o setpoint recebido. Isto é um indicativo positivo para o funcionamento correto do algoritmo.

A Figura 5.15 ilustra os diferentes volumes de instruções executados por cada processador escravo, sendo escravo 1, escravo 2 e escravo 3 em $(A),(B)$ e $(C)$, respectivamente. Nesta Figura, cada sinal digital que varia entre nível lógico 0 e nível lógico 1 representa que uma instrução foi executada.

Com base no contador de instruções executadas incluído na descrição VHDL do processador UPEM2 do protótipo da AMM, estimou-se aproximadamente 19,4 MIPS nesta aplicação, para cada processador escravo. 


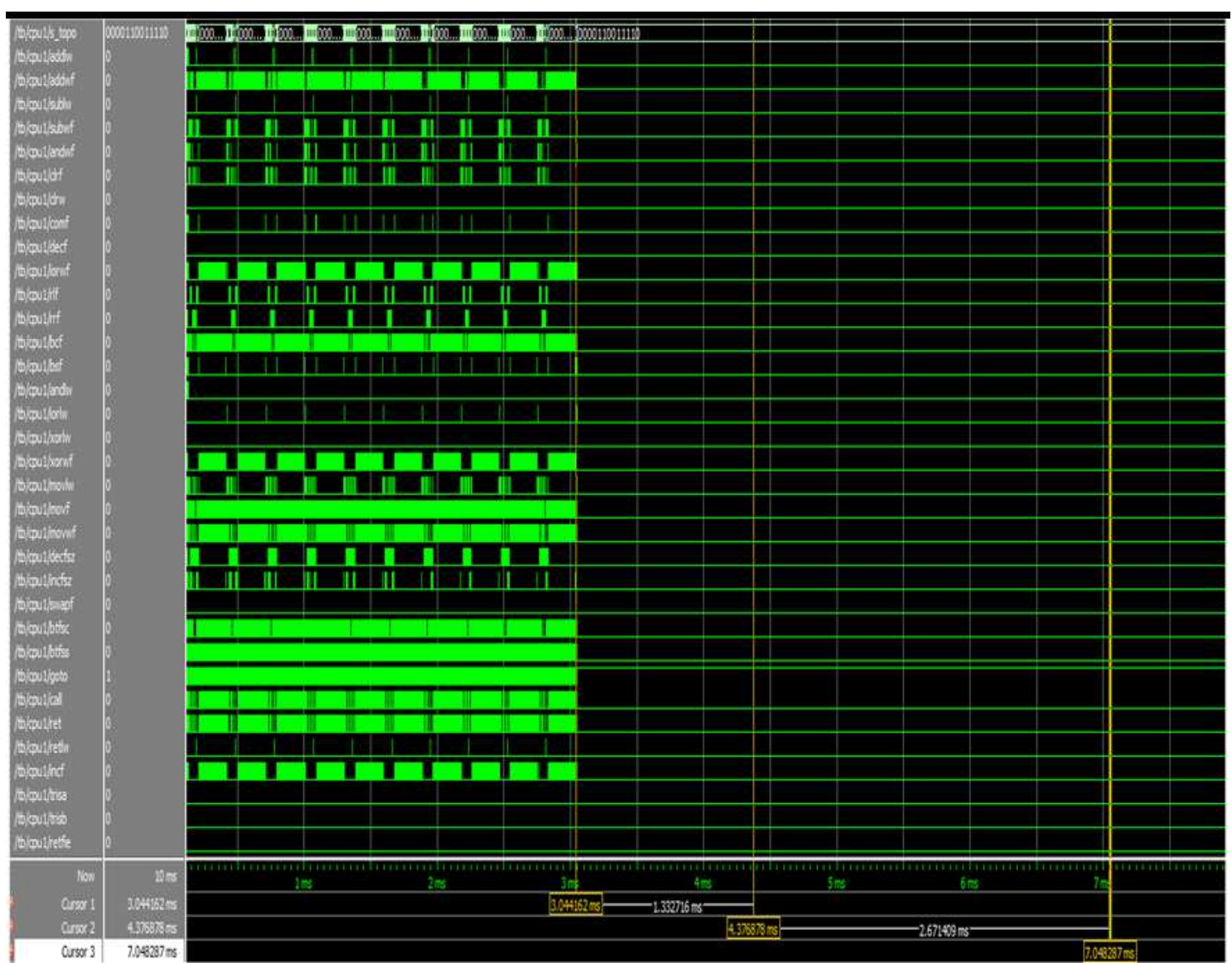

Figura 5.15(a): Vista processamento de controle PID por cada processador escravo

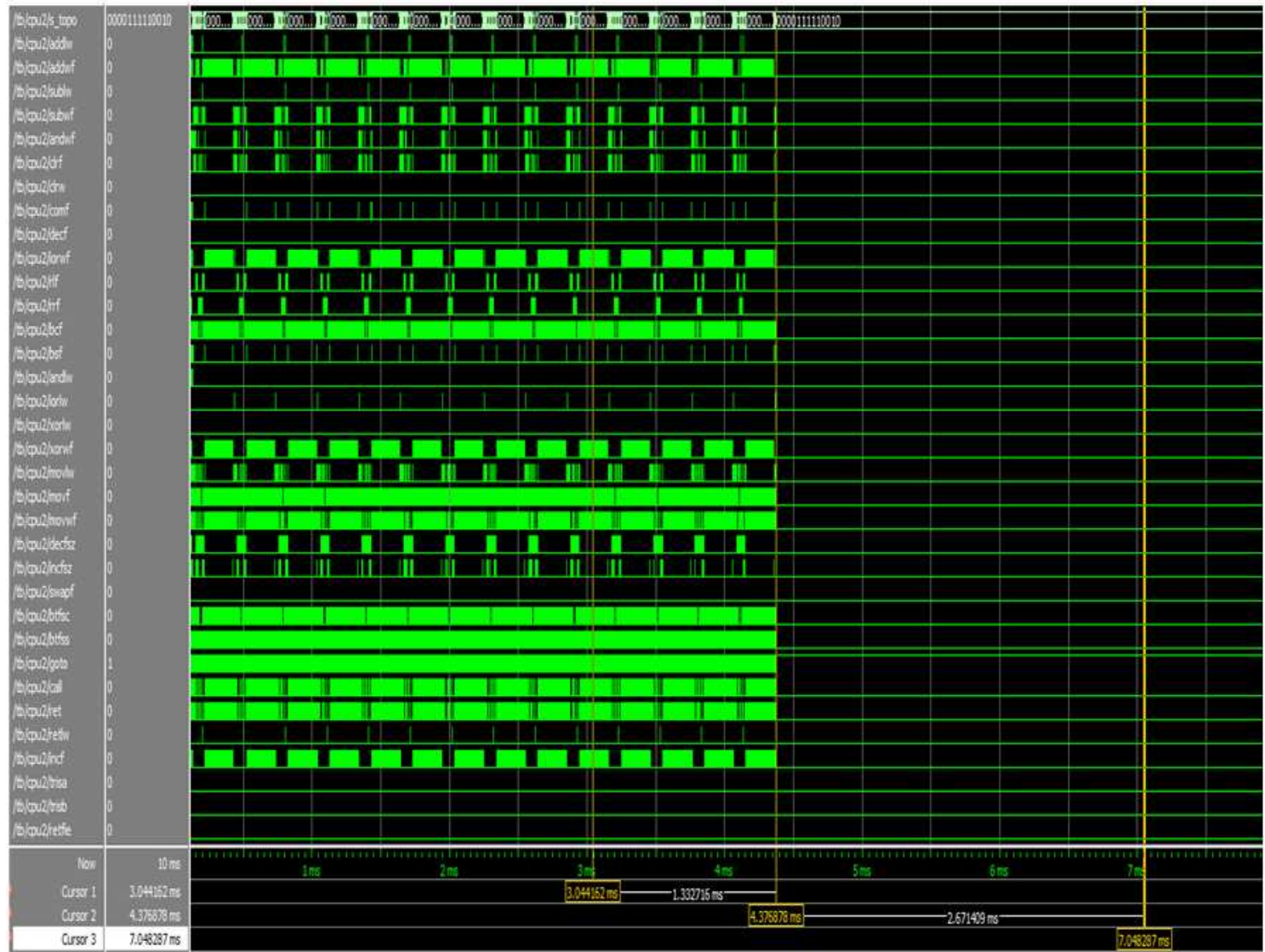

Figura 5.15(b): Vista processamento de controle PID por cada processador escravo 


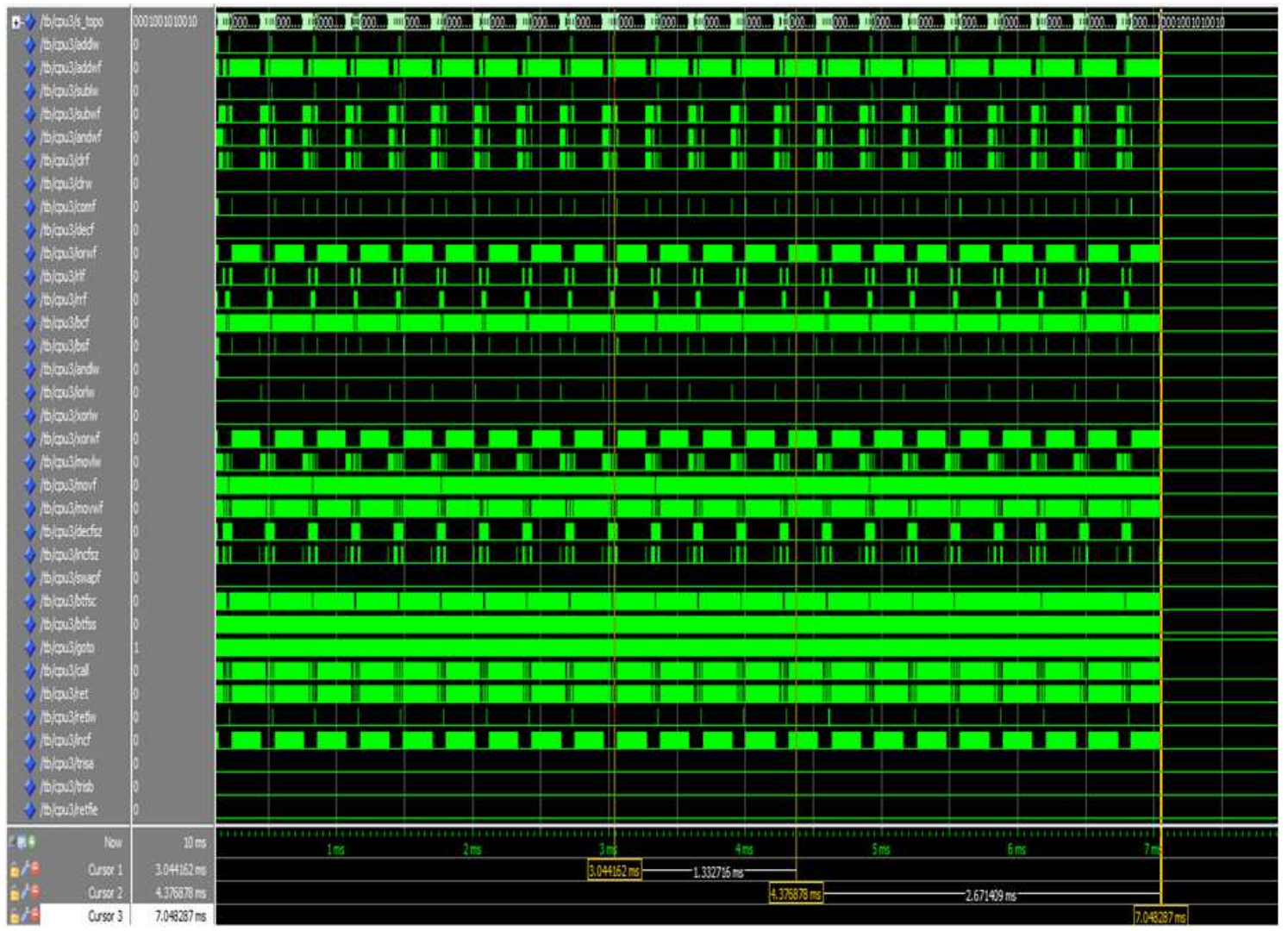

Figura 5.15(c): Vista processamento de controle PID por cada processador escravo

\subsection{Controle proporcional integral diferencial redundante, na AMM}

Idealizou-se uma aplicação composta por quatro processadores, sendo um eleito como o processador principal e três processadores escravos redundantes executando o controle PID. O processador principal envia um único setpoint simultaneamente para cada processador escravo iniciar seu processamento para atingir o setpoint solicitado. Os processadores escravos, configurados como redundantes, são carregados com a mesma cópia do programa presente na memória de programa do processador escravo B, na Figura 5.9. Desta forma, assumindo-se que cada processador escravo seja estimulado externamente de forma idêntica, o processamento obtido também será idêntico.

Aproveitando-se da característica do sistema de intercomunicação desenvolvido que permite mensagens serem enviadas de forma independente entre si, utilizou-se o envio simultâneo de mensagens, descrito no capítulo 3 desta tese.

Desta forma, o processador eleito como central dispara mensagens simultâneas para que os processadores escravos iniciem seu processamento em 
total sincronia. A Figura 5.16 ilustra a configuração desta aplicação idealizada para o controle PID redundante.

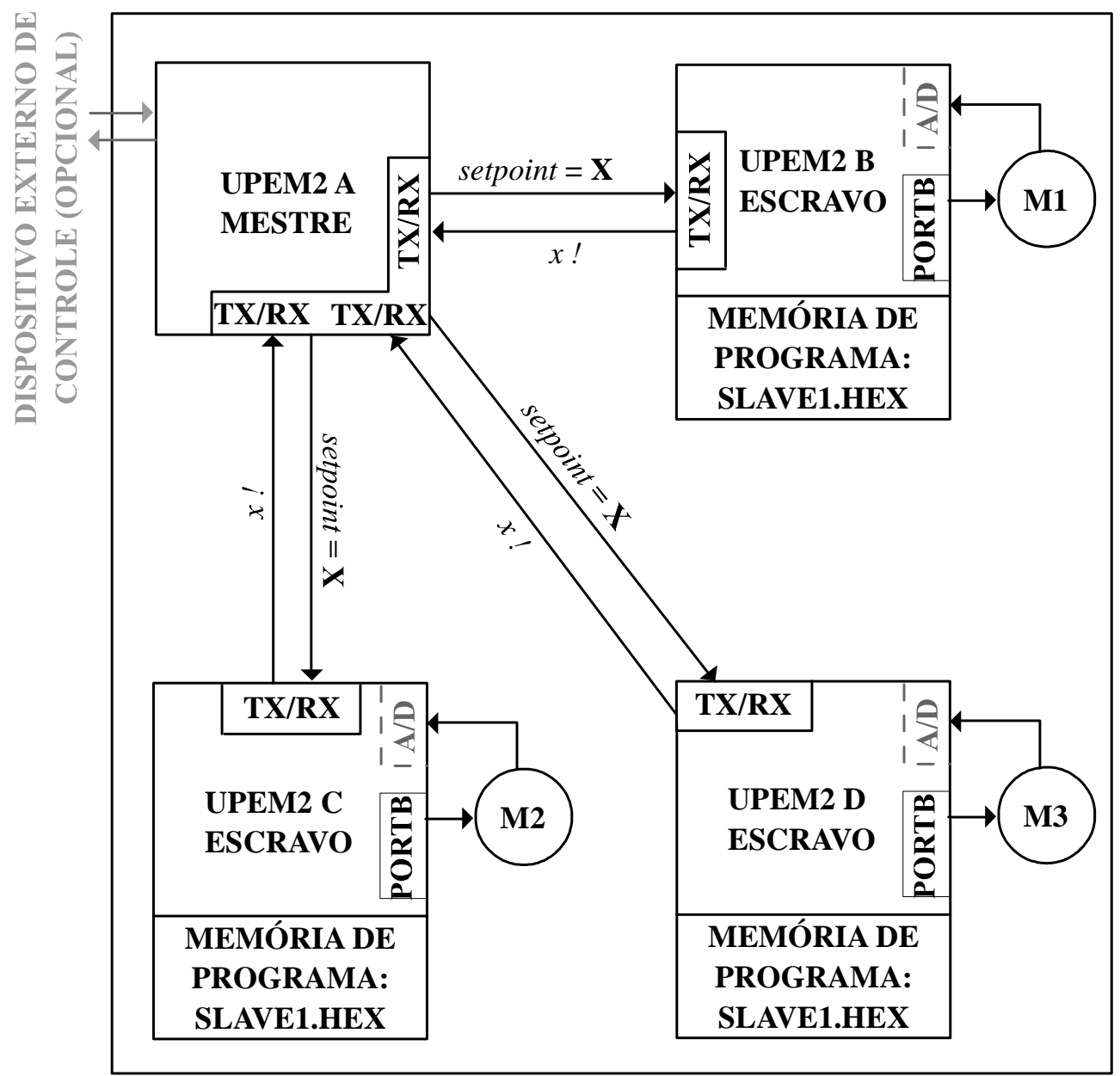

Figura 5.16: Processador mestre controla três escravos redundantes com o controle PID

A Figura 5.17 ilustra um trecho do código desenvolvido para executar no processador mestre. O programa difere do programa apresentado na Figura 5.10, pois, neste caso o mesmo setpoint (25) é enviado aos três processadores escravos. Além disso, os controladores de transmissão são configurados para enviar mensagens somente quando todos possuírem dados à serem enviados, de forma síncrona. 


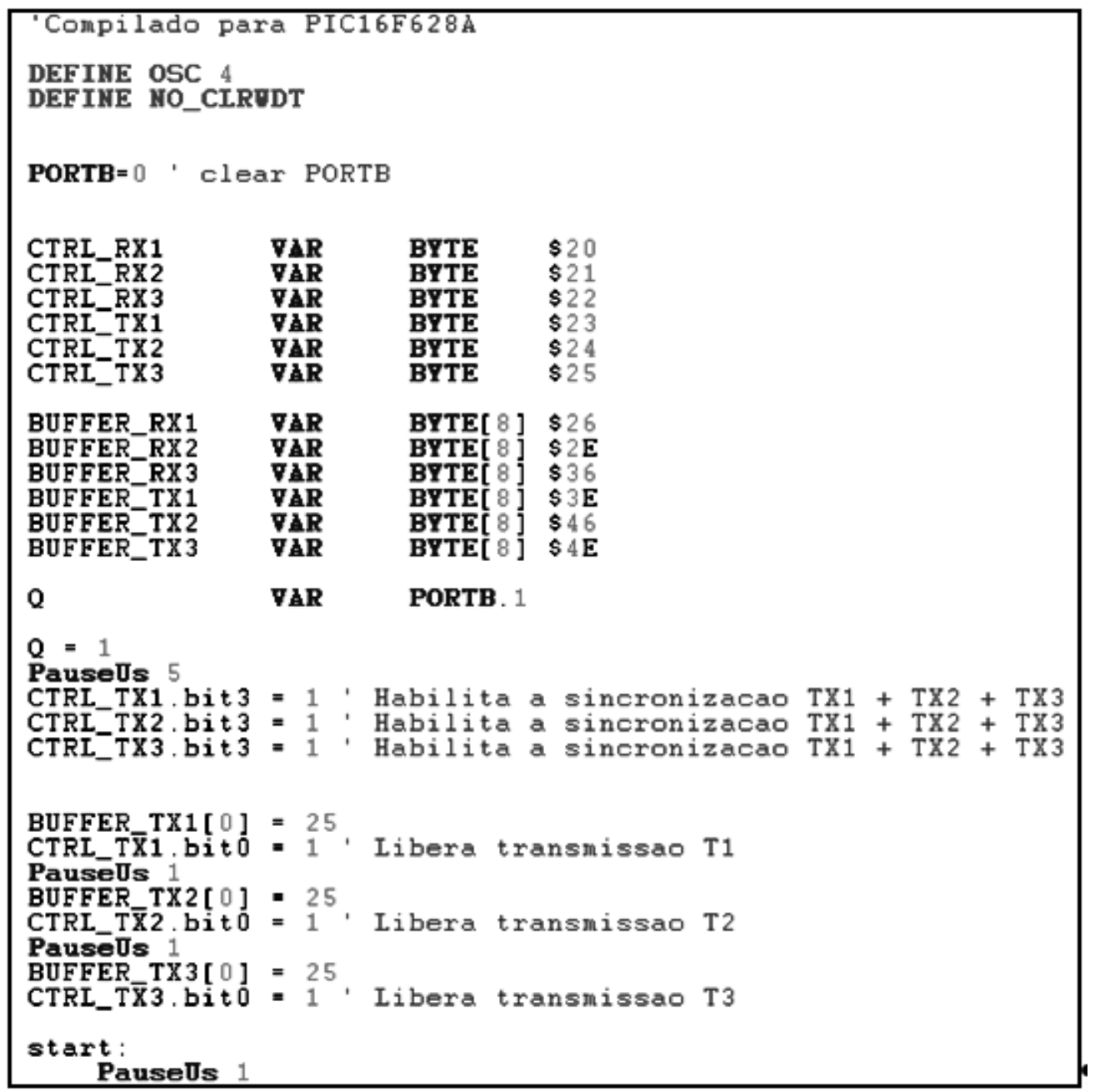

Figura 5.17: Trecho do código fonte no processador mestre para o controle PID redundante

Seguindo o fluxo apresentado na Figura 5.5, para inserir o programa no processador eleito como mestre foi simulado no PIC Simulator IDE, apresentou resultados positivos, foi convertido para memória $\mathrm{ROM}$ de programa por meio do programa HEX2VHD e carregado no software de simulação Modelsim. Nesta aplicação aproveitou-se um dos códigos funcionais destinado a um dos processadores escravos.

Os resultados da simulação do protótipo da AMM executando os programas que compõe a aplicação do controle PID redundante são visualizados nas Figuras 5.17 e 5.18 .

A Figura 5.18 mostra o processador eleito como mestre enviando três mensagens síncronas aos processadores escravos. As mensagens, indicadas pelas três setas, contém informações para o mesmo setpoint, 25. 


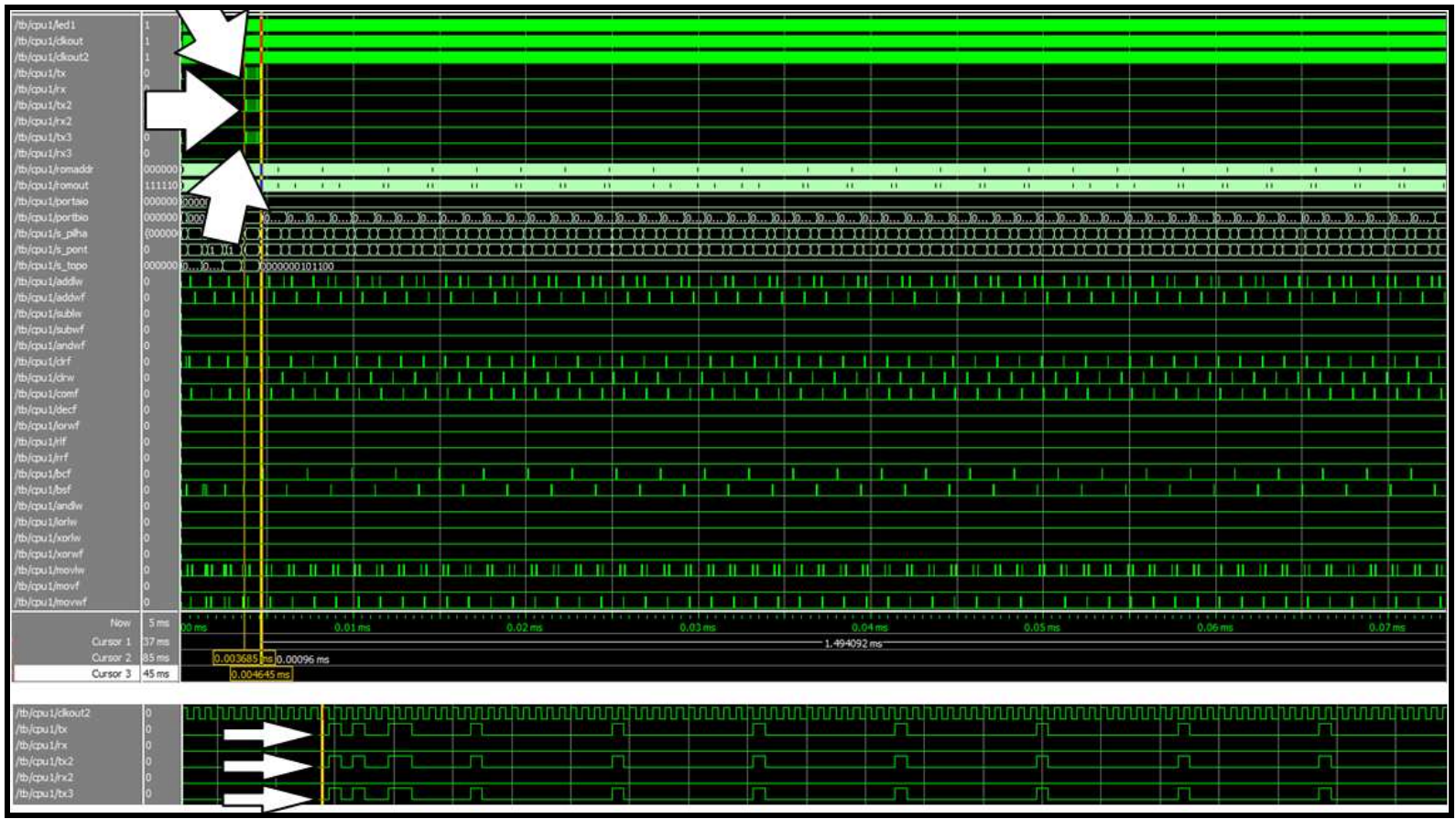

Figura 5.18: Processador configurado como mestre enviando três mensagens síncronas

A Figura 5.19 mostra a simulação dos processadores escravos redundantes executando o controle PID para os setpoints recebidos, no caso, 25, para os três processadores. Os três processadores escravos alcançam o setpoint recebido no mesmo instante, indicado pelas setas.

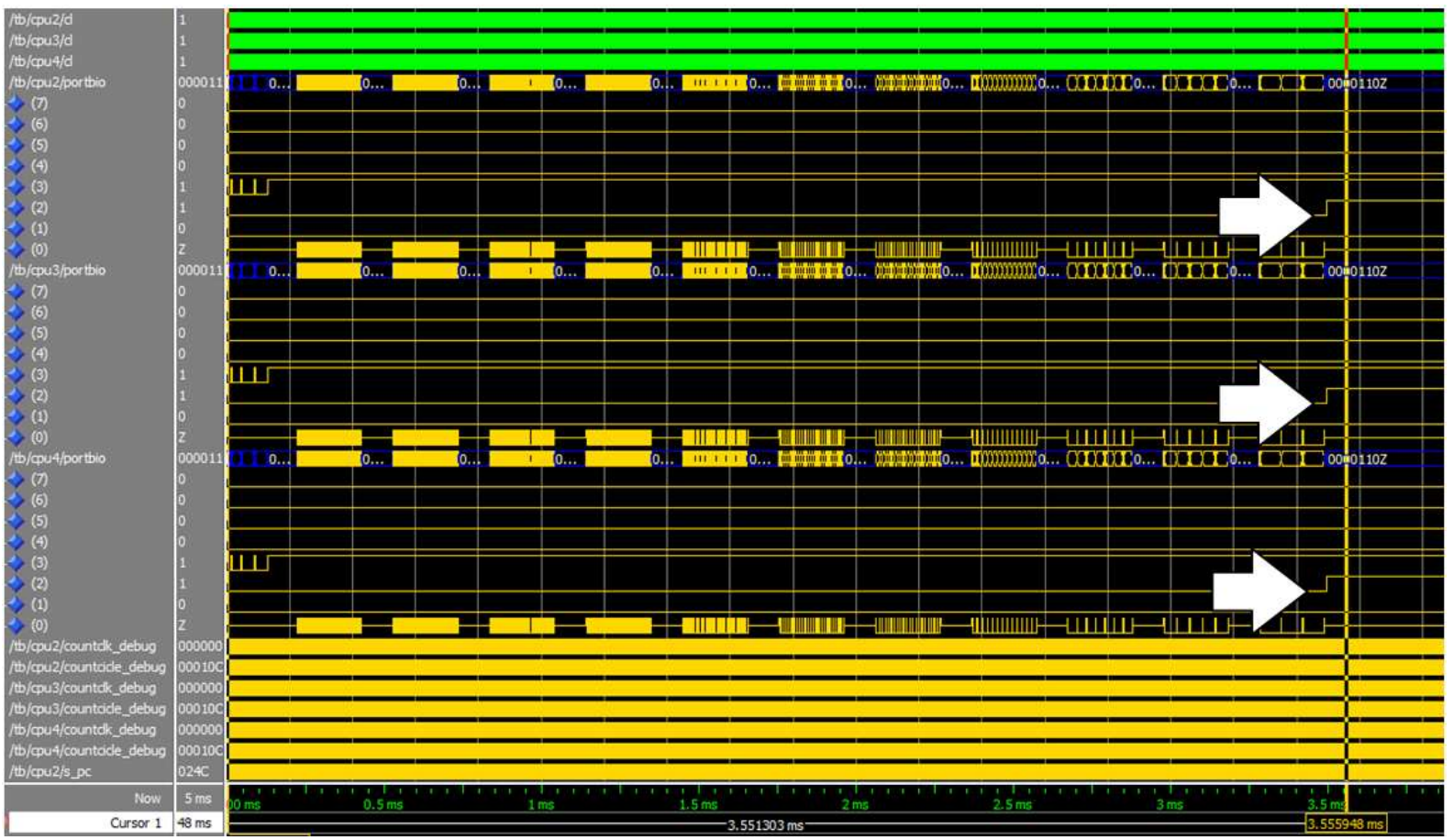

Figura 5.19: Processadores do protótipo da AMM configurados como escravos redundantes. 
A Figura 5.20 destaca a redundância alcançada nos três processadores escravos. Os dados indicados pelas setas A, B e C mostram o comportamento de três sinais selecionados, cpu2/s_w, cpu3/s_w e cpu4/s_w. Estes sinais formam o registrador de trabalho $\mathrm{W}$ presente em cada processador eleito como escravo nesta aplicação.

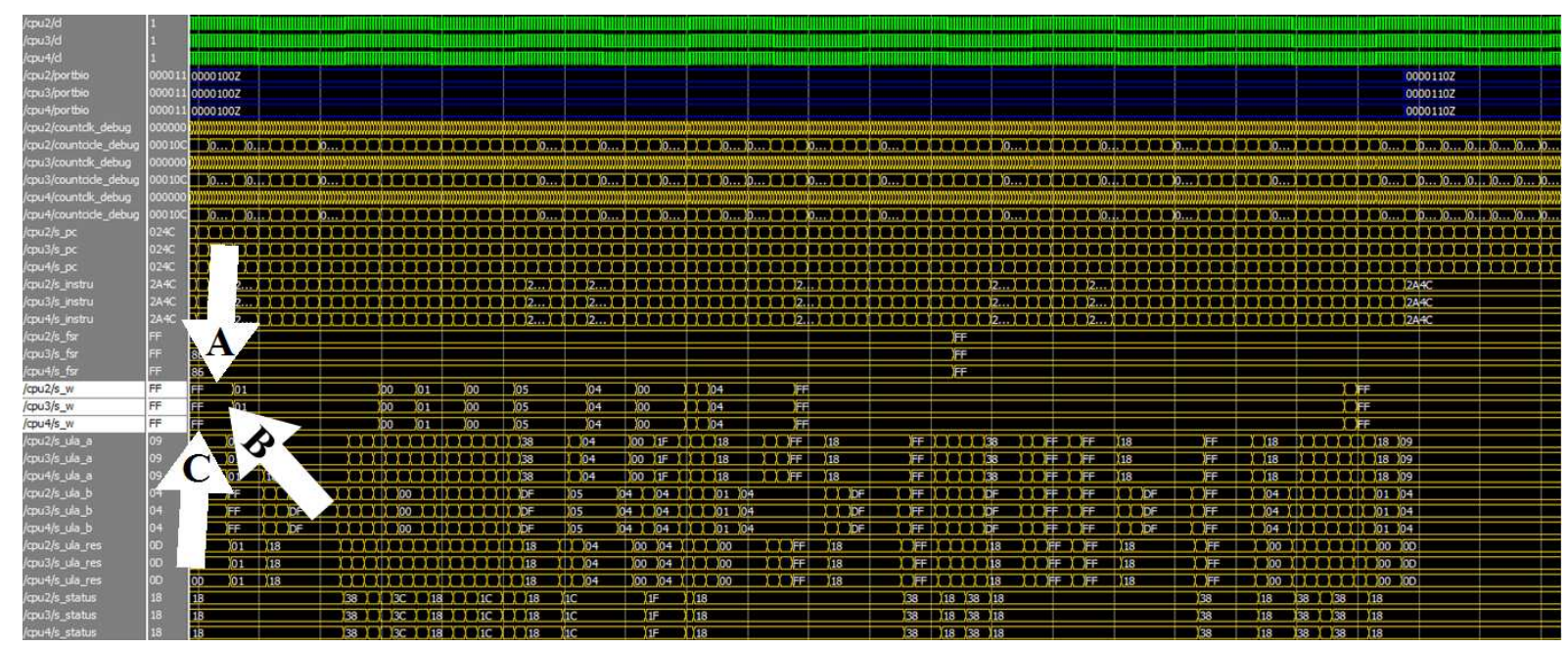

Figura 5.20: Simulação da redundância entre três processadores eleitos como escravos

É possível perceber que os valores destes sinais são totalmente simétricos. Isto é válido também para outros registradores dos mesmos processadores, selecionados aleatoriamente e agrupados para simplificar a visualização na simulação.

Com os resultados desta simulação é possível afirmar que os programas de controle PID executados nos processadores configurados de forma redundante funcionaram corretamente, obtendo-se exatamente o mesmo comportamento nos três processadores. Isto inclui valores idênticos do Program Counter e número de ciclos idênticos a partir do reset.

\subsection{Controle PID tolerante a falhas, na AMM}

Idealizou-se o controle PID sendo executado no protótipo da AMM com suporte de tolerância a falhas (capítulo 2) entre dois processadores eleitos como escravos. A aplicação idealizada para verificar a tolerância a falhas é bastante 
similar a aplicação descrita para o controle PID redundante. Os programas para o processador eleito como mestre e os processadores eleitos como escravos são exatamente os mesmos utilizados na aplicação para controle PID redundante. A única diferença entre a aplicação de controle PID redundante e a aplicação de controle PID tolerante a falhas é que, nesta última, são analisados dados referente ao hardware de comparação entre processadores e seu respectivo log. (capítulo 3).

Uma dificuldade foi a simulação de eventos de falhas, uma vez que os softwares de síntese e os softwares de mapeamento em FPGA são concebidos para detectar possíveis anomalias, na fase de descrição. Recorreu-se a mutação manual de componentes (capítulo 2).

Foi necessário incluir uma modificação na descrição VHDL do processador do protótipo da AMM, para ser possível incluir um método de inserção de falhas. É importante lembrar aqui que esta modificação não é sintetizável, ou seja, foi criada apenas para propósitos de simulação. O software de síntese não aceita a estrutura criada ser implementada em FPGA. Porém, para propósitos de simulação apenas, o software Modelsim aceita e inclui as falhas nos pontos determinados. A estrutura de falhas incluída no processador é ilustrada na Figura 5.21.

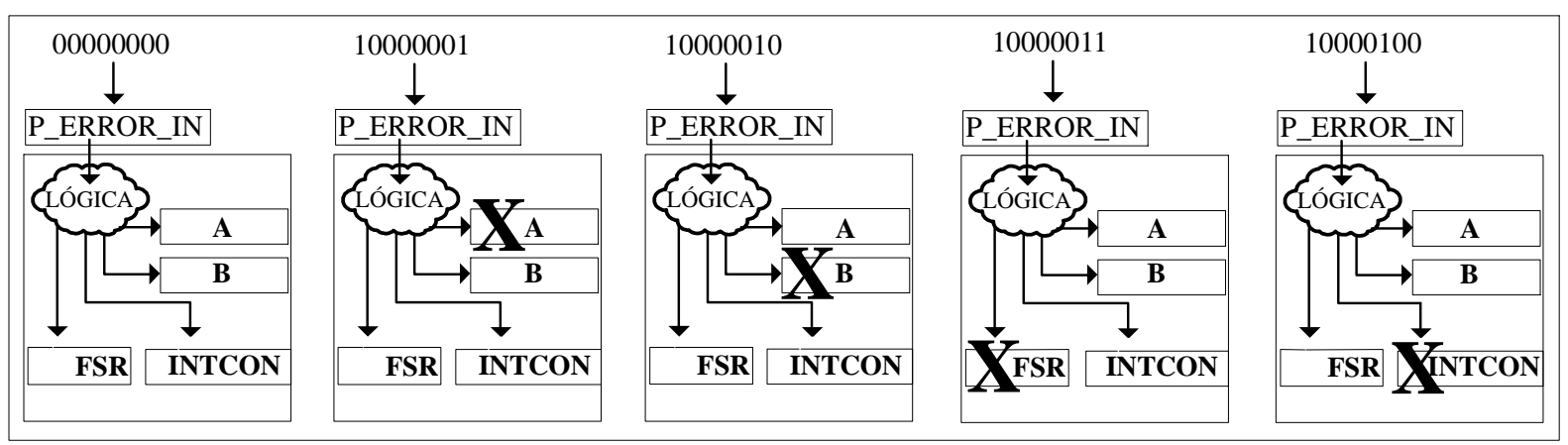

Figura 5.21: Lógica criada para inclusão proposital de falhas controladas no hardware.

A lógica idealizada necessitou da adição de uma porta de entrada, chamada por P_ERROR_IN, a qual forma uma simples estrutura de decisão que pode ser controlada externamente para causar ou não erros específicos no hardware. Assim, por meio de "comandos" externos é possível determinar se haverá a inclusão de erro, bem como direcioná-lo para um ponto específico de interesse. Foram criados apenas quatro erros controlados em alguns registradores de interesse. Porém não há impedimentos para que sejam criados outros erros em outros pontos de interesse 
futuro. O trecho de código incluído na descrição VHDL do processador está em destaque na Figura 5.22.

Na Figura 5.22, é possível observar que o sinal S_ULA_A recebe um estímulo que representa um sinal 'U' (indefinido) no seu terceiro bit, caso exista o "comando" externo 10000001 que indique a inclusão deste erro.

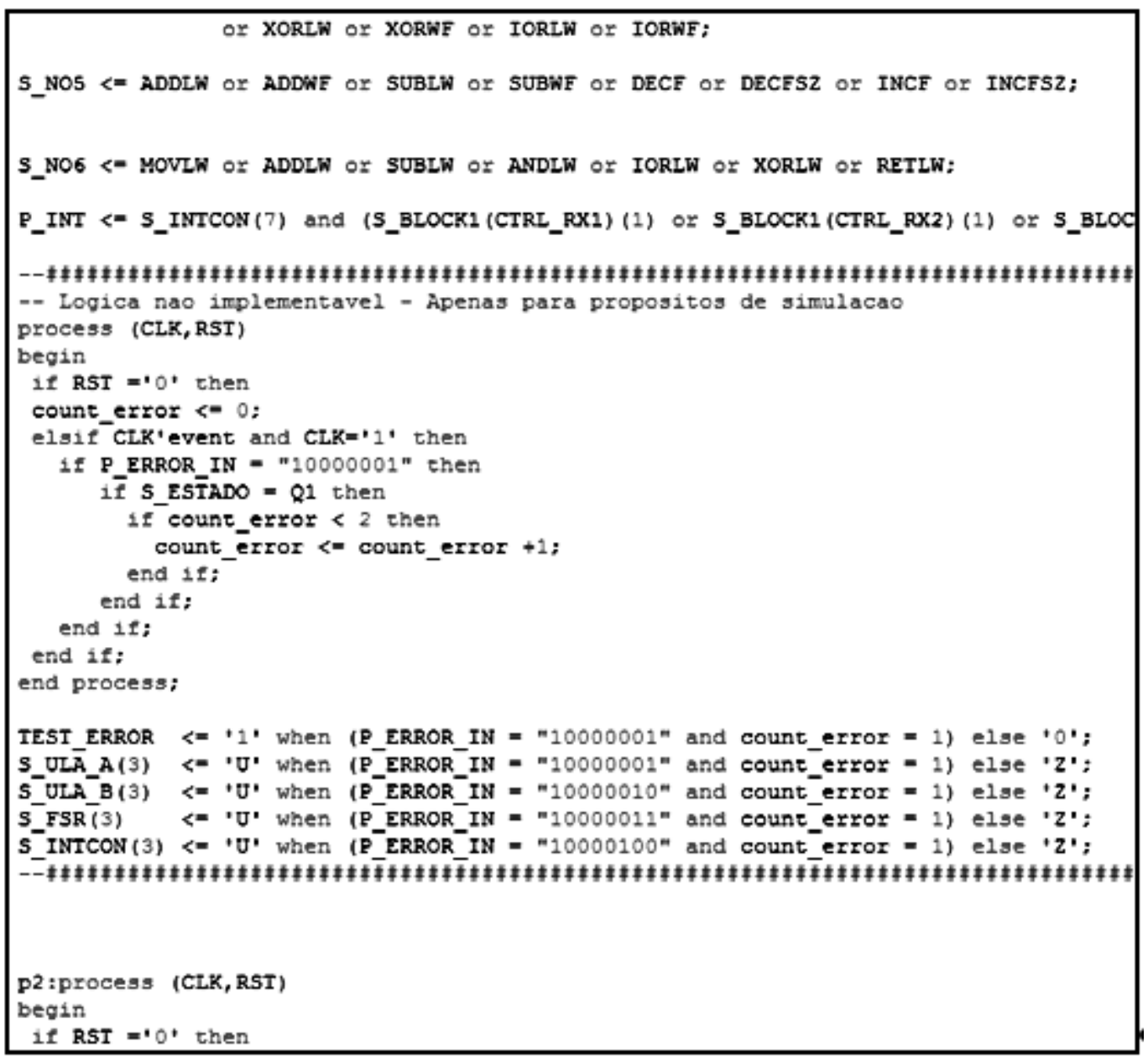

Figura 5.22: Trecho de código incluído na descrição VHDL do processador para gerar falhas

Em caso de não inclusão do erro, a estrutura é levada a alta impedância e assim o comportamento do hardware é normal.

Com a inclusão da estrutura de criação de falhas foi possível idealizar uma aplicação tolerante a falhas. A aplicação é ilustrada na Figura 5.23 e consiste em um processador eleito como mestre controlando a execução de dois processadores eleitos como escravos executando o algoritmo de controle PID. Os programas são os mesmos utilizados na aplicação do controle PID redundante e algumas alternativas para tolerância a falha são descritas inteiramente em hardware. 


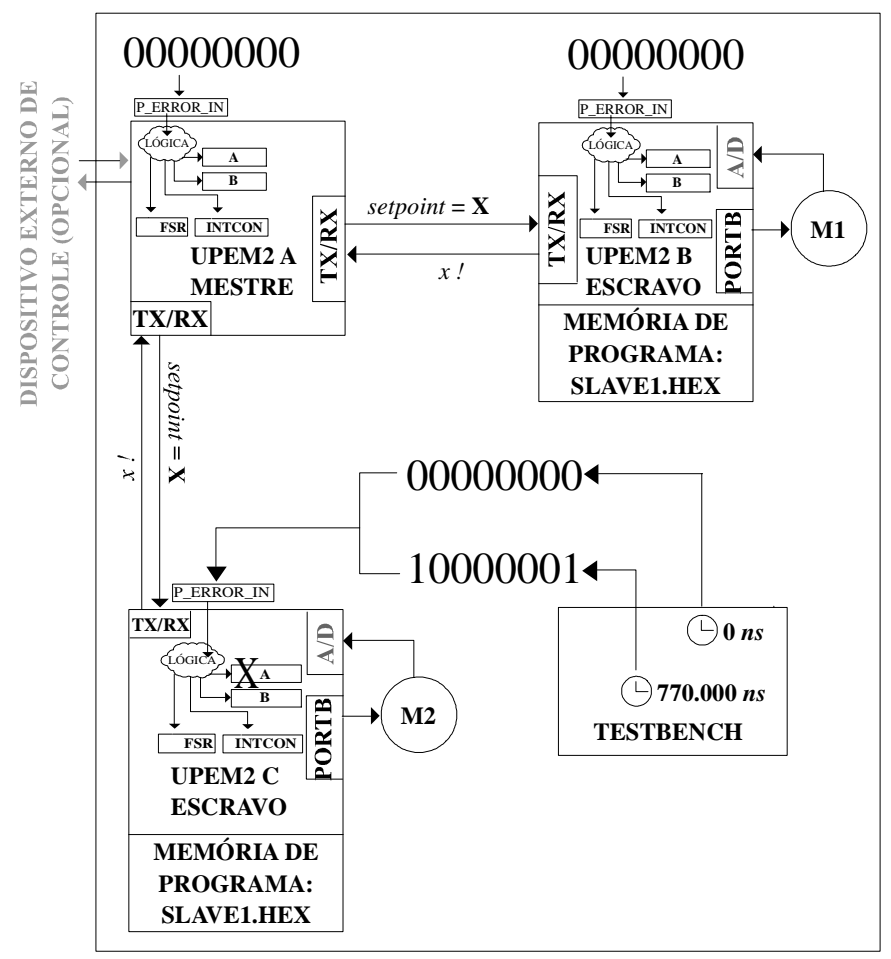

Figura 5.23: Metodologia para criar uma falha em um processador executando controle PID

A Figura 5.24 ilustra a simulação para a geração da falha. A seta destaca o instante exato onde a falha foi incluída no sinal p_ula_a2, o qual está interligado, nesta simulação, ao registrador " $A$ " existente no processador 2 , respeitando 0 "comando" disparado no arquivo de testbench.

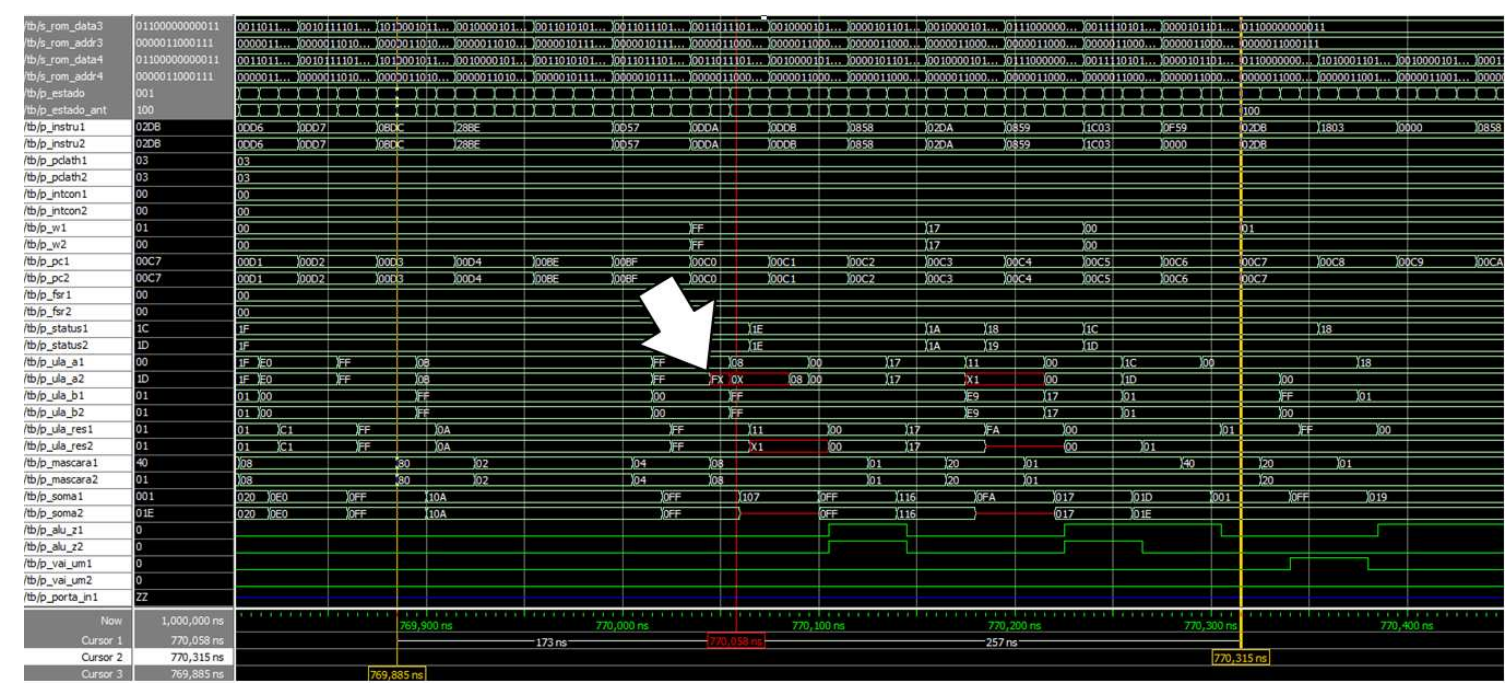

Figura 5.24: Simulação de uma falha controlada em um processador da AMM. 
A Figura 5.25 ilustra a visualização dos dados na estrutura de log. Conforme comentado no capítulo 3, dez ciclos do processador são armazenados na memória de $\log$, identificados na figura pelo primeiro nível da hierarquia w_log, ou seja, $(0)(1)(2)(3)(4)(5)(6)(7)(8)(9)$ e (10). Os estados Q1, Q2, Q3 e Q4 são identificados expandindo-se o nível (0) e visualizando-se $(0)(0)(1)(2)$ e (3). Estes estados estão organizados de forma similar em todos os dez níveis. Por fim, os valores correntes em cada registrador e componentes armazenados iniciam-se no terceiro nível da hierarquia, sendo o $(0)(0)(0)$ o primeiro valor e $(0)(0)(20)$ o último valor, para o primeiro ciclo, estado Q1. Assim sucessivamente, os valores são visualizados, expandindo-se cada nível.

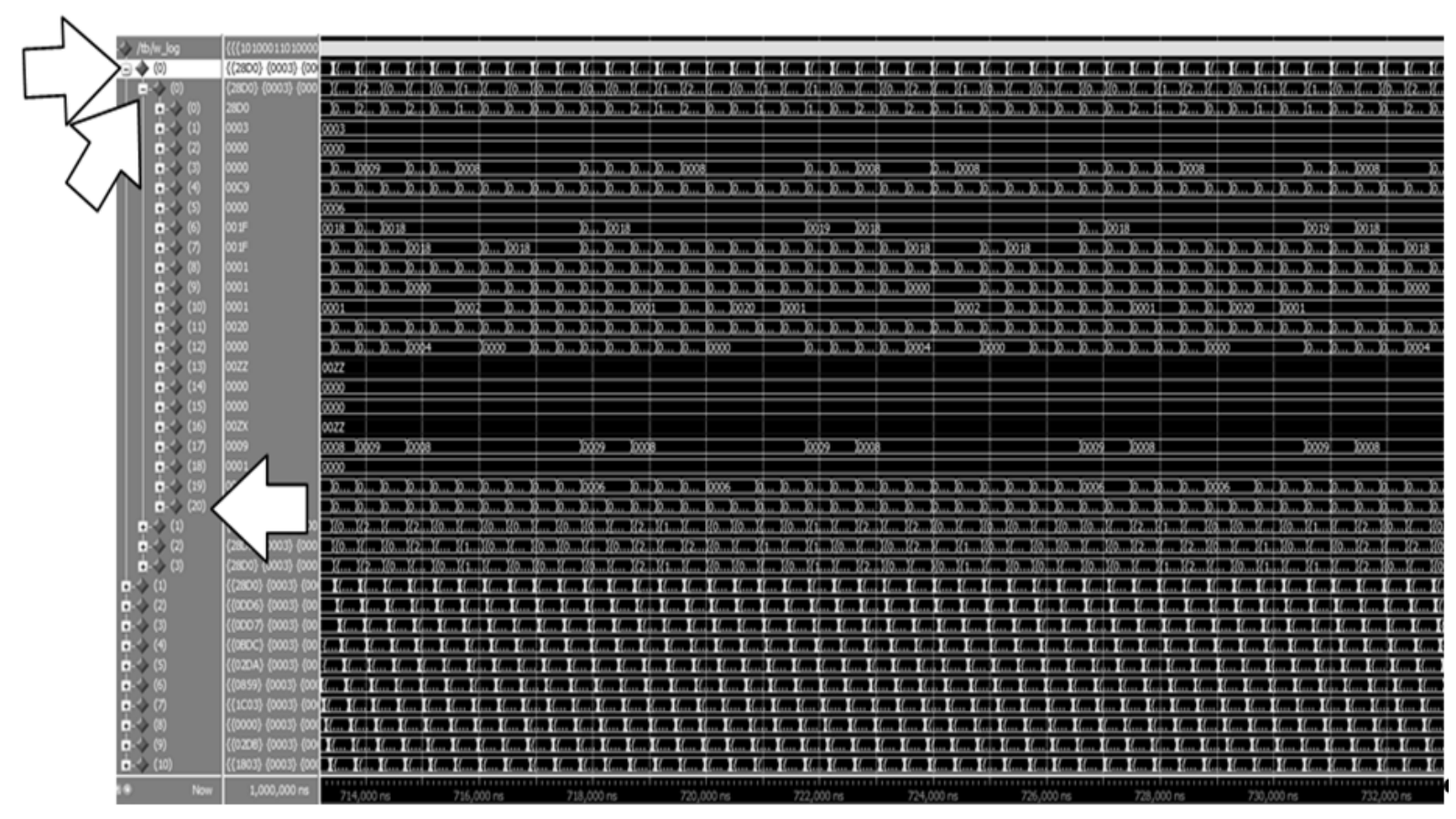

Figura 5.25: Visualização da simulação da hierarquia da estrutura de log da AMM.

A Figura 5.26 mostra que a estrutura de log armazenou a ocorrência da falha indicada pela seta "A", onde ocorre "00FX" em um dos endereços armazenados. A seta "B" indica que a falha ocorreu no ciclo 2863 do processador monitorado pela estrutura de log. 


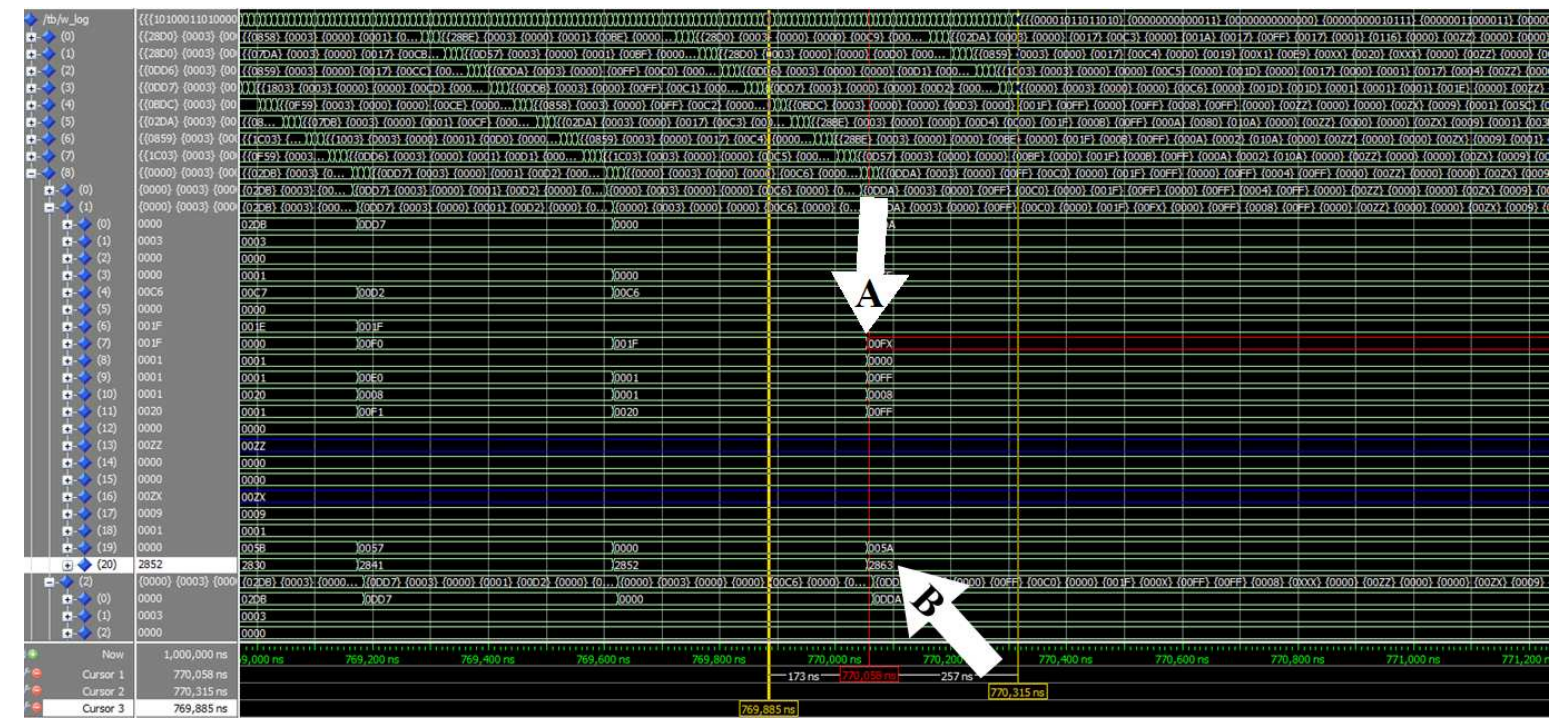

Figura 5.26: Simulação mostra que a estrutura de log armazenou a ocorrência da falha

A Figura 5.27 mostra que a estrutura de log armazenou também a propagação da ocorrência da falha indicada pela seta "A", onde ocorre "00X1" em um dos endereços armazenados. A seta "B" indica que a falha se propagou até o ciclo 2866 do processador monitorado pela estrutura de log, até ser detectado pela estrutura de detecção de falhas.

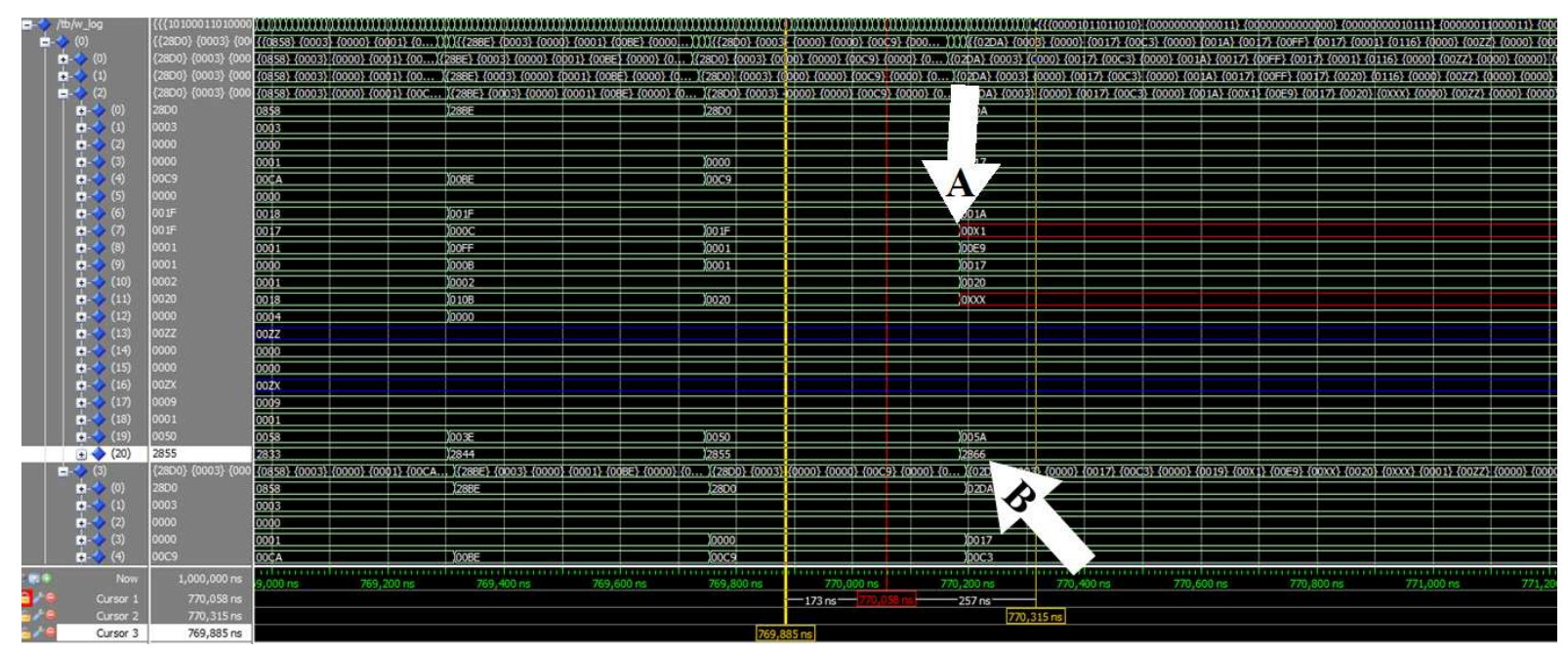

Figura 5.27: Simulação mostra que a estrutura de log armazenou a propagação da falha

Analisando os dados armazenados na estrutura de log é possível concluir que a falha ocorreu no ciclo 2863; o estado foi Q2, pois, a estrutura (8)(1) representa este estado; a falha iniciou-se no registrador "A", pois, (8)(1)(7) é destinado ao registrador "A"; a falha se propagou até o ciclo 2866; o ultimo estado onde a falha se 
propagou é Q3, pois, (0)(2) representa este estado e; a falha resultou em perda do valor do registrador "A", indexado por (0)(2)(7) e do valor do registrador $(0)(2)(11)$ o qual armazena o resultado da soma da ULA.

A Figura 5.28 mostra que após a falha ter sido detectada, o clock do processador identificado como cpu3 na simulação é suspenso. Obviamente, todo o sua atividade de processamento também é suspensa, enquanto que o processador identificado como cpu2 na simulação continua seu processamento normalmente.

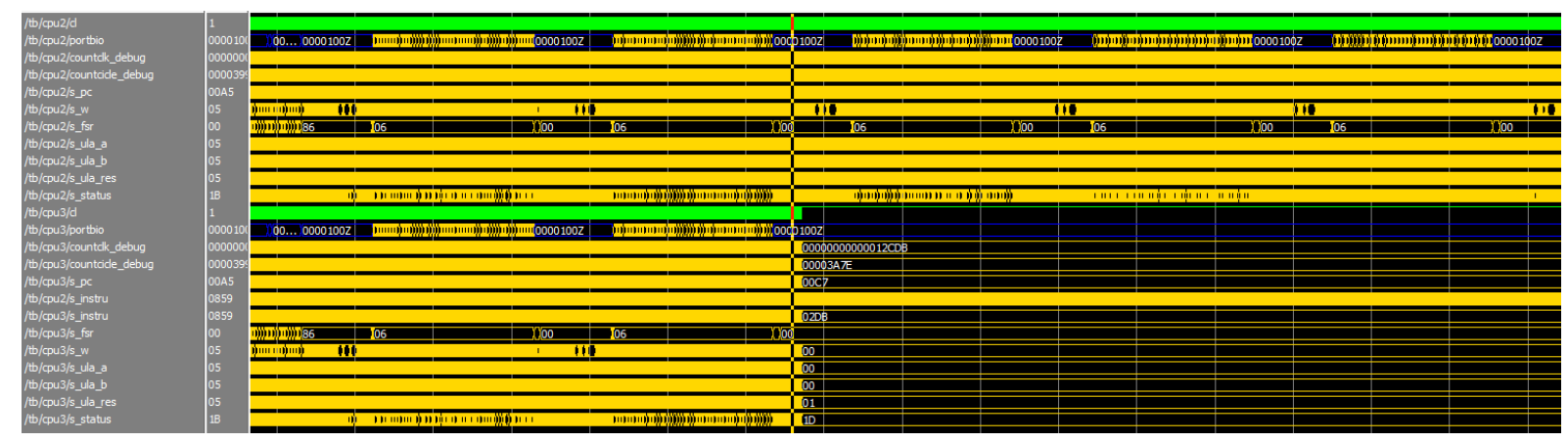

Figura 5.28: Suspensão da cpu3 após detecção da falha, enquanto cpu2 continua

\subsection{AES na AMM}

Em Criptografia, o Advanced Encryption Standard (AES), também conhecido por algoritmo de Rijndael, é uma cifra de bloco adotada como padrão de criptografia e é um dos algoritmos mais populares usados para criptografia de chave simétrica.

O AES opera sobre uma matriz de bytes com 4x4 posições, que consistem em seus estados. Para criptografar, cada rodada do AES (exceto o último) consiste em quatro estágios: (i) AddRoundKey - cada byte do estado é combinado com a subchave própria da rodada (RoundKey); cada subchave é derivada da chave principal usando o algoritmo de agendamento de chaves; (ii) SubBytes- é uma etapa de substituição não linear onde cada byte é substituído por outro de acordo com uma tabela de referência; (iii) ShiftRows- é uma etapa de transposição onde cada fileira do estado é deslocada de um determinado número de posições; (iv) MixColumns - é uma operação de mescla que opera nas colunas do estado e combina os quatro bytes de cada coluna usando uma transformação linear e ; (v) a 
rodada final, que substitui o estágio de MixColumns por um novo estágio de AddRoundKey. KAMAL, A. A.; YOUSSEF, A. M., 2009)

O AES é descrito em blocos na Figura 5.29.

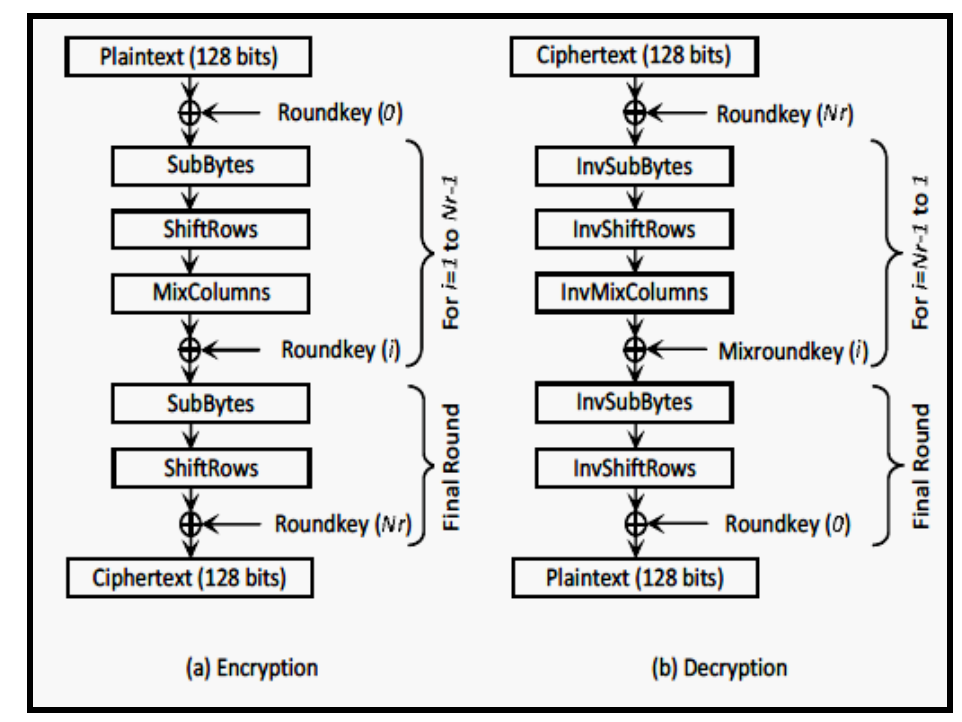

Figura 5.29: Algoritmo de criptografia AES, em blocos, (KAMAL, A. A.; YOUSSEF, A. M., 2009)

O AES é amplamente difundido e encontra-se muita literatura detalhando suas operações. Assim, não é objetivo aqui aprofundar-se na descrição detalhada do AES. É importante ressaltar que o AES necessita de cálculos computacionais complexos e rotinas de software avançadas. Foi escolhido para demonstrar a possibilidade incluir a segurança com criptografia no protótipo da AMM.

A saída cifrada padrão para o algoritmo AES 128 bits é visualizada na Figura 5.30 e pode ser confirmada com o uso do aplicativo AES Block Cipher Calculator, (BROWN, L, 2005), cuja saída AES é visualizadas na Figura 5.31.

\begin{tabular}{|llllllllllllllllll|}
\hline Algoritmo de cifra do AES, saída padrão & & & & & & & & & \\
Texto plano & $:$ & 00 & 00 & 00 & 00 & 00 & 00 & 00 & 00 & 00 & 00 & 00 & 00 & 00 & 00 & 00 & 00 \\
Chave & $:$ & 00 & 00 & 00 & 00 & 00 & 00 & 00 & 00 & 00 & 00 & 00 & 00 & 00 & 00 & 00 & 00 \\
Cifra & $:$ & 66 & E9 & 4B & D4 & EF & $8 A$ & $2 C$ & $3 B$ & 88 & $4 C$ & FA & 59 & CA & 34 & 2B & 2E \\
\hline
\end{tabular}

Figura 5.30: Texto cifrado pelo AES 128 bits 


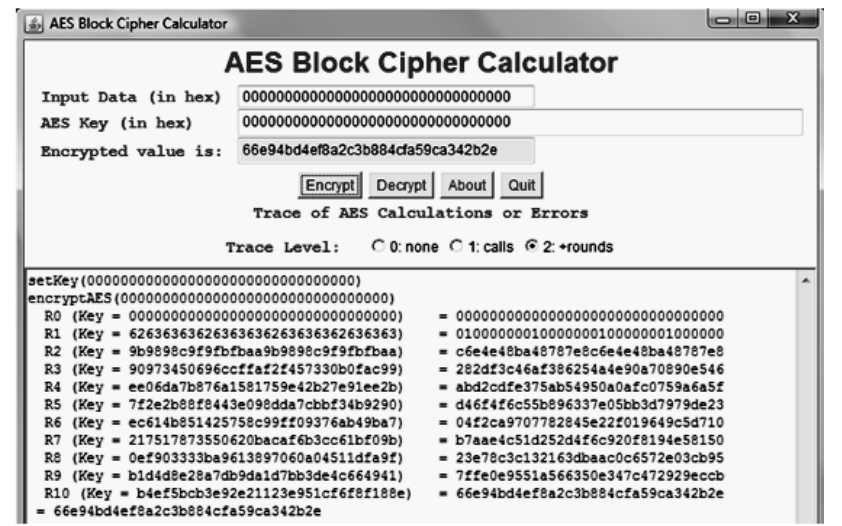

Figura 5.31: Cifra no programa AES Block Cipher Calculator, (BROWN L, 2005)

O programa de cifra e decifra utilizado nesta tese é uma adaptação dos programas de cifra e decifra AES de (PERMADI, 2008), escrito em linguagem assembly para microcontroladores PIC16FX, da Microchip. A adaptação realizada consistiu na inclusão dos endereços dos controladores e buffers da AMM, uma reorganização geral dos endereços das variáveis de programas, algumas funções específicas e questões de compilação.

Os processos de cifra e decifra foram executados isoladamente em um único processador da AMM, em dois testes distintos, comentados a seguir.

Comprova-se a correta execução do AES no processador UPEM2 para o processo de cifra, conforme ilustrado na Figura 5.32.

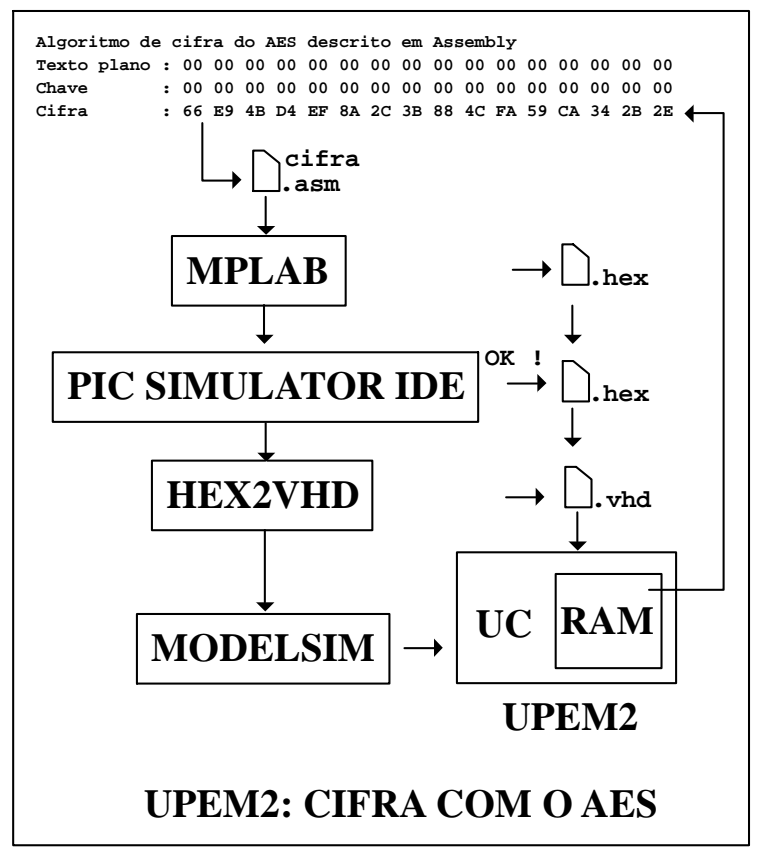

Figura 5.32: Processo para validação da cifra AES no processador da AMM 
A Figura 5.33 ilustra um texto plano composto por 16 valores hexadecimais 00h sendo cifrado com o AES 128 bits, utilizando uma chave composta também por 16 valores hexadecimais 00h. Com estes parâmetros, a saída obtida pelo processador UPEM2 do protótipo da AMM foi 66 E9 4B D4 EF 8A 2C 3B 88 4C FA 59 CA 34 2B 2E, comprovando-se a correta simulação da execução do algoritmo de cifra do AES.

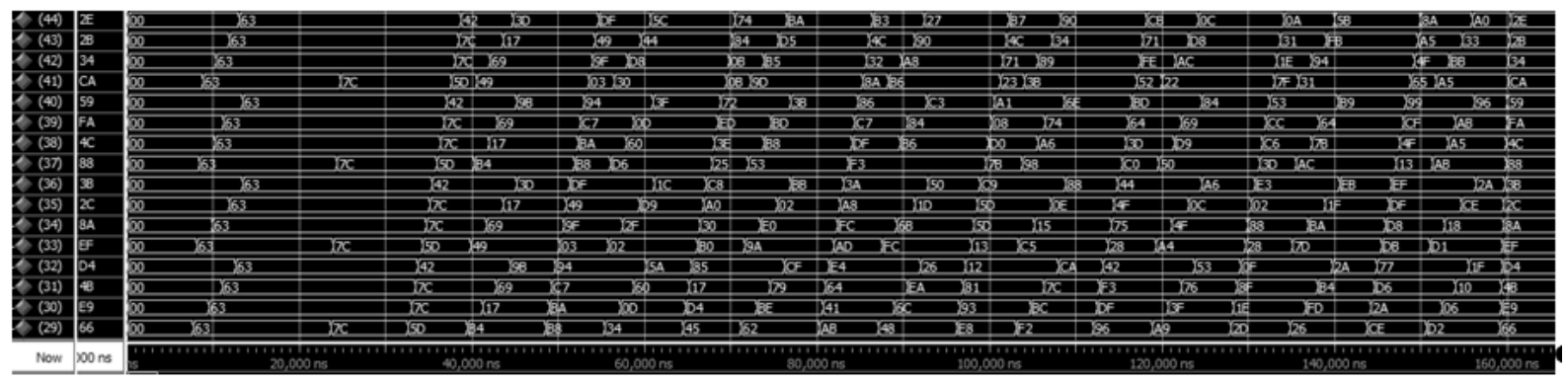

Figura 5.33: Resultado da simulação da cifra AES 128 bits no processador do AMM

A saída decifrada para o algoritmo AES 128 bits, tendo por base o texto padrão cifrado, é visualizada na Figura 5.34 e pode ser confirmada com o uso do aplicativo AES Block Cipher Calculator, cuja saída AES é visualizada na Figura 5.35.

\begin{tabular}{|llllllllllllllllll|}
\hline Algoritmo de decifra do AES: saída retorna ao texto plano \\
Texto plano & $:$ & 66 & E9 & 4B & D4 & EF & $8 A$ & $2 C$ & $3 B$ & 88 & 4C & FA & 59 & CA & 34 & 2B & 2E \\
Chave & $:$ & 00 & 00 & 00 & 00 & 00 & 00 & 00 & 00 & 00 & 00 & 00 & 00 & 00 & 00 & 00 & 00 \\
Decifra & $:$ & 00 & 00 & 00 & 00 & 00 & 00 & 00 & 00 & 00 & 00 & 00 & 00 & 00 & 00 & 00 & 00 \\
\hline
\end{tabular}

Figura 5.34: Texto decifrado pelo AES 128 bits

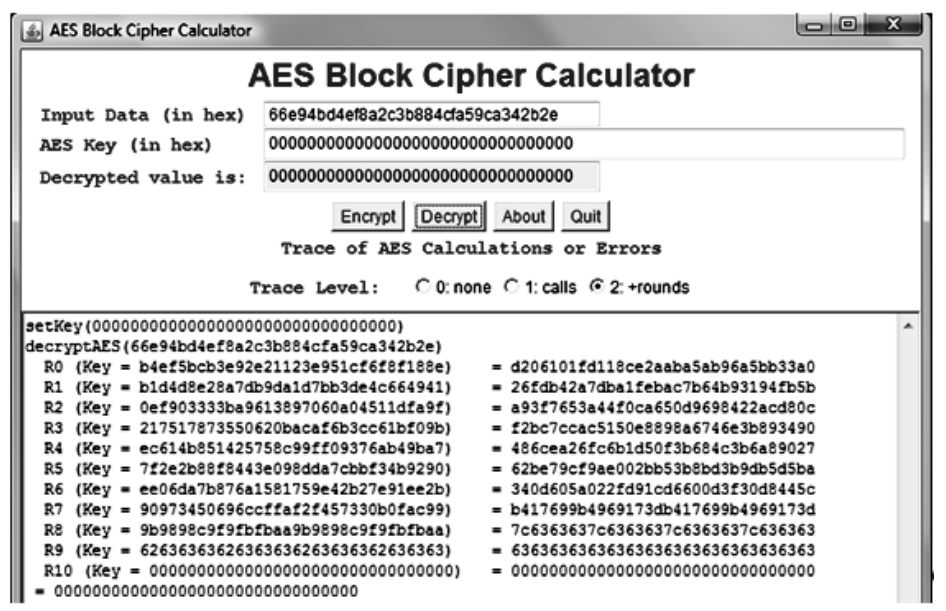

Figura 5.35: Decifra no programa AES Block Cipher Calculator, (BROWN L, 2005) 
Comprova-se a correta execução do AES no processador UPEM2 para o processo de decifra, conforme ilustrado na Figura 5.36.

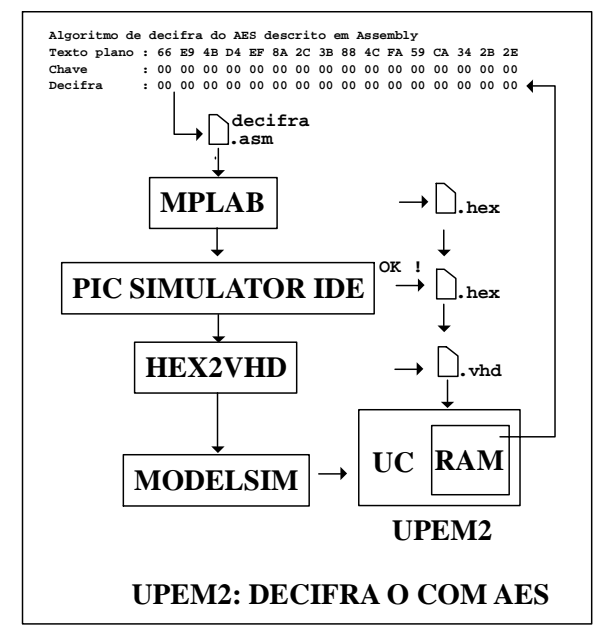

Figura 5.36: Processo para validação da decifra AES no processador do AMM

A Figura 5.37 ilustra a simulação da execução do processo de decifra do AES. Assim, os resultados cifrados no processo anterior de cifra, 66 E9 4B D4 EF 8A 2C 3B 88 4C FA 59 CA 34 2B 2E, são injetados como entrada no processo de decifra, mantendo-se a mesma chave utilizada para cifra, ou seja, dezesseis valores hexadecimais $00 \mathrm{~h}$.

A Figura 5.37 resulta então nos dezesseis valores hexadecimais $00 \mathrm{~h}$, retornando no texto cifrado e comprovando a simulação da execução do algoritmo de decifra do AES na UPEM2.

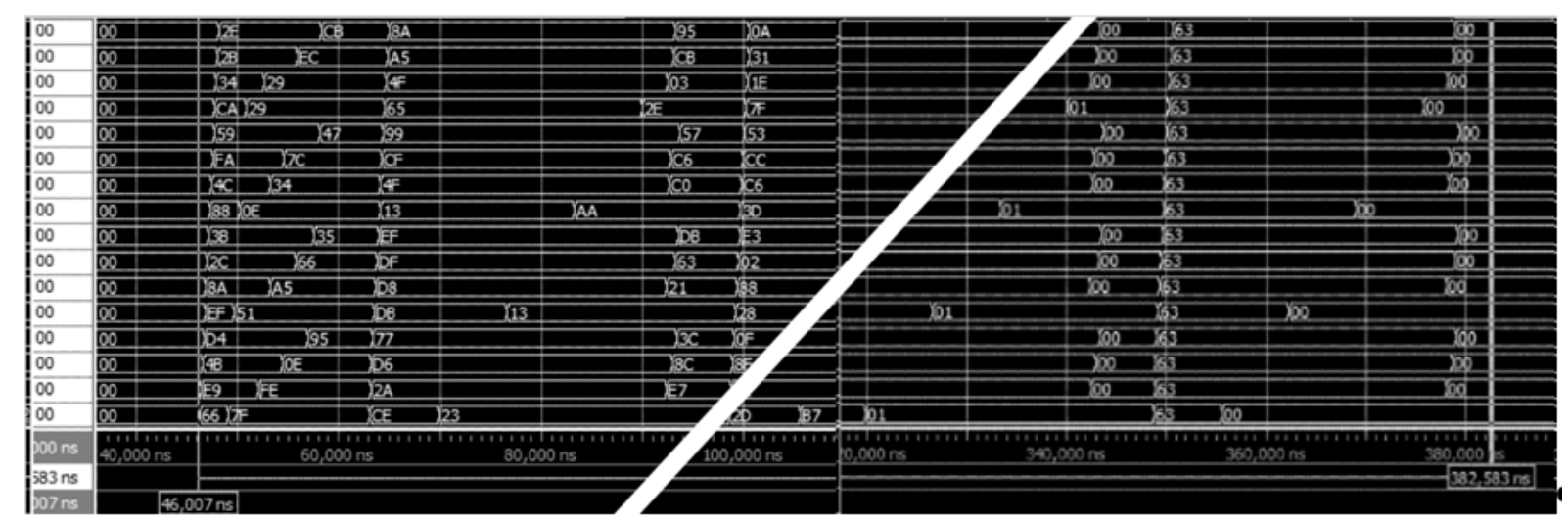

Figura 5.37: Resultado da simulação da decifra AES 128 bits no processador do AMM 


\subsection{Envio de texto a ser cifrado em um processador executando o algoritmo de criptografia AES na AMM}

Após comprovar-se a funcionalidade dos processos de cifra e decifra do AES no processador da AMM, idealizou-se que um processador eleito como mestre envie um texto a ser cifrado em um processador eleito como escravo.

Assim, a seqüência enviada escolhida foram os valores hexadecimais 41, 42, 43, 44, 45, 46, 47, 48, 49, 4A, 4B, 4C, 4D, 4E, 4F e 50, referentes aos valores da seqüência "ABCDEFGHIJKLMNOP" da tabela ASCII. Como a estrutura de mensagens utilizada possui o limite de 8 bytes, foram utilizadas duas mensagens, para transmitir toda a informação. Para estes dados como entrada de texto a ser cifrado, a saída obtida com o AES 128 bits com uma senha composta por 16 valores hexadecimais 00h, é 61 D7 8258 EB 1A BD 6F FF 47 9D 1D AB B6 10 3B. A saída pode ser confirmada com o uso do programa AES Block Cipher Calculator, na Figura 5.38 .

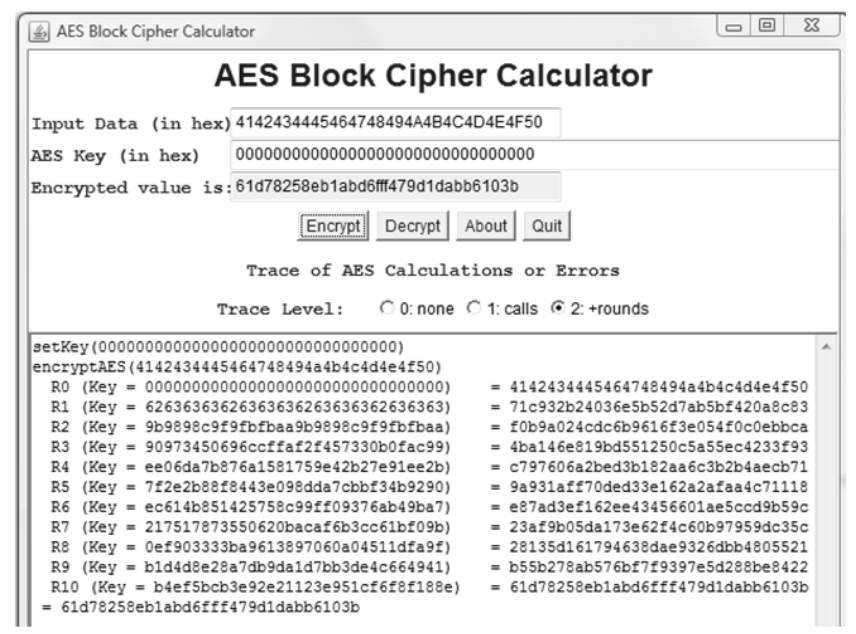

Figura 5.38: Saída do AES Block Cipher Calculator, com os valores testados no protótipo da AMM

A Figura 5.39 mostra o teste idealizado para este teste de envio de texto entre processadores e respectiva cifra AES. A Figura 5.40 ilustra as mensagens sendo organizadas no buffer transmissor de mensagens no processador eleito como mestre.

A Figura 5.41 ilustra o resultado do texto cifrado pelo processador eleito como escravo e com o algoritmo de cifra em seu código de programa. 


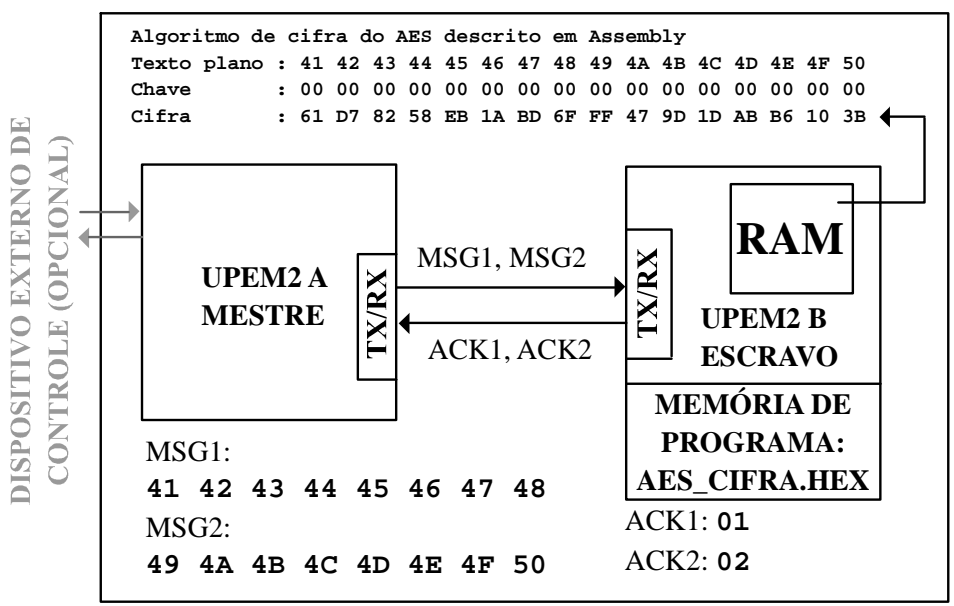

Figura 5.39: Organização do teste para troca de texto a ser cifrado

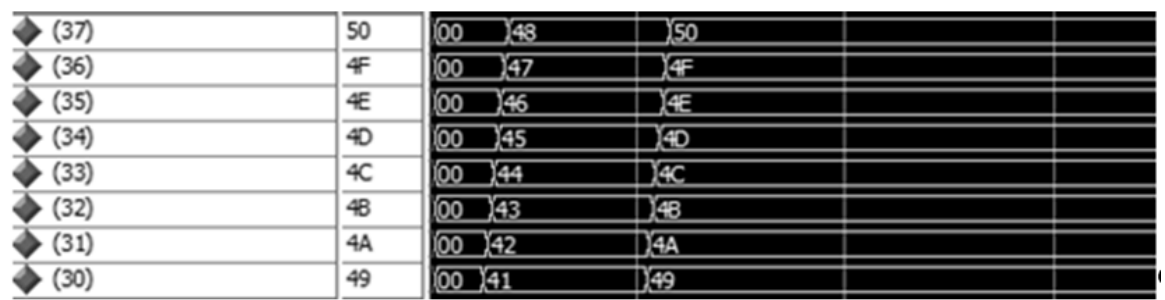

Figura 5.40: Mensagens sendo depositadas no transmissor do processador eleito como mestre.

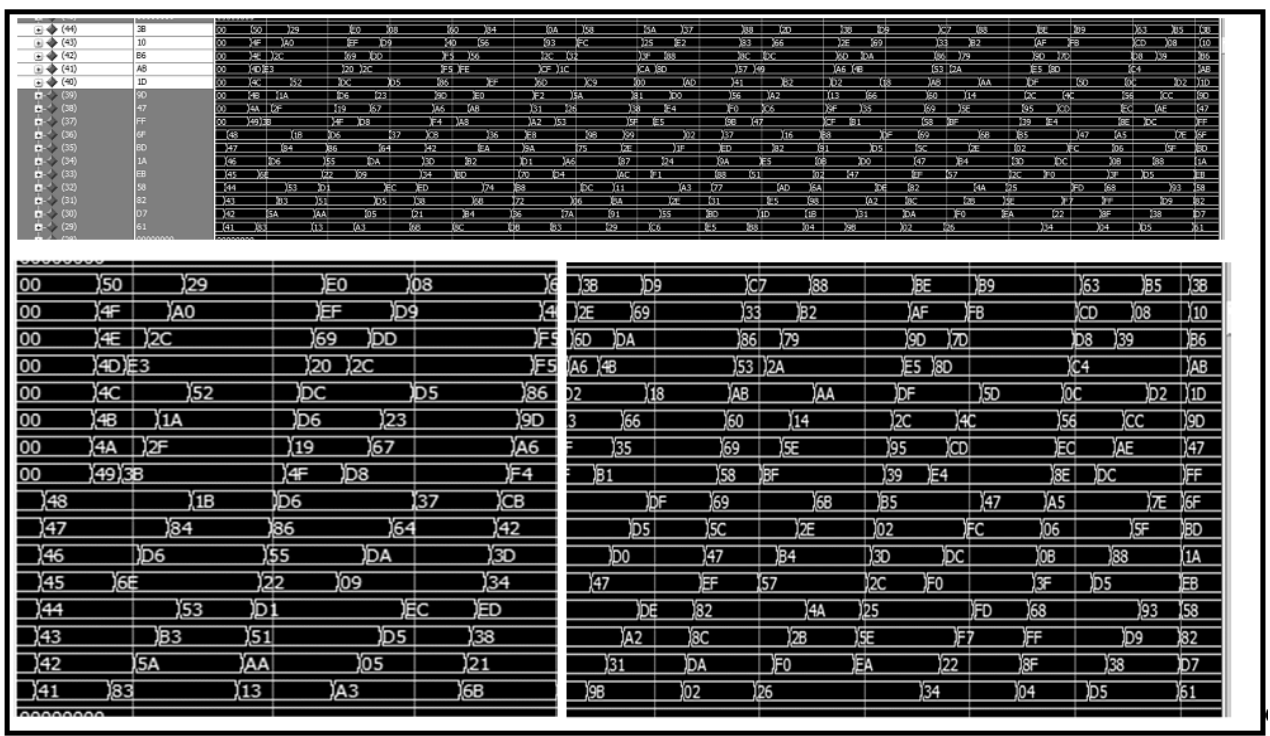

Figura 5.41: Resultados da troca de mensagens e algoritmo de cifra AES no protótipo da AMM.

Com os resultados obtidos nos testes realizados em simulação comprova-se a correta execução dos programas no processador base da AMM, a correta troca de mensagens no mecanismo de comunicação desenvolvido, bem como a correta interação entre os programas e os componentes de hardware que compõem a AMM. 


\subsection{Protótipo em FPGA e desempenho}

A UPEM2 foi mapeada no FPGA XC2S200 e os dados de utilização em FPGA foram 480 slices (20\%) para a CPU e 2108 slices para o conjunto composto pela CPU, quatro bancos de RAM e ROM com programa do jogo Tetris. A UPEM2 funcionou perfeitamente, executando 0 jogo sem nenhum problema de compatibilidade entre as instruções descritas em VHDL e as instruções previstas para executarem no processador real do microcontrolador PIC16F628. A Figura 5.42 mostra o teste físico realizado.

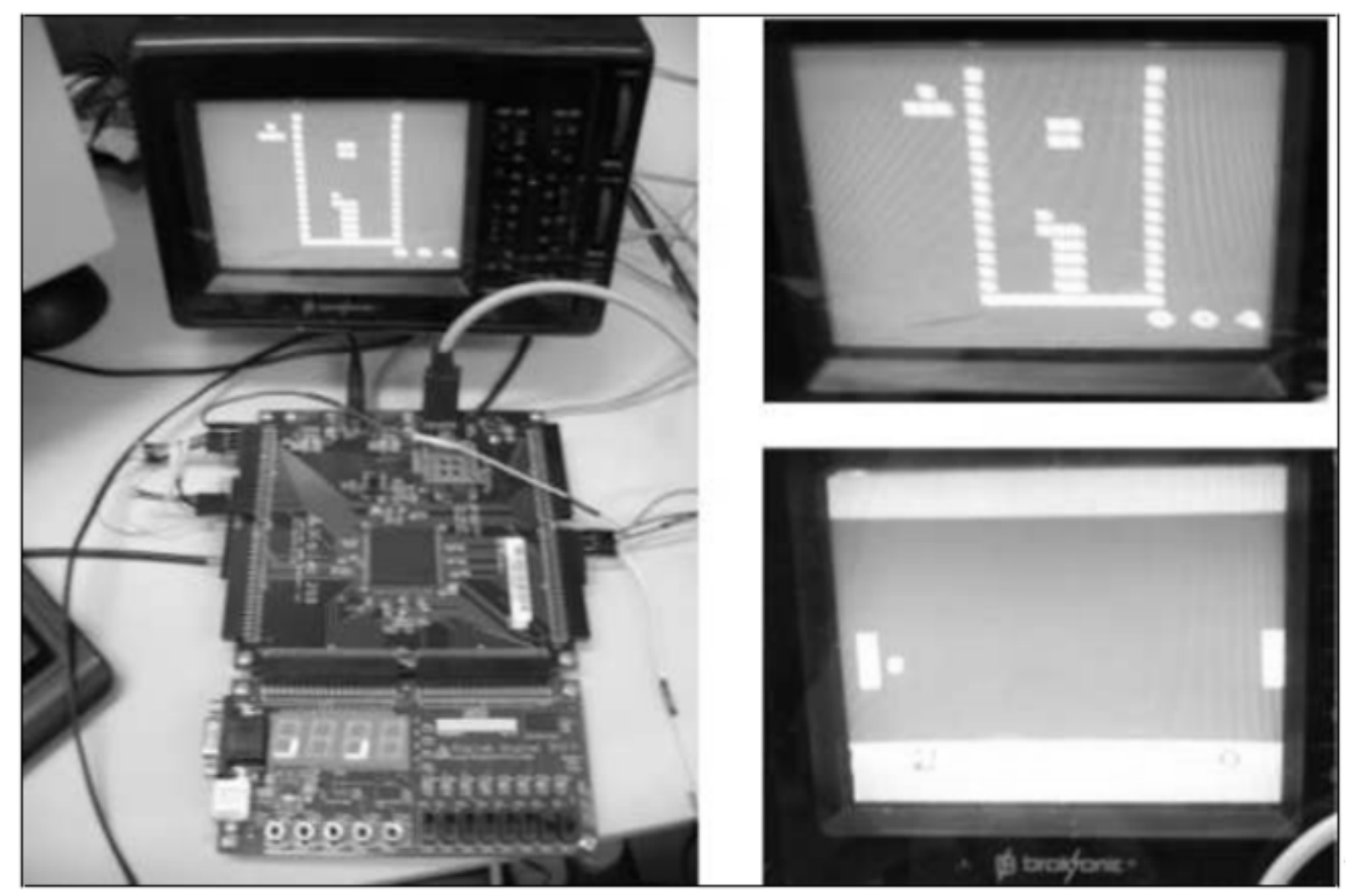

Figura 5.42: Teste real em FPGA da UPEM2: Os jogos Tetris e Pong (GUNEÉ, 2008), na TV.

Acredita-se que os programas que formam estes jogos utilizam cerca de $90 \%$ de todo o potencial da CPU e, com a correta execução em FPGA, a UPEM2 está funcional.

Até o presente momento, outros programas foram escritos no compilador PicBasic simulados no Pic Simulator IDE e carregados na UPEM2. O software Modelsim com a UPEM2 e os programas carregados indicou comportamento 
idêntico ao esperado, sem diferenças entre a execução no processador presente no microcontrolador PIC16F628 e a UPEM2.

$\mathrm{Na}$ tabela 5.1, são mostrados alguns dados de implementação física em FPGA da UPEM e da UPEM2. Esta tabela mostra que a UPEM2 consome mais recursos do FPGA em relação a UPEM. Este resultado já era esperado pois o objetivo da implementação da UPEM2 foi obter mais recursos de hardware. Na tabela 5.2 são mostrados dados de utilização das memórias RAM descritas para a UPEM e UPEM2. Na tabela 5.3 a CPU da UPEM2 é comparada com três processadores, o AEMB, (NGIAP, 2007), o Picoblaze (CHAPMAN, 2006) e Leon3, (WONG, 2008).

\begin{tabular}{lccc}
\multicolumn{4}{c}{ Tabela 5.1: Recursos utilizados entre UPEM e UPEM2 no FPGA Xilinx XC2S200E } \\
\hline Recursos & $\begin{array}{c}\text { Uso da CPU da } \\
\text { UPEM }\end{array}$ & $\begin{array}{c}\text { Uso da CPU da } \\
\text { UPEM2 }\end{array}$ & Total \\
\hline № de Slices & 480 & 553 & 2352 \\
№ de Slice Flip & 281 & 398 & 4704 \\
Flops & & & \\
№ de 4 Input LUTs & 890 & 1.029 & 4704 \\
№ de bonded IOBs & 10 & 48 & 146 \\
№ de GCLKs & 1 & 1 & 4 \\
\hline
\end{tabular}

Tabela 5.2: Recursos utilizados entre a RAM da UPEM e a RAM da UPEM2 no FPGA Xilinx XC2S200E

\begin{tabular}{lcc}
\hline \multicolumn{1}{c}{ Componente } & Slices & Total \\
\hline RAM da UPEM 64bytes & 480 & \\
RAM da UPEM2 & 1728 & 2352 \\
224bytes & & \\
\hline
\end{tabular}

Tabela 5.3: Comparação de área utilizada entre UPEM2, AEMB e PICOBLAZE

\begin{tabular}{lr}
\hline \multicolumn{1}{c}{ Componente } & № Equivalente Gates \\
\hline UPEM2 & 10.140 \\
AEMB & 38000 \\
PICOBLAZE & 79.043 \\
LEON3 & $1.015 .990^{*}$ \\
& * Implementação de (WONG, 2008) \\
\hline
\end{tabular}

Diferentes configurações mostradas na Figura 1.2 (capítulo 1), foram descritas em VHDL e implementadas no FPGA Xilinx XC2VP30 para o protótipo AMM completo: CPU, memória RAM, memória ROM e os respectivos barramentos para interconexão. Os dados de ocupação destas implementações podem ser vistos na tabela 5.4 .

Implementar em FPGA sistemas que contém memória RAM é difícil pois a memória RAM pode ocupar área significativa. Assim, para as versões $A, B$ e $C$, os processadores foram mapeados com 96x8bits de RAM, ou seja, somente um banco 
de memória RAM, dos quatro disponíveis. Para a versão D, 7 processadores foram mapeados sendo que o "mestre" foi mapeado com 176x8bits de RAM - dois bancos de memória RAM - e os outros 6 "escravos" foram mapeados apenas com 96x8bits de RAM cada - um único banco de memória RAM.

Todas as versões implementadas do protótipo AMM atingiram em torno de 100Mhz de freqüência de operação no FPGA Xilinx XC2VP30, com todos os componentes mapeados.

Tabela 5.4: Ocupação de diferentes versões do protótipo da AMM no XC2VP30

\begin{tabular}{lccc}
\hline \multicolumn{1}{c}{ Componente } & $\begin{array}{c}\text { Versão } \\
{ }^{*}\end{array}$ & Slices & Utilização \\
\hline Barramento (1-1 processador) & - & 559 & $4 \%$ \\
1 processador & - & 579 & $4 \%$ \\
2 processadores & - & 1353 & $9 \%$ \\
3 processadores & - & 2047 & $14 \%$ \\
4 processadores & - & 2535 & $18 \%$ \\
AMM (2 processadores) & A & 3105 & $22 \%$ \\
AMM (4 processadores) & B & 6119 & $44 \%$ \\
AMM (3 processadores) & C & 4999 & $33 \%$ \\
AMM (4 processadores) & C & 6042 & $44 \%$ \\
AMM (5 processadores) & C & 8630 & $63 \%$ \\
AMM (6 processadores) & C & 10274 & $75 \%$ \\
AMM (7 processadores) & D & 12725 & $92 \%$ \\
& * Ver configuração na Figura 1.2 \\
\hline
\end{tabular}

O sistema de interconexão, o qual inclui barramento, buffers e controle é descrito junto a memória RAM do processador da AMM. Sendo assim, é difícil isolálo completamente para fins de estatísticas de ocupação. Para isso, descreveu-se o sistema com os componentes mínimos necessários para executar uma comunicação entre dois processadores, o que inclui 35 posições de memória RAM (18 de cada processador).

Por usar RAM, o sistema de interconexão parece ocupar área significativa, o que não é verdade. Quando mapeado em conjunto com o processador e memória RAM, o sistema de interconexão compartilha endereços da RAM, ocupando uma área menor em relação à área ocupada quando implementado isoladamente.

A tabela 5.5 compara a área estimada em contagem de portas (gates) para o processador da AMM com o processador PicoBlaze e Leon3. Também compara-se a área de um sistema SMP composto por 2 ou 4 processadores (WONG, 2008), com as implementações sugeridas para a $\mathrm{AMM}$, versão $\mathrm{C}$, a qual consiste em $n$ processadores totalmente interconectados. 
Tabela 5.5: AMM versus PicoBlaze e Leon3

\begin{tabular}{lcr}
\hline \multicolumn{1}{c}{ Componente } & No CPUs & \multicolumn{2}{c}{$\begin{array}{c}\text { No Equivalente } \\
\text { Gates }\end{array}$} \\
\hline CPU AMM & 1 & 10.140 \\
PICOBLAZE & 1 & 79.043 \\
CPU LEON3 & 1 & 1.015 .990 \\
LEON3 SMP* & 2 + Periféricos & 2.591 .690 \\
LEON3 SMP* & 4 + Periféricos & 6.203 .015 \\
& 2 & 37.783 \\
& 3 & 80.930 \\
AMM SMP & 4 & 109.546 \\
& 5 & 183.288 \\
& 6 & 235.835 \\
& 7 & 313.298 \\
& & * Implementação de (WONG, 2008) \\
\hline
\end{tabular}

Com os dados da tabela 5.5 é possível perceber que o protótipo AMM ocupa área menor em relação ao processador Xilinx Picoblaze e o processador utilizado no sistema Leon3, um SPARC V8. O AMM composto por 3 processadores totalmente interconectados ocupa a área equivalente do processador Picoblaze.

Mesmo a versão implementada com 7 processadores totalmente interconectados é consideravelmente menor que a área ocupada por um sistema SMP Leon3 implementado com 2 processadores e periféricos.

Não é objetivo da AMM concorrer com o desempenho de um único processador SPARC V8, o qual é destinado à alto desempenho e segmentos de aplicações diferentes da AMM. Assim, a comparação da tabela 5.5 tem caráter apenas ilustrativo em relação á área ocupada pelos sistemas.

A AMM é direcionada a aplicações que requerem menor desempenho em relação às aplicações alvo do Leon3, como já comentado no capítulo 2.

Os dados de desempenho do sistema de interconexão de diferentes versões do protótipo da AMM descritas e implementadas em FPGA aparecem na tabela 5.6. Os dados tracejados na tabela foram estimados.

Tabela 5.6: Desempenho da comunicação

\begin{tabular}{|c|c|c|c|c|}
\hline $\begin{array}{l}\text { № de } \\
\text { CPUs }\end{array}$ & Versão & $\begin{array}{c}\text { № de } \\
\text { barramentos }\end{array}$ & \multicolumn{2}{|c|}{$\begin{array}{l}\text { Transferência por } \\
\text { barramento (max) }\end{array}$} \\
\hline 2 & A & 1 & 17.82 & Mbits/s \\
\hline 3 & D & 2 & 17.64 & Mbits/s \\
\hline 4 & D & 3 & 13.43 & Mbits/s \\
\hline 5 & D. & 4 & 10.80 & Mbits/s \\
\hline 6 & D & 5 & 8.61 & Mbits/s \\
\hline 7. & D. & 6 & 6.08 & Mbits/s \\
\hline 8 & D & 7 & 3.55 & Mbits/s \\
\hline 9. & D & 8 & 1.03 & Mbits/s \\
\hline
\end{tabular}


Para obtenção destes resultados, as versões A e D, mostradas na Figura 1.2 (capítulo 1), foram descritas em VHDL e verificou-se o comportamento usando o software de simulação ModelSim, ajustando o clock de estímulo para 100 Mhz.

Seguiu-se então a metodologia adotada pelo trabalho de (Kavadias, 2010), no qual o benchmark STREAM (MCCALPIN, 1995) foi utilizado para medir a largura de banda máxima de intercomunicação entre processadores de seu trabalho. Como o benchmark STREAM foi originalmente escrito para arquiteturas diferentes da AMM, idealizou-se reproduzir o comportamento padrão do benchmark por meio de programas simples inseridos em cada processador, dedicados à transferência de dados entre processadores. Assim, um programa similar ao STREAM foi desenvolvido para uso na AMM.

Com escritas sucessivas no buffer de transmissão de dados e leituras sucessivas no buffer de recepção de dados, os programas nos processadores: (i) recebem 64bis; (ii) realizam alguma operação nestes bits, tal como por exemplo uma soma ou subtração; (iii) depositam as repostas de suas computações no buffer de escrita e; (iv) autorizam o envio dos dados por meio do canal de comunicação. Com estas simulações foi possível conhecer os dados reais da largura de banda máxima do sistema de interconexão em diferentes configurações.

Adicionalmente, foram descritas algumas funções simples - pulsos - nas portas de cada processador, configuradas como saída.

A sincronização entre os programas foi garantida com a utilização de interrupção. Cada buffer de recepção gera uma interrupção para a CPU quando o buffer contém dados atualizados. Desta forma o processador pode executar outras tarefas, até que novos dados estarem disponíveis para serem tratados e enviados.

A CPU base utilizada executa uma instrução a cada 4 ou a cada 8 ciclos de clock, sendo que utiliza 8 clocks somente em alguns casos de instruções de saltos de programa (JUMP). Para avaliar o desempenho dos processadores foi incluído um contador de instruções na arquitetura descrita em VHDL. Este contador ignora a instrução de não-operação (NOP) e incrementa a cada instrução executada, independe do número de ciclos de clock gasto.

Assim, para a versão com 5 processadores em configuração mestre-escravo, versão D da Figura 1.2 (capítulo 1) para a AMM, mapeou-se nas memórias de programa dos processadores da AMM o programa similar ao STREAM desenvolvido e o sistema foi carregado no software ModelSim. 
Após o software Modelsim executar por mais de 10 horas em um Pentium Core 2 Quad com 6G de memória RAM, alcançou-se pouco mais de $100 \mathrm{~ms}$ de tempo de simulação. Assim, considerando-se que o comportamento do programa desenvolvido similar ao STREAM não possui variações estimou-se em 21 MIPS para o processador mestre e 18 MIPS para os quatro processadores escravos, sendo que os 4 processadores escravos executam cópias do mesmo programa.

Para comparação, o processador PicoBlaze da empresa Xilinx executa suas instruções sempre em dois ciclos, atingindo 50MIPS a 100Mhz e o processador Leon3 da empresa Aeroflex Gaisler executa em um ou dois ciclos.

Foi idealizado um protótipo do processador UPEM2 em silício, para questões de levantamento de área ocupada. Utilizou-se uma tecnologia de 0,6 $\mu$, considerada a menos custosa atualmente. Os resultados do layout físico para o processador e para a memória RAM de 224x8 Bytes são visualizados nas Figuras 5.43 e 5.44 respectivamente. Para a memória de programa, idealizou-se o uso de uma memória FLASH padronizada da tecnologia adotada, composta por oito módulos fechados de 256x16 bits e $0.511 \mathrm{~mm} 2$ de área. Neste caso, a memória FLASH padronizada oferece a melhor relação possível entre área de lógica e área de roteamento.

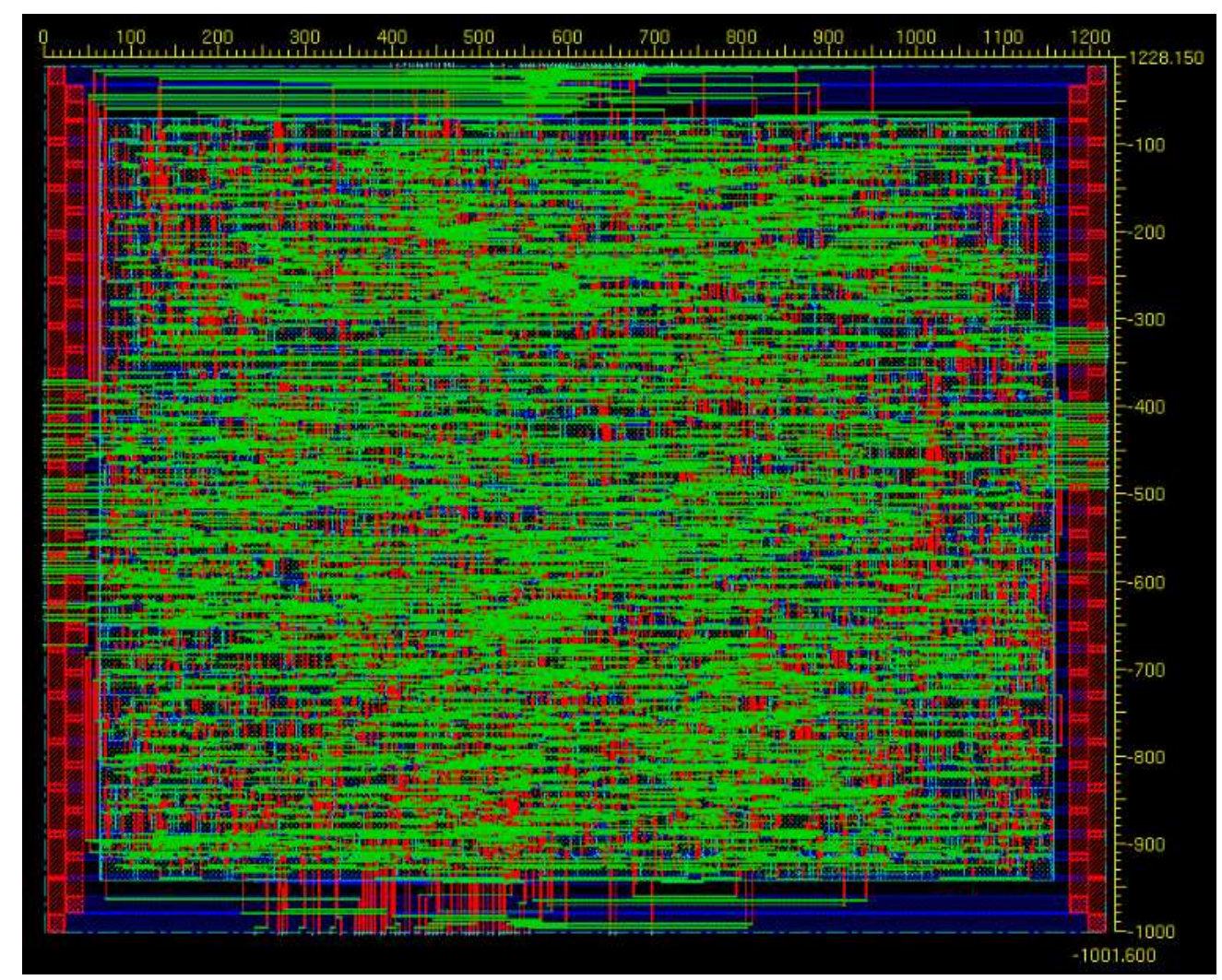

Figura 5.43: Layout preliminar do processador UPEM2, utilizado na AMM 


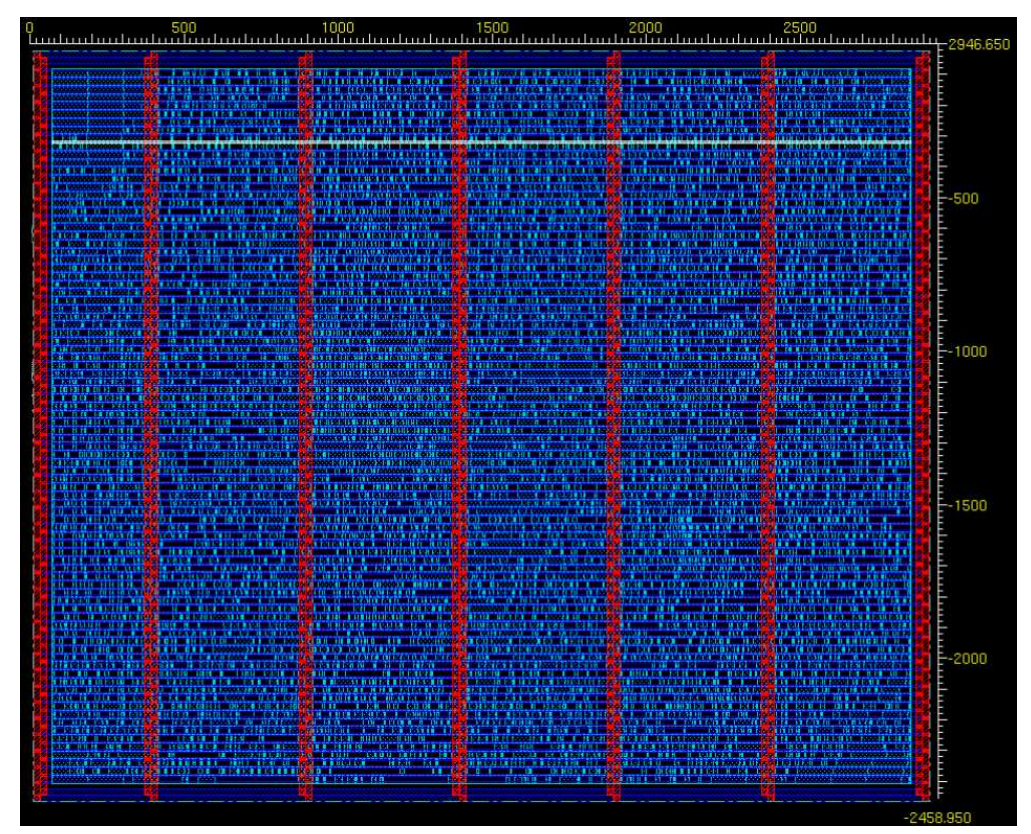

Figura 5.44: Layout preliminar da memória RAM do processador UPEM2

Um protótipo em silício com todos os componentes básicos do processador UPEM2 é apresentado na Figura 5.45, o qual ocupa uma área de aproximadamente $3 \mathrm{~mm} \times 4,5 \mathrm{~mm}$, na tecnologia de $0,6 \mu$, desconsiderando-se os PADs e demais blocos analógicos necessários. Assim, estima-se que de 30 à $40 \%$ do protótipo final em silício está concluído.

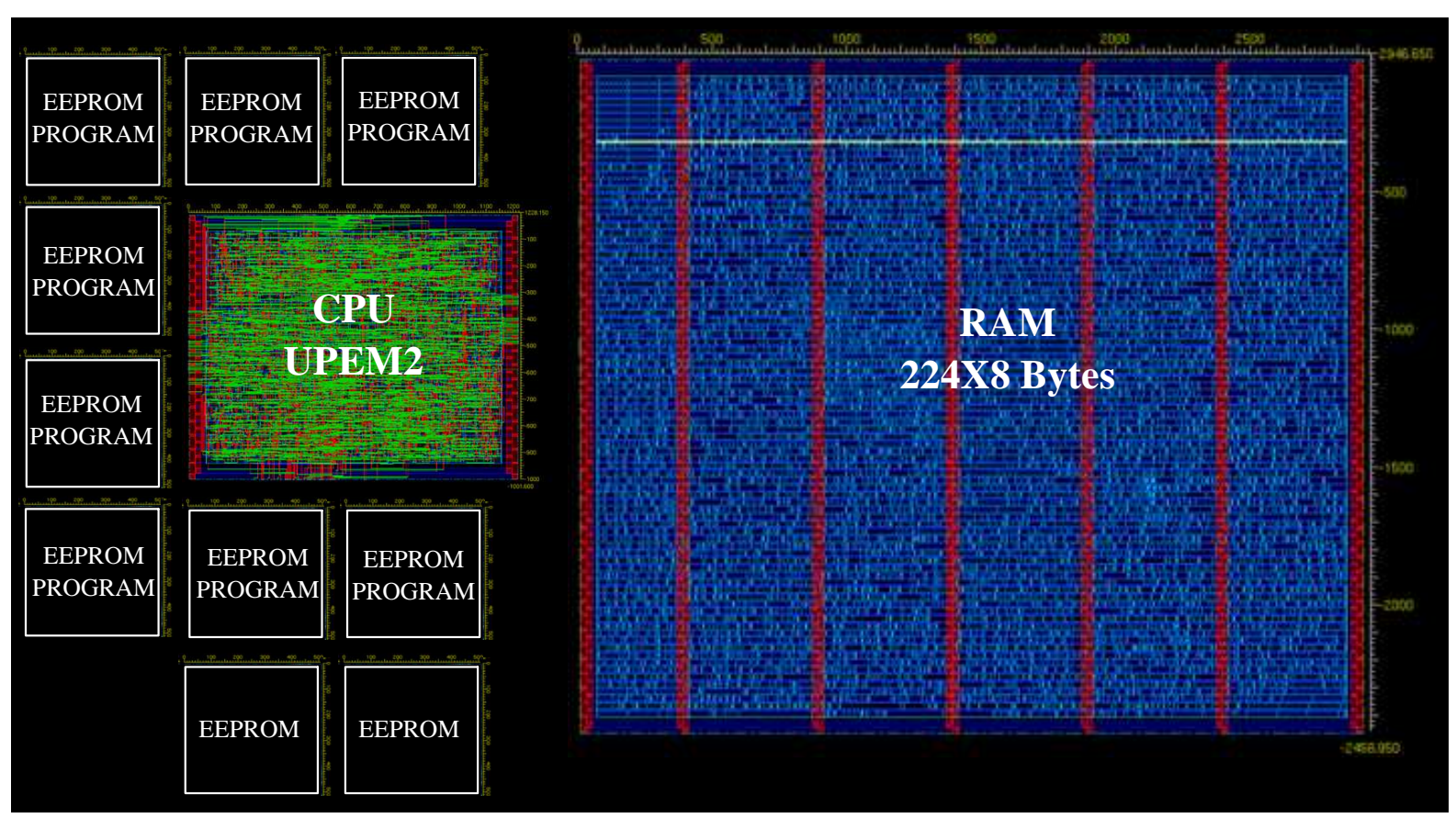

Figura 5.45: Estimativa de área em silício para a UPEM2: 3mm x 4,5mm em tecnologia 0,6 $\mu$ 
Estima-se aproximadamente $6 \mathrm{~mm} \times 9 \mathrm{~mm}$ de área de silício para uma versão AMM composta por 4 processadores homogêneos, em uma tecnologia de 0,6 $\mu$, com os processadores dispostos como no exemplo da Figura 5.46. Para outras composições de processadores, estima-se $9 \mathrm{~mm} \times 9 \mathrm{~mm}$ para 6 processadores, 12 $\mathrm{mm} \times 9 \mathrm{~mm}$ para 8 processadores, $12 \mathrm{~mm} \times 13,5 \mathrm{~mm}$ para 12 processadores e 12 $\mathrm{mm} \times 9 \mathrm{~mm}$ para 16 processadores, para a mesma tecnologia.

O projeto físico em silício do protótipo também foi realizado em uma tecnologia de $0,18 \mu$, com 6 metais. Considerando o maior número de metais, obteve-se um layout compacto. A área ocupada para um único processador UPEM2, incluindo CPU, memória RAM e memória de programa, foi de aproximadamente $0.621 \mathrm{~mm} \times 0.517 \mathrm{~mm}$, na tecnologia de 0,18 , sem os PADs. Não considerou-se a área de silício necessária para os blocos analógicos de suporte aos blocos digitais.

Para comparação, um único processador Leon3 e seus respectivos periféricos ocupou uma área de $4.3 \mathrm{~mm} \times 4.3 \mathrm{~mm}$ em uma tecnologia de $0,18 \mu$, no trabalho de (HOFSTÄTTER, M., 2010).
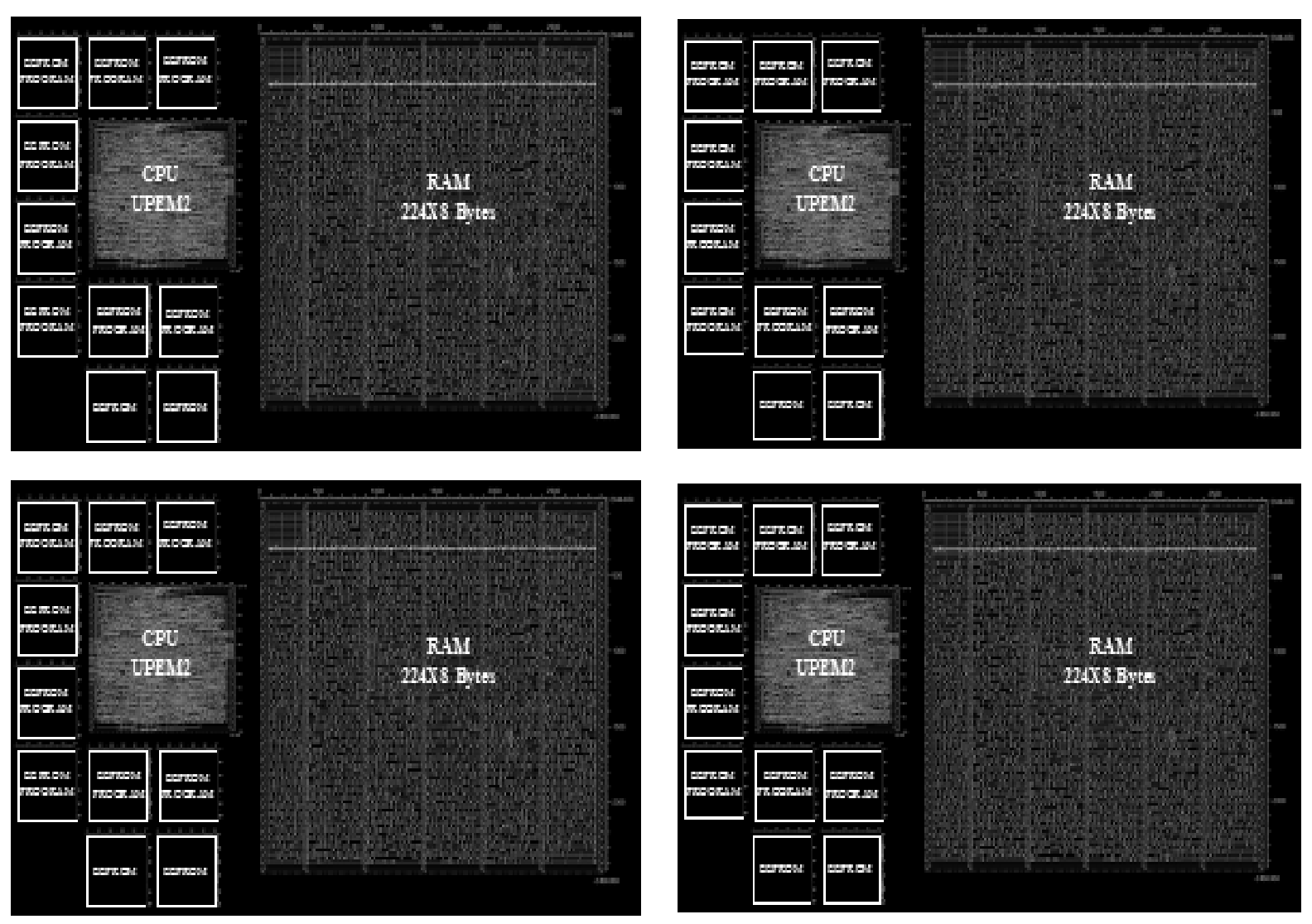

Figura 5.46: Protótipo AMM 4 processadores, estimado em 9x6mm em tecnologia 0,6 $\mu$ 


\subsection{Síntese do capítulo}

Este capítulo mostrou as ferramentas de software e o fluxo manual empregado para testes e simulações em um protótipo da AMM, composta por 4 processadores UPEM2. As simulações indicaram execução correta dos programas de controle PID e AES, comprovando o funcionamento, tanto dos processadores quanto do sistema de intercomunicação desenvolvido.

Os resultados de síntese e mapeamento em FPGA, por meio do software Xilinx, indicam que a área total necessária para mapeamento do protótipo atual da AMM é relativamente pequena e consideravelmente menor que outras implementações citadas. 


\section{Capítulo 6 Conclusões e Trabalhos Futuros}

\subsection{Conclusões}

Este trabalho propõe uma arquitetura modular multicore para sistemas embarcados ciberfísicos. Obteve-se uma arquitetura flexível que, com poucas modificações em sua estrutura, pode ser descrita para comportar $n$ processadores.

Com cada processador sendo capaz de executar códigos locais e executar processamento independente, é possível obter várias características consideradas importantes em sistemas embarcados ciberfísicos, tais como segurança de informação, redundância de processamento e flexibilidade de adequação à diversos requisitos.

As principais características da AMM:

- Segurança - A segurança é obtida por uso de um dos processadores sendo dedicado a cifa/decifra de dados de programa, comprovado pela correta execução do algoritmo AES no processador do protótipo da AMM. Os dados pode ser cifrados em uma memória externa e um processador dedicado decifra e carrega estes dados nas memórias dos outros processadores. O uso de memórias internas, RAM e de programa agrega proteção ao sistema, uma vez que os dados são mantidos internamente. Um componente auxiliar pode ser futuramente desenvolvido para geração de ruídos elétricos ou eletromagnéticos e dificultar acesso ao conteúdo dos processadores por meio do uso de técnicas de tampering.

- Tolerância a falhas - Um dos requisitos para tolerância a falhas, a redundância de processamento, foi alcançada na AMM. Para a tolerância a falhas ser concluída, é necessário o desenvolvimento de um hardware de votação entre três processadores e um hardware adicional para recuperação de informações do log de ocorrência gerado. Assim, estudos de adicionais de técnicas de rollback de informações serão também necessários.

- Flexibilidade - Alcançou-se flexibilidade arquitetural e flexibilidade de programa. A flexibilidade arquitetural foi alcançada por meio de componentes 
de comunicação independentes aos processadores, os quais permitem várias configurações de interconexão entre processadores. A flexibilidade de programa foi comprovada por meio de programas distintos sendo executados simultaneamente em vários processadores da AMM. Assim, diversas funções digitais podem ser executadas nos processadores, obtendo-se adequação à diversos projetos.

Foi possível obter processamento de controle PID independente em três processadores na AMM, configurados como processadores escravos e controlados por um processador mestre. A configuração "mestre-escravo" foi alcançada apenas via software.

Comprovou-se a flexibilidade da arquitetura, dado que diferentes programas foram executados nos processadores, coordenados por um processador mestre, ou executando de forma independente.

Foi possível obter a redundância de processamento, na qual processadores eleitos como escravo executam suas computações de forma idêntica, incluindo número de ciclos após o reset inicial do sistema.

Foi possível detectar a ocorrência de uma falha, armazená-la em log de atividades e suspender as atividades do processador, manualmente identificado.

Com o processador atual, a escalabilidade da arquitetura atingiu o limite de oito processadores em um único agrupamento. É possível unir vários agrupamentos como este, redirecionando-se um dos componentes de intercomunicação para o outro agrupamento.

Alcançou-se uma arquitetura adaptável à outros processadores, diferentes do utilizado no protótipo. Seguindo-se a organização sugerida para a memória e os respectivos endereços dos controladores de comunicação, é possível adaptar e utilizar outros processadores na arquitetura proposta.

Obteve-se uma forma simples e funcional de interconexão entre dois processadores e comprovou-se que informações assíncronas são tratáveis e controláveis no software presente nos processadores da arquitetura.

Foi possível gerar log de processamento, armazenando dez ciclos de ocorrência em um esquema de substituição dos estados mais antigos. 
Alguns periféricos de comportamento exclusivamente digital podem ser emulados em software nos processadores, como por exemplo, comunicação serial, geração de pulso por modulação de largura, dentre outros de interesse.

O processador simulado, tanto em ferramentas destinadas à FPGA quanto em ferramentas destinadas à ASIC, executou corretamente os programas testados.

O protótipo do sistema AMM, composto por quatro processadores interconectados, também apresentou resultados funcionais, em simulação. $O$ processador mapeado em FPGA executou corretamente os programas testados.

O protótipo em ASIC para um único processador em tecnologia CMOS $0.18 \mu \mathrm{m}$ necessita de $0.621 \mathrm{~mm} \times 0.517 \mathrm{~mm}$, enquanto que um único processador Leon3 e seus periféricos ocupou $4.3 \mathrm{~mm} \times 4.3 \mathrm{~mm}$, na mesma tecnologia.

Limitações do trabalho

O protótipo desenvolvido não possui periférico A/D. Sendo assim, simula-se os dados referente à conversão A/D no próprio programa de controle PID. Isso torna os resultados "artificiais", de modo que os processadores sempre alcançam o setpoint esperado.

O programa de controle PID utilizado realiza operações sobre os valores absolutos e não executa operações de ponto flutuante. Sendo assim, é difícil determinar a precisão obtida pelo cálculo de controle PID resultante. Não foram realizados testes físicos com um motor real, os quais, poderiam indicar erros na execução do controle PID não detectáveis apenas por simulação.

O programa de controle PID redundante envia mensagens simultâneas aos escravos. Estes por sua vez, devem aguardar em um laço eterno de programa até que a mensagem seja recebida. Isso faz com que o processador escravo, configurado como redundante, permaneça em um estado ocioso enquanto não recebe a mensagem com o setpoint.

No programa de controle PID redundante, não foram realizados testes com comunicação em duas vias entre mestre-escravo. Somente o mestre envia mensagens aos escravos redundantes e estes realizam seu processamento, sem qualquer retorno ao processador mestre. Desta forma, não é possível determinar se a redundância "um-a-um" se manteria após n mensagens entre mestre e escravos. 
Ambos programas, no mestre e no escravo, necessitam de laços de espera de mensagens para sincronizarem-se.

No teste de tolerância a falhas foi necessário criar fontes de falhas no código VHDL do processador, para ser possível simular falhas em tempo de simulação. As falhas idealizadas neste teste cobrem somente alguns componentes do processador. Não foram realizados testes injetando-se falhas no sistema de interconexão, as quais, resultariam em perdas de mensagens e, portanto, perda da redundância.

Não foram executados testes de falhas específicos na memória de configuração do FPGA, simulando-se os eventos TID, SELs e SEUs.

Não foi implementado o sistema de votação entre processadores. Somente detecta-se a falha e demonstra-se que é possível suspender automaticamente o processador no qual a falha ocorreu.

Apesar da geração do log de eventos, as informações não são recuperadas no protótipo desenvolvido. Também, não foi estimada a área necessária para o hardware de geração de logs, devido às partes não sintetizáveis do circuito de injeção de falhas.

$O$ teste de criptografia para cifra e decifra AES utilizou somente dados nas memórias RAM locais de um único processador. Para se afirmar que o processador e a AMM são seguros, será necessário estudar e desenvolver técnicas para que os dados do próprio programa, presente em cada processador, sejam também criptografados.

A área final obtida para a CPU é reduzida. Porém, um processador contém área adicional de memória de programa e de trabalho.

\subsection{Trabalhos futuros}

Um ambiente de desenvolvimento integrado, no qual, compiladores, depuradores e ferramentas de síntese de lógica programável para a AMM proposta.

Estudo e levantamento de resultados da AMM composta por outros processadores base, diferentes da UPEM2 utilizada na AMM. Assim, será possível obter-se outras versões do mesmo sistema e destiná-las a aplicações com diferentes requisitos. 
Melhorar o sistema de interconexão, permitindo troca de mensagens com número variável de bytes. Esta melhoria poderá incluir comunicação full duplex em uma única linha, similar ao comportamento da comunicação One-Wire(R).

Estudo e melhorias nas rotinas de software para garantir a sincronia entre processadores eleitos redundantes. Testes de sincronia para garantir a redundância entre processadores, mesmo após n mensagens.

Estudo e utilização de técnicas padronizadas para injeção de falhas, em diversos pontos da arquitetura. Desenvolver técnicas para avaliar e testar falhas no sistema de interconexão dos processadores.

Estudo de técnicas para hardware de votação e eleição entre processadores para garantir a correta execução mesmo em caso de falhas. Técnicas de rollback de processamento podem ser desenvolvidas utilizando-se e evoluindo-se o sistema de log desenvolvido

Melhorias no sistema de geração de logs, interligando-o com o hardware e os mecanismos necessários para rollback de processamento após possíveis falhas.

Melhorias na arquitetura para prover a cifra e decifra dos dados em todos os processadores, tornando as memórias de programa, memórias de trabalho e acesso a E/S também criptografados. Assim, serão necessários novos programas e algoritmos para avaliar especificamente a questão da segurança de dados. 


\section{Referências}

ARM Versatile Platform, plataforma de desenvolvimento da empresa ARM, 2010. Disponível em http://www.arm.com/products/tools/versatile.php Acesso em: $24 / 10 / 2010$

BAVARESCO, M. I. Simple RTOS for microchip baseline and midrange MCUs. 2010. Disponível em: http://www.piclist.com/techref/member/IMB-yahooJ86/SimpleRTOS.htm. Acesso em: 24/10/2010

BECKER, C.A. Detecção distribuída de falhas em SoC multiprocessado. Dissertação para obtenção do título de mestre no Programa de Pós-Graduação em Engenharia Elétrica - Pontifícia Universidade Católica do Rio Grande do Sul, 2008.

BOBDA, C. et al. Design of adaptive multiprocessor on chip systems. In: Proceedings of the 20th Annual Conference on Integrated Circuits and Systems Design. Copacabana, Rio de Janeiro: ACM, 2007. p. 177-183.

BONAKDARPOUR, B. Challenges in transformation of existing real-time embedded systems to cyber-physical systems. SIGBED Rev. [S.I.], v. 5, n. 1, p. 1-2, 2008.

BROWN, L. AES block cipher calculator. Disponível em: http://www.unsw.adfa.edu.au/ /pb/src/AEScalc/index.html. Acesso em: Acesso em 24/10/2010.

BRUISTER, J. How to design a 3DES security microcontroller, SoC Soluctions LLC, apresentação técnica, 2003. Disponível em: http://cdserv1.wbut.ac.in/81-3120257-7/Xilinx/files/Xcell\%20Journal\%20Articles/xcell_46/xc_3des46.pdf Acesso em 24/10/2010.

CARDENAS, A. A. et al. Secure control: towards survivable cyber-physical systems. In: Distributed Computing Systems Workshops, 2008. ICDCS '08. 28th International Conference on, 17-20 June 2008. 2008. p. 495-500.

CASTELAN, E. B. N. Notas de aula sobre controle PID, 2010, Universidade Federal de Santa Catarina, 2010. Disponível em: http://www.das.ufsc.br/ eugenio/DAS5121/PID/transpPID2.pdf. Acesso em 24/10/2010.

CHAPMAN, K. PicoBlaze, Xilinx technical presentation. Disponível em: http://www.xilinx.com/products/boards/s3estarter/files/s3esk_picoblaze_nor_flash_pr ogrammer.pdf, 2006 Acesso em 24/10/2010

CHUN-MING, H. et al. Implementation and prototyping of a complex multi-project system-on-a-chip. In: Circuits and Systems, 2009. ISCAS 2009. IEEE International Symposium on, 24-27 May 2009. p. 2321-2324. 
Code design e pic pasic pro compiler, ambiente e compilador para microcontrolador PIC. Disponível em: http://melabs.com/ources/win_ide.htm . Acesso 29/09/2009

CortexA9 MPCore technical reference manual, revision: r2p0, ARM, 2008-2009. Disponível em: http://infocenter.arm.com/help/index.jsp?topic=/com.arm.doc.ddi0407 e/index.html . Acesso em: 24/10/2010

Domeika, M. Software development for embedded multi-core systems : a practical guide using embedded Intel architecture. Local: USA : Elsevier, 2008. 420p.

ECKER, W. et al. Hardware-dependent software: principles and practice. Local: USA, Springer, 2009. 300p

EDMISON, J.N. Hardware architecture for software security. Tese de doutorado submetida a Faculdade de Virginia para obtenção do título de Doutor em Engenharia da Computação, Junho 2006.

EGHBAL, A. et al. Fault tolerance assessment of PIC microcontroller based on fault injection. In: Test Workshop, 2009. LATW '09. 10th Latin American, 2-5 March 2009. p. 1-6.

Real Time Engineers Ltd. FreeRTOS, sistema operacional minimalista para microcontroladores, 2010. Disponível em: <http://www.freertos.org/>. Acesso em: $24 / 10 / 2010$

GAISLER, J. The LEON processor user's manual. Disponível em: http://www.gaisler.com/cms/index.php?option=com_content\&task=section\&id=5\&lte $\mathrm{mid}=51$. Acesso em 24/10/2010

GERICOTA, M. G. O. Metodologias de teste para FPGAs (Field Programmable Gate Arrays) integradas em sistemas reconfiguráveis. Tese de Doutorado apresentada a Faculdade de Engenharia da Universidade do Porto, Porto, Portugal, 2003.

GILL, H. Cyber-physical systems, apresentação técnica em S5: Safe \& Secure Software \& Systems Symposium, Beavercreek, OH, June 15, 2010 CISE/CNS, National Science Foundation

GOLANDER, A. et al. DDMR: Dynamic and scalable dual modular redundancy with short validation intervals. In: Computer Architecture Letters [S.I.], v. 7, n. 2, p. 6568, 2008.

GONZALEZ, J. Uma metodologia de projetos para circuitos com reconfiguração dinâmica de hardware aplicada a support vector machines. Tese de Doutorado apresentada a Escola Politécnica da Universidade de São Paulo, São Paulo, Brasil, 2006

GUNEÉ R., Tetris project, 2008, Disponível em: http://www.rickard.gunee.com/ projects/ Acesso em: 29/09/2009 
Henzinger T. A. ; Sifakis, J. The embedded systems design Challenge. In: Proceedings of the 14th International Symposium on Formal Methods (FM), Lecture Notes in Computer Science, Springer, 2006, p. 1-15

High-confidence medical devices: cyber-physical systems for 21st century health care, 2009. Disponível em http://www.whitehouse.gov/files/documents/cyber/NITRD\%20-\%20High-

Confidence\%20Medical\%20Devices.pdf. Acesso 24/10/2010

HOFSTÄTTER, M.; SCHÖN, P.; POSCH, C.; A sparc-compatible general purpose address-event processor with 20-bit IOns-resolution asynchronous sensor data interface in $0.18 \mu \mathrm{m}$ cmos. In: Proceedings of the IEEE International symposium on circuits and systems (ISCAS), p. 4229-4232, junho 2010

HSIUNG, S. C., The use of PIC microcontrollers in multiple DC motors control applications. In: Proceedings of the Journal of Industrial Technology, v. 23, September 2007

HUFFMIRE, T. et al. Moats and drawbridges: an isolation primitive for reconFigurable hardware based systems. In: Security and Privacy, 2007. SP '07. IEEE Symposium on, 20-23 May 2007. p. 281-295.

HUTORNY, E. VELLOS - Very low overhead operating system, 2010. Disponível em: <http://hutorny.in.ua/ projects/pic/very-low-overhead-operating-system>. Acesso em: 24/10/2010

IHRIG, C. J. et al. Automated modeling and emulation of interconnect designs for many-core chip multiprocessors. In: Proceedings of the 47th Design Automation Conference. Anaheim, California: ACM, 2010. p. 431-436.

INOUE, H. A multi-core processor platform for open embedded systems. Dissertação de mestrado apresentada a Graduate School of Science and Technology of Keio University, Setembro 2009.

JANI, Y. Combining vector control and user interface/machine functions into a single microcontroller for white goods applications. In: Industry Applications Conference, 2007. 42nd IAS Annual Meeting. Conference Record of the 2007 IEEE. 2007. p. 1056-1063.

JENN, E. et al. Fault injection into VHDL models: the MEFISTO tool. In: FaultTolerant Computing, 1994. FTCS-24. Digest of Papers, Twenty-Fourth International Symposium on, 15-17 June 1994. p. 66-75.

JOHNSON, J. M.; WIRTHLIN, M. J. Voter insertion algorithms for FPGA designs using triple modular redundancy. In: Proceedings of the 18th annual ACM/SIGDA international symposium on Field programmable gate arrays. Monterey, California, USA: ACM, 2010. p. 249-258. 
KAMAL, A. A.; YOUSSEF, A. M. An FPGA implementation of AES with fault analysis countermeasures. In: Microelectronics (ICM), 2009 International Conference on, 19-22 Dec. 2009. p. 217-220.

KAVADIAS, S. G. et al. On-chip communication and synchronization mechanisms with cache-integrated network interfaces. In: Proceedings of the 7th ACM international conference on Computing frontiers. Bertinoro, Italy: ACM, 2010. p. 217-226.

KONDO, $\mathrm{H}$. et al. Design and implementation of a configurable heterogeneous multicore SoC with nine CPUs and two matrix processors. Solid-State Circuits, IEEE Journal of [S.I.], v. 43, n. 4, p. 892-901, 2008.

LEE, E. A. Cyber-physical systems: design challenges. In: Proceedings of the 2008 11th IEEE Symposium on Object Oriented Real-Time Distributed Computing: IEEE Computer Society, 2008. p. 363-369.

LEE, I. Cyber Physical Systems: the next computing revolution apresentação técnica em: CIS 480, University of Pennsylvania, 2009. Disponível em : http://www.seas.upenn.edu/ lee/09cis480/lec-CPS.pdf Acesso em: 13/12/2010

LIMA, F. et al. A fault injection analysis of Virtex FPGA TMR design methodology. In: Radiation and Its Effects on Components and Systems, 2001. 6th European Conference on, 10-14 Sept. 2001. p. 275-282.

MARTIN, J., Propeller manual, v.1.1, Parallax, 2009. Disponível em: http://www.parallax.com/Portals/0/Downloads/docs/prod/prop/WebPM-v1.1.pdf Acesso em 24/10/2010

MCCALPIN, J. STREAM benchmark, 1995. Disponível em http://www.cs.virginia. edu/stream/ref.html\#what. Acesso em 24/102010

MCMILLIN, B. Complexities of information security in cyber-physical power systems. In: Power Systems Conference and Exposition, 2009. PSCE '09. IEEE/PES, 1518 March 2009. p. 1-2.

MEAKIN, B.; GOPALAKRISHNAN, G. Hardware Design, Synthesis, and Verification of a Multicore Communication API. In: TECHCON 2009, University of Utah

MILLER, T. et al. Flexible redundancy in robust processor architecture. In: Workshop on Energy-Efficient Design (WEED2009). June 20, 2009 Austin, Texas

MINHASS, W. H. et al. Design and implementation of a plesiochronous multi-core 4x4 network-on-chip FPGA platform with MPI HAL support. In: Proceedings of the 6th FPGAworld Conference. Stockholm, Sweden: ACM, 2009. p. 52-57.

Morioka, S., Projeto CQPIC, 1999. Disponível em: <http://www002.upp.sonet. ne.jp/morioka/papers.html>. Acesso em: 29/09/2009 
Freescale, MPC8569E PowerQUICC III Processor, 2009. Disponível em: www.freescale.com/files/32bit/doc/fact_sheet/MPC8569EFS.pdf Acesso em: $24 / 10 / 2010$

Ngiap, S. T. S. AEMB 32-bit microprocessor core datasheet, 2007 Disponível em: www.scribd.com/doc/39360752/AeMB-Datasheet Acesso em 24/10/2010

Nios II Processor Reference Handbook, Altera Corporation, 2010. Disponível em: http://www.altera.com/ literature/hb/nios2/n2cpu_nii5v1.pdf. Acesso em: 24/10/2010

Novo RTOS, SourceBoost Technologies, 2008. Disponível em http://www.sourceboost.com/Products/NovoRtos/Docs/Novo_RTOS.pdf Acesso em $24 / 10 / 2010$

Oshon Software, PIC simulator IDE, 2010. Disponível em: http://www.oshonsoft.com/ Acesso 29/09/2009

PENTEADO, C. G., UPEM: um sistema que integra microcontroladores e FPGAs - arquiteturas protótipo e desempenho de periféricos. Dissertação de mestrado; UNIVEM, Marília - SP, 2004

PENTEADO, C. G.; MORENO, E. D. A specialized processor for emulating peripherals of the PIC microcontroller. Latin America Transactions, IEEE (Revista IEEE America Latina) [S.I.], v. 7, n. 2, p. 133-140, 2009.

PERMADI, E. Implementation of AES (Rijndael) 128 bit on PIC16F877, concluído em 06/02/2008. Disponível em http://edipermadi.wordpress.com/2008/02/09/an-aesimplementation-on-pic16f877/. Acesso 29/09/2009

PicoBlaze 8-bit Embedded Microcontroller User Guide. Disponível em: http://www.xilinx.com/support/documentation/ip_documentation/ug129.pdf. Acesso em: $24 / 10 / 2010$

PLATONE, I. uGNU/RTOS PIC. 2008. Disponível em: <http://micrognurtos. sourceforge.net/>. Acesso em: 24/10/2010

PUMPKIN, Salvo Compiler Reference Manual, 2004 Disponível em http://www.pumpkininc.com/content/doc/manual/rm-picc.pdf Acesso em: 24/10/2010

QIANG, L. et al. The study of PWM methods in permanent magnet brushless DC motor speed control system. In: Electrical Machines and Systems, 2008. International Conference, 2008. p. 3897-3900.

RAJEST S. et al., Fault tolerance in multicore processors with reconFigurable hardware unit. In: Proceedings of the IEEE International Conference on High Performance Computing, Bangalore, India, 2008

RAJKUMAR, R. et al. Cyber-physical systems: the next computing revolution. In: Proceedings of the 47th Design Automation Conference. Anaheim, California: ACM, 2010. p. 731-736. 
ROBERTS, J. F. et al. Quadrotor using minimal sensing for autonomous indoor flight. In: Proceedings of the 3rd US-European Competition and Workshop on Micro Air Vehicle Systems (MAV07) \& European Micro Air Vehicle. Conference and Flight Competition (EMAV2007)

ROBERTS, S. "PID2010.pbp", programa para proporcional integral diferencial em basic para microcontroladores PIC16, concluído em 21/01/2010. Disponível em: http://www.maelabs.ucsd.edu/mae_guides/howto/lab-

x2/how/programing/closed_loop_motor_control/ Acesso em 24/10/2010

ROGERS, A. Designing cost-efective secure processor for embedded systems: principles, challenges, and architectural soluctions Tese de Doutorado apresentada à University of Alabama, 2010

SAVAGE, J. E.; ZUBAIR, M. A unified model for multicore architectures. In: Proceedings of the 1st international forum on Next-generation multicore / manycore technologies. Cairo, Egypt: ACM, 2008. p. 1-12.

SCHUBERT, T.; BECKER, B. Lemma exchange in a microcontroller based parallel SAT solver. In: VLSI, 2005. Proceedings. IEEE Computer Society Annual Symposium, 11-12 May 2005. p. 142-147.

SHIH-YI, Y. et al. The power stability of FPGA-based microcontroller design and measurement. In: Electromagnetic Compatibility (APEMC), 2010 Asia-Pacific Symposium, 12-16 April 2010. p. 1096-1099.

SONI, C. et al. Embedded system for velocity measurement of projectile. In: Emerging Trends in Engineering and Technology, 2008. ICETET '08. First International Conference, 2008. p. 1321-1324.

TANOUE, S. et al. A novel states recovery technique for the TMR softcore processor. In: Field Programmable Logic and Applications, 2009. FPL 2009. International Conference on, Aug. 31 2009-Sept. 2 2009. p. 543-546.

TIMOFEEV, V. OSA RTOS . 2010. Disponível em: <http://wiki.pic24.ru/doku.php/ en/osa/ref/download/intro>. Acesso em: 24/10/2010

TMS320C6474 multicore digital signal processor data manual (Rev. F), Texas Instruments, 2009. Disponível em: http://focus.ti.com/lit/ds/sprs552f/sprs552f.pdf Acesso em: 24/10/2010

TONG, J. G. et al. Soft-core processors for embedded systems. In: Microelectronics, 2006. ICM '06. International Conference, 16-19 Dec. 2006. p. 170-173.

VADLAMANI, R. et al. Multicore soft error rate stabilization using adaptive dual modular redundancy. In: Design, Automation \& Test in Europe Conference \& Exhibition (DATE), 2010, 8-12 March 2010. p. 27-32. 
WING, J. M. Cyber-Physical Systems, apresentação técnica, 2008 Cyber-Physical Systems Summit, St. Louis, MO, April 24, 2008. Disponível em: http://www.cra.org/ccc/docs/cps-summit.pdf. Acesso em: 24/10/2010

WONG, T. LEON3 System-on-chip port for BEE2 and ASIC implementation, Technical Report, 2008. Disponível em: Acesso em: 24/10/2010

ZEMVA, A. et al. A rapid prototyping environment for teaching digital logic design. Education, IEEE Transactions, [S.I.], v. 41, n. 4, p. 8, 1998. 